\title{
Circumferential Cracking of Steam Generator Tubes
}

Manuscript Completed: April 1997

Date Published: April 1997

Prepared by

K. J. Karwoski

Prepared by

Division of Engineering

Office of Nuclear Reactor Regulation

U.S. Nuclear Regulatory Commission

Washington, DC 20555-0001 


\section{DISCLAMMER}

Portions of this document may be illegible in electronic image products. Images are produced from the best available original document. 


\section{DISCLAIMER}

This report was prepared as an account of work sponsored by an agency of the United States Government. Neither the United States Government nor any agency thereof, nor any of their employees, make any warranty, express or implied, or assumes any legal liability or responsibility for the accuracy, completeness, or usefulness of any information, apparatus, product, or process disclosed, or represents that its use would not infringe privately owned rights. Reference herein to any specific commercial product, process, or service by trade name, trademark, manufacturer, or otherwise does not necessarily constitute or imply its endorsement, recommendation, or favoring by the United States Government or any agency thereof. The views and opinions of authors expressed herein do not necessarily state or reflect those of the United States Government or any agency thereof. 
ABSTRACT

\begin{abstract}
On April 28, 1995, the U.S. Nuclear Regulatory Commission (NRC) issued Generic Letter (GL) 95-03, "Circumferential Cracking of Steam Generator Tubes." GL 95-03 was issued to obtain information needed to verify licensee compliance with existing regulatory requirements regarding the integrity of steam generator tubes in domestic pressurized-water reactors (PWRs).

This report briefly describes the design and function of domestic steam generators and summarizes the staff's assessment of the responses to GL 95-03. The report concludes with several observations related to steam generator operating experience.
\end{abstract}

This report is intended to be representative of significant operating experience pertaining to circumferential cracking of steam generator tubes from April 1995 through December 1996. Operating experience prior to April 1995 is discussed throughout the report, as necessary, for completeness. 


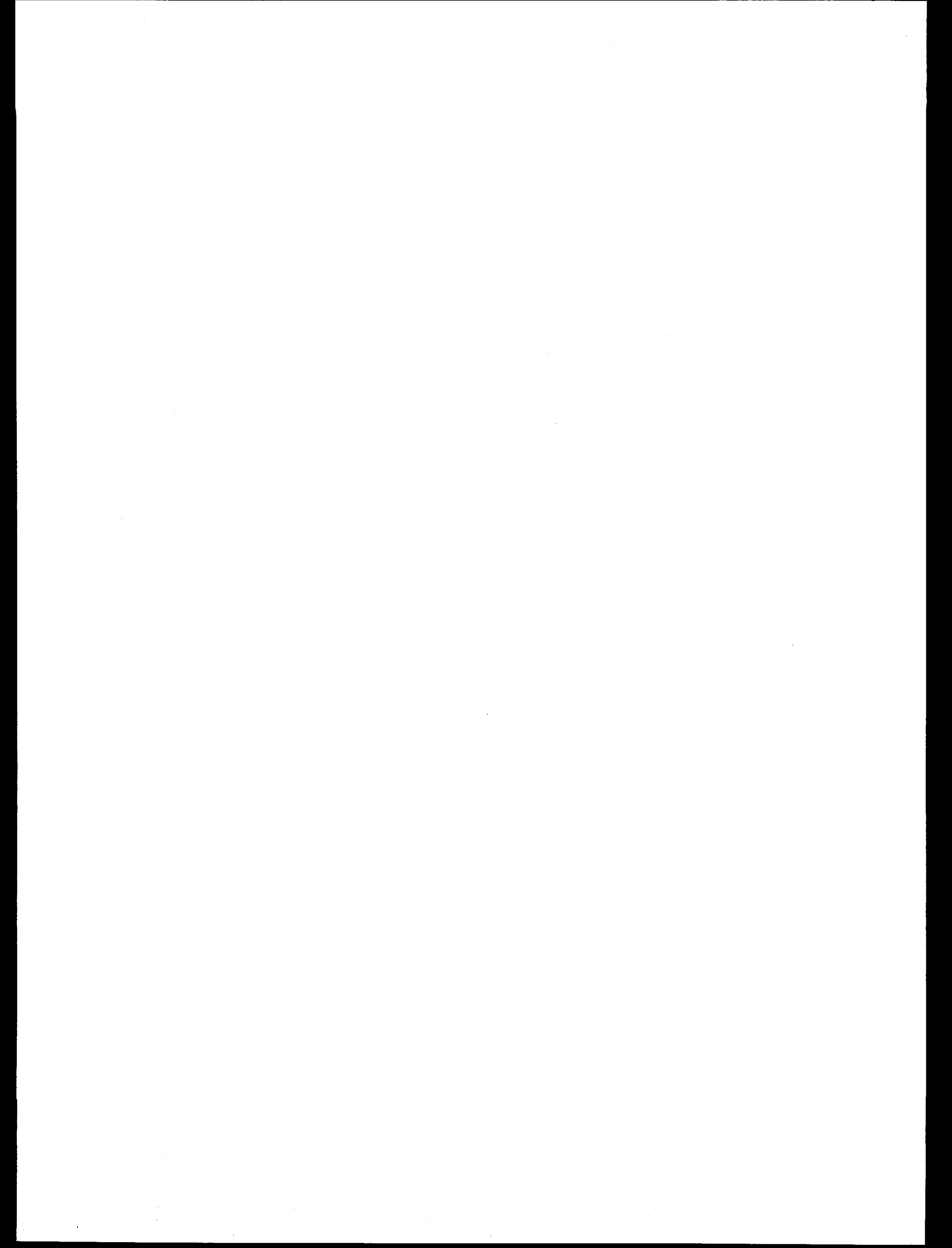




\section{CONTENTS}

ABSTRACT $\ldots \ldots \ldots \ldots \ldots \ldots \ldots \ldots \ldots \ldots \ldots \ldots \ldots \ldots \ldots \ldots \ldots \ldots \ldots$

LIST OF FIGURES $\ldots \ldots \ldots \ldots \ldots \ldots \ldots \ldots \ldots \ldots \ldots \ldots \ldots \ldots$

LIST OF TABLES $\ldots \ldots \ldots \ldots \ldots \ldots \ldots \ldots \ldots \ldots \ldots \ldots \ldots \ldots \ldots \ldots$

EXECUTIVE SUMMARY $\ldots \ldots \ldots \ldots \ldots \ldots \ldots \ldots \ldots \ldots \ldots \ldots \ldots \ldots$

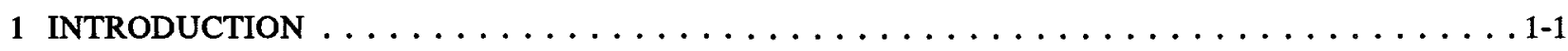

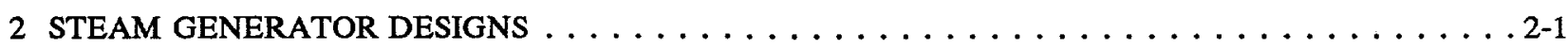

3 GL 95-03, "CIRCUMFERENTIAL CRACKING OF STEAM GENERATOR TUBES" $\ldots \ldots \ldots$. . 3-1

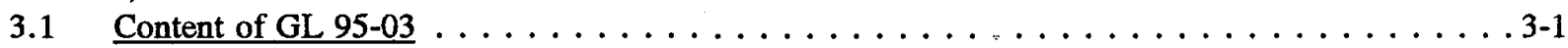

3.2 Generic Assessment of the Industry's Responses to GL 95-03 . . . . . . . . . . 3-1

4 INSPECTION, REPAIR, AND ASSESSMENT OF STEAM GENERATOR TUBES $\ldots \ldots \ldots \ldots$. . 4-1

4.1 Purpose of Steam Generator Tube Inspections . . . . . . . . . . . . . . . . 4-1

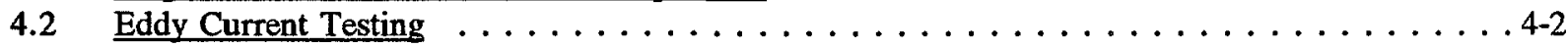

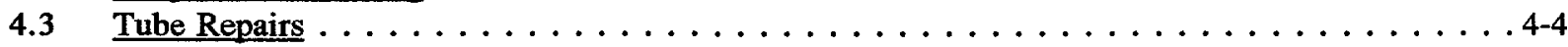

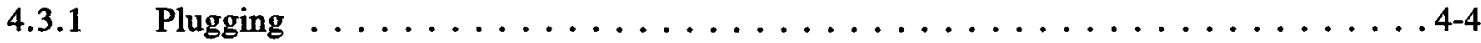

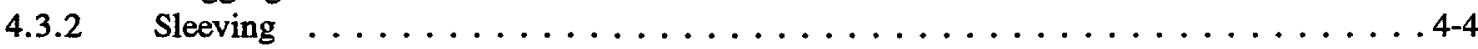

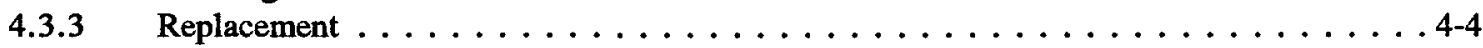

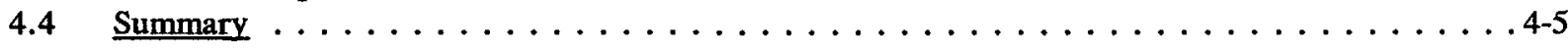

5 BABCOCK AND WILCOX ONCE-THROUGH STEAM GENERATORS $\ldots \ldots \ldots \ldots \ldots \ldots$

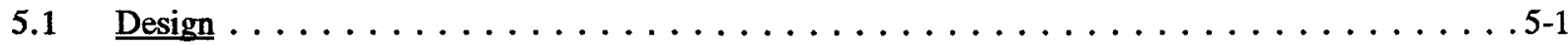

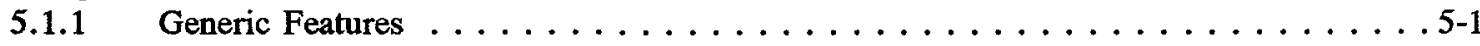

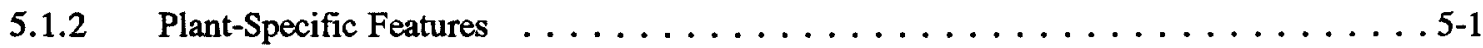

5.2 Locations Susceptible to Circumferential Cracking . . . . . . . . . . . . . . 5-3

5.2.1 Uppermost Span of Unsleeved Tubes in the Lane/Wedge Region . . . . . . . . . . 5-3

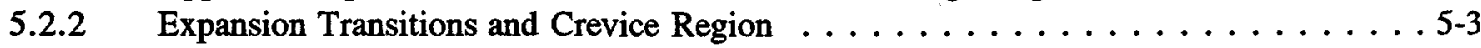

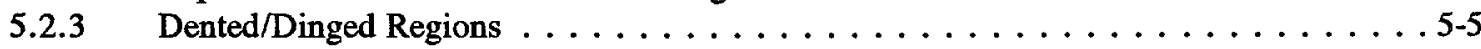

5.2 .4 Sleeve Joints . . . . . . . . . . . . . . . . . . . . . .5-6

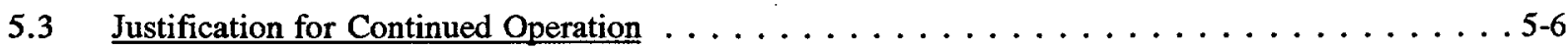

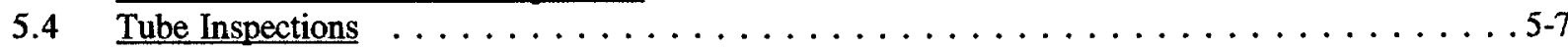

6 COMBUSTION ENGINEERING STEAM GENERATORS $\ldots \ldots \ldots \ldots \ldots \ldots \ldots \ldots \ldots$

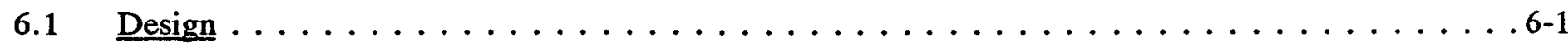

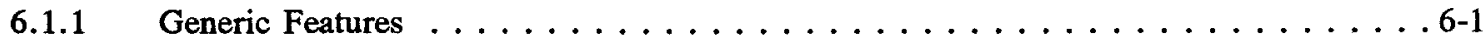

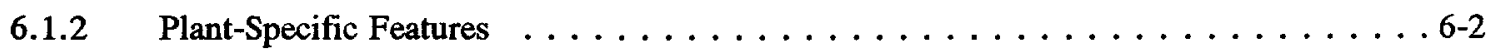

6.2 Locations Susceptible to Circumferential Cracking . . . . . . . . . . . . . . . . 6-3

6.2 .1 Top of Tubesheet Region . . . . . . . . . . . . . . . . . . . 6-3

6.2.2 Dented Locations Including Dented Tube Support Areas . . . . . . . . . . 6-4

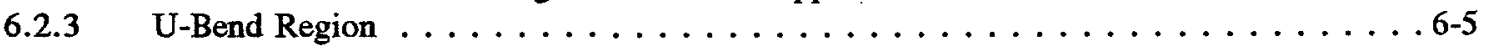

6.2 .4 Sleeve Joints . . . . . . . . . . . . . . . . . . . .6-5 
6.2.5 Circumferential Cracking Experiences in the Pre-Replacement Palisades and Millstone Steam Generators . . . . . . . . . . . . . . . . . . . . 6-5

6.2.5.1 Pre-Replacement Palisades Steam Generators . . . . . . . . . . . . 6-5

6.2.5.2 Pre-Replacement Millstone 2 Steam Generators . . . . . . . . . . . 6-7

6.2.5.3 Summary of Operating Experience from the Pre-Replacement Palisades and Millstone 2 Steam Generators . . . . . . . . . . . . . . 6-9

6.3 Justification for Continued Operation $\ldots \ldots \ldots \ldots \ldots \ldots \ldots \ldots \ldots \ldots \ldots \ldots$

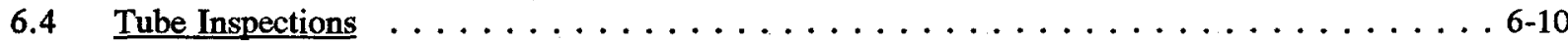

7 WESTINGHOUSE STEAM GENERATORS $\ldots \ldots \ldots \ldots \ldots \ldots \ldots \ldots \ldots \ldots \ldots \ldots \ldots$

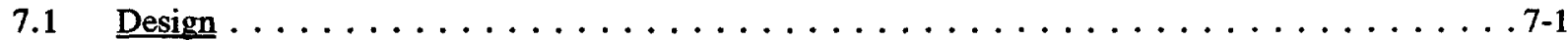

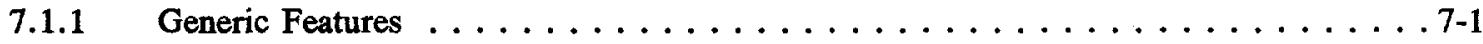

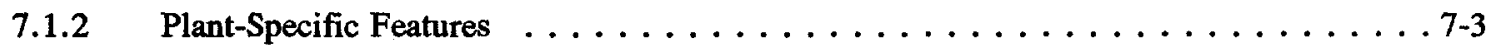

7.2 Locations Susceptible to Circumferential Cracking $\ldots \ldots \ldots \ldots \ldots \ldots \ldots \ldots \ldots \ldots$

7.2.1 Expansion Transition and/or Top of Tubesheet Region . . . . . . . . . . . . 7-4

7.2.1.1 Partial-Depth Hardroll Steam Generators . . . . . . . . . . . 7-4

7.2.1.2 Full-Depth Hardroll Steam Generators . . . . . . . . . . . 7-5

7.2.1.3 WEXTEX Steam Generators . . . . . . . . . . . . . . 7-8

7.2.1.4 Hydraulic Steam Generators . . . . . . . . . . . . . 7-9

7.2.2 Small-Radius U-Bends . . . . . . . . . . . . . . . . . . 7-11

7.2.3 Dented Locations . . . . . . . . . . . . . . . . . . . . . . 7-14

7.2.3.1 Fatigue Cracks at North Anna 1 and Indian Point $3 \ldots \ldots \ldots \ldots$ 7-16

7.2.3.2 Non-Fatigue Cracks . . . . . . . . . . . . . . . 7-17

7.2 .4 Sleeve Joints . . . . . . . . . . . . . . . . . . 7-21

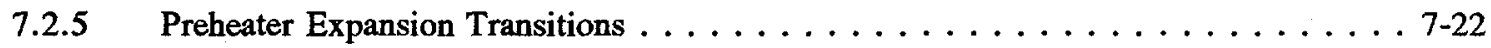

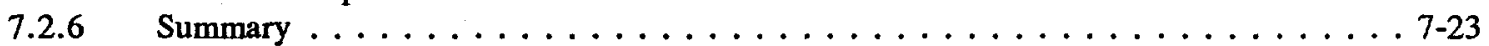

7.2.6.1 Partial-Depth Hardroll Steam Generators . . . . . . . . . . . . 7-23

7.2.6.2 Full-Depth Hardroll Steam Generators . . . . . . . . . . . . . . . 7-23

7.2.6.3 WEXTEX Steam Generators . . . . . . . . . . . . . . 7-24

7.2.6.4 Hydraulic Steam Generators . . . . . . . . . . . . 7-24

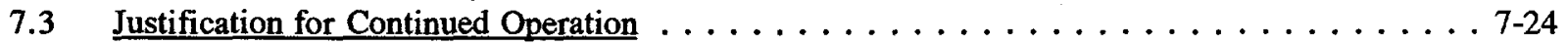

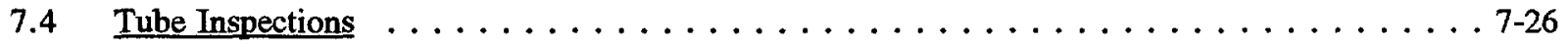

8 STEAM GENERATORS WITH ALLOY 690 TUBES $\ldots \ldots \ldots \ldots \ldots \ldots \ldots \ldots \ldots \ldots$. . . . . . . . . .

8.1 Design and Locations Susceptible to Circumferential Cracking $\ldots \ldots \ldots \ldots \ldots \ldots \ldots$.1

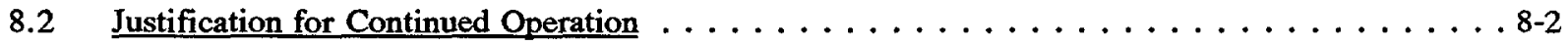

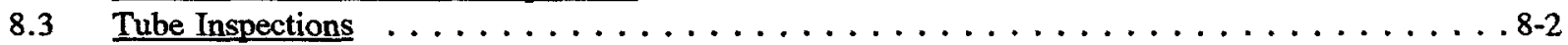

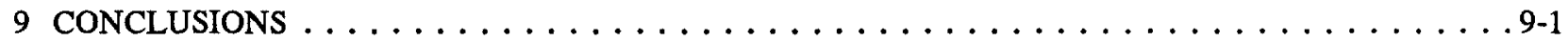

APPENDIX A: STEAM GENERATOR TUBE SLEEVES $\ldots \ldots \ldots \ldots \ldots \ldots \ldots \ldots \ldots$

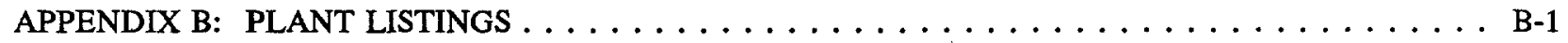

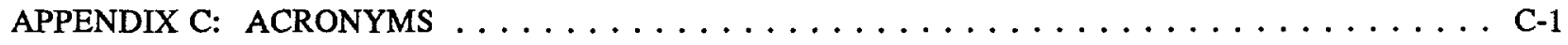

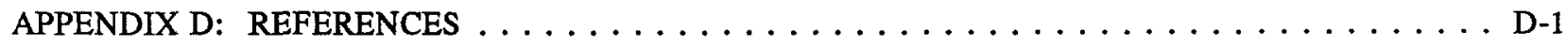




\section{LIST OF FIGURES}

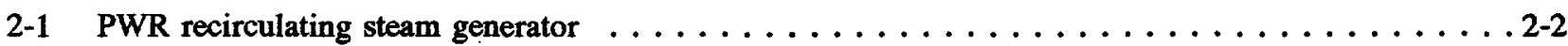

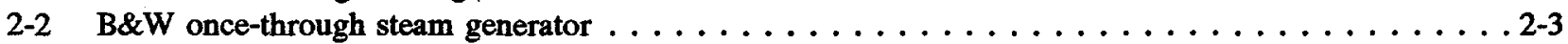

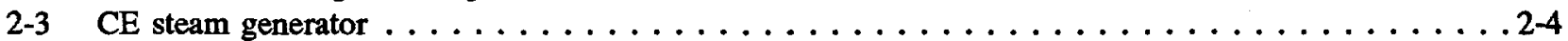

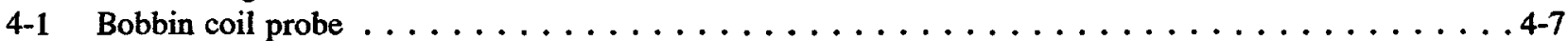

4-2 Rotating pancake coil probe . . . . . . . . . . . . . . . . . . . 4-8

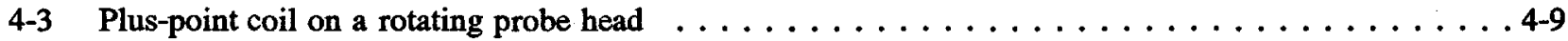

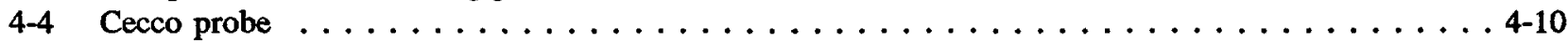

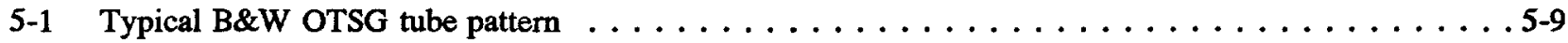

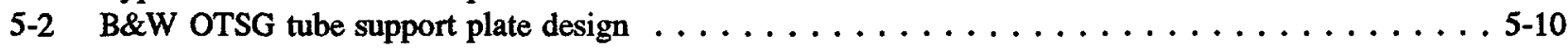

6-1 Typical CE recirculating steam generator (RSG) tube pattern $\ldots \ldots \ldots \ldots \ldots \ldots \ldots \ldots$ 6-12

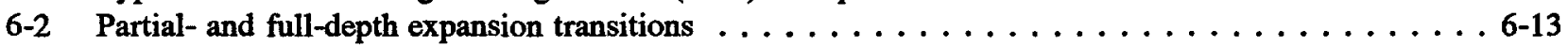

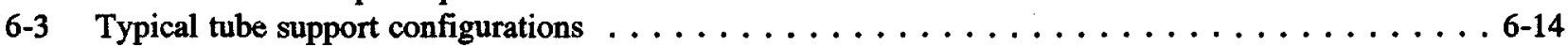

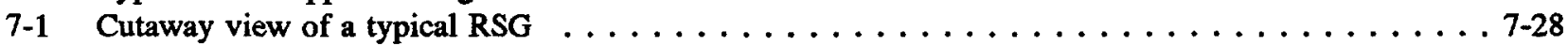

7-2 Typical Westinghouse Model 51 RSG tube pattern . . . . . . . . . . . . . . . . 7-29

7-3 Typical Westinghouse steam generator with a preheater (Model D-2) $\ldots \ldots \ldots \ldots \ldots \ldots$. . . . . .

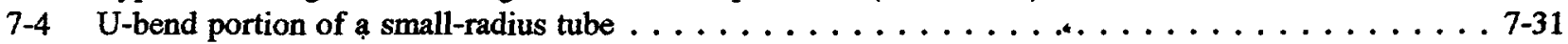

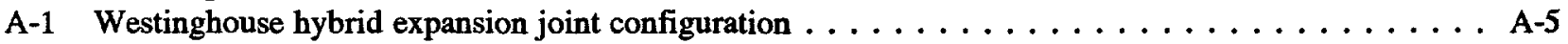

A-2 Westinghouse hybrid expansion joint sleeve $\ldots \ldots \ldots \ldots \ldots \ldots \ldots \ldots \ldots \ldots \ldots$

A-3 B\&W kinetically welded tube support plate sleeve $\ldots \ldots \ldots \ldots \ldots \ldots \ldots \ldots \ldots \ldots \ldots$ A-7

A-4 B\&W kinetically welded tubesheet sleeve $\ldots \ldots \ldots \ldots \ldots \ldots \ldots \ldots \ldots \ldots \ldots \ldots \ldots$

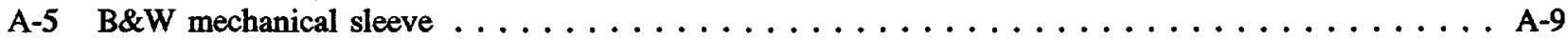

A-6 CE TIG-welded expansion transition zone sleeve $\ldots \ldots \ldots \ldots \ldots \ldots \ldots \ldots \ldots \ldots \ldots$

A-7 CE TIG-welded tubesheet sleeve $\ldots \ldots \ldots \ldots \ldots \ldots \ldots \ldots \ldots \ldots \ldots \ldots \ldots$. . . . . . . . . . .

A-8 CE TTG-welded tube support plate sleeve $\ldots \ldots \ldots \ldots \ldots \ldots \ldots \ldots \ldots \ldots \ldots \ldots \ldots$ A-12

A-9 Westinghouse laser-welded full-length tubesheet sleeve $\ldots \ldots \ldots \ldots \ldots \ldots \ldots \ldots \ldots \ldots$ A-13

A-10 Westinghouse laser-welded elevated tubesheet sleeve $\ldots \ldots \ldots \ldots \ldots \ldots \ldots \ldots \ldots$. . . . . . . .

A-11 Westinghouse laser-welded tube support plate sleeve $\ldots \ldots \ldots \ldots \ldots \ldots \ldots \ldots \ldots$ A-15 



\section{LIST OF TABLES}

5-1 Inspections at the expansion transition region in B\&W plants

$5-11$

5-2 Inspections at the lane/wedge region in B\&W plants

$5-12$

5-3 Inspections at dented locations in $B \& W$ plants

$5-13$

5-4 Inspections at sleeve joints in B\&W plants

$5-14$

6-1 Millstone 2 steam generator tube inspections (1987 to replacement)

6-15

6-2 Inspections at the expansion transition region in $\mathrm{CE}$ plants

6-16

6-3 Inspections at dented locations in CE plants

6-18

6-4 Inspections in the U-bend region of small-radii tubes in CE plants

6-20

6-5 Inspections at sleeve joints in CE plants

6-22

7-1 Inspections at the expansion transition region in Westinghouse partial-depth hardroll plants

7-32

7-2 Inspections at the top-of-tubesheet dented locations in Westinghouse partial-depth hardroll plants

$7-33$

7-3 Inspections in the U-bend region of small-radii tubes in Westinghouse partial-depth hardroll plants

$7-34$

$7-4$

Inspections at dented locations in Westinghouse partial-depth hardroll plants

$7-35$

Inspections at sleeve joints in Westinghouse partial-depth hardroll plants

7-36

Inspections at the expansion transition region in Westinghouse full-depth hardroll plants

$7-37$

7-38

Inspections in the U-bend region of small-radii tubes in Westinghouse full-depth hardroll plants

$7-39$

7-8 Inspections at dented locations in Westinghouse full-depth hardroll plants

$7-40$

7-9 Inspections at sleeve joints in Westinghouse full-depth hardroll plants

7-10 Inspections at the expansion transition region in Westinghouse WEXTEX plants

$7-41$

7-11 Inspections in the U-bend region of small-radii tubes in Westinghouse WEXTEX plants

$7-43$

7-12 Inspections at dented locations in Westinghouse WEXTEX plants

$7-44$

7-13 Inspections at sleeve joints in Westinghouse WEXTEX plants

$7-45$

7-14 Inspections at the expansion transition region in Westinghouse hydraulic plants

7-15 Inspections in the U-bend region of small-radii tubes in Westinghouse hydraulic plants 4

7-16 Inspections at dented locations in Westinghouse hydraulic plants

$7-49$

7-17 Inspections at sleeve joints in Westinghouse hydraulic plants

8-1 Inspections at the expansion transition region in plants with alloy 690 steam generator tubes

8-2 Inspections in the U-bend region of small-radii tubes in plants with alloy 690 steam generator tubes

8-3 Inspections at dented locations in plants with alloy 690 steam generator tubes

B-1 Plant Listing by Name

8-6

B-2 Plant Listing by Tube Material

B-2

B-3 Plant Listing by Vendor

B-4

B-4 Westinghouse Plant Listing by Tube Expansion Type and Material

B-5

B-5

Westinghouse Plant Listing by Steam Generator Model

B-6

B-6 Plants with Replacement Steam Generators (December 1996)

B-7

B-8 


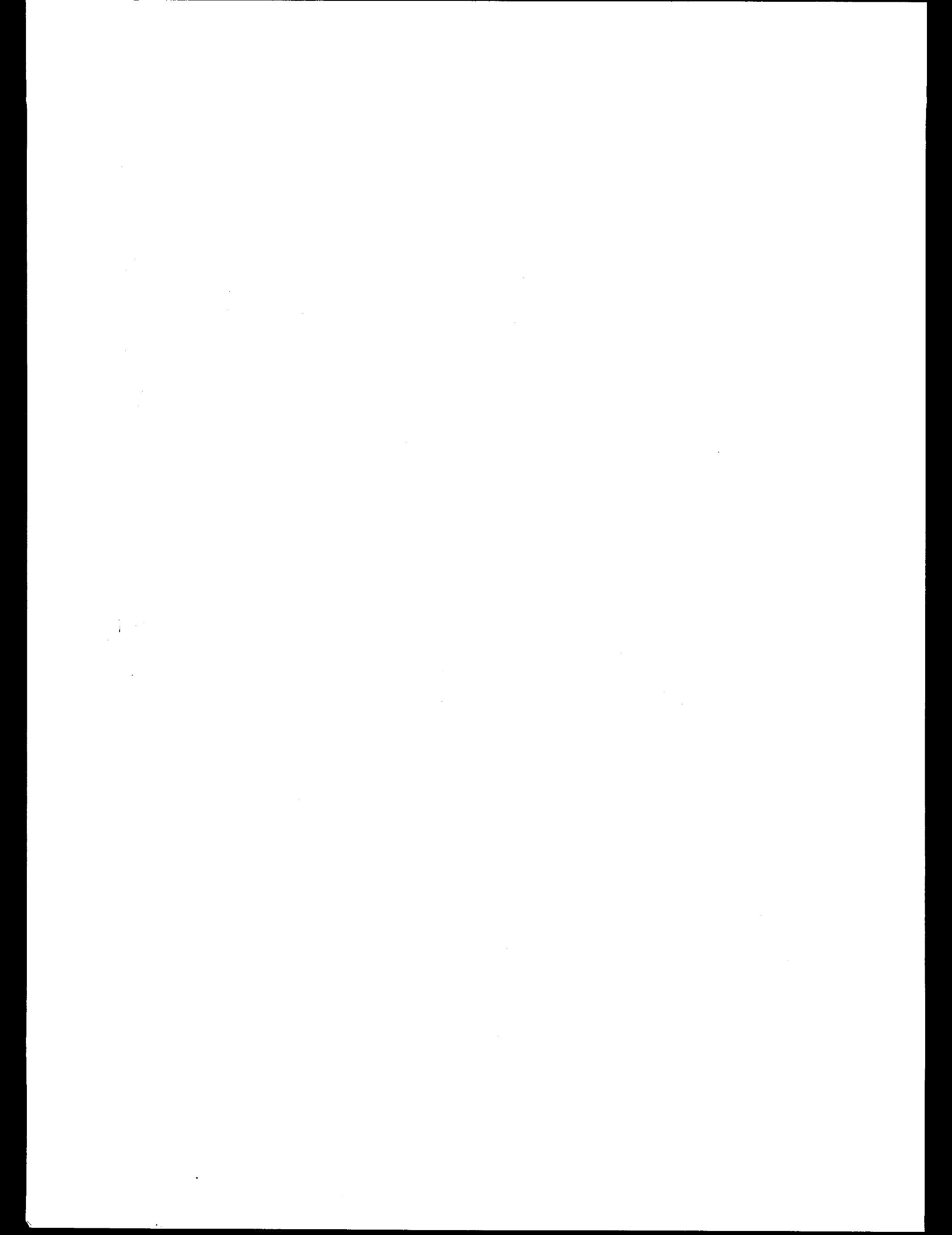




\section{EXECUTIVE SUMMARY}

Steam generator tubes in pressurized-water reactors (PWRs) were manufactured using materials susceptible to various forms of degradation. As steam generators in operating PWRs age, the number of tubes susceptible to degradation is expected to increase. Consequently, the U.S. Nuclear Regulatory Commission (NRC) has monitored steam generator operating experience for many years and has issued many generic communications related to steam generator tube integrity (Refs. 1 through 33).

The types of degradation affecting steam generator tubes include pitting, wear, thinning, wastage, and intergranular stress corrosion cracking (IGSCC). The orientation of these types of degradation is either axial, circumferential, or volumetric. Historically, these forms of degradation have been detected and characterized with a bobbin coil probe, a type of eddy current inspection probe. The bobbin coil probe is primarily sensitive to degradation with an axial component (i.e., axial and volumetric flaws). Circumferentially oriented tube degradation is particularly noteworthy since detection of this form of degradation requires the use of specialized eddy current inspection probes.

Circumferentially oriented steam generator tube degradation has been identified at various locations as a result of inspections and primary-to-secondary leaks. Circumferential indications have been detected in the expansion-transition region, dented locations (including dented tube-to-tube support locations), tube-to-sleeve joints, the U-bend region of small-radius tubes, and the 15th tube support plate and upper tubesheet secondary face (UTSF) in the lane/wedge region of once-through steam generators (OTSGs). The circumferential indications are attributed primarily to IGSCC and, to a lesser extent, to high cycle fatigue.

Large circumferential indications (in circumferential extent and depth of degradation) were identified at a few plants. In addition, the licensees for a few plants identified a significant number of circumferential indications. Although a number of tubes exhibited circumferential indications, the majority of these indications were of little or no safety significance, given the current practice of repairing all circumferential indications upon detection. However, a few severe indications were detected which warranted inspections at more frequent intervals to provide reasonable assurance that a safety-significant indication will not develop before the next inspection.

Because of the number of tubes identified with circumferential indications and the extent (i.e., size) of some of these indications, the NRC staff held several meetings with the PWR owners groups, the industry (Electric Power Research Institute), and various licensees. These meetings focused on efforts being undertaken to improve the ability to detect and size circumferential indications. During the period when these meetings were being conducted, the licensee for Maine Yankee Atomic Power Station began to identify a number of circumferential indications that were larger than anticipated for the 6-to-7-month operating time between inspections. These results, in part, led the licensee to perform additional inspections using a more sensitive technique. These inspections identified many more tubes with circumferential indications than had previously been identified. Penetrant testing and destructive examination of some tubes that had been removed from the steam generators confirmed that several indications identified with this more sensitive technique were, in fact, circumferential cracks.

In consideration of the events at Maine Yankee, the NRC staff issued Generic Letter (GL) 95-03, "Circumferential Cracking of Steam Generator Tubes," on April 28, 1995 (Ref. 2). GL 95-03 requested, in part, that all holders of PWR operating licenses or construction permits submit a safety assessment justifying continued operation, as well as a summary of their inspection plans for the next scheduled steam generator tube inspection outage as they pertained to the detection of circumferential cracking.

By late June 1995, the NRC staff received the majority of the PWR licensee submittals in response to GL 95-03. An initial review of these submittals and other supporting documentation (e.g., steam generator inspection reports) provided by the various licensees and vendors did not identify any significant safety concern that would warrant immediate NRC action. However, the NRC review did identify additional information that was needed for the staff to 
complete its evaluation. As a result, a number of plant-specific requests for additional information (RAIs) were prepared and sent to the licensees. In many instances, these RAIs asked licensees to explicitly address in their responses all areas potentially susceptible to circumferential degradation. In most cases, these RAIs were provided to the licensees before the next scheduled steam generator tube inspection outages to ensure that the licensees evaluated all appropriate areas before (or during) their next scheduled outages. Responses to the RAIs were received from September 1995 through December 1996.

In evaluating the responses to GL 95-03, the staff took into consideration that most circumferential indications are attributed to IGSCC, a time-dependent material degradation process which depends on many plant-specific factors. These factors include tube material (e.g., alloy 600, alloy 690), operating characteristics (e.g., cumulative operating time, temperature), tube microstructure (e.g., grain size and carbide distribution), and water chemistry practices. The staff also considered that IGSCC is exacerbated by the presence of crevices, residual stresses, material sensitization, cold work, and corrosive environments.

After reviewing various licensee submittals, the staff concluded that, in all cases, PWR licensees provided sufficient justification to operate their facilities as a result of circumferential steam generator tube degradation until inspections could be conducted or repairs (e.g., steam generator replacement) could be implemented. The staff based its conclusions on the following factors:

(1) the scope and results of the prior inspection

(2) the operating experience at similarly designed and operated units

(3) the operating conditions at the plant (e.g., hot-leg temperature, water chemistry practices, leakage monitoring, cumulative steam generator operating time)

(4) mitigating actions taken by the licensee (e.g., shotpeening, rotopeening, in situ stress relief)
(5) the operating time until the next steam generator tube inspections were to be conducted or repairs (i.e., steam generator replacement) were to be implemented by the individual PWR licensees

(6) the risk and potential consequences of a range of steam generator tube rupture events as discussed in NUREG-0844, "NRC Integrated Program for the Resolution of Unresolved Safety Issues A-3, A-4, and A-5 Regarding Steam Generator Tube Integrity," which was issued in September 1988 (Ref. 27)

In general, reasonable assurance of tube integrity was provided through a combination of inservice inspection, tube repair, primary-to-secondary leak rate monitoring, preventive measures (such as chemistry control), and analyses (e.g., condition monitoring and operational assessments) to verify that safety objectives were being met. These methods were used to provide defense-in-depth, and all plants relied on these methods to provide reasonable assurance of steam generator tube integrity and plant safety.

The staff has assessed the results of several inspections performed since GL 95-03 was issued. These assessments confirmed the various licensees justifications for operating until the next steam generator tube inspection outage. In some cases (e.g., Byron 1), many circumferential indications were detected; however, the structural and leakage integrity of the tubes was not compromised by these indications. It is important to note that although a number of tubes exhibited circumferential indications, the size of the circumferential indications is of greater safety significance than the number of indications. 


\section{INTRODUCTION}

Steam generator tubes in pressurized-water reactors (PWRs) are susceptible to various forms of degradation, including pitting, wear, thinning, wastage, and intergranular stress corrosion cracking (IGSCC). Historically, these forms of degradation have been detected and characterized with a bobbin coil probe, a type of eddy current inspection probe. The bobbin coil probe is primarily sensitive to degradation with an axial component (i.e., axial and volumetric flaws). As a result, forms of degradation which are circumferentially oriented are particularly noteworthy since detection of these forms of degradation requires the use of specialized eddy current inspection probes.

Inspections with the bobbin coil probe proved ineffective at detecting circumferentially oriented tube degradation that began to emerge in the late 1970s. As a result, the nuclear industry developed new probes to supplement inspections performed with the bobbin coil probe. These new probes were more effective at detecting both circumferentially and axially oriented tube degradation. Inspections with these probes and primary-to-secondary tube leaks resulted in the identification of circumferentially oriented tube degradation at various locations in the steam generator, including the expansion-transition region, dented locations (including dented tube-to-tube support locations), tube-to-sleeve joints, the U-bend region of small-radius tubes, and the 15th tube support plate and upper tubesheet secondary face (UTSF) in the lane/wedge region of once-through steam generators (OTSGs). Identification of circumferentially oriented tube degradation resulted in the publication of several U.S. Nuclear Regulatory Commission (NRC) information notices (Refs. 8, 11, 14, and 17).

Circumferentially oriented steam generator tube degradation is generally attributed to IGSCC. Axially and circumferentially oriented IGSCC has been observed for a number of years and was identified in 1990 by the NRC as a source of significant degradation to tubes in PWR steam generators (Ref. 17). In addition to IGSCC, circumferential cracks have also been attributed to high cycle fatigue. Several NRC generic communications were issued in response to the detection of high cycle fatigue cracks in steam generator tubes (Refs. 16 and 23).
Rotating probes and Cecco probes are currently used to inspect locations susceptible to circumferentially oriented tube degradation. Rotating probes frequently have three eddy current coils per probe head, and the coils typically used in rotating probes for the detection of circumferential degradation include the pancake coil and the plus-point coil. Cecco probes are available in several different designs. The designs most commonly used in the United States are the Cecco-3 and Cecco-5 probes. Both of these designs have multiple transmit/receive coil pairs.

In the early 1990s, a few plants identified circumferential indications which were large in circumferential extent and depth of degradation. In addition, a significant number of circumferential indications were identified at a few plants, including Arkansas Nuclear One, Unit 2 (ANO-2) and Maine Yankee Atomic Power Station.

Because of the number of tubes identified with circumferential indications and the size of the indications, the NRC staff held several meetings with the PWR owners groups, the industry (Electric Power Research Institute), and various licensees. On September 26, September 27, and November 15, 1994, the NRC staff discussed circumferential steam generator tube cracking and the importance of detecting this degradation with the Westinghouse, Combustion Engineering (CE), and Babcock \& Wilcox (B\&W) owners groups, respectively. In addition, on January 12 and February 22, 1995, the NRC staff and industry representatives from the Steam Generator Strategic Management Program (SGMP) met to discuss ongoing efforts to improve the methods for detecting and sizing circumferential indications. Representatives from the SGMP stated that qualified techniques for detecting circumferential indications were available and that a qualified technique for sizing circumferential indications was under development. Subsequent to these meetings, the SGMP shared with the industry points to consider in circumferential crack detection and length sizing that reflected the results of plant inspections and laboratory testing up to that time (Ref. 34).

On December 23, 1994, the NRC issued Information Notice (IN) 94-88, "Inservice Inspection Deficiencies Result in Severely Degraded Steam Generator 
Tubes, " to all holders of operating licenses for PWRs (Ref. 8). This notice provided information related to inspection findings at Maine Yankee. In particular, Reference 8 highlighted weaknesses in the licensee's analysis of pancake coil data. (A pancake coil is one type of coil that is sensitive to circumferential degradation.) After Reference 8 was issued, the licensee performed additional pancake coil inspections during a refueling outage. These inspections led the licensee to identify a number of circumferential indications that were larger than anticipated for the 6-to-7-month operating time between the inspections. These results, in part, led the licensee to perform additional inspections using a rotating probe with a plus-point coil. The plus-point coil inspections identified many more tubes with circumferential indications than had previously been identified with the pancake coil screening criteria. Penetrant testing and destructive examination of some tubes that had been removed from the steam generators confirmed that several indications identified with the plus-point coil were circumferential cracks.

In consideration of the events at Maine Yankee, the NRC staff issued Generic Letter (GL) 95-03, "Circumferential Cracking of Steam Generator Tubes," on April 28, 1995 (Ref. 2). GL 95-03 requested, in part, that all holders of operating licenses or construction permits for PWRs submit a safety assessment justifying continued operation until the next planned steam generator tube inspections. In addition, GL 95-03 requested a summary of the inspections to be performed during the next steam generator tube inspection outage as they pertained to the detection of circumferential cracking.

By late June 1995, the NRC staff received the majority of the PWR licensee submittals in response to GL 95-03. An initial review of these submittals and other supporting documentation (e.g., steam generator inspection reports) provided by the various licensees and vendors did not identify any significant safety concern that would warrant immediate NRC action. However, the NRC review did identify additional information that was needed for the staff to complete its evaluation. As a result, a number of plant-specific requests for additional information (RAIs) were prepared and sent to the licensees. In many instances, these RAIs asked licensees to explicitly address in their responses all areas potentially susceptible to circumferential degradation. In most cases, these RAIs were provided to the licensees before the next scheduled steam generator tube inspection outages to ensure that the licensees evaluated all appropriate areas before (or during) their next scheduled outages. Responses to these RAIs were received between September 1995 and December 1996.

Since the issuance of GL 95-03, many PWR licensees have inspected their steam generator tubes to identify indications of circumferentially oriented degradation. These inspections have revealed the presence of this form of degradation; however, in all cases evaluated by the staff, the severity of the indications was limited (i.e., the tubes were capable of performing their intended safety function with additional regulatory margins).

This report provides background information and the current status of circumferential cracking in PWR steam generator tubes. Section 2 describes PWR steam generator designs. Section 3 discusses GL 95-03 and presents a generic summary of the staff's assessment of the responses. Section 4 briefly summarizes the nondestructive examination techniques typically used to inspect steam generator tubes for degradation. Sections 5, 6, and 7 respectively discuss the plant-specific reviews of the GL 95-03 responses for Babcock \& Wilcox (B\&W), Combustion Engineering (CE), and Westinghouse plants with steam generators containing alloy 600 tubes. Similarly, Section 8 discusses the plant-specific review for plants with steam generators containing alloy 690 tubes. Section 9 gives the staff's conclusions regarding the issue of circumferential cracking of steam generator tubes.

This report also includes a number of appendices. Appendix A discusses the various types of sleeve designs and the associated operating experience with respect to circumferentially oriented degradation. Appendix B lists plants by name, vendor, steam generator tube material, and steam generator tube expansion technique. Appendix $\mathrm{C}$ lists acronyms and abbreviations used in this report. Appendix D lists the references.

This report is intended to be representative of significant operating experience pertaining to circumferential cracking of steam generator tubes from April 1995 through December 1996. Steam generator operating experience prior to April 1995 is included in this report, as appropriate, for 
completeness. The figures provided in this report are for illustrative purposes only and are not to scale. This document only summarizes some of the more pertinent information supplied by licensees and their vendors and is not intended to replace the original material. For additional information pertaining to plant-specific actions and responses, the reader should refer to the appropriate reference material. 


\section{STEAM GENERATOR DESIGNS}

The steam generators in PWRs are shell-and-tube heat exchangers that use the heat from the primary reactor coolant to make steam to drive turbine generators. A typical PWR plant has two to four steam generators per reactor, each with several thousand tubes (up to 15,531 ). The primary reactor coolant passes through the steam generator tubes and boils water on the outside of the tubes (secondary side) to make dry saturated steam for turbine generators and auxiliary systems. The steam generators also serve as a heat sink for the reactor coolant system under normal, abnormal, and emergency conditions.

The steam generators are designed to confine radioactivity from neutron activation or fission products to the primary coolant during normal operation. However, the primary reactor coolant is at a higher pressure than the secondary coolant, so any leakage through defects in the tubes (or PWR tubesheets) is from the primary (radioactive) to the secondary (nonradioactive) side. Consequently, a defect penetrating through a steam generator tube can release radioactivity outside the reactor containment through the pressure relief valves, the condenser off-gas, or other paths in the secondary system (Ref. 24). To minimize the potential for release of radionuclides, the steam generator tubes must have adequate integrity.

Steam generators currently operating in the United States are of two major types: the recirculating U-tube type, manufactured primarily by Westinghouse and CE (Figure 2-1), and the once-through type manufactured by B\&W (Figure 2-2). The following paragraphs briefly describe each of these steam generator types with an emphasis on those aspects that may affect steam generator tube degradation and, in particular, circumferential cracking. A more detailed description of the different designs is presented in Sections 5.1, 6.1, and 7.1 for $B \& W, C E$, and Westinghouse steam generators, respectively.

Figure 2-1 presents a cross-section of a simplified PWR recirculating steam generator (U-tube type). In this design, the tube bundle consists of many thousands of individual tubes, each welded to a thick plate (called a tubesheet) with a hole for each tube end located near the bottom of the recirculating steam generator vessel. The tubes are expanded into the tubesheet either for the entire thickness of the tubesheet (full-depth expansion) or for a portion of the tubesheet (partial-depth expansion). The tubes are supported above the tubesheet with plates or eggcrate-type dividers at a number of fixed axial locations along the tube bundle and with various shaped bars and small plates in the U-bend region of the tube bundle (Ref. 24). All of the steam generator tubes in the Westinghouse-designed steam generators are U-shaped, while the larger-radius tubes in the CE steam generators have two 90-degree bends, as shown in Figure 2-3.

The once-through steam generators (OTSGs) manufactured by $B \& W$ use straight heat exchanger tubes with a tubesheet at both the top and bottom of the tube bundle, as shown in Figure 2-2. The B\&W plants have two steam generators per plant, each with approximately 15,500 tubes arranged in a triangular pattern. The tubes are installed in the tubesheet in the same way as the tubes in the recirculating steam generators (i.e., partially expanded and welded). The OTSG design has an "untubed" lane, which provides access for secondary-side inspections (Ref. 24). 


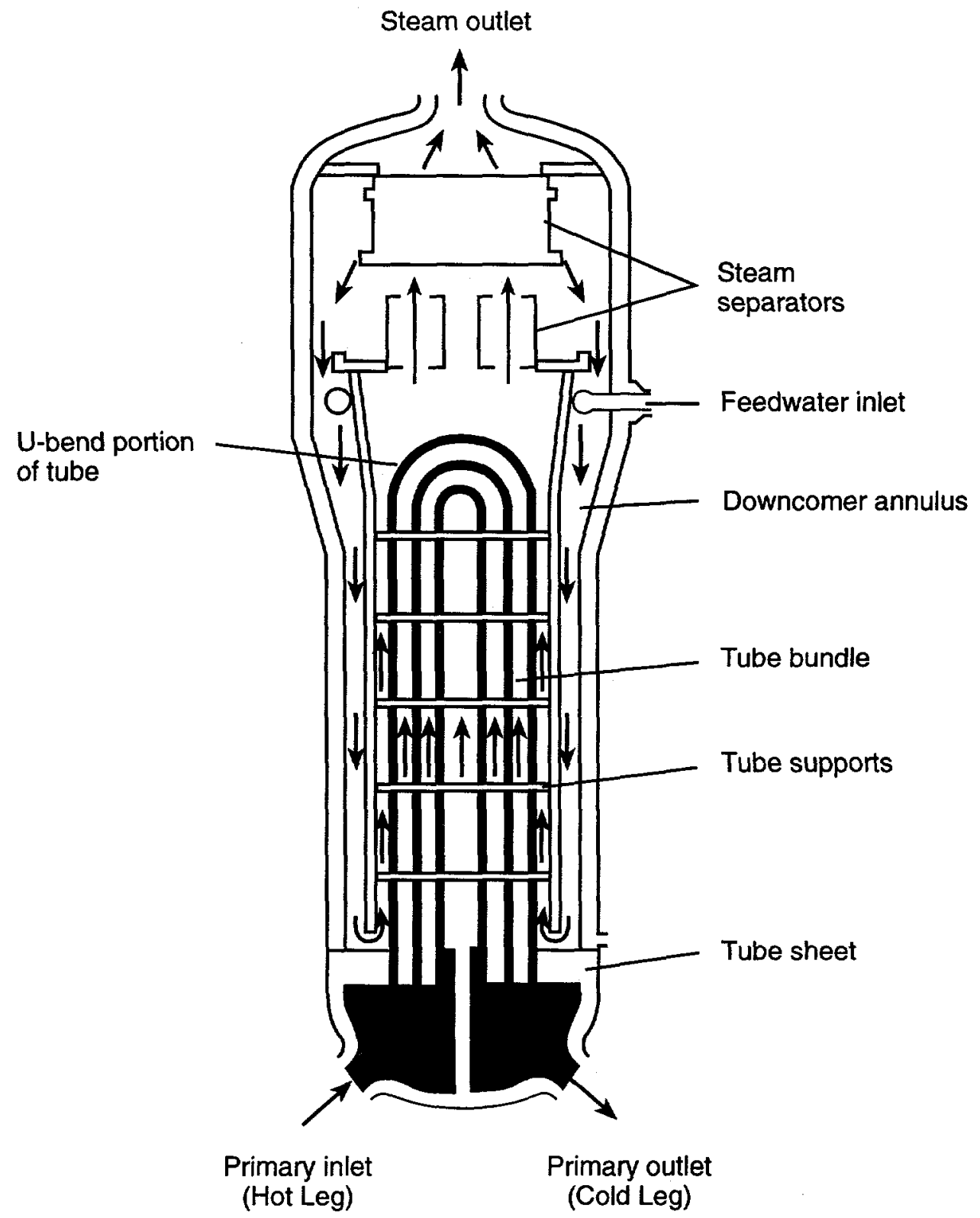

Figure 2-1 PWR recirculating steam generator 


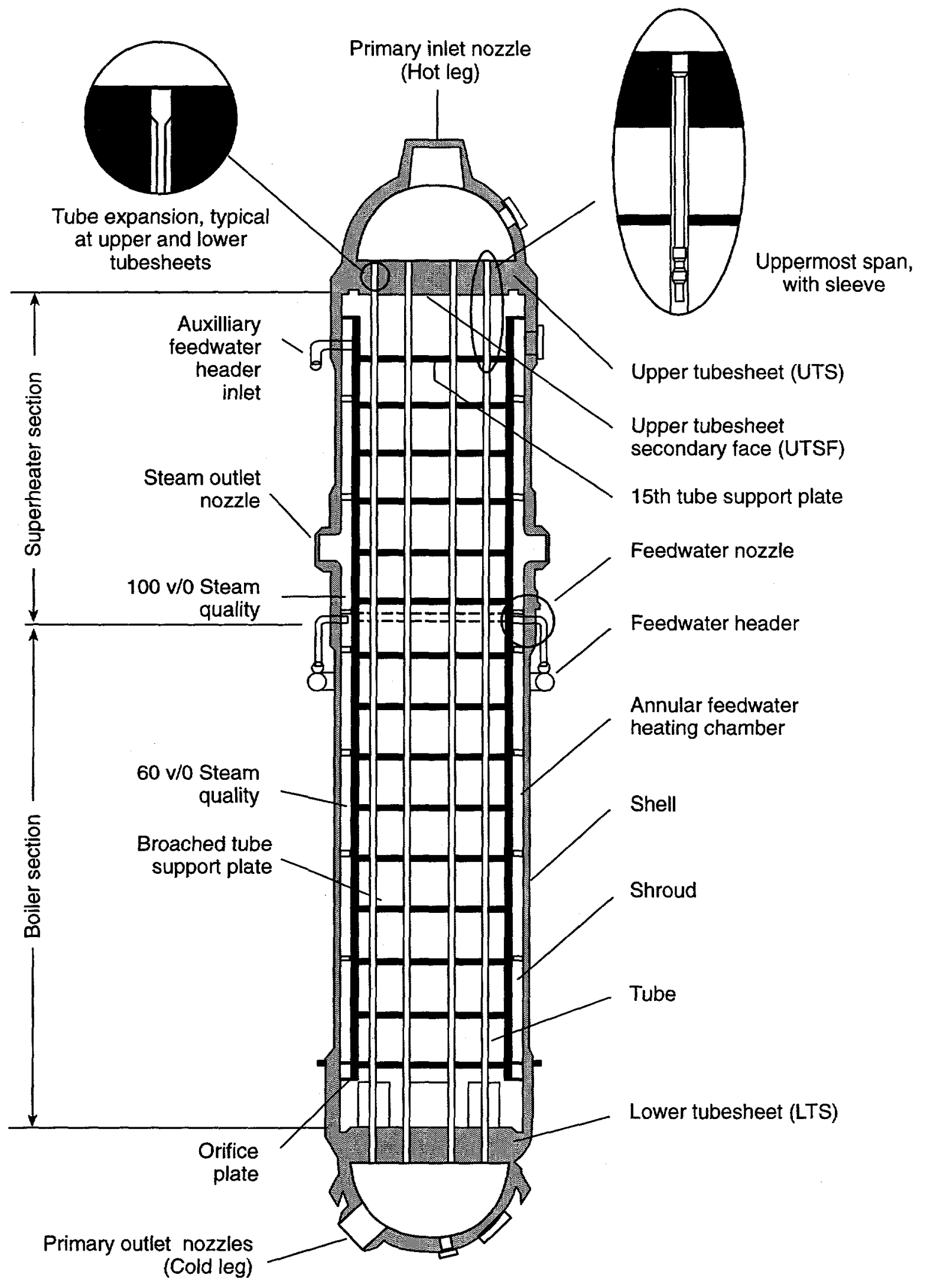

Figure 2-2 $B \& W$ once-through steam generator 


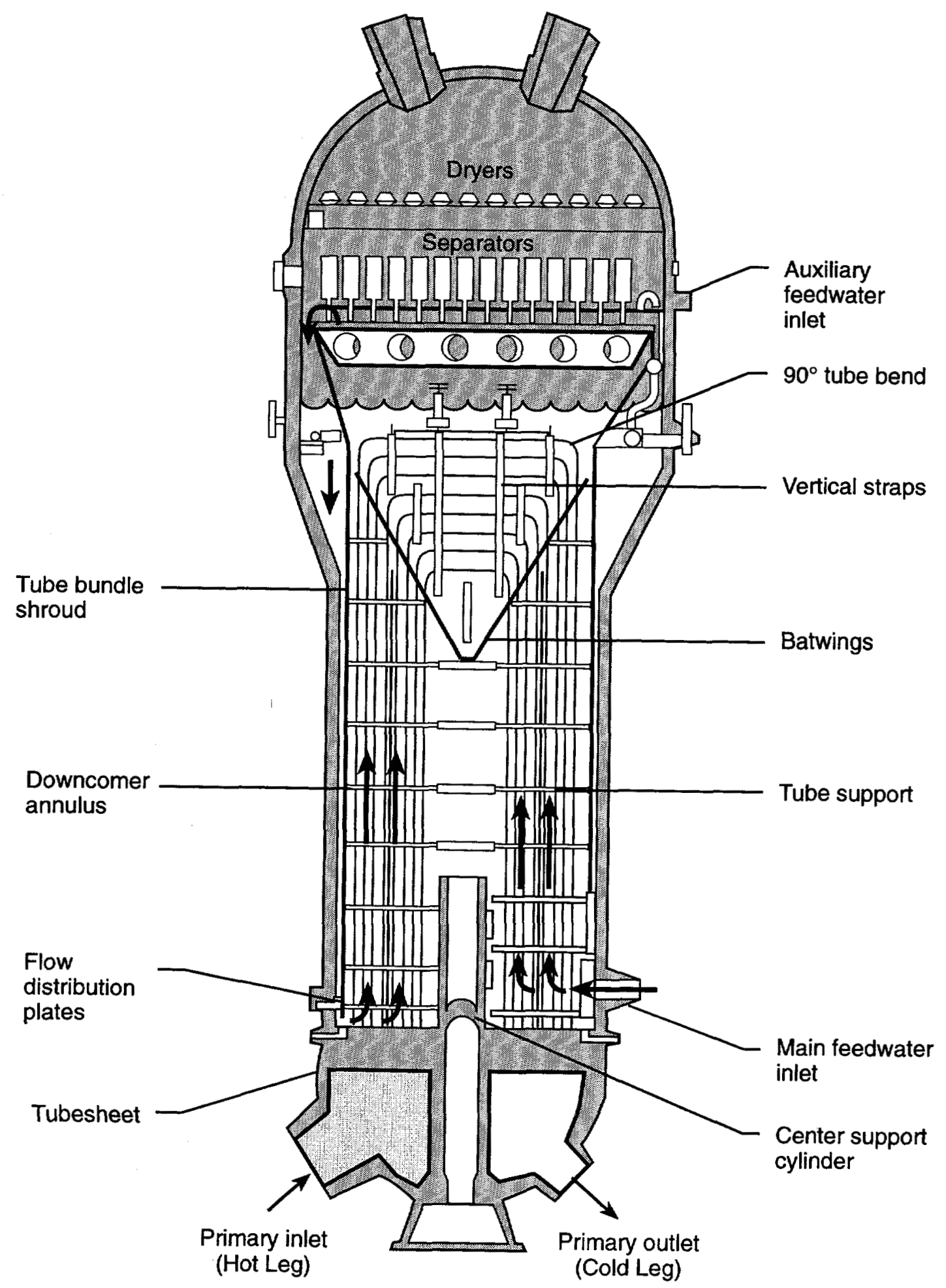

Figure 2-3 CE steam generator 


\section{GL 95-03, "CIRCUMFERENTIAL CRACKING OF STEAM GENERATOR TUBES"}

\subsection{Content of GL 95-03}

On April 28, 1995, the NRC issued GL 95-03, "Circumferential Cracking of Steam Generator Tubes," (Ref. 2) to all holders of operating licenses or construction permits for PWRs. The NRC issued GL 95-03 for three principal reasons:

(1) Notify addressees about the safety significance of the recent steam generator tube inspection findings at Maine Yankee Atomic Power Station.

(2) Request that all addressees implement the actions described within the generic letter.

(3) Require that all addressees submit to the NRC a written response regarding implementation of the requested actions.

In addition, GL 95-03 alerted addressees to the importance of performing comprehensive examinations of steam generator tubes using techniques and equipment capable of reliably detecting the types of degradation to which the steam generator tubes may be susceptible. The staff also noted that the performance of steam generator tube examinations is controlled, in part, by Appendix B to Title 10, Part 50, of the Code of Federal Regulations (10 CFR Part 50).

In GL 95-03, the NRC staff also requested that licensees take the following actions:

(1) Evaluate recent operating experience with respect to the detection and sizing of circumferential indications to determine the applicability to their plants.

(2) On the basis of the evaluation in Item (1) above, as well as past inspection scope and results, susceptibility to circumferential cracking, threshold of detection, expected or inferred crack growth rates, and other relevant factors, develop a safety assessment justifying continued operation until the next scheduled steam generator tube inspections.
(3) Develop plans for the next steam generator tube inspections as they pertain to the detection of circumferential cracking. The inspection plans should address, but not be limited to, scope (including sample expansion criteria, if applicable), methods, equipment, and criteria (including personnel training and qualification).

To document the outcome of these actions, the NRC staff requested that addressees prepare and submit the following:

(1) a safety assessment justifying continued operation, predicated on the evaluation performed in accordance with requested actions 1 and 2 (above)

(2) a summary of the inspection plans developed in accordance with requested action 3 (above) and a schedule for the next planned inspection

\subsection{Generic Assessment of the Industry's Responses to GL 95-03}

The NRC's review of the plant-specific responses to GL 95-03 specifically addressed the two areas listed above.

In evaluating the justification for continued operation, the staff considered the following factors:

(1) past inspection scope and results

(2) operating parameters (such as the hot-leg operating temperature (i.e., T-hot) and cumulative steam generator operating time)

(3) tube material and properties (e.g., heat treatment and stress relieving actions, tube loads, heat of material, tube location)

(4) past steam generator operating experience

(5) schedule for the next steam generator tube inspection 
(6) defense-in-depth measures (such as primary-to-secondary leakage monitoring and emergency operating procedures)

(7) risk and potential consequences of a range of steam generator tube rupture events

To facilitate its reviews, the NRC divided the industry's steam generators into several groups. First, plants with alloy 600 steam generator tubes were distinguished from plants with alloy 690 steam generator tubes. The plants with alloy 690 steam generator tubes were treated as a single distinct group. The plants with alloy 600 steam generator tubes were further subdivided on the basis of steam generator vendor (B\&W, CE, or Westinghouse). The Westinghouse alloy 600 steam generators were then subdivided on the basis of the type of expansion transition (i.e., partial-depth roll expansion, full-depth roll expansion, explosive expansion, and hydraulic expansion), since most circumferential indications have been observed at this location. The staff elected to group the plants on the basis of expansion transition type, since plants with similar expansion transitions typically are of the same vintage. All CE plants with alloy 600 steam generator tubes have tubes which were explosively expanded the full length (i.e., depth) of the tubesheet. All B\&W OTSGs have tubes with partial-depth roll expansions, with the exception that Three Mile Island 1 (TMI-1) has kinetic expansions in the upper tubesheet (UTS) as a result of a significant chemistry excursion which is discussed in Section 5.1.2.

To evaluate the GL 95-03 responses, the staff first determined which locations were most likely to exhibit circumferential cracking. (The staff based this determination primarily on operating experience.) Circumferential cracking of steam generator tubes normally occurs at the tube locations where significant axial stresses are present.

For recirculating steam generators, these locations include expansion transition locations, dented locations, the U-bend region of tubes (particularly small-radius U-bend tubes), and sleeve joints. Among the entire PWR steam generator population, circumferential cracking has been observed at all of these locations. Other portions of tubes where axial stresses occur include tubes expanded into the tube support plate. These tubes are normally located on the cold-leg side of Westinghouse Model D4 and D5 steam generators. To the knowledge of the NRC, no circumferential cracking has been observed at these locations. Tubes have also been expanded at the hot-leg tube support plate elevations at Byron 1 and Braidwood 1 for implementation of a voltage-based tube repair criterion that applies to axially oriented tube degradation. These tubes are not in service (i.e., they are plugged), although they are relied upon to limit the motion of the tube support plate under postulated accident conditions. Similar tube expansions have also been performed in several $C E$ units at drilled tube support plate locations. These tubes are not in service.

For OTSGs, locations with axial stresses include expansion transition locations, dented regions, and sleeve joints. For these steam generators, only a limited number of service-induced circumferential indications have been observed at these locations. However, at TMI-1 a significant number of circumferential indications near the expansion transition in the UTS region were observed as a result of a significant chemistry excursion when the unit was shutdown, as discussed in Section 5.1.2. Most of the circumferential cracks in B\&W OTSGs occur in the lane/wedge region as a result of high cycle fatigue.

In order to evaluate the acceptability of each PWR licensee's justification for operation to the next steam generator tube inspection, the NRC reviewed the licensee's initial GL 95-03 response. This initial review focused on determining whether the licensee had adequately monitored all locations that are potentially susceptible to circumferentially oriented degradation (with particular emphasis on the expansion transition, since the majority of circumferentially oriented degradation occurs at this location).

In instances where locations were susceptible to circumferential cracking and monitored with techniques capable of reliably detecting such degradation, the NRC reviewed the licensee's inspection results. In all of these instances, either the results were acceptable, or the licensees had already implemented the appropriate action (e.g., limited the amount of time between tube inspections).

In instances where locations susceptible to circumferential cracking were either not monitored or were not inspected with techniques capable of reliably 
detecting such degradation, the staff evaluated various parameters to determine whether the justification for continued operation was acceptable. These evaluations considered such parameters as the operating time of the steam generators at the plant, the operating experience of the particular steam generators and similarly designed steam generators, the time interval until the next steam generator tube inspections, and the leakage monitoring program for the plant.

On the basis of these reviews, the NRC concluded that, in all cases, sufficient technical justification existed to justify operation of the units until the next steam generator tube inspection or until replacement of the steam generator could be implemented.

The staff then used a similar approach to evaluate each licensee's inspection plans for the next scheduled steam generator tube inspection. That is, the staff reviewed the operating experience of the plant and similarly designed plants, as well as the scope of the licensee's inspection program, to ensure that all locations susceptible to circumferentially oriented degradation were being monitored or that there was adequate justification not to monitor those locations at this time. (For example, a newly replaced steam generator with limited operating time would not necessarily require a full examination of all tube locations susceptible to circumferential cracking with a technique capable of detecting such degradation.)

As discussed above, the staff reviewed the information provided by the various licensees and vendors and did not identify any significant safety concern that would warrant immediate NRC action. However, the review did identify additional information the staff needed to complete its review. As a result, a number of plant-specific requests for additional information (RAIs) were prepared and sent to the licensees. In many instances, these RAIs focused on having the licensee explicitly address all areas potentially susceptible to circumferential degradation. In most cases, these RAIs were provided to the licensees before the next scheduled steam generator tube inspection outages to ensure that the licensees evaluated all appropriate areas before (or during) their next scheduled outages.

Responses to the RAIs were received from September 1995 through December 1996. In many instances, the staff held discussions with the licensees regarding their inspection scope and results before, during, and after the steam generator tube inspection outages to provide additional confidence that the licensees had performed comprehensive steam generator tube inspections including a detailed evaluation of the inspection results. The results of the NRC evaluation are contained in Sections 5 through 8. These sections primarily contain operating experience related to circumferentially oriented tube degradation; however, these sections also contain information pertaining to the scope of the next inspection. 


\section{INSPECTION, REPAIR, AND ASSESSMENT OF STEAM GENERATOR TUBES}

\subsection{Purpose of Steam Generator Tube Inspections}

The requirements for the inspection of steam generator tubes are intended to ensure that this portion of the reactor coolant system maintains its structural and leakage integrity. Structural integrity refers to maintaining adequate margins against gross failure, rupture, and collapse of the steam generator tubes. Leakage integrity refers to limiting primary-to-secondary leakage during normal operation and postulated accidents to within acceptable limits.

The structural criteria that the tubes are intended to meet are specified in Regulatory Guide 1.121, "Bases for Plugging Degraded PWR Steam Generator Tubes" (Ref. 33). Adequate leakage integrity during transients and postulated accidents is demonstrated by showing that the resulting leakage from the tubes will not exceed a rate that would violate offsite or control room dose criteria. These criteria are specified, in part, in 10 CFR Part 100 and in General Design Criteria 19 of Appendix A to 10 CFR Part 50.

To provide assurance of adequate structural and leakage integrity, licensees perform inservice inspections of the steam generator tubes. These inspections are intended to detect mechanical or corrosive damage to the tubes, which may result from manufacturing and/or inservice conditions. In addition, the inservice inspections of the steam generator tubes provide a means of characterizing the nature and cause of any tube degradation so that corrective measures can be taken. Tubes that show an indication of degradation that exceeds the tube repair limits specified in a plant's technical specifications are removed from service (by plugging) or are repaired (by sleeving), as discussed in Section 4.3.

The frequency of the inservice inspections of the tubes in at least one steam generator is generally every 12 to 24 calendar months, as specified in a plant's technical specifications. The specified maximum interval may need to be reduced to every 20 months in cases where previous inspections have shown extensive degradation, and may be increased to as much as every 40 months in cases where previous inspections have revealed minor degradation. These intervals are reduced or extended on the basis of the categorization of inspection results, as defined in the plant's technical specifications.

Although the technical specifications include a general provision to extend surveillances by 25 percent of the specified interval, this provision is not considered applicable to steam generator tube inspections; the above criteria indicate the only conditions under which the surveillance interval for steam generator tube inspections may be changed. This position was delineated in NRC GL 91-04, "Changes in Technical Specification Surveillance Intervals to Accommodate a 24-Month Fuel Cycle," issued on April 2, 1991 (Ref. 3). As a practical matter, however, utilities generally perform inspections at each refueling outage, which typically occurs every 12 to 18 months.

Since the purpose of the steam generator tube inspections is, in part, to ensure adequate structural and leakage integrity of the tube bundle, more frequent inservice inspections may be required, depending on the severity of the indications detected. To ensure that the frequency was adequate for the prior cycle, licensees for PWRs should assess the inspection results following every outage to ensure that the tubes, individually and collectively, retained adequate structural and leakage integrity. This type of assessment is typically referred to as "condition monitoring." In addition, licensees should project the condition of the tubes from the current inspection to the next inspection to ensure that the tubes will retain adequate integrity for the next operating interval. This type of assessment is typically referred to as an "operational assessment." These assessments should be performed since the inspection frequencies and tube repair criteria specified in the technical specifications were established on the basis of specific assumptions concerning various parameters such as the forms of degradation to which the tubes may be susceptible (if any), limitations of nondestructive examination techniques, and the rate of steam generator tube degradation. If any of these parameters exceed what was assumed during the development of the inspection intervals, the basis for 
the inspection frequency and tube repair criteria would no longer be considered valid.

In summary, the inservice inspection of steam generator tubes should be conducted at appropriate intervals, such that the structural and leakage integrity of the steam generator tubes is maintained with appropriate margins. These inspections should be adequate to detect degradation (such as circumferential cracking) at a sufficiently early stage to preclude the progression of the degradation to the point that the regulatory criteria regarding steam generator tube structural and leakage integrity can no longer be met during the interval between inspections.

\subsection{Eddy Current Testing}

Eddy current testing (ECT) is the primary means for inspecting steam generator tubes. This method involves inserting a test coil inside the tube and pushing and pulling the coil so that it traverses the tube length. The test coil is then "excited" by alternating current, thereby creating a magnetic field that induces eddy currents in the tube wall. Disturbances of the eddy currents caused by flaws in the tube wall produce corresponding changes in the electrical impedance as seen at the test coil terminals. Instruments are used to translate these changes in test coil impedance into an output that can be monitored by the data analyst. The depth of certain types of flaws can be determined by the observed phase angle response of this output signal. The test equipment is calibrated using tube specimens containing artificially induced flaws of known depth. Geometric discontinuities (such as the expansion transition and dents) and support structures (such as the tubesheet and tube support plates) also produce eddy current signals, making it very difficult to discriminate defect signals at these locations. Reference 24 contains a discussion regarding some of the basic principles of ECT.

In the 1970 s, single-frequency bobbin coil probes (illustrated in Figure 4-1) were typically the only probes used to inspect steam generator tubes. This probe was adequate for detecting and characterizing wastage, which was the dominant form of degradation observed at that time. The bobbin coil probe permits a rapid screening of the tube for degradation; however, it has several limitations:
- a general inability to permit characterization of identified degradation (e.g., axial, circumferential, or volumetric; single or multiple axial indications; etc.)

- relative insensitivity to detecting circumferentially oriented tube degradation

- limited capability to detect degradation in regions with geometric discontinuities (e.g., expansion transitions, U-bends, and dents) and deposits

In the late 1970 s and early 1980 s, other forms of tube degradation began to emerge. These new forms of tube degradation, in combination with the limitations of the bobbin coil discussed above, led to the development and refinement of additional eddy current inspection techniques. Some of these improvements were also a result of advancements in computer technology.

Among these emerging improvements in inspection technology, multifrequency techniques enabled test coils (such as the bobbin coil) to be "excited" at multiple frequencies rather than a single frequency. Multifrequency techniques were an improvement in eddy current technology since they could more readily detect very small-volume flaws (such as intergranular attack, stress corrosion cracks, fatigue cracks, and small pits) that were traditionally hard to detect with the single-frequency ECT methods. This improvement in detection capabilities resulted, in part, from the ability to isolate the signal produced by a defect by suppressing the changes produced by other unwanted parameters such as support plates and denting. Because the responses from the defect signal and those produced by the unwanted parameters are frequency-dependent, the analyst can essentially subtract the unwanted signal from the signal consisting of the defect and the unwanted signal. The signals used in this signal mixing process are from two different frequencies.

During the late 1970 s and early 1980s, both circumferential and axial cracking mechanisms were beginning to emerge as the dominant degradation mechanism. At the same time, the industry was developing probes that could more readily detect these forms of degradation. For example, in the 1982 time-frame, a 4x4 differentially linked surface riding pancake probe was used at Palisades to detect circumferentially oriented tube degradation. In 
subsequent outages, more advanced probes such as the $4 \mathrm{C} 4 \mathrm{~F}$ probe were used. The $4 \mathrm{C} 4 \mathrm{~F}$ probe was similar to the $4 \times 4$ probe except that it could traverse the bend in the tubes. With the pancake coil used in these probes, flaws of any orientation (axial, circumferential, or branched) can be detected since the eddy currents induced into the tube are impeded by flaws of any orientation.

In the mid-1980s, additional inspection probes were developed and implemented in the field. These probes included the $8 \times 1$ pancake array probe and the rotating probe with a pancake coil (typically referred to as a rotating pancake coil probe), illustrated in Figure 4-2. The licensee for Farley 1 and 2 was among the first to perform extensive examinations of the expansion transition region of the steam generator tubes. After conducting these examinations using the $8 \times 1$ probe; however, the licensee indicated that the signal-to-noise characteristics of this probe were of such an order that little improvement over bobbin probes was realized (Ref. 35). As rotating pancake coil probes evolved during the 1980 s, they were initially used on a limited basis to characterize various bobbin coil indications such as from the tubesheet region. When it became practical to use rotating pancake coil probes for large inspection programs, some utilities began inspecting 100 percent of the tubes at the expansion transition region.

Since the late 1980s and early 1990s, additional improvements have been made in eddy current inspection probes. Currently, inspections of steam generator tubes generally employ both a bobbin coil probe and an additional probe, such as a rotating probe, a Cecco probe, or both. The bobbin coil probe permits rapid screening of the tube for degradation and can be pulled through a tube at speeds exceeding 40 inches per second, while the rotating probes and/or Cecco probes circumvent some of the limitations of the bobbin coil (discussed above).

Early versions of the rotating probes generally contained one to three specialized test coils, which usually included at least one pancake coil that was sensitive to both axially and circumferentially oriented degradation. Other test coils used on these early rotating probe heads (early 1990s), if any, included an axially wound coil (which was sensitive to circumferentially oriented degradation) and/or a circumferentially wound coil (which was sensitive to axially oriented degradation). In late 1994 and early 1995, coils such as the plus-point coil and high-frequency pancake coil were used in the field. The plus-point coil reduced volumetric influences and was sensitive to both axially and circumferentially oriented degradation. It was originally developed for surface examination of reactor vessel welds and was designed to reduce geometry and permeability effects. (A plus-point coil on a rotating probe is depicted in Figure 4-3.) This probe configuration differentially pairs the axial and circumferential coils in one gimbal-mounted surface riding coil shoe, as depicted in Figure 4-3, to reduce the effects of geometry variations in the tube (Ref. 36).

Currently, the types of coils included on the rotating probe head depend on the user's needs. For example, the user may request that the rotating probe head include a mid-range pancake coil, a high-frequency pancake coil, and a mid-range plus-point coil. In addition, the licensee may specify whether the coil is magnetically biased or not. Magnetically biased coils can reduce interfering signals (i.e., permeability variations). The coils used in the rotating probe head at a specific plant depend on many factors including optimizing the coils for detecting the forms of degradation to which a tube may potentially be susceptible.

Each of the above mentioned test coils can be designed and driven at specific frequencies to ensure an optimal inspection of the tubing. In general, lower frequencies are better for detecting degradation initiating from the outside diameter of the tube, while higher frequencies are better for detecting degradation initiating from the inside diameter of the tube. The advantages of the rotating probes are that they are sensitive to circumferentially oriented degradation (which the bobbin probe is not), can better characterize the defect, and are less sensitive to geometric discontinuities. The major disadvantage of the rotating probes is their slow inspection speed (typically less than 1 inch per second). Because of this slow inspection speed, rotating probes are only used at specific locations (e.g., U-bends, sleeves, expansion transitions, dents, locations where there is a bobbin coil indication, and locations where a more sensitive inspection is needed).

Cecco probes (Cecco 3 and Cecco 5) operate differently from rotating probes. For example, a Cecco probe (depicted in Figure 4-4) contains 
multiple transmit and receive coils (rather than just a combined coil) and the Cecco probe is not rotated as it is pulled through the tube. Like the rotating probes, the Cecco probes are sensitive to circumferentially oriented degradation; however, characterization of degradation with these probes is currently limited. A major advantage of the Cecco probes is that they are capable of a much higher inspection speed (i.e., 12 to 15 inches per second) than the rotating probes.

\subsection{Tube Repairs}

The plant technical specifications set plugging and repair limits for the maximum allowable wall degradation beyond which the tubes must be removed from service by plugging or repaired by sleeving. Tube degradation is typically discovered during scheduled inservice examinations of steam generator tubes, and tube repair (plugging or sleeving) is required for all tubes with indications of tube degradation exceeding the tube repair limits. All plants have a depth-based repair limit that is applicable to all forms of steam generator tube degradation. Alternatives to this depth-based limit have been approved; however, no alternative tube repair limits have been approved for circumferential indications (in part because no qualified method exists for characterizing circumferential indications in a manner that can be reliably related to the integrity of those indications that may be left in service). The depth-based repair limit varies from plant to plant, but is typically 40 percent of the tube wall thickness. (That is, tubes with indications of degradation greater than or equal to 40 percent must be plugged or repaired.)

The plugging and repair limits are established on the basis of the minimum tube wall thickness necessary to provide adequate structural margins (in accordance with Reference 33) during normal operating and postulated accident conditions. These limits allow for eddy current error and incremental wall degradation that may occur before the next inservice inspection of the tube. These plugging and repair limits are conservatively established according to an assumed mode of degradation in which the walls are uniformly thinned over a significant axial length of tubing. These limits do not consider additional structural margins associated with defects such as small-volume thinning and pitting, and they do not consider the external structural constraints against gross tube failure provided by such support structures as the tubesheet and tube support plates.

Because of its conservative basis, the depth-based limit tends to be inappropriate for highly localized flaws (such as stress corrosion cracks) and flaws within the tubesheet. As a result, the industry has developed, and the NRC has approved, various alternative forms of repair criteria for specific forms of steam generator tube degradation. (For example, the GL 95-05 (Ref. 1) voltage-based limits are used for predominantly axially oriented outside diameter stress corrosion cracking (ODSCC) at tube support plate elevations, and the F-star limits are used for degradation confined within the tubesheet below the expansion-transition.)

\subsubsection{Plugging}

The plugging technique involves installing plugs at the tube inlet and outlet. After plugging, the tube no longer functions as the boundary between the primary and secondary coolant systems.

\subsubsection{Sleeving}

To prolong the life of severely degraded steam generator tubes, some utilities, with prior NRC approval, have repaired defective tubes by sleeving, as discussed in Appendix A. After sleeving, the repaired tube may remain in service.

\subsubsection{Replacement}

To avoid the need for derating the plant and the excessive downtime associated with inspecting and repairing steam generator tubes, some utilities are considering or have elected to replace severely degraded steam generators. The decision to replace a steam generator is largely economic rather than technical. Several utilities have decided to replace their original steam generators, others have chosen to operate the plant with the original steam generators until it is no longer economically viable to operate the plant. The duration of an outage for steam generator replacement varies; however, at the present time, steam generators can be replaced in 2 to 3 months.

To minimize the potential for the modes of tube degradation that have been identified to date, the replacement steam generators currently being installed contain the following improvements: 
(1) stainless steel lattice grid tube supports Stainless steel is more corrosion resistant than carbon steel resulting in a lower potential for tube support corrosion which can lead to tube denting and stress corrosion cracking. A lattice grid tube support configuration can result in a reduced amount of contact area between the tube and the tube support when compared to drilled hole tube support plates. This lower contact area can result in greater secondary coolant flow around the tubes which can lower the potential for accumulating corrosive deposits in the tube-to-tube support crevice.

(2) thermally treated alloy 690 tubes - These features (i.e., thermal treatment and alloy 690 tubes) reduce the potential for SCC throughout the tube bundle. Thermal treatment involves subjecting the mill-annealed tubes to a final heat treatment, thereby relieving fabrication stresses and further improving the tube's microstructure and its corrosion resistance.

(3) full-depth hydraulically expanded tubes Hydraulically expanding the tubes the full length (i.e., depth) of the tubesheet eliminates the crevice between the tube and the tubesheet and reduces the stresses at the expansion transition (when compared to other expansion techniques such as mechanically rolling the tube into the tubesheet).

Appendix B lists plants that have replaced steam generators.

\subsection{Summary}

Inspections of steam generator tubes at operating plants have demonstrated the capability to reliably detect certain forms of degradation (such as tube wear and wastage). However, the threshold for reliable detection of other forms of degradation (e.g., SCC) continues to be an issue. In addition, the reliable sizing of indications, both above and below the tube repair limit(s), remains an issue since very few degradation mechanisms can reliably be sized.

Limitations in the apparent ability of eddy current techniques to detect degradation led, in part, to the issuance of GL 95-03. Specifically, the identification of many more indications of circumferentially oriented tube degradation with the plus-point coil than with the pancake coil at Maine Yankee contributed to the issuance of GL 95-03. However, it is not necessarily the number of indications which is the prime concern, but the severity of those indications. In the case of Maine Yankee, evaluation of the inspection findings was completed after GL 95-03 was issued. This evaluation indicated that the tubes had adequate integrity (structural and leakage integrity). These results indicate that even though the ECT techniques at Maine Yankee had limitations, they enabled the licensee to detect the flaws at an early enough stage in the prior outage such that they did not become significant (i.e., from a structural and leakage integrity standpoint) following the operating interval between the inspections. However, it should be noted that the inspection interval at Maine Yankee was only approximately 6 months.

In summary, tube integrity can be ensured given a knowledge of the limitations of the techniques employed at a specific plant (including the procedures and analysts) and the implementation of appropriate restrictions on operating parameters (e.g., hot-leg temperature, water chemistry, and operating interval duration). Nonetheless, it is important to note that the techniques used at one plant may not ensure tube integrity at another plant. This is a result of plant-specific circumstances, including the susceptibility of the tubes to degradation, the growth rate of the degradation, the nature of any signals that may interfere with the eddy current data analysis, and the frequency of inspections.

As a result of these plant-specific circumstances affecting the ability to ensure tube integrity, it is important to implement the following precautions:

- Optimize examination methods to minimize noise and interfering signals in order to maximize flaw detection.

- Evaluate the influence of interfering signals on flaw detection.

- Evaluate the examination and analysis procedures to maximize the discrimination of flaws from unavoidable noise and interfering signals.

- Evaluate unique plant-specific circumstances necessitating special examination techniques or analysis procedures. 
Furthermore, it is important to have (1) site-specific steam generator eddy current data analysis guidelines that afford the data analyst valuable information on the unique conditions present at the plant; (2) site-specific training and performance demonstration programs for all steam generator data analysts; (3) qualified inspection techniques to detect known or postulated tube degradation mechanisms and to address the conditions that could exist in the steam generator tube bundle; (4) a protocol for ensuring adequate inspections (e.g., independent two-party review of the data; briefing analysts during the course of the outage when their evaluation differs from the final resolution of the indication) to reduce the probability of flaw signals being missed and not reported; (5) a tube removal program to validate nondestructive examination measurements, to assess tube structural conditions, and to determine the cause of the degradation mechanism; and (6) an assessment of the significance of the nondestructive examination results with regard to safe, reliable plant operation.

As mentioned above, limitations exist in the ability to size certain forms of degradation. The inability to reliably size degradation with current ECT methods results in the following costly and undesirable actions:

- Tubes may be repaired upon detection of a degradation mechanism that can not be reliably sized, since it is unknown whether the indication exceeds the tube repair limits, and NRC regulations require the use of qualified methods for performing nondestructive examination.

- Other techniques (such as ultrasonic testing and penetrant testing) may be required to further characterize the degradation and/or to ensure that tube integrity has not been compromised.

- In situ pressure testing of the tubes may be necessary to demonstrate that an indication has not compromised tube integrity.

- Tube pulls (removal of tube specimens) may be necessary to confirm the degradation mechanism, identify the root cause of the degradation, assess tube integrity, and/or assess inspection reliability (to detect and size degradation).
Assessment of tube integrity is necessary to ensure that the operating interval between inspections is appropriate. This assessment should be performed regardless of whether a tube, or a population of tubes, is repaired. Since pressure testing of tubes and tube pulls can not readily be performed for all tubes, sampling of the worst indications is necessary. However, given the inability to reliably size indications, questions arise regarding the ability to determine which indications to test. Fortunately, ECT data analysts are capable of qualitatively assessing the relative severity of indications of tube degradation. That is, a limited population of indications can be identified as being qualitatively more severe than another set of indications although absolute determination of the severity of the indications in this limited population can not be made.

Tubes removed and analyzed from Byron 1 in the 1994-1996 time-frame confirmed that it is possible to qualitatively assess the severity of indications. This permits licensees to select several (e.g., 10) of the most severe tubes for further evaluation (e.g., tube pulls, pressure testing) in order to assess whether tube integrity margins were met. However, caution must be used when comparing results from outage to outage since differences in acquisition techniques, the effects of deposits, and other interfering signals may change from outage to outage. Consequently, it may be necessary to perform additional pressure tests and/or tube pulls in order to confirm the inspection results and the degradation morphology. 


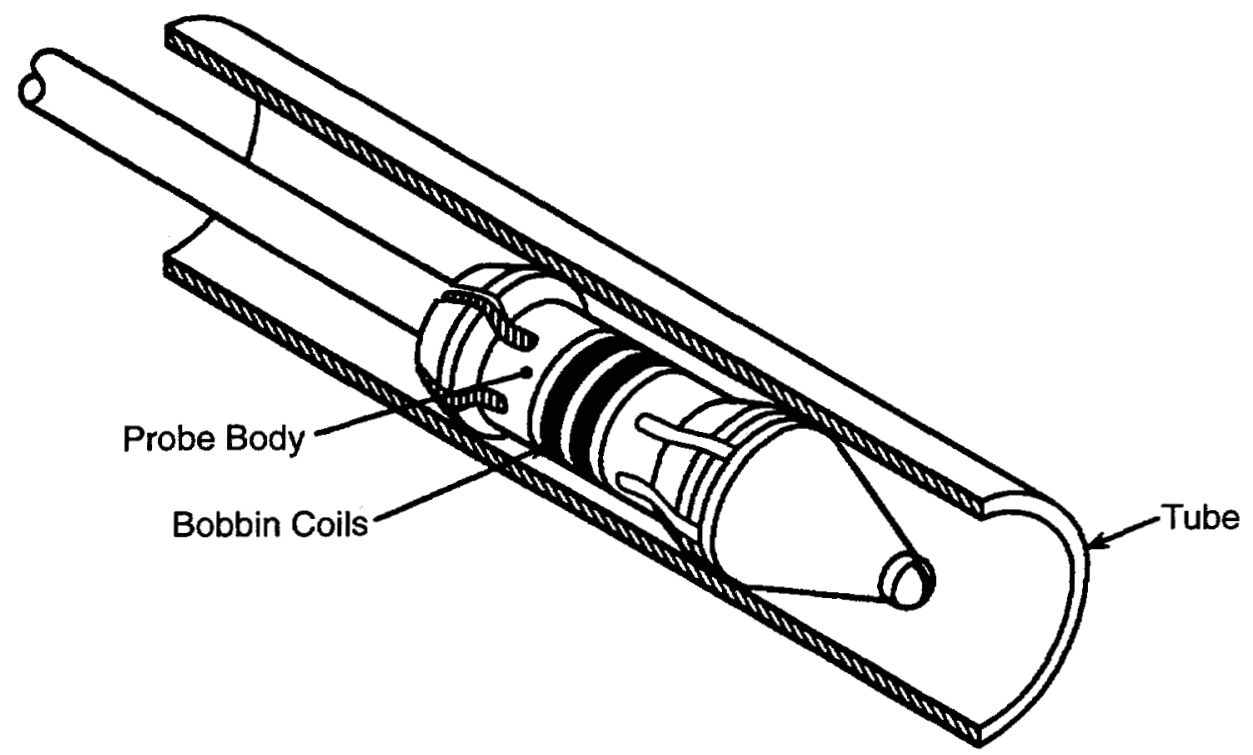

Figure 4-1 Bobbin coil probe 


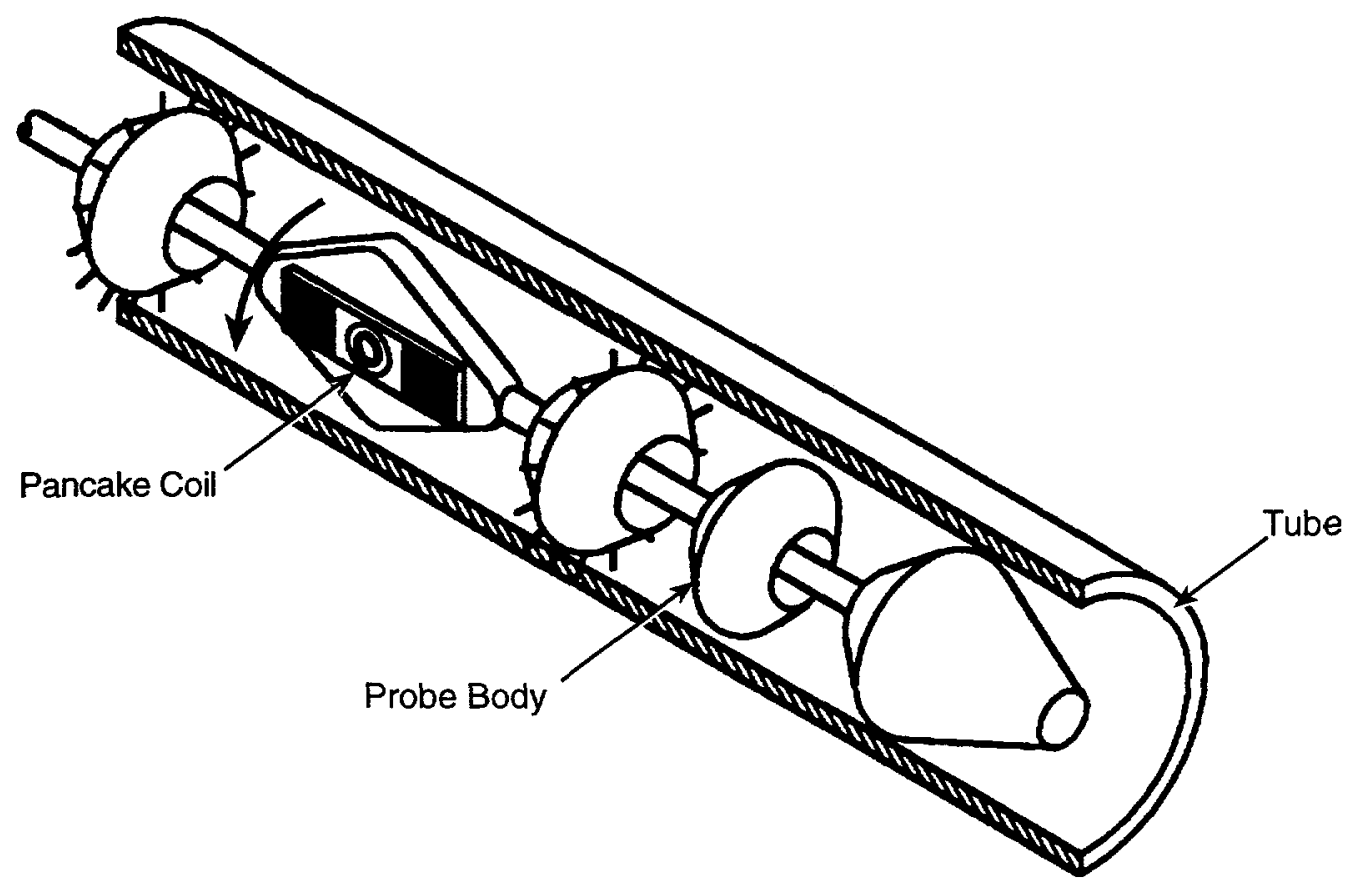

Figure 4-2 Rotating pancake coil probe 


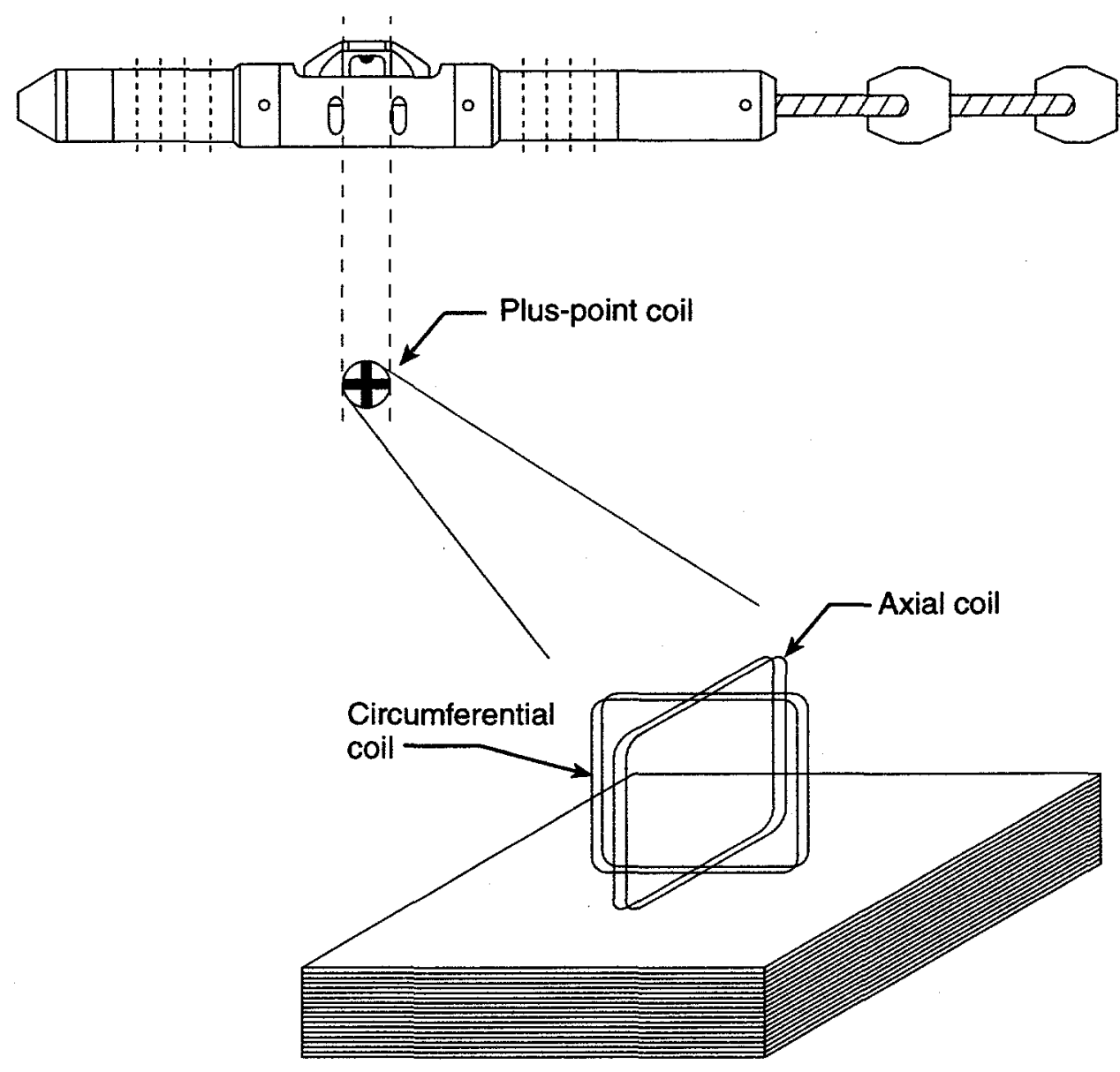

Figure 4-3 Plus-point coil on a rotating probe head 

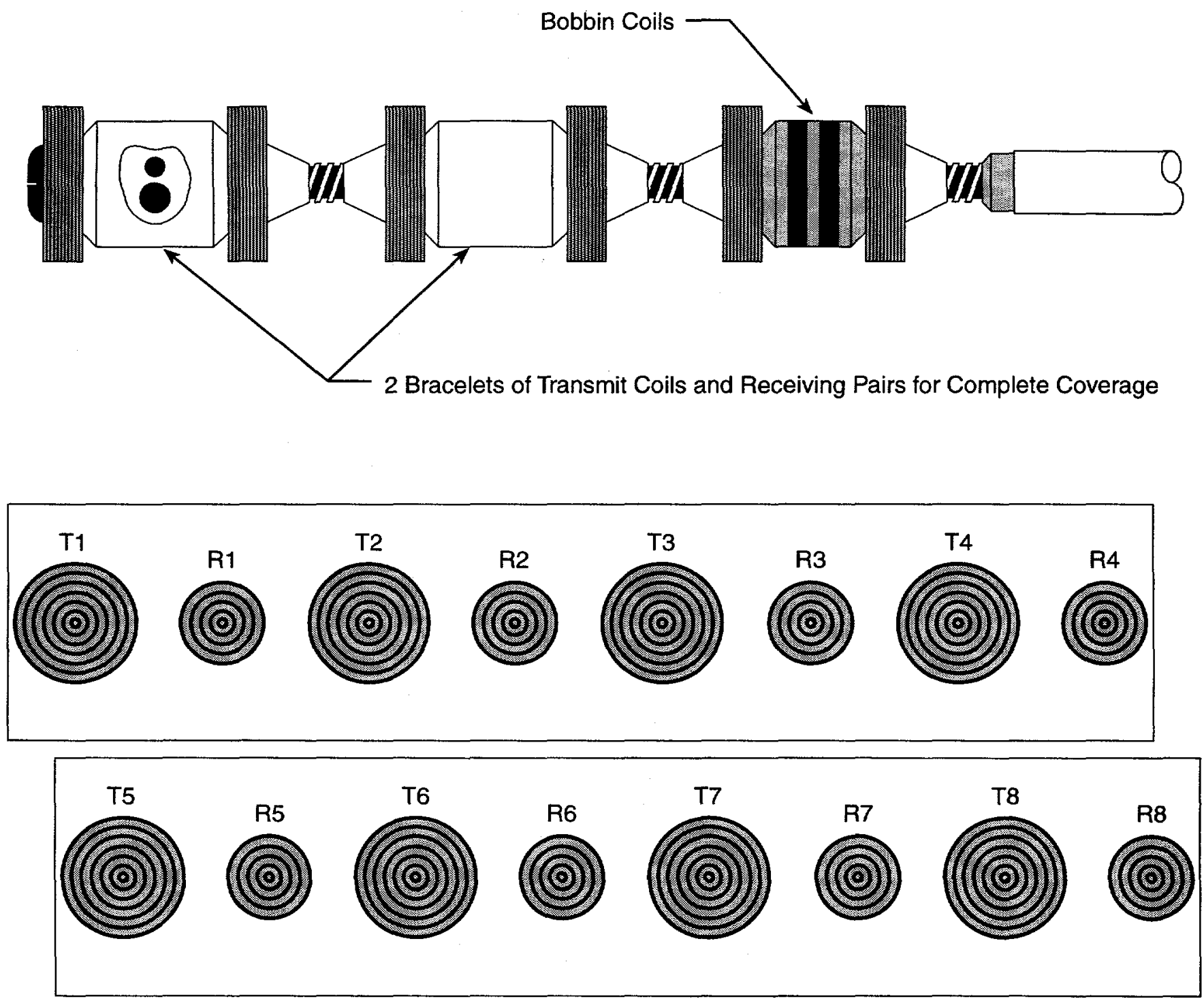

Figure 4-4 Cecco probe 


\section{BABCOCK AND WILCOX ONCE-THROUGH STEAM GENERATORS}

\subsection{Design}

The designs of the currently operating B\&W OTSGs are very similar; however, there are some differences between the various OTSGs as a result of design considerations or the operation of the steam generator. Generic features of the OTSGs are discussed in Section 5.1.1, while features unique to a given plant (or set of plants) are discussed in Section 5.1.2.

\subsubsection{Generic Features}

The B\&W OTSGs have straight heat exchanger tubes with an upper and lower tubesheet (UTS and LTS), as shown in Figure 2-2. Primary coolant is pumped through the tubes from top to bottom, while the secondary coolant moves around the outside of the tubes from bottom to top in a counter-flow direction. The secondary-system water enters a feed annulus above the ninth tube support plate, where it mixes with steam aspirated from the tube bundle area and is preheated to saturation. The saturated water flows down the annulus, across the LTS, and up into the tube bundle where it becomes steam. Boiling occurs about two-thirds of the way up the tube bundle. The area above the boiling region is the steam region in which the tubes are exposed to steam. The steam is superheated in this region. After passing through the superheated region near the UTS, the steam flow shifts from vertically upward to radially outward near the top of the tube bundle and then down the annulus to the steam outlet connection. Most of the secondary coolant is completely evaporated in a single pass through the steam generator (Refs. 24 and 31).

There are currently seven plants operating with B\&W OTSGs. These have two steam generators per plant, each with approximately 15,500 tubes arranged in a triangular pattern as shown in Figure 5-1. The tubes were made from mill-annealed alloy 600 and have a nominal outside diameter of approximately 15.875 millimeters $(\mathrm{mm})(0.625 \mathrm{inch})$ and a wall thickness of $0.889 \mathrm{~mm}$ ( $0.035 \mathrm{inch})$. During manufacture, each tube was mechanically roller expanded approximately $25 \mathrm{~mm}$ ( 1 inch) into the primary face of both the UTS and LTS. Since the tubesheet has a thickness of approximately 61 centimeters $(\mathrm{cm})$ (24 inches), this partial-depth expansion of the tubes resulted in a tube to tubesheet crevice of approximately $58 \mathrm{~cm}(23$ inches). The entire steam generator was heat treated after tube installation to reduce residual stresses from tube fabrication and installation and to increase resistance to primary water stress corrosion cracking (PWSCC) by developing more carbides at the grain boundaries. However, this process also resulted in sensitization (chromium depletion at grain boundaries), making the tubing susceptible to other forms of corrosion (including SCC in oxidizing acidic conditions).

The sensitized, mill-annealed alloy 600 tubes are supported and aligned between the tubesheets by 15 carbon steel tube support plates. The first 14 tube support plates have broached holes to provide three-point support (i.e., broached trefoil design) and a space for axial flow around each tube, as depicted in Figure 5-2. The highest (fifteenth) tube support plate has approximately 1600 drilled holes in the outer periphery of the plate, with the remaining holes being of the broached trefoil design.

The B\&W OTSG design has an "untubed" lane, which can be used to provide access for secondary side inspections. This untubed inspection lane extends from the periphery to the center of the tube bundle along Row 76 of the tube layout, as conceptually depicted in Figure 5-1.

\subsubsection{Plant-Specific Features}

There are unique features that affect steam generator tube integrity in several of the B\&W OTSGs. These features primarily involve differences in, or near, the expansion transition region (i.e., the transitional region of the tube where the tube changes from fully expanded against the tubesheet to non-expanded). The following paragraphs describe some of the more pertinent features that may affect a tube's susceptibility to circumferential cracking or its inspectability.

In many of the B\&W OTSGs, there is a limited population of tubes that were not stress relieved at the expansion transition. During the manufacturing process, several tubes were re-rolled following the full furnace stress relief to temporarily seal the tube 
during the shop hydrostatic tests (i.e., less than 200 known non-stress relieved tubes exist). These expansions did not have a post-roll stress relief, which makes them more likely candidates for cracking.

Four of the operating B\&W OTSG plants (including Crystal River 3) have tubesheet bore sizes of $\mathbf{1 6 . 1 3}$ $+0.15 /-0.05 \mathrm{~mm}(0.635+0.006 /-0.002$ inch $)$ which are smaller than those of the other B\&W units. The licensee for Crystal River 3 expects these smaller hole sizes resulted in a lower strain to mechanically roll the $15.875 \mathrm{~mm}(0.625$-inch) outside diameter OTSG tube into the tubesheet during the manufacturing process. With all other parameters being equal, the licensee believes that degradation such as PWSCC would be expected to occur first in areas of higher residual stresses (Ref. 37).

The expansion transitions in several tubes at Crystal River 3 are somewhat unique. Several tube ends in the UTS of the "B" OTSG were damaged as a result of the breakup of a burnable poison rod assembly (i.e., a loose part) in 1978 and 1979 (Refs. 31 and 37). The resulting damage to the seal weld of the tubes (i.e., the weld between the tube and the primary face of the tubesheet) caused some leakage from these tubes. To reduce the potential for these tubes to leak, a tube end repair was performed over the course of several outages. This process consisted of drilling out the flattened tube ends to an inside diameter which would more readily permit the passage of an eddy current probe. Tube end repairs performed during refueling outages 8 and 9 (1994) were followed by a field re-rolling, which was performed over the original UTS shop roll. No stress relief was performed following the field re-roll. In 1996, the repair process was revised such that, in general, the seal weld was left intact eliminating the need for the field re-roll. This modification to the repair process was adopted because of concerns regarding the creation of new locations potentially susceptible to circumferential cracking. During refueling outage 10 (1996), only nine tubes required field re-rolling. These nine re-rolls were performed as a result of over-drilling of the tube end during the repair process.

The TMI-1 OTSG expansion transitions in the UTS are also significantly different than the typical roll-expanded transitions in the other B\&W OTSGs, as a result of a significant chemical excursion in the early 1980s. In November 1981, primary-to-secondary leakage was detected in both OTSGs during a reactor coolant system hydrostatic test. Subsequent detailed examinations revealed many defective tubes. Metallographic examination of portions of tubes confirmed that the tube failures were initiated from the primary side (i.e., inside diameter) of the tubes in the form of circumferential intergranular stress corrosion cracks. The active chemical impurity causing the corrosion was sulfur in reduced forms, which had been inadvertently introduced into the reactor coolant system from sodium thiosulfate that had been used in the past as a containment spray additive for iodine removal. The vast majority of the defects occurred within 5.1 to $7.6 \mathrm{~cm}$ ( 2 to 3 inches) of the primary face of the 61 cm (24-inch) thick UTS (i.e., near the original roll transition). As a result, some tubes were plugged, and all tubes remaining in service were kinetically (explosively) expanded part-length through the UTS to create a new load-carrying and leak-limiting joint (Refs. 29 and 38). These kinetic expansion transitions were not stress relieved.

Another unique design feature for the TMI-1 OTSGs involves the "untubed" lane. Specifically, the UTS and LTS of the TMI-1 "A" OTSG were drilled before implementation of the open lane design. In order to accommodate the untubed lane, the UTS holes were plugged with welded tubesheet plugs. The LTS holes were plugged by installing a short thick-walled tube section that extends from the primary face to just beyond the secondary face of the tubesheet. The primary side of the tube was rolled to the tubesheet and seal welded using the same process used for normal tubes. The opposite end of the tube, protruding above the tubesheet, was sealed with a welded end cap (Ref. 39).

In addition to the unique plant-specific features mentioned above, Oconee 3 has three tubes that have been explosively expanded full length in both the UTS and LTS. Since the residual stresses in an explosive expansion transition may differ from those in a typical roll-expanded transition, the relative susceptibility of these locations to degradation may be different. 


\subsection{Locations Susceptible to Circumferential Cracking}

At the time of the original responses to GL 95-03, the $B \& W$ owners and licensees identified four regions as being potentially susceptible to circumferential cracking. Specifically, these regions included the uppermost span of tubes in the lane/wedge region; tube-to-tubesheet expansion transitions, including approximately 189 tubes that have not been stress-relieved and are therefore expected to be more susceptible to cracking; tube kinetic expansion transitions that have not been stress relieved (TMI-1 UTS only); and tube/sleeve expansions at sleeve roll transitions (Ref. 38).

\subsubsection{Uppermost Span of Unsleeved Tubes in the Lane/Wedge Region}

In June 1995, when the original GL 95-03 responses were submitted, the B\&W Owners Group reported that distinct service-induced circumferential cracking in B\&W units had only been observed in the uppermost span of unsleeved tubes in the lane/wedge region. The uppermost span includes the portion of a tube between the uppermost (fifteenth) tube support plate and the upper tubesheet secondary face (UTSF).

The lane/wedge region has been defined as a region of tubes abutting the outer half of the inspection lane (i.e., the "untubed" or open lane) and then flaring out into a wedge shape near the periphery of the tube bundle. The lane/wedge region, graphically depicted in Figure 5-1, includes about three rows of tubes on either side of the inspection lane and a few additional rows at the periphery of the tube bundle. The lane/wedge region, however, has not been defined in the technical specifications for all plants, and the tubes generally referred to as lane/wedge tubes in a plant's technical specifications may vary from plant to plant.

Many of the circumferential cracks that occur in this region are corrosion initiated. These initiations sites propagate through-wall and continue circumferentially in both directions around the tube as a result of a high-frequency, low-stress fatigue mechanism. Corrosion is initiated by concentrated chemical species carried by small water droplets in the inspection lane and then deposited on the tubes. The open lane is a cooler area of the generator, which in turn allows wet steam to deposit contaminants higher in the tube bundle, contributing to local degradation. The fatigue is vibration induced as a result of steam exiting the tube bundle (Ref. 28). The steam flow in the uppermost tube span is primarily across the tubes as it turns to exit the bundle (Ref. 38).

Circumferential cracks in the lane/wedge region have resulted in a number of outages as a result of tube leaks; however, no tube ruptures have occurred as a result of this degradation mechanism. Defective tubes with circumferential indications are plugged and frequently stabilized from the UTS to prevent damage to an adjacent tube should the degradation in the plugged tube continue to the point that the tube severs (Ref. 28).

The uppermost span of some tubes in the lane/wedge region were sleeved. Sleeving has been performed in all operating B\&W OTSG plants either to repair defective tubes or to stiffen the tubes to limit the potential for tube failure as a result of high cycle fatigue. As discussed in Appendix A, these sleeves are mechanical sleeves which are approximately $203 \mathrm{~cm}$ (80-inches) long. The sleeves are installed in the uppermost span of the tube, which is the location operating experience has indicated is susceptible to high cycle fatigue. The discussion above pertains to unsleeved tubes in the lane/wedge region.

\subsubsection{Expansion Transitions and Crevice Region}

Circumferential indications have been detected in B\&W OTSGs at the expansion transition and in the tubesheet crevice region. For the circumferential indications detected at the expansion transition, the indications were not service-induced. However, for the circumferential indications detected in the crevice region, both service-induced and non-service-induced indications were observed, although the service-induced indications were associated with intergranular attack. (Intergranular attack is typically volumetric in nature and more readily detectable with the bobbin coil than distinct circumferential cracks.) The following paragraphs provide additional details related to these events.

Non-service-induced circumferential cracks were observed in the TMI-1 steam generators as a result of a chemical excursion in the early 1980s (as discussed above). These circumferential cracks occurred while the unit was shut down (i.e., they were not service-induced) and were the reason for repairing the 
tubes using the kinetic expansion method mentioned above. These circumferentially oriented cracks initiated from the inside diameter and the vast majority occurred within 5.1 to $7.6 \mathrm{~cm}$ (2 to 3 inches) of the primary face of the $61 \mathrm{~cm}$ (24-inch) thick UTS (i.e., near the original roll transition). The repair process for these tubes involved kinetically (explosively) expanding the tubes part length through the UTS. These kinetic expansions were not subjected to a stress relief process; therefore, they are considered a potential site for circumferential cracking.

Service-induced circumferential indications were identified in the UTS crevice region in at least one plant (ANO-1). At ANO-1, one tube was removed for destructive examination to verify the type of indication and determine the damage extent and mechanism. As a result of the destructive examinations, the indications were attributed to intergranular attack initiating from the outside diameter of the tube. Some of the indications were circumferentially oriented (Ref. 40). The licensee concluded that the mechanism leading to the development of these indications most likely involved reduced sulfur species in an acidic environment (Ref. 40). The circumferential indications on the pulled tube were located at several axial elevations along one axis of the tube. Since the pulled tube was from the lane region and the indications were axially aligned, the licensee believed that axial stress may have played some role in their formation. In addition, these circumferential indications in the pulled tube were not in the uppermost span of the tube as defined above in Section 5.2.1 (i.e., they were above the UTSF).

The tube roll transition area (i.e., the expansion transition) is potentially susceptible to circumferential cracking. As mentioned previously, a small number of tubes were not stress relieved following re-rolling. The B\&W Owners Group concluded that these tubes were more likely candidates for cracking at the roll transition than tubes that were stress relieved. This is because stress relieving reduces the residual stresses and enhances the resistance of alloy 600 to caustic corrosion. In addition, the B\&W Owners Group concluded that since the roll transitions in B\&W OTSG units are normally in compression during operation, unlike a recirculating steam generator in which the tubes are under tension, the likelihood of circumferential cracking in the transitions is reduced (Ref. 38).

Although the tube roll transition area is potentially susceptible to circumferential cracking, no service-induced circumferential indications have been reported to occur at this location. In addition, no appreciable, if any, axial cracking had been observed at this location before June 1995. However, subsequent to the original submission of responses to GL 95-03 (June 1995), the expansion transition region was identified and confirmed to be susceptible to service-induced cracking (axial rather than circumferential cracks were observed). Specifically, axial indications associated with the expansion transitions have been noted in at least three B\&W units (Crystal River 3, Davis-Besse, and ANO-1). The inspection findings at these plants are discussed below.

At Crystal River 3, a single axial indication was detected in the roll transition in a tube that was re-rolled following the full bundle stress relief and a multiple axial indication was detected in the tube end, above the shop re-roll in the same tube. These indications were located in the roll transition in the UTS (i.e., the hot leg). The eddy current data provided clear indications that the tube had been rolled multiple times. The licensee believes the indication is attributable to PWSCC (Ref. 37).

At Davis-Besse, an axially oriented indication was detected during the examination of what was believed to be a non-stress-relieved roll transition. Similar to Crystal River 3, this indication was in the roll transition in the UTS (i.e., the hot leg). Subsequent review of shop records indicated that the expansion transition had not been re-rolled and was, therefore, stress relieved (Ref. 41). The licensee removed the roll transition portion of this tube for destructive examination. The destructive examination indicated that the indication was attributable to PWSCC. To ascertain whether the tube had been stress relieved, the licensee performed additional analyses and testing; however, the results were unavailable at the time this document was prepared (Ref. 37).

At ANO-1, several axially oriented and volumetric indications were detected in stress-relieved roll transitions in the UTS (i.e., the hot leg). The axial indications were attributed by the licensee to inside diameter initiated degradation (i.e., PWSCC). The 
volumetric indications were outside diameter initiated which may indicate that the indications are attributable to intergranular attack or closely spaced cracks. To further characterize the nature and cause for the upper roll transition indications (and other indications), the licensee for ANO-1 removed several tube sections for destructive examination. The results from this examination were not available at the time this document was prepared (Ref. 42).

These events indicate that roll transitions in B\&W OTSGs are susceptible to cracking. Furthermore, these events indicate that both stress-relieved and non-stress relieved transitions are susceptible.

\subsubsection{Dented/Dinged Regions}

Denting is the plastic deformation (constriction or mechanical deformation) of the steam generator tubes, which has resulted from both corrosion and mechanical processes. Sections 6.1.2, 6.2.2, and 7.2.3 contain further details on tube denting, with Section 7.2.3 providing additional details regarding the nature and consequences of tube denting.

Tube diameter reductions have been referred to as dings in most OTSGs by the $\mathrm{B} \& W$ owners to distinguish them from the more severe classical denting observed in the recirculating steam generators. The classical denting observed in recirculating steam generators was to such an extent that it frequently caused licensees to use smaller than nominally sized eddy current test probes to ensure that the probe could pass through the tube. The majority of the denting currently observed in recirculating steam generators, however, is minor compared to the "classical" denting observed in the late 1970s and early 1980s. That is, the majority of the dents currently being observed at most plants with recirculating steam generators are of such a size that a nominally sized inspection probe can pass through the dented region of the tube. As a result, although their causes may be different, dents and dings can be viewed as similar in terms of potential sites for degradation.

For the B\&W OTSGs, denting is most prevalent at the secondary faces of the UTS and LTS; however, denting has also been observed at the tube support plates, within the tubesheets, and in free span locations (Refs. 39 and 43). Free-span denting has occurred in periphery tubes in the region of the abandoned and secured auxiliary feedwater header. This header is located in the span between the fifteenth tube support plate and the UTS secondary face. The dents were caused by loose parts (i.e., dowel pins) contacting the tubes and by contact with the header itself. Damaged tubes in this area have generally been plugged or sleeved. The auxiliary feedwater ring header is a circular pipe attached to the inner wall of the steam generator which distributes water into the steam generator from the auxiliary feedwater system. The ring header moved because of the collapse of steam inside the header during occasional injection of relatively cold auxiliary feedwater (Ref. 29). Denting in the tubesheet, in at least one plant (e.g., TMI-1), was caused by the distortion of the tubesheet ligament as a result of the installation of explosive plugs in adjacent tubes. The dents are generally midway between the primary and secondary faces of the LTS (Ref. 39).

Dented locations were not identified as being potentially susceptible to circumferential cracking in the original GL 95-03 response made by the B\&W Owners Group. Subsequent to the original submission of responses to GL 95-03 (June 1995), dented (dinged) regions were identified as being potentially susceptible to cracking in B\&W OTSGs. In fact, degradation has been observed in these "minor" dents (dings) in once-through steam generators. Dented locations are a possible area of susceptibility to circumferential cracking because of the associated increase in stress levels within the tubing (Ref. 44). Circumferentially oriented indications associated with dented locations have been observed in at least two plants with B\&W OTSGs (ANO-1 and Oconee 1). The inspection findings at these plants related to these indications are discussed below.

At ANO-1 in 1993, two volumetric indications with circumferentially oriented crack-like indications associated with a dent were identified using a motorized rotating pancake coil probe at the UTS secondary face (Ref. 44). This plant had also observed circumferentially oriented intergranular attack indications at non-dented locations in the same region; therefore, one licensee reported that it could not determine whether the indications were attributable to the dents or to general intergranular attack coincidental to the dent (Ref. 37). In the 1996 steam generator tube inspection outage, the licensee for ANO-1 identified an axially oriented crack-like 
indication associated with a free-span dent (Ref. 42) indicating that cracks can potentially occur at these dented locations in B\&W OTSGs. This indication leaked under main steam line break differential pressure conditions during an in situ pressure test (Ref. 42).

At Oconee 1 in 1995, indications were also detected at dented locations at a tube support plate within the upper boiling region of the OTSGs. These indications were associated with dents in the drilled hole portion of the fifteenth tube support plate. One of the indications was circumferential in nature, the other was volumetric (Refs. 37 and 45).

At Crystal River 3 in 1996, an eddy current indication was detected at a dented location. This indication was detected with the bobbin coil and confirmed with a pancake and plus-point coil to be volumetric in nature (Ref. 37). Volumetric indications can be a result of closely spaced cracks, although it is not known whether this is the cause of this indication.

In summary, circumferential indications can occur as a result of tube denting. These indications can occur at mechanically or corrosion induced dents regardless of the location in the tube bundle.

\subsubsection{Sleeve Joints}

Sleeve joints were also identified (in June 1995) as being potentially susceptible to circumferential cracking. As discussed in Appendix A, various sleeve designs exist and some have exhibited circumferentially oriented degradation. B\&W mechanical sleeves have been installed in all operating B\&W OTSG plants in order to mitigate tube leaks caused by high cycle fatigue and to repair tubes with other indications of degradation. The mechanical sleeves have roller-expanded joints at each end to seal them into the parent tube. These tube/sleeve joints have not undergone any stress relief process. As a result, the B\&W Owners Group identified this region as a potential site for circumferential cracking. The material composition of the sleeves is either alloy 600 or alloy 690 .

Hydraulically expanded sleeves (i.e., sleeves that have been hydraulically expanded into the tube rather than mechanically (i.e., roll) expanded) have also been used on a very limited basis. (Oconee 1 has two tubes with a total of four sleeves currently in service.) The B\&W Owners Group also identified these joints as potential sites for circumferential cracking.

\subsection{Justification for Continued Operation}

The staff evaluated each of the B\&W owner's responses to GL 95-03 to confirm that each plant could safely operate until the next scheduled steam generator tube inspection outage. The operating experience to date has shown that widespread service-induced circumferential cracking of safety significance is not occurring in B\&W OTSGs. In fact, before June 1995, circumferential cracks (excluding the TMI-1 circumferential cracks which were initiated following a chemical excursion while the plant was shut down) had, for the most part, only been detected in OTSG tubes at the top (fifteenth) tube support plate and at the bottom of the UTSF in the lane/wedge region. As stated above, these cracks were primarily a result of high cycle fatigue. As a preventive measure, the OTSG plant licensees have installed sleeves in the top span of some of the tubes in the lane/wedge region. These sleeves stiffen the tubes and provide an inner pressure boundary (Ref. 38).

The staff concluded that all of the B\&W units could operate until their next scheduled steam generator tube inspection. The following factors contributed to this conclusion:

(1) the minimal number and severity of the circumferential indications detected in the $B \& W$ OTSGs

(2) the preventive measures taken by the licensees (e.g., sleeving of tubes in the lane/wedge region)

(3) the operating time until the next scheduled steam generator tube inspections

(4) the requirement to monitor primary-to-secondary leakage and to shut down the plant when leak rate limits are exceeded

(5) the use of procedures (including emergency operating procedures) to diagnose and address steam generator tube leaks and ruptures 
(6) the risk and potential consequences of a range of steam generator tube rupture events as discussed in NUREG-0844, "NRC Integrated Program for the Resolution of Unresolved Safety Issues A-3, A-4, and A-5 Regarding Steam Generator Tube Integrity," which was issued in September 1988 (Ref. 27) - In Reference 27, the staff estimated the risk contribution due to the potential for single and multiple steam generator tube ruptures. In addition, this study examined the expected consequences of steam generator tube rupture scenarios, including beyond design basis situations, such as the potential for release due to containment bypass via failed tubes concurrent with a breach of secondary system integrity.

\subsection{Tube Inspections}

GL 95-03 requested, in part, a safety assessment justifying continued operation on the basis of past inspection results and a summary of inspection plans for the next scheduled steam generator tube inspection outage as they pertain to the detection of circumferential cracking. The inspection plans were to consist of both an initial scope and sample expansion criteria. For the B\&W units, the staff summarized in several tables at the end of this section some of the information provided by the licensees with respect to the previous and next inspection for each of the areas identified as being potentially susceptible to circumferential cracking. The designation of "previous" refers to inspections performed before issuing or responding to GL 95-03. The designation of "next" (and/or "future") refers to inspections performed after issuing or responding to GL 95-03. The phrase, "if detect", is used to describe the inspection expansion criteria when a circumferential indication is detected. In many instances, the next (and/or future) inspections have already been completed as a result of the time taken to prepare this document for publishing.

Table 5-1 summarizes the scope of the past and future inspections at the expansion transition for each of the seven operating B\&W units, along with some pertinent notes. Tables 5-2, 5-3, and 5-4 provide similar information for the lane/wedge region, dented locations, and sleeve joints, respectively. Tube inspections performed using a technique not capable of reliably detecting circumferentially oriented degradation were recorded as "None" in Tables 5-1 through 5-4. In instances where the results of the tube inspections were readily available, the results were included in the tables. For example, at Crystal River 3, the RAI was submitted subsequent to the completion of the "next" steam generator tube inspection. As a result, the licensee provided their actual scope and some of the results from the examination. These results were included in the tables, as appropriate. Acronyms and abbreviations used in the tables are explained in Appendix C.

As can be seen from evaluating the data in Tables 5-1 through 5-4, there are plant-specific differences in the inspection plans (e.g., probe type, scope of examination). These differences in the inspection plans were considered along with other plant-specific circumstances (e.g., preventive measures taken) in evaluating the acceptability of a licensee's response as discussed in Section 5.3. For example, even though a licensee may have implemented a smaller initial inspection scope than another licensee, this may have been considered acceptable if the cumulative operating time for the plant was less than that of the other plant (all other parameters being equal).

Many of the licensees stated that their inspections would be expanded on the basis of an engineering evaluation of the results. The staff agrees that this is a prudent measure; however, the staff notes the following considerations:

(1) The expansion criteria defined in the technical specification must be followed for all examinations performed, regardless of probe type.

(2) Because of time constraints in an outage, it would be beneficial to have a well thought out tube inspection expansion plan, which anticipates possible results before commencing the steam generator tube inspections.

(3) The root cause of any "new form" of degradation will not likely be known during the outage (since tube pulls are necessary for a conclusive root cause evaluation and for confirming that the degradation at one plant is similar to that at another). Consequently, the inspection expansion criteria should include a sampling of tubes not believed to be susceptible to this "new form" of degradation to confirm 
that the inspections performed bounded the affected areas.

(4) Any tube inspection expansion criteria should also be contingent on providing reasonable assurance that all tubes in the steam generator would retain adequate structural and leakage integrity, consistent with other regulatory guidance, until the next scheduled inspection for those tubes. Such an evaluation would require, in part, technically justified assumptions regarding (a) the size of flaws in tubes not inspected (most likely similar sizes to those found in the tubes inspected), (b) the probability of detection, (c) the uncertainty in estimating the size of the flaws, and (d) the growth rate of the flaws.

The staff has reviewed the submissions provided by the licensees with B\&W OTSGs and has concluded that they contain the information requested in GL 95-03. General conclusions regarding the responses are discussed in Section 9. 

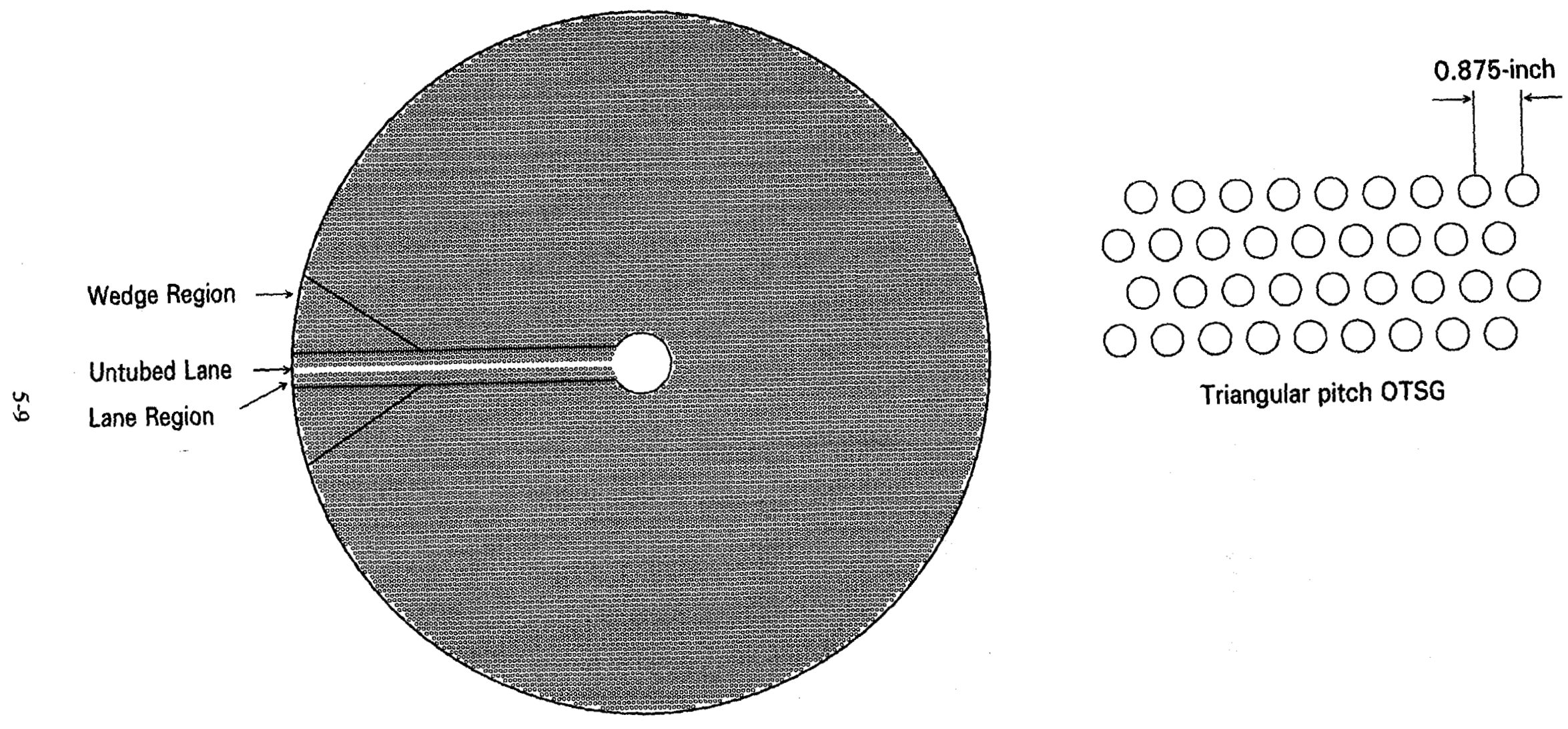

Triangular pitch OTSG

Figure 5-1 Typical B\&W OTSG tube pattern

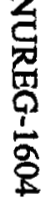



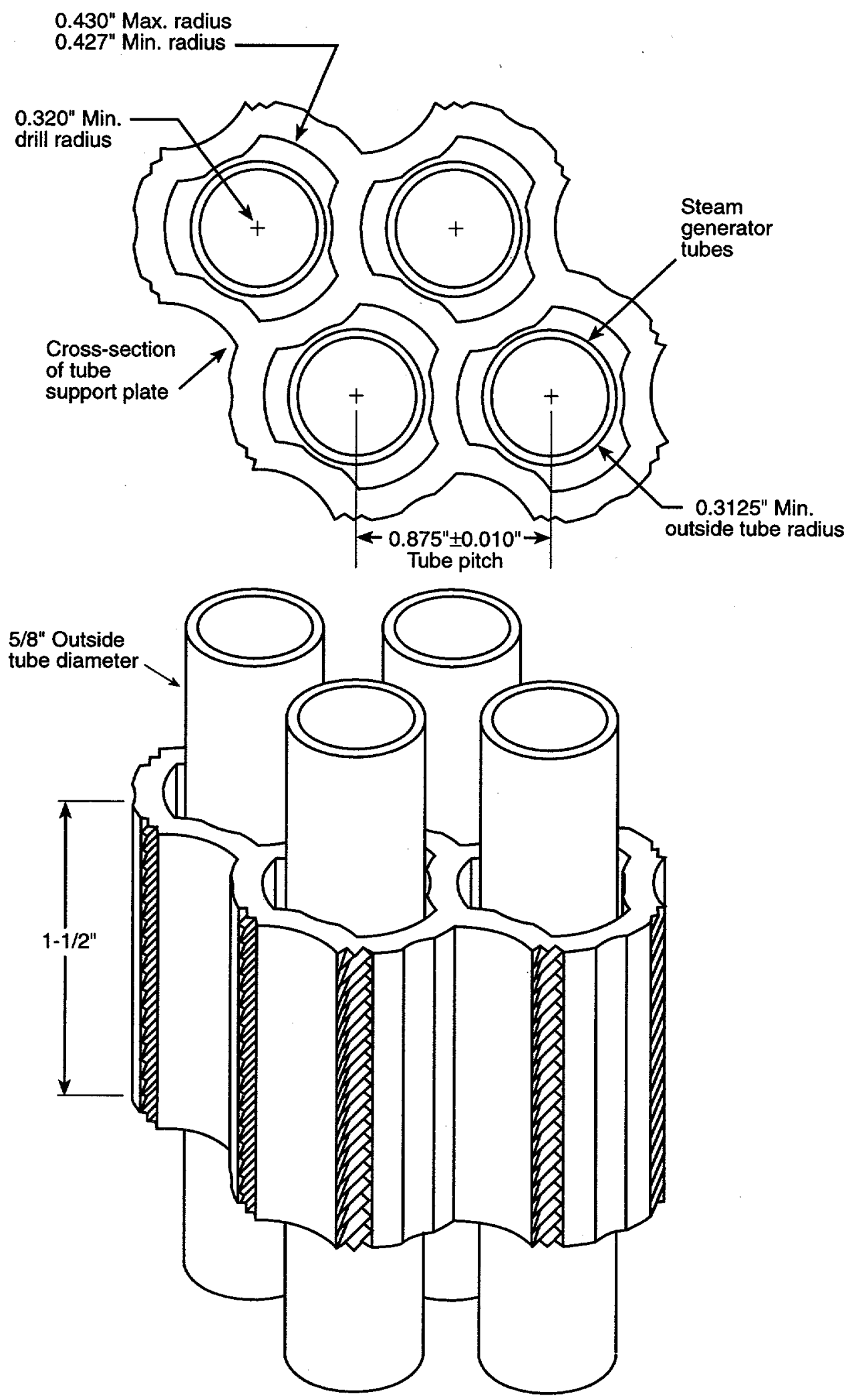

Figure 5-2 B\&W OTSG tube support plate design 
Table 5-1 Inspections at the expansion transition region in B\&W plants

\begin{tabular}{|c|c|c|c|}
\hline Plant & $\begin{array}{l}\text { Expansion Transition } \\
\text { Past Inspection }\end{array}$ & $\begin{array}{l}\text { Expansion Transition Future } \\
\text { Inspection }\end{array}$ & Notes \\
\hline Arkansas Nuclear One - 1 & None & $\begin{array}{l}\text { 100\% of non-stress-relieved joints with } \\
\text { Appendix } \mathrm{H} \text { circ. cracking technique. } \\
\text { If detect, will evaluate expanding } \\
\text { sample into stress-relieved transitions. }\end{array}$ & $\begin{array}{l}13 \text { transitions rerolled following stress relief. } \\
\text { References } 44 \text { and } 46 .\end{array}$ \\
\hline Bellefonte & & & $\begin{array}{l}\text { Will provide response to GL } 95-03 \text { prior to initial } \\
\text { fuel loading. Reference } 47 \text {. }\end{array}$ \\
\hline Crystal River 3 & None & $\begin{array}{l}\text { 100\% RPC of non-stress-relieved } \\
\text { joints. If detect, will evaluate } \\
\text { expanding sample into stress-relieved } \\
\text { transitions. [Based on finding an axial } \\
\text { indication, expanded sample to include } \\
\text { tubes rerolled for tube end repairs.] }\end{array}$ & $\begin{array}{l}10 \text { transitións rerolled following stress relief. } \\
0.635^{n} \text { bore size in tubesheet (smaller than } \\
\text { several other B\&W SGs). Detected SAI and MAI } \\
\text { in UTS in one tube during } 1996 \text { inspection. MAI } \\
\text { above shop re-roll. Indications believed to be } \\
\text { PWSCC, Damaged tube ends in SG B as a result } \\
\text { of a loose part - repaired by drilling tube end and } \\
\text { rerolling during } 8 \mathrm{R} \text {, 9R, and } 10 \mathrm{R} \text { (rerolling not } \\
\text { performed for all repairs in 10R). References } 37 \\
\text { and } 48 \text {. }\end{array}$ \\
\hline Davis-Besse & None & $\begin{array}{l}100 \% \text { of non-stress-relieved joints with } \\
\text { Appendix } \mathbf{H} \text { circ. cracking technique. } \\
\text { If detect, will evaluate expanding } \\
\text { sample into stress-relieved transitions. }\end{array}$ & $\begin{array}{l}8 \text { transitions rerolled following stress relief. } \\
\text { These } 8 \text { transitions are believed to be stress } \\
\text { relieved (i.e., they were not rerolled) based on } \\
\text { subsequent evaluations. References } 41,43 \text {, and } \\
49 .\end{array}$ \\
\hline Oconee 1 & $\begin{array}{l}100 \% \text { RPC of } \\
\text { non-stress-relieved HL } \\
\text { (upper tubesheet) } \\
\text { transitions }\end{array}$ & $\begin{array}{l}100 \% \text { RPC of non-stress-relieved } \\
\text { joints. If detect, } 20 \% \text { of stress-relieved } \\
\text { joints. }\end{array}$ & $\begin{array}{l}132 \text { transitions rerolled following stress relief. } \\
\text { References } 50,51 \text {, and } 52 \text {. }\end{array}$ \\
\hline Oconee 2 & $\begin{array}{l}100 \% \text { RPC of } \\
\text { non-stress-relieved } \\
\text { transitions }\end{array}$ & $\begin{array}{l}100 \% \text { RPC of non-stress-relieved } \\
\text { joints. If detect, } 20 \% \text { of stress-relieved } \\
\text { joints. }\end{array}$ & $\begin{array}{l}4 \text { transitions rerolled following stress relief. } \\
\text { References } 50,51 \text {, and } 52 \text {. }\end{array}$ \\
\hline Oconee 3 & $\begin{array}{l}100 \% \text { RPC of } \\
\text { non-stress-relieved } \\
\text { transitions }\end{array}$ & $\begin{array}{l}100 \% \text { RPC of non-stress-relieved } \\
\text { joints. If detect, } 20 \% \text { of stress-relieved } \\
\text { joints. } 3 \text { explosively expanded tubes } \\
\text { will be inspected or removed from } \\
\text { service. }\end{array}$ & $\begin{array}{l}4 \text { transitions rerolled following stress relief. } 3 \\
\text { tubes explosively expanded into the upper and } \\
\text { lower tubesheet. References } 50,51 \text {, and } 52 \text {. }\end{array}$ \\
\hline Three Mile Island 1 & $\begin{array}{l}\text { Roll transitions (CLATS): } \\
\text { None. Kinetic Expansions } \\
\text { (HL/UTS): 8xi array coil } \\
\text { for tubes in lane/wedge } \\
\text { region ( } 217 \text { tubes per SG } \\
\text { were inspected) }\end{array}$ & $\begin{array}{l}100 \% \text { RPC of non-stress-relieved joints } \\
\text { (CL/LTS). If detect, will evaluate } \\
\text { expanding sample into stress-relieved } \\
\text { transitions. For kinetic expansions, all } \\
\text { unsleeved tubes in the lane/wedge } \\
\text { region will be examined [ } 589 \text { tubes } \\
\text { were examined with RPC]. If detect, } \\
\text { expand based on engineering } \\
\text { evaluation. [No circ. cracks observed.] }\end{array}$ & $\begin{array}{l}11 \text { transitions rerolled following stress relief -- } \\
\text { records are not clear on exact locations. As a } \\
\text { result of a sulfur intrusion which resulted in ID } \\
\text { initiated circ. cracking, the tubes in the UTS in } \\
\text { both SGs were repaired by kinetically expanding } \\
\text { the tubes into the tubesheet. There is at least a } 2^{n} \\
\text { defect-free unexpanded section associated with a } \\
17^{\prime \prime} \text { or } 22^{n} \text { expansion length. Most expansions } \\
(-14,000) \text { are } 17^{\prime \prime} \text {. LTS in SG A has short } \\
\text { thick-walled tube section in the holes drilled in } \\
\text { the open lane region. References } 39,53 \text {, and } 54 \text {. }\end{array}$ \\
\hline
\end{tabular}


Table 5-2 Inspections at the lane/wedge region in B\&W plants

\begin{tabular}{|c|c|c|c|}
\hline Plant & $\begin{array}{c}\text { Lane/Wedge Past } \\
\text { Inspection (Unsleeved } \\
\text { tubes) }\end{array}$ & $\begin{array}{l}\text { Lane/Wedge Future Inspection } \\
\text { (Unsleeved tubes) }\end{array}$ & Notes \\
\hline Arkansas Nuclear One -1 & None & $\begin{array}{l}1 \text { tube border around sleeved region } \\
\text { with Appendix H circ. cracking } \\
\text { lechnique at } 15 \text { th TSP and UTSF. If } \\
\text { detect, expand until bounded. }\end{array}$ & $\begin{array}{l}1 \text { tube was confirmed via a tube pull in the early } \\
1980 \text { s to have circumferential ODSCC associated } \\
\text { with IGA in the UTS crevice region. References } \\
44 \text { and } 46 .\end{array}$ \\
\hline Bellefonte & & & $\begin{array}{l}\text { Will provide response to GL } 95-03 \text { prior to initial } \\
\text { fuel loading. Reference } 47 \text {. }\end{array}$ \\
\hline Crystal River 3 & None: Preventive sleeving & $\begin{array}{l}1 \text { tube border around sleeved region } \\
\text { with RPC (185 tubes at } 15 \text { th TSP and } \\
\text { UTS secondary face). [No indications } \\
\text { observed.] }\end{array}$ & References 37 and 48. \\
\hline Davis-Besse & None & $\begin{array}{l}1 \text { tube border around sleeved region } \\
\text { with Appendix H circ. cracking } \\
\text { technique at } 15 \text { th TSP and UTSF. If } \\
\text { detect, expand until bounded. }\end{array}$ & References 41,43 , and 49 . \\
\hline Oconee 1 & $\begin{array}{l}100 \% \text { RPC at } 15 \text { th TSP } \\
\text { and UTS }\end{array}$ & $\begin{array}{l}2 \text { tube border around sleeved region } \\
\text { with RPC probe at 15th TSP and } \\
\text { UTSF. If detect, expand until } \\
\text { bounded. }\end{array}$ & References 50,51 , and 52. \\
\hline Oconee 2 & $\begin{array}{l}100 \% \text { RPC at 15th TSP } \\
\text { and UTS }\end{array}$ & $\begin{array}{l}2 \text { tube border around sleeved region } \\
\text { with RPC probe at } 15 \text { th TSP and } \\
\text { UTSF. If detect, expand until } \\
\text { bounded. }\end{array}$ & References 50,51 , and 52 . \\
\hline Oconee 3 & $\begin{array}{l}100 \% \text { RPC at } 15 \text { th TSP } \\
\text { and UTS }\end{array}$ & $\begin{array}{l}\text { T tube border around sleeved region } \\
\text { with RPC probe at } 15 \text { th TSP and } \\
\text { UTSF. If detect, expand until } \\
\text { bounded. }\end{array}$ & References 50,51 , and 52 . \\
\hline Three Mile Island I & $\begin{array}{l}217 \text { tubes } w / 8 \times 1 \text { in each } \\
\text { SG at } 15 \text { th TSP and UTS } \\
\text { secondary face }\end{array}$ & $\begin{array}{l}1 \text { tube border around sleeved region } \\
\text { with RPC at } 15 \text { th TSP and UTSF. If } \\
\text { detect, expand until bounded. [No } \\
\text { defects observed.] }\end{array}$ & $\begin{array}{l}\text { A leakage event associated with a TMI-1 } \\
\text { lane/wedge tube is discussed in NRC Information } \\
\text { Notice } 91-43 \text { (Ref. 16). References } 39,53 \text {, and } \\
54 .\end{array}$ \\
\hline
\end{tabular}


Table 5-3 Inspections at dented locations in B\&W plants

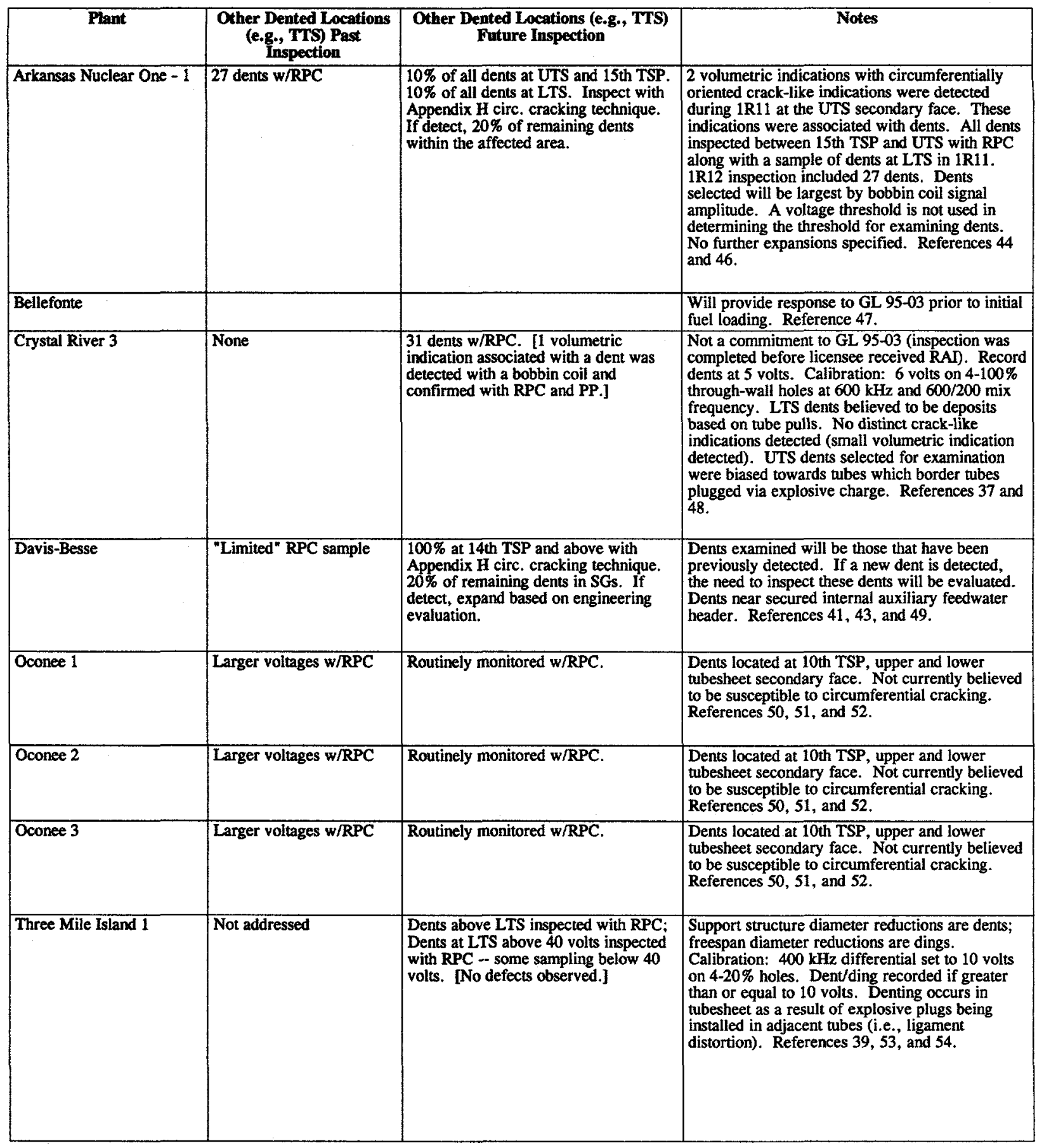


Table 5-4 Inspections at sleeve joints in B\&W plants

\begin{tabular}{|c|c|c|c|}
\hline Plant & Sleeve Past Inspection & Sleeve Future Inspection & Notes \\
\hline Arkansas Nuclear One - 1 & 222 sleeves with PP & $\begin{array}{l}20 \% \text { with Appendix H circ. cracking } \\
\text { technique. If detect, } 100 \% \text { exam or } \\
\text { until bounded. }\end{array}$ & References 44 and 46. \\
\hline Bellefonte & & & $\begin{array}{l}\text { Will provide response to GL } 95-03 \text { prior to initial } \\
\text { fuel loading. Reference } 47 \text {. }\end{array}$ \\
\hline Crystal River 3 & Installation inspections & $\begin{array}{l}20 \% \text { PP. If detect, } 100 \% \text { exam or until } \\
\text { bounded. [No crack-like indications } \\
\text { observed.] }\end{array}$ & References 37 and 48. \\
\hline Davis-Besse & None (crosswound) & $\begin{array}{l}20 \% \text { PP. If detect, } 100 \% \text { exam or until } \\
\text { bounded. }\end{array}$ & References 41,43 , and 49 . \\
\hline Oconee 1 & $100 \%$ RPC at upper rolls & $\begin{array}{l}20 \% \text { PP. If detect, } 100 \% \text { exam or until } \\
\text { bounded. The } 2 \text { tubes w/hydraulic } \\
\text { sleeves and the } 32 \text { sleeves at the } 14 \text { th } \\
\text { TSP will be inspected or removed from } \\
\text { service. }\end{array}$ & $\begin{array}{l}2 \text { tubes contain hydraulic sleeves at } 15 \text { th TSP and } \\
\text { UTS. } 32 \text { sleeves at } 14 \text { th TSP. Sleeves installed } \\
\text { in } 10 / 87 \text {. References } 50,51 \text {, and } 52 \text {. }\end{array}$ \\
\hline Oconee 2 & $100 \%$ RPC at upper rolls & $\begin{array}{l}20 \% \text { PP. If detect, } 100 \% \text { exam or until } \\
\text { bounded. }\end{array}$ & $\begin{array}{l}\text { Lane/wedge sleeves installed in } 9 / 90 \text { and } 10 / 94 . \\
\text { References } 50,51 \text {, and } 52 .\end{array}$ \\
\hline Oconee 3 & $100 \%$ RPC at upper rolls & $\begin{array}{l}20 \% \text { PP. If detect, } 100 \% \text { exam or until } \\
\text { bounded. }\end{array}$ & $\begin{array}{l}\text { Lane/wedge sleeves installed in } 8 / 88 \text { and } 6 / 95 \text {. } \\
\text { References } 50,51 \text {, and } 52 \text {. }\end{array}$ \\
\hline Three Mile Island 1 & None (crosswound) & $\begin{array}{l}20 \% \text { PP. If detect, } 100 \% \text { exam or until } \\
\text { bounded. [No defects observed.] }\end{array}$ & References 39,53 , and 54. \\
\hline
\end{tabular}




\section{COMBUSTION ENGINEERING STEAM GENERATORS}

\subsection{Design}

CE plants have steam generators with either alloy 600 or alloy 690 steam generator tubes. Sections 6.1.1 and 6.1.2 describe the generic and plant-specific features of CE plants that have steam generators with alloy 600 steam generator tubes. CE plants with alloy 690 steam generator tubes are discussed in Section 8.

\subsubsection{Generic Features}

The CE recirculating steam generators (RSGs) are vertical, shell, and U-tube heat exchangers with integral moisture-separation equipment. A large cylindrical vessel encloses an inverted $U$-shaped tube bundle consisting of many thousands of individual tubes, each welded to a thick plate (called a tubesheet) with a hole for each tube end located near the bottom of the steam generator vessel. The reactor coolant enters the hemispherical bottom head through an inlet nozzle, flows through the U-tubes and exits the lower plenum through an outlet nozzle. A divider plate in the lower plenum below the tubesheet separates the inlet and outlet primary coolant and directs the flow through the tubes.

For most of the CE steam generators, the secondary system water (feedwater) is fed through a feedwater nozzle, to a feedring into the downcomer, where it mixes with recirculating water draining from the moisture separators. This downcomer water flows to the bottom of the steam generator, across the top of the tubesheet, and then up through the tube bundle where steam is generated. Some of the CE steam generators (e.g., Palo Verde 1, 2, and 3), however, have a separate economizer section (preheater) in the steam generator near the cold-leg outlet. The feedwater flows into the preheater through nozzles located in the lower part of the vessel. Heat from the primary fluid leaving the steam generator is used to preheat the feedwater nearly to saturation temperature before it enters the evaporator section (Refs. 24 and 55).

There are currently 15 operating CE units. Of these units, 13 are currently operating with their original steam generators, while 2 (i.e., Millstone 2 and Palisades) have replaced their steam generators.
Only the Millstone 2 replacement steam generators have alloy 690 tubes; these are discussed in Section 8. The remaining steam generators (including the pre-replacement Millstone 2 steam generators and the pre-replacement and replacement Palisades steam generators) have alloy 600 tubes and are discussed in this section.

With the exception of Maine Yankee, which has three steam generators, all CE plants have two steam generators. The number of tubes in a steam generator varies from approximately 5,000 to 11,000 and these tubes are arranged in a triangular pattern as shown in Figure 6-1. There is an open lane down the center of the steam generator between the legs of the innermost U-tubes.

A number of different $\mathrm{CE}$ steam generator designs exist in the United States. (An example of a CE steam generator is illustrated in Figure 2-3.) These designs have been categorized by one CE licensee as early models (i.e., before series 67), series 67, 3410 series, and system 80 (Ref. 55). Differences exist between the four categories, as well as within individual categories. Design differences that are pertinent to steam generator tube integrity (and particularly circumferential cracking) are discussed in the following paragraphs.

The steam generator tube bundles in CE plants generally consist of both U-shaped tubes and tubes with two 90-degree bends. The U-shaped tubes (sometimes referred to as tubes with 180-degree bends) are located in the lower row (smaller bend radii) tubes. By contrast, the tubes with two-90 degree bends are located in the higher row (larger bend radii) tubes. Most of the tubes in a typical CE steam generator tube bundle are of the design with two 90-degree bends.

The tubes in CE steam generators were explosively expanded through the full length (i.e., thickness) of the tubesheet, thereby eliminating the tube-to-tubesheet crevice that is present in other steam generator designs. As a result, the expansion transition region where the tube changes from fully expanded to non-expanded (i.e., nominal tube diameter), is nominally located at the top of the tubesheet (i.e., the secondary face of the tubesheet); 
however, there are a minimal number of tubes that have not been fully expanded. Partial- and full-depth tube expansions are illustrated in Figure 6-2. The tubes are expanded into the tubesheet in both the primary coolant inlet region (hot leg) and the outlet region (cold leg). As a result, the expansion transitions are frequently referred to as the hot-leg and cold-leg expansion transitions, as appropriate. The tubes are seal welded to the tubesheet cladding in both the hot and cold legs of the steam generator.

The tubes in most CE steam generators are supported with plates or eggcrate-type dividers at a number of fixed axial locations along the tube bundle, as well as variously shaped bars and small plates in the U-bend region of the tube bundle. (Examples of tube support configurations used in steam generators are illustrated in Figure 6-3.) These tube supports are either horizontally, vertically, or diagonally oriented. Most of the supports in the $\mathrm{CE}$ steam generators are formed from a lattice arrangement of bars (i.e., eggcrate tube supports); however, drilled plates are also used. The tube support material is generally either carbon steel (in earlier models) or stainless steel (in later models such as Palo Verde).

The horizontally oriented tube supports are primarily eggcrate supports; however, drilled plates are also used. The drilled tube support plates are primarily located in the upper portion of the tube bundle near the U-bend (or 90-degree bend) region and are frequently partial plates; that is, they do not support all of the tubes. However, some of the drilled plates are located in the lower portion of the bundle. For example, Palo Verde 1, 2, and 3 have a drilled plate, which serves as a flow distribution baffle, located directly above the tubesheet (Ref. 55). Similarly, the lower six tube supports in the original Palisades steam generators were drilled plates.

The batwing supports, referred to as anti-vibration bars (AVBs) in Westinghouse steam generators, are used in the U-bend region to stiffen the tubes and/or prevent tube-to-tube contact. These supports are diagonally oriented in the tube bundle. Vertical straps are also used in many $C E$ steam generators to provide vertical support for the horizontal section of the tube between the 90-degree bends.

The number of supports vary from plant to plant. For example, ANO-2 has a total of eleven horizontally oriented tube supports. These include seven full eggcrate tube supports, two partial eggcrate tube supports, and two partially drilled tube support plates (Ref. 46).

\subsubsection{Plant-Specific Features}

There are unique features that affect steam generator tube integrity in several of the CE RSGs. The following paragraphs describe some of the more pertinent features that may affect a tube's susceptibility to circumferential cracking or its inspectability.

As mentioned above, the tube support structures can vary from plant to plant. In general, stainless steel tube support structures have shown to be relatively corrosion resistant compared to carbon steel tube support structures. This corrosion resistance is important in reducing the likelihood of tube denting, which has, in some instances, led to the development of circumferential cracks. Denting is the plastic deformation (constriction or mechanical deformation) of the steam generator tubes; it typically occurs when tube support structures (e.g., carbon steel tube support plates) corrode. Such corrosion results in the buildup of corrosion products (typically magnetite) in the crevice between the tube and the tube support plate. This buildup of magnetite (iron oxide) leads directly to the mechanical deformation of tubes where they meet the tube support plate intersections; when this buildup is extensive, denting can lead to the deformation and cracking of the tube support plates themselves. In general, many of the newer steam generators (including Palo Verde 1, 2, and 3 and the Palisades replacement steam generators) have tube support structures made with stainless steel. Most of the remaining $\mathrm{CE}$ units have carbon steel tube support structures.

The steam generators at Fort Calhoun contain 19.05 $\mathrm{mm}(0.75$-inch) thick orifice plates installed in the primary channel heads on the hot-leg tubesheets (i.e., primary face of the tubesheet). These plates limit the primary coolant flow to the tubes in rows 1 through 18. The orifice plates were installed before initial plant startup to eliminate the potential for phosphate corrosion caused by steam blanketing in the U-bend area of the low row tubes. These plates were not removed when the licensee decided to operate with an all-volatile treatment secondary water chemistry rather than phosphates. However, the licensee believes that the orifice plates have probably played 
a role in reducing the susceptibility of the steam generator tubes to both steam blanketing assisted intergranular stress corrosion cracking (IGSCC) in the U-bend region and circumferential cracking at the expansion transitions. This is because the orifice plates reduce the primary coolant flow and subsequently lower tube wall temperatures in the tubes with orifices. The orifice holes in this plate are too small to pass an inspection probe through the tube from the hot-leg side. As a result, the orifice plates render approximately 22-percent of the tubes inaccessible for inspection from the hot-leg side of the steam generators.

Subsequent to their original GL 95-03 response, the licensee for Fort Calhoun decided to remove the existing orifice plates from both steam generators. This decision arose from the uncertainty regarding the actual temperature differences that may be encountered behind the orifice plates compared to other locations in the steam generator, as well as the potential susceptibility of these tubes to circumferential cracking. After tube inspection and repair, the licensee will install new orifice plates to maintain reactor coolant system total flow equivalent to current conditions (Ref. 56).

\subsection{Locations Susceptible to Circumferential Cracking}

At the time of the original responses to GL 95-03, the CE Owners Group identified three regions as having exhibited circumferential cracking. Specifically these regions included the top of the tubesheet, the U-bend (or the 90-degree bend), and the tube-to-tube support intersections. However, circumferential cracking of steam generator tubes in service as of June 1995 had only been observed at the top of the tubesheet. The circumferential cracks in the U-bend (or 90-degree bend) region and at, or near, the tube-to-tube support intersections were observed in the pre-replacement Palisades steam generators; circumferential cracks at, or near, the tube-to-tube support intersections were also detected in the pre-replacement Millstone 2 steam generators (Ref. 57).

In general, most $\mathrm{CE}$ licensees consider the following locations currently susceptible to circumferential cracking:
- dented regions (particularly dented tube support regions) (Refs. 36, 46, 56, and 58)

- expansion transitions (Refs. 36, 46, 56, and 58)

- sleeve joints (Refs. 36 and 46)

The operating experience for the pre-replacement Millstone 2 and Palisades steam generators is discussed separately (in Section 6.2.5) for clarity.

\subsubsection{Top of Tubesheet Region}

As discussed above, the expansion transition location in CE steam generator tubes exists at the top of the tubesheet and is susceptible to circumferential cracking. As of June 1995, circumferential cracking in this region was observed in 10 of the $14 \mathrm{CE}$ plants with alloy 600 steam generator tubes, excluding the pre-replacement Millstone 2 and Palisades steam generators. Depending on the plant, this cracking initiated from either the inside diameter, outside diameter, or both. As of June 1995, all of the circumferential indications were observed at the hot-leg expansion transition, with the possible exception of one cold-leg expansion transition indication at Maine Yankee. (The licensee for Maine Yankee has stated that this cold-leg indication, which was detected and plugged in 1990, may have been mistakenly diagnosed as circumferential cracking on the basis of the techniques available at the time (Ref. 59).)

Several utilities have removed the expansion transition portion of tubes from their plants for destructive examination. These utilities include ANO-2 (Ref. 46), Maine Yankee (Ref. 59), Millstone 2 (Ref. 57), and Calvert Cliffs 2 (Ref. 60). The results from these tube pulls generally confirm that the circumferential cracks at the hot-leg expansion transition initiated from either the inside or outside diameter of the tube and are attributed to IGSCC. The tube pulls from several plants indicate that both inside and outside diameter initiated circumferential cracks generally consist of a series of short circumferential cracks connected by thin ligaments of non-corroded material (Refs. 46 and 61). The axial elevation of these cracks varies within the crack network (i.e., they are typically not coplanar).

Subsequent to the original GL 95-03 responses, the licensees for a few plants detected circumferential 
indications at the cold-leg expansion transition. At ANO-2, 36 circumferential indications were detected at the cold-leg expansion transition during an inspection in the fall of 1995 (Ref. 62). In addition, 10 cold-leg expansion transition circumferential indications were detected at St. Lucie 1 during an inspection in the spring of 1996 (Ref. 63). These inspection results indicate that hot- and cold-leg expansion transitions are susceptible to cracking.

Virtually all CE units (including several of the newer units such as Waterford 3) have exhibited circumferential cracking at the expansion transition (Ref. 64).

\subsubsection{Dented Locations Including Dented Tube Support Areas}

As discussed in Section 6.1.2, denting is the plastic deformation (constriction or mechanical deformation) of the steam generator tubes, which has resulted from both corrosion and mechanical processes. (Section 7.2.3 contains further details regarding the nature and consequences of tube denting.) Corrosion and mechanically induced dents have been observed at a number of locations in CE steam generators.

Corrosion induced dents generally occur at tube locations next to support structures fabricated from carbon steel (e.g., eggcrate tube support, drilled hole tube support plates, tie rods). These dents result from corrosion of the tube support structure and have been observed in some CE steam generator tubes near horizontally oriented tube support structures and at the top of the tubesheet next to the tie rods. Tie rods are carbon steel rods (similar in diameter to tubes) that are used at various locations in the tube bundle to maintain the support structure alignment before completion of tube installation. It is postulated that corrosion of the tie rods at the top of the tubesheet, similar to the corrosion of tube support structures (as discussed in Sections 6.1.2 and 7.2.3), results in tie rod expansion. It is further postulated that tie rod expansion is transmitted to adjacent tubes, resulting in the potential for denting of the adjacent tubes (Ref. 65).

Mechanically-induced dents generally occur throughout the steam generator tube bundle and are frequently located in the tube free span (i.e., the region of the tube between tube support structures).
These dents are generally a result of steam generator fabrication and loose parts in the steam generator.

Dented regions are of concern because they can lead to axially and circumferentially oriented tube degradation as a result of increasing the stress levels within the tubing. In CE steam generators, circumferential indications have occurred at dented regions (generally at corrosion-related dents). In addition, circumferential indications have been observed at locations where there is no dent, but where denting of tubes is believed to have contributed to the development of the circumferential indications.

Circumferential cracks near tube support locations (e.g., eggcrates, drilled plates, and batwings) were detected in the pre-replacement Palisades and Millstone 2 steam generators (as discussed in Sections 6.2.5.1 and 6.2.5.2, respectively). Recently, circumferential indications were identified at St. Lucie 1 at both dented and non-dented tube support locations. These circumferential indications were identified on both the hot- and cold-leg sides of the steam generator.

The top two supports (ninth and tenth) in the St. Lucie Unit 1 steam generators are partial drilled plates. The ninth tube support plate extends from tube row 91 through 140 . The tenth drilled tube support plate extends from tube row 117 through 140. The inner edge of the drilled plates (row 91 and 117) is typically referred to as the chord or scallop bar, and surrounds only half of the tube circumference for tubes in these rows. To relieve denting stresses at these tube support plate levels, the support lug attachments for these two plates were cut and the edges of the plates were trimmed to allow for movement of the plate (in the horizontal direction). Selected tubes were expanded and staked to limit the vertical movement of the plate.

During the 1996 inspection at St. Lucie 1, four circumferential indications were identified in the drilled hole tube support plates (i.e., the ninth and tenth supports). Three of the four indications were located at the ninth support and are along the chord edge in tube row 91 or 92 . Two of these three indications were in the hot leg and one was in the cold leg. The fourth indication was located at the 10th tube support, nine rows from the chord edge in tube row 126. Two of the four indications were associated with minor dents (i.e., one of the ninth 
tube support hot-leg circumferential indications and the 10th tube support hot-leg circumferential indication). Of the three tubes with circumferential indications at the ninth tube support plate, two were determined to face toward the divider plate while one faced away from the divider plate. The licensee postulated that accumulated stresses due to denting, lockup, movement, and bending of tubes could have contributed to the development of the circumferential indications (Ref. 66).

In summary, circumferential indications can occur as a result of tube denting. These indications can occur at mechanically or corrosion induced dents regardless of the location in the tube bundle. In addition, circumferential indications have been postulated to occur at non-dented regions as a result of accumulated stresses related to the denting phenomena.

\subsubsection{U-Bend Region}

Circumferential indications have been detected in the $\mathrm{U}$-bend portion of tubes with small bend radii (i.e., rows 1 and 2) in certain Westinghouse steam generators (as discussed in Section 7.2.2); however, no such indications have been detected in the tight-radius U-bends (i.e., rows 1 and 2) of any steam generator supplied by CE (Refs. 60 and 67).

Circumferential indications have, nonetheless, occurred in the upper portion of CE steam generator tube bundles. These indications were detected in the pre-replacement Palisades and Millstone 2 steam generators. (The circumstances surrounding the development of these indications are discussed in Sections 6.2.5.1 and 6.2.5.2, respectively.)

Although no circumferential indications have been detected in the U-bend region of tubes with small bend radii in CE steam generators, axial indications have been detected in this region in at least one CE plant (e.g., Palo Verde 2). These indications are believed to have initiated from the outside diameter of the tube rather than the inside diameter. The indications observed in the U-bend region of small radii tubes in Westinghouse plants are predominantly inside diameter initiated.

\subsubsection{Sleeve Joints}

As discussed in Appendix A, various types of sleeve designs exist, and some have exhibited circumferentially oriented degradation. The steam generators at CE plants use several sleeve designs, including the $B \& W$ double kinetically welded sleeves, CE tungsten inert gas (TIG) welded sleeves, and Westinghouse laser-welded sleeves. At the time the original GL 95-03 responses were submitted (June 1995), the only CE plants that had installed sleeves (or were in the process of installing them) were ANO-2 and Maine Yankee. During the summer of 1995, Maine Yankee was in the process of installing Westinghouse laser-welded sleeves at the hot-leg expansion transition region in all tubes that were to remain in service (Ref. 59); ANO-2 had already installed B\&W double kinetically welded sleeves in 1992 (Ref. 44) and was in the process of installing CE TIG-welded sleeves in the fall of 1995 (Ref. 46).

\subsubsection{Circumferential Cracking Experiences in the Pre-Replacement Palisades and Millstone Steam Generators}

Since the pre-replacement Palisades and Millstone 2 steam generators are similar, in some respects, to the currently operating $C E$ steam generators, the operating experience for these steam generators are summarized in the following sections.

\subsubsection{Pre-Replacement Palisades Steam Generators}

The retired Palisades steam generators were unique with respect to the design of the tube supports, which consisted of solid tube support plates with flow holes, plates without flow holes but with flow slots, full eggcrates, and partial drilled plates (Ref. 68).

Circumferential cracks were identified at several locations in the pre-replacement Palisades steam generators. In March 1982, the first two circumferential indications were observed as a result of a primary-to-secondary leakage event. These indications included one in the tube at row 20 , line 83 , which was slightly (approximately $2.5 \mathrm{~mm}(0.1$ inch)) above the ninth tube support plate and approximately $10 \mathrm{~cm}$ (4 inches) below the U-bend and one in the horizontal section of the tube at row 127 , line 22, at the first batwing support past the hot-leg U-bend (actually a 90-degree bend). Neither of these indications was associated with a dent greater 
than $0.025 \mathrm{~mm}$ (0.001-inch) (i.e., denting levels were less than 1 mil in both tubes); however, these indications were associated with dents (Refs. 69 and 70). Since these tubes were not removed for destructive examination, the results are predicated on the ECT capabilities at that time.

The licensee removed more than 50 tubes for destructive examination during their 1983/1984 steam generator tube inspection outage, in part, to characterize the circumferential crack-like indications that were being detected. The destructive examination revealed that the defects contained relatively large amounts of sulfur, and the tubes containing the defects were highly sensitized. It is believed that the corrosion was caused by a reduced form of sulfur on sensitized, alloy 600 tubing. (Sulfur, in the form of sodium sulfite, was used in the 1973 to 1974 time-frame for controlling the oxygen content in the secondary water at Palisades.) Furthermore, most defects were located adjacent to dents at the upper or lower edge of the tube support plate. All three of the circumferential cracks confirmed during the 1983/1984 tube pulls were located within the confines of the ninth tube support plate and were associated with a deep patch of intergranular attack. In summary, the results of the tube pulls indicated, in part, that the type of corrosion observed in the steam generator tubes was primarily sulfur-induced intergranular attack and, in some cases, was accompanied by circumferential IGSCC (Ref. 71).

During a 1985 inspection, no circumferential crack-like indications were detected (Ref. 72); however, in December 1987, a tube leak occurred as a result of a circumferential indication associated with a small dent at the lower edge (both inside and outside) of the thirteenth tube support plate. During the December 1987 inspection, a total of 12 circumferential indications were detected at the tube support plates, the vertical straps (sometimes referred to as the batwing and AVBs 1, 2, 3, 4, and 5 by the licensee), and the cold-leg bends. (These cold-leg bend indications were frequently associated with the diagonal straps, which were sometimes referred to as batwings and AVBs by the licensee).

From 1987 until steam generator replacement in 1991, additional circumferential indications were detected in both the hot and cold legs of the Palisades steam generators. These indications occurred at various horizontally oriented tube support elevations and were typically located within the bounds and near the top edge of the affected tube support. In addition, as mentioned above, circumferential indications had also been detected at other regions in the upper portion of the tube bundle (i.e., at the batwing, AVBs, diagonal straps, bend region, and/or vertical supports) (Ref. 73).

The licensee identified two possible causes for the cracking (specifically the cold-leg cracking):

\section{(1) in-plane loads caused by severe denting}

(2) out-of-plane loads caused by thermal expansion

On the basis of operating experience, dented tubes are known to be susceptible to circumferential cracking. The dented tubes in the original Palisades steam generators would be considered susceptible to circumferential cracking, since the denting in these steam generators would be considered severe (i.e., an average of $0.508 \mathrm{~mm}$ to $0.762 \mathrm{~mm}(0.020$ - to 0.030 -inch) of denting at one tube support plate) compared to the denting currently (1996) being observed in most steam generators that have exhibited circumferential indications at dented tube support locations.

In addition to the loads caused by denting, the Palisades licensee postulated that higher-than-normal thermal expansion loads could lead to circumferential cracking. These higher-than-normal loads were postulated to occur in tubes adjacent to areas of plugged tubes. The licensee believed that this was particularly true in the case of small-radius tubes, which would have the "hottest" primary water at the cold-leg tubesheet. Since most of the tubes in rows 1 through 12 were plugged (as a result of wastage), the unplugged tubes closest to the divider plate should see the highest out-of-plane loads in the steam generators because of thermal expansion stresses. In addition to these thermal expansion loads, the licensee postulated that another probable area of high stress would be at tubes located in the lug (i.e., wedge) regions. The restraining force of the lug, in addition to thermal expansion stresses between the "cold" lug and a "hot" tube, were postulated to make this a high stress area that could lead to circumferential cracking of the tubes (Ref. 73). 
In summary, the retired Palisades steam generators had not experienced circumferential cracking at the top of the tubesheet, but had experienced circumferential cracking in the upper portion of the steam generator tube bundle. The postulated failure mechanism for the Palisades circumferential cracks was ODSCC. The tubes were considered to be locked into the tube support plates as a result of denting. During operation, the plates and tubes moved relative to one another, thereby imposing bending stresses on the tubes. The bending stresses then initiated circumferential cracks (Ref. 68).

\subsubsection{Pre-Replacement Millstone 2 Steam Generators}

The pre-replacement Millstone-2 steam generators were CE series 67 units that contained seven full eggcrate tube support structures, two partial eggcrates, two partial drilled tube support plates, two diagonal (batwing) supports, and three vertical supports. All of these were fabricated from carbon steel.

Circumferential SCC indications were first detected in Millstone 2 as a result of a leaking tube in January 1987. The leaking tube had a circumferential indication at the top of the tubesheet. This tube was pulled for destructive examination during the subsequent refueling outage in January 1988 (i.e., end-of-cycle (EOC) 8). Approximately 25 additional hot-leg circumferential indications were detected as a result of the EOC 8 examination. The tube pull indicated that the tube had a circumferentially oriented outside diameter initiated stress corrosion crack, which was greater than 50 percent through-wall over 260 degrees (190 degrees of which was 100 percent through-wall). The remaining 100 degrees of the tube circumference contained several microcracks less than 50 percent through-wall. The licensee evaluated the indicated crack sizes and concluded that the tube should not have been able to withstand operating loads; therefore, the cracks must have grown during the time the tube was plugged (i.e., from the January 1987 to January 1988 outage). On the basis of a careful examination of the fracture surface, the licensee postulated:

- caustic species were concentrating in the sludge area and initiated circumferentially oriented microcracks on the outside diameter of the tube.
- Existing microcracks propagated as additional microcracks initiated.

- As the microcracks propagated, the inside diameter of the tube was breached when a crack reached approximately 14 to 21 degrees around the circumference.

- The through-wall portion of the crack enlarged until it began to leak.

After operating through cycle 9, the licensee detected several hundred circumferential cracks at the top of the tubesheet in February 1989 (i.e., EOC 9). Cracks were observed on both the hot and cold legs of the steam generator near the top of the tubesheet. The licensee concluded that this location had a corrosive environment and high tube stress. The corrosive environment was a result of the sludge pile located on top of the tubesheet. The high tube stress was a result of tubesheet denting and tube support corrosion, which imparted stresses on the tube as a result of shifting of the tube bundle and bowing of the tubes. Tube bowing was confirmed by the licensee through the inability to successfully pass long rigid objects (such as sleeves and stabilizers) through the top of the tubesheet region of some tubes. A midcycle inspection was performed in October 1989 (outage 10A) to identify stress corrosion cracks that had developed to a detectable size since the last inspection and to ensure that the corrosion process responsible for the cracking was under control. During the inspection, approximately 100 top-of-tubesheet cracks were detected. Three tubes were removed during the October 1989 outage for burst testing and destructive examination.

On the basis of the three previous inspections, the cracks in the steam generator tubes were characterized by the licensee as follows:

- The cracks are located at the top of the tubesheet, within approximately $5.1 \mathrm{~mm}(0.2$ inches) from where the expansion transition meets the nominal tube diameter, and are circumferentially oriented.

- The macrocrack, as defined by rotating probe eddy current tests, is made up of several discontinuous microcracks separated by ligaments of sound material. 
- The microcracks are located at different axial planes (i.e., they are not coplanar), typically within a $2.5 \mathrm{~mm}$ (0.1-inch) band (Ref. 74).

Additional planned and unplanned steam generator tube inspections were performed by the licensee from the October 1989 outage until steam generator replacement in late 1992 and early 1993 . In May 1990, the licensee performed a second midcycle inspection (outage 10B) as a result of increasing primary-to-secondary leakage (Ref. 75). This time, the licensee attributed the leakage to leaking plugs and sleeves; however, 23 tubes were identified that had circumferential indications at the top of the tubesheet (Refs. 76 and 77). Indications were found in both the hot and cold legs of the steam generator.

Following the May 1990 midcycle outage, the licensee performed inspections of the steam generator tubes during a scheduled refueling outage in September 1990 (i.e., EOC 10). During this inspection, the licensee found seven additional circumferential indications at both the hot- and cold-leg expansion transition areas. In April 1991, the licensee performed a limited inspection of the steam generator tubes as a result of primary-to-secondary leakage. This leakage was attributed to a circumferential crack in the outermost tube of row 37 and $7.6 \mathrm{~mm}(0.3$-inch) below the top of eggcrate 8, which is an eggcrate support just below the 90-degree bend of this tube. The inspections performed during this outage were concentrated in row 37 and two adjacent rows each side of row 37 in the area where the indication was observed (i.e., tube support 8 near the 90-degree bend). No additional circumferential indications were detected, although one axial indication was detected. The leaking tube was located in the chord region (i.e., the region of the tube bundle near the edge of a partial tube support).

In late May 1991, the licensee performed another midcycle outage (outage 11B) as a result of another primary-to-secondary leak. During this inspection, the licensee examined the top of the tubesheet region and in and around the chord region for eggcrate supports 8 and 9 (rows 32 through 38 and 62 through 68 , respectively). The leaking tube, in row 64 , was identified to have a circumferential crack at the 90-degree hot-leg bend above the ninth eggcrate tube support. The crack was at the lower edge of the first batwing strap, and the tube was in the chord region.
During the May 1991 inspection, the licensee identified approximately 35 circumferential indications in the hot and cold legs near the top of the tubesheet region (i.e., near the expansion transition) (Ref. 77).

In January 1992, the licensee performed another midcycle inspection in response to increasing primary-to-secondary leakage. During the inspection, two leaking tubes were identified. One leaking tube had a circumferential indication about $5.1 \mathrm{~cm} \mathrm{(2}$ inches) above the top of the tubesheet in the sludge pile region. This defect was located in a region where other similar indications had been identified. The other leaking tube, in row 87 (row 87 is in the chord region for tube support 10), had a circumferential indication in the 90-degree bend area adjacent to, and oriented with, a batwing support. The licensee concluded that the cause of both defects was SCC. Both defects were found in regions containing high copper deposits. The scope of the tube examinations during this outage were limited to the areas immediately surrounding the leaking tubes (Ref. 78).

The replacement of the original Millstone 2 steam generators began in approximately June 1992. A summary of the inspection findings is provided in Table 6-1.

In summary, circumferential indications were identified in the pre-replacement Millstone 2 steam generators. Circumferential indications were identified in both the hot and cold legs of the steam generators near the top of the tubesheet. Many of these indications were located in a region of the tube bundle where sludge accumulates (i.e., the sludge pile). Circumferential indications were also identified at or near the horizontally oriented tube supports and batwing supports (near the bend area).

The licensee believed that the upper bundle cracking was probably caused by caustic SCC, similar to the $\mathrm{SCC}$ at the top of the tubesheet. In addition, the licensee believed that the upper bundle indications were caused by bending stresses at the eggcrate and 90-degree bend producing local circumferential cracks. The bending stresses were probably induced as a result of extensive tube denting and bowing, as discussed below. 
Degradation of the eggcrates and tube support plates occurred in the original Millstone 2 steam generators, as a result of acidic chemistry conditions early in the operating life of the steam generators. The acidic conditions caused the carbon steel tube support material to corrode and form magnetite. The build up of the magnetite corrosion product in turn caused denting of the tubes and shifting of the supports. The progression of the denting was reported by the licensee to be essentially zero since cycle 7. A visual inspection of the first eggcrate tube support during the EOC 9 refueling outage confirmed that tube bowing was occurring (Ref. 74). One licensee indicated that denting-related expansion and shifting of the eggcrates, and locking of the tubes at the batwing and vertical supports, produced the undesired stresses in the Millstone 2 steam generators and led, in part, to the circumferential cracks (Ref. 68).

\subsubsection{Summary of Operating Experience from the Pre-Replacement Palisades and Millstone 2 Steam Generators}

The tight U-bend circumferential cracking that has occurred in some Westinghouse steam generators has not been observed in CE steam generators; however, circumferential cracking did occur in the upper bundle region of the pre-replacement Palisades and Millstone 2 steam generators in tubes with double 90-degree bends. These cracks occurred either in the 90-degree bends at or adjacent to diagonal supports, or in the horizontal run between the bends at or adjacent to vertical supports (Refs. 60 and 67). Circumferential cracking also occurred at or near eggcrate and drilled plates in these steam generators. Denting of the tubes and/or shifting of the tube supports with respect to the tubes is believed to have contributed to the circumferential cracking.

\subsection{Justification for Continued Operation}

For the CE plants with original steam generators, the majority of circumferential indications have been observed at the expansion transition region. The severity of these indications has led to midcycle inspections at one plant (i.e., ANO-2) and to the sleeving of all hot-leg expansion transitions at another plant (i.e., Maine Yankee). In addition, a limited number of circumferential indications, typically of less severity, have been observed at dented locations and in sleeve joints.
The staff evaluated each of the GL 95-03 responses submitted by CE plant owners with alloy 600 steam generator tubes to confirm that the plants could safely operate until the next scheduled steam generator tube inspection outage. The staff concluded that all of these CE units could operate until their next scheduled steam generator tube inspection. The staff based this conclusion on the following factors:

(1) scope and results of the prior inspection - In steam generators that do not exhibit signals that interfere with eddy current inspections (e.g., copper, denting), inspections may have been more effective in identifying tube degradation.

(2) preventive measures taken (e.g., sleeving of all tubes at the hot-leg expansion transition)

(3) removal of tubes for destructive examination Data from steam generator tubes removed for destructive examination provide useful information concerning the causal effects and morphology of the degradation. In many instances, tube pull data provide information that tubes with circumferential indications are able to withstand the pressure loadings specified in Reference 33. Because of the inability to reliably size and characterize the degradation, tube pulls are sometimes necessary to confirm tube integrity and degradation morphology.

(4) in situ pressure test data indicating that the circumferential indications are capable of withstanding the pressure loadings specified in Reference 33 - When all circumferential indications are removed from service before an operating interval (i.e., the time between tube inspections) and the most severe indications identified at the end of this operating interval have adequate integrity based on in situ testing, it would be reasonable to conclude that the steam generator could be safely operated for a similar operating interval.

(5) operating conditions at the plant (e.g., hot-leg operating temperature, water chemistry practices) - Stringent water chemistry control in accordance with industry standards designed to prevent uncontrolled tube degradation (i.e., mitigate the initiation and propagation of SCC) provides confidence that tube integrity will be 
maintained consistent with previous observations. Sludge lancing and chemical cleaning to reduce sludge accumulation provides confidence that impurities that may affect the rate of crack initiation and growth and the ability to reliably inspect the tube are controlled.

Since SCC is a thermally activated process, reducing the hot-leg operating temperature takes advantage of the temperature dependence of SCC growth and initiation rates (i.e., the growth and initiation would be slower, with all other parameters being equal).

(6) operating time until the next steam generator tube inspections were to be conducted

(7) requirement to monitor primary-to-secondary leakage and to shut down the plant when leak rate limits are exceeded - Leakage monitoring is a defense-in-depth operating practice that can provide operators with a timely indication of a steam generator tube leak or tube rupture. Nitrogen 16 monitors can permit faster identification and isolation of a steam generator that has a tube that has degraded to the point of leakage. Improved integrated leak rate monitoring programs provide added confidence that tube integrity will be maintained. These programs feature administrative limits on primary-to-secondary leakage. They also use equipment and procedural upgrades to enable plant operators to detect and respond to changes in steam generator primary-to-secondary leakage, and to shut down the unit before a significant leak or steam generator tube rupture if tube degradation should exceed expected values.

(8) use of procedures (including emergency operating procedures) to diagnose and address steam generator tube leaks and ruptures Procedures, equipment, and training programs that are in place to identify and mitigate the consequences of failed tubes provide confidence that, in the event of a loss of tube integrity, the plant can be safely operated. These programs include simulator training on steam generator tube leaks and ruptures for control room operators.
(9) the risk and potential consequences of a range of steam generator tube rupture events as discussed in Reference 27 - In Reference 27, the staff estimated the risk contribution due to the potential for single and multiple steam generator tube ruptures. In addition, this study examined the expected consequences of steam generator tube rupture scenarios, including beyond design basis situations, such as the potential for release due to containment bypass via failed tubes concurrent with a breach of secondary system integrity.

\subsection{Tube Inspections}

GL 95-03 requested, in part, a safety assessment justifying continued operation on the basis of past inspection results and a summary of inspection plans for the next scheduled steam generator tube inspection outage as they pertain to the detection of circumferential cracking. The inspection plans were to consist of both an initial scope and sample expansion criteria. For the $\mathrm{CE}$ units with alloy 600 steam generator tubes, the staff summarized some of the information provided by the licensees with respect to the previous and next inspection for each of the areas identified as being potentially susceptible to circumferential cracking. The designation of "previous" refers to inspections performed before issuing or responding to GL 95-03. The designation of "next" (and/or "future") refers to an inspection performed after issuing or responding to GL 95-03. The phrase, "if detect", is used to describe the inspection expansion criteria when a circumferential indication is detected. In many instances, the next (and/or future) inspections have already been completed as a result of the time taken to prepare this document for publishing.

Table 6-2 summarizes the scope of the past and future inspections at the expansion transition along with some pertinent notes. Tables 6-3, 6-4, and 6-5 provide similar information for the dented locations, U-bend region, and sleeve joints, respectively. Tube inspections performed using a technique not capable of reliably detecting circumferentially oriented degradation were recorded as "None" in Tables 6-2 through 6-5. In instances where the results of the tube inspections were readily available, the results were included in the tables, as appropriate. For example, at St. Lucie 2, the results of the inspection were readily available, so the results were 
incorporated into the tables, as appropriate. Acronyms and abbreviations used in the tables are explained in Appendix C.

As can be seen from evaluating the data in Tables 6-2 through 6-5, there are plant-specific differences in the inspection plans (e.g., probe type, scope of examination). These differences in the inspection plans were considered along with other plant-specific circumstances (e.g., preventive measures taken) in evaluating the acceptability of a licensee's response as discussed in Section 6.3. For example, even though a licensee may have implemented a smaller initial inspection scope than another licensee, this may have been considered acceptable if the cumulative operating time for the plant was less than that of the other plant (all other parameters being equal).

The staff has reviewed the submissions provided by the licensees that have $C E$ steam generators with alloy 600 tubes and has concluded that they contain the information requested in GL 95-03. General conclusions regarding the responses are discussed in Section 9. 


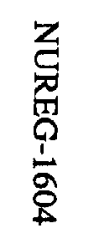
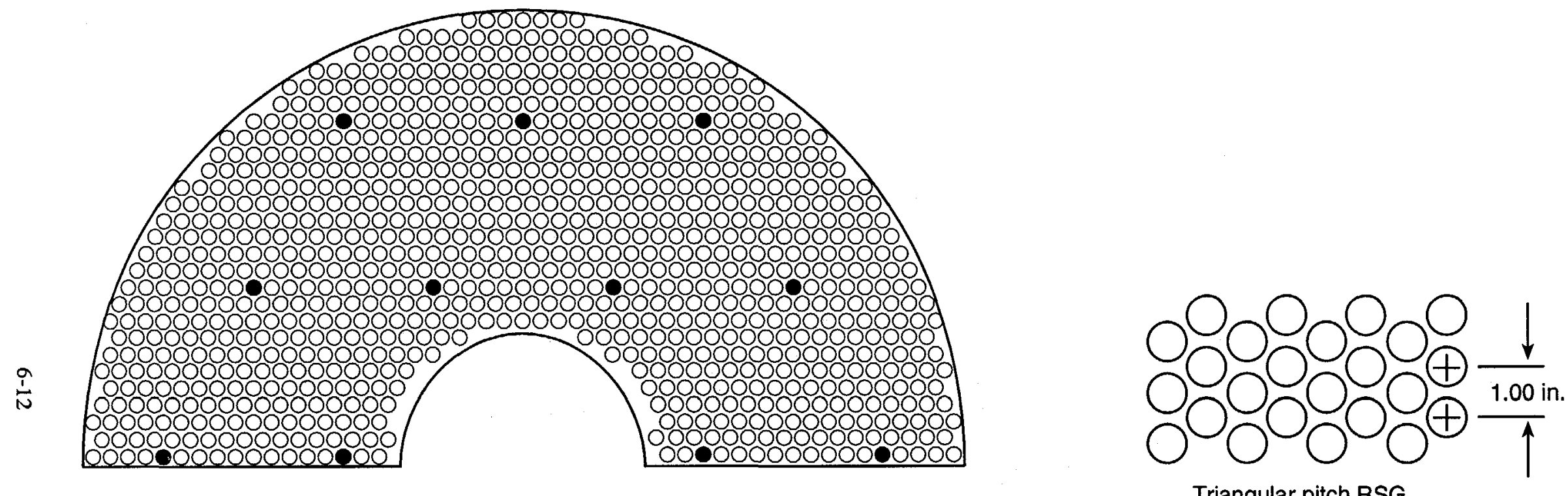

Figure 6-1 Typical CE recirculating steam generator (RSG) tube pattern 


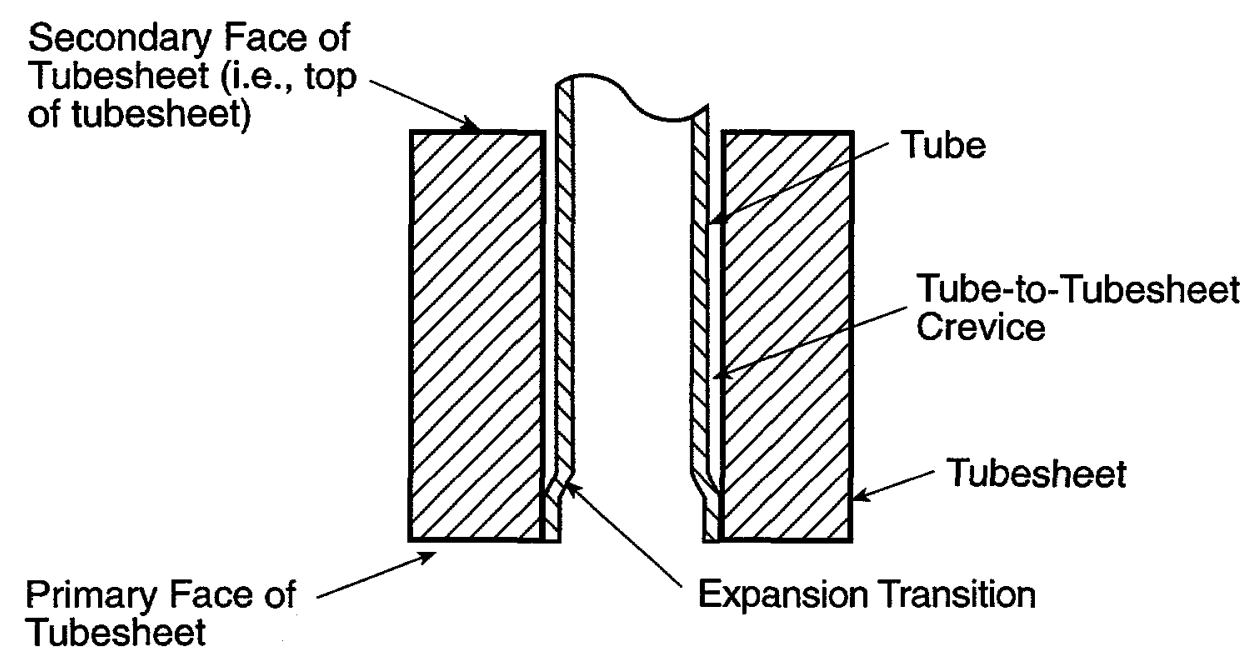

Partial-Depth Expansion Transition

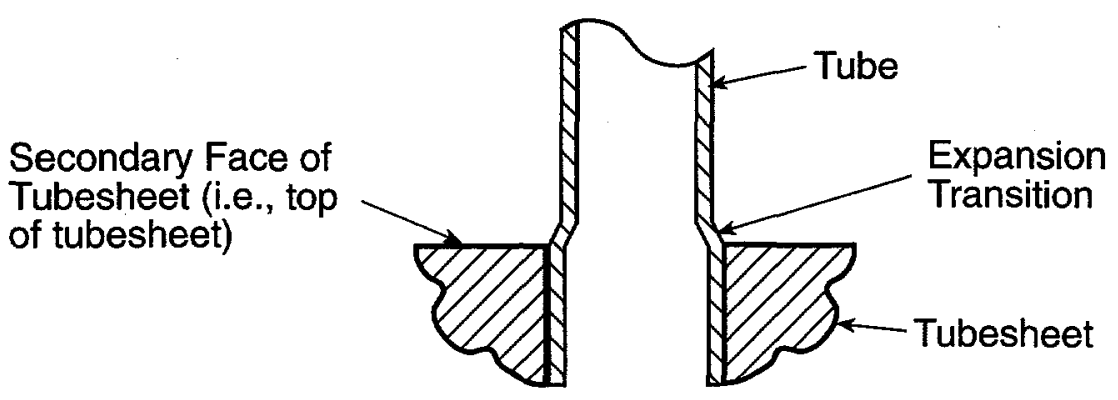

Full-Depth Expansion Transition

Figure 6-2 Partial and full-depth expansion transitions 


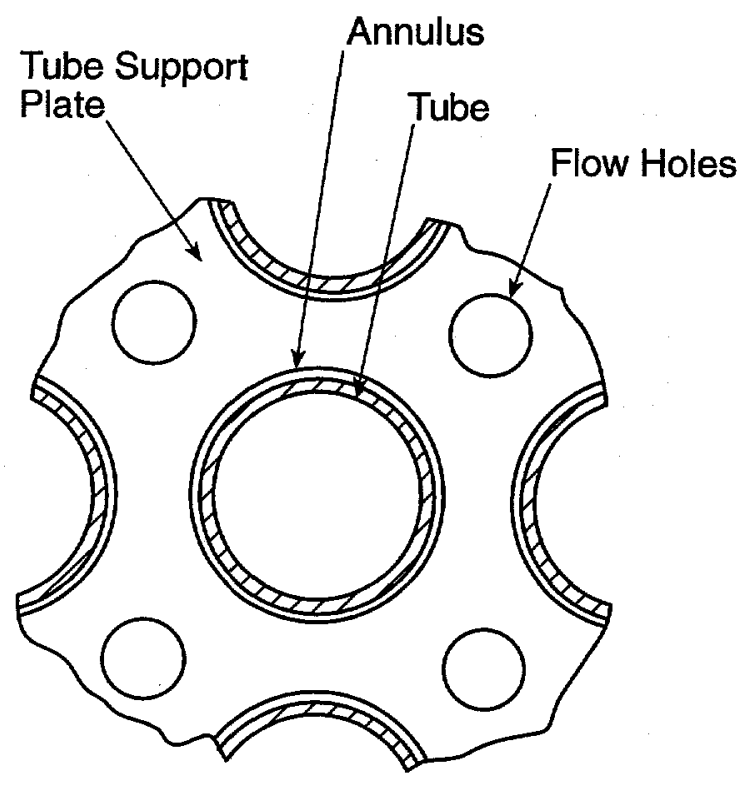

Drilled Plate

(with flow holes)

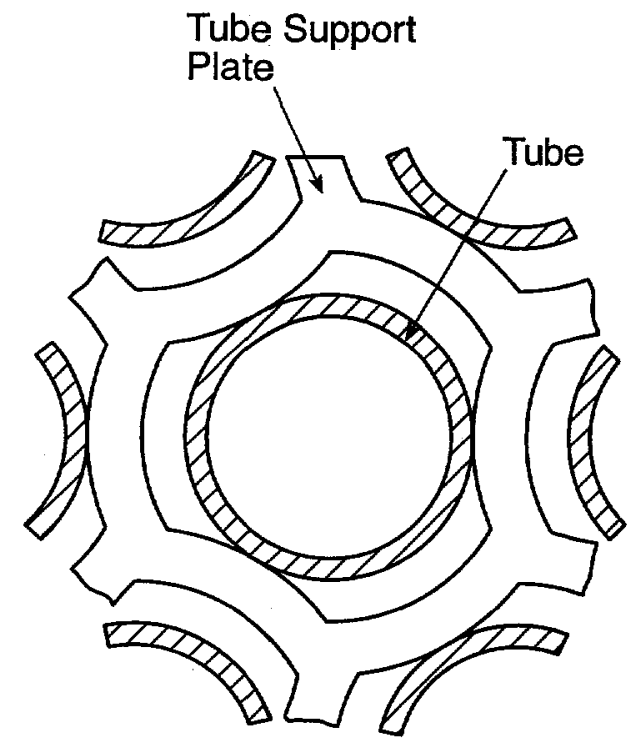

Broach-Trefoil

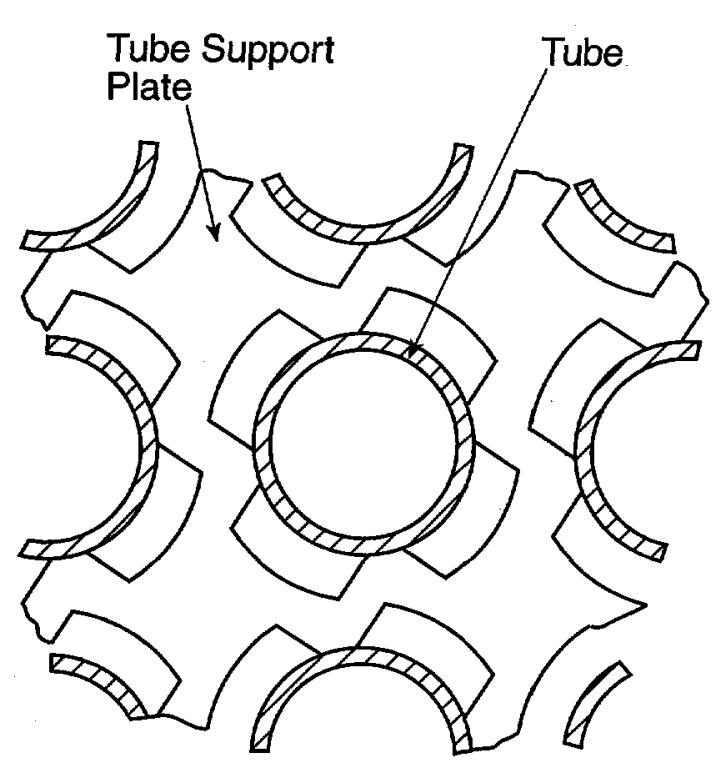

Broach-Quatrefoil

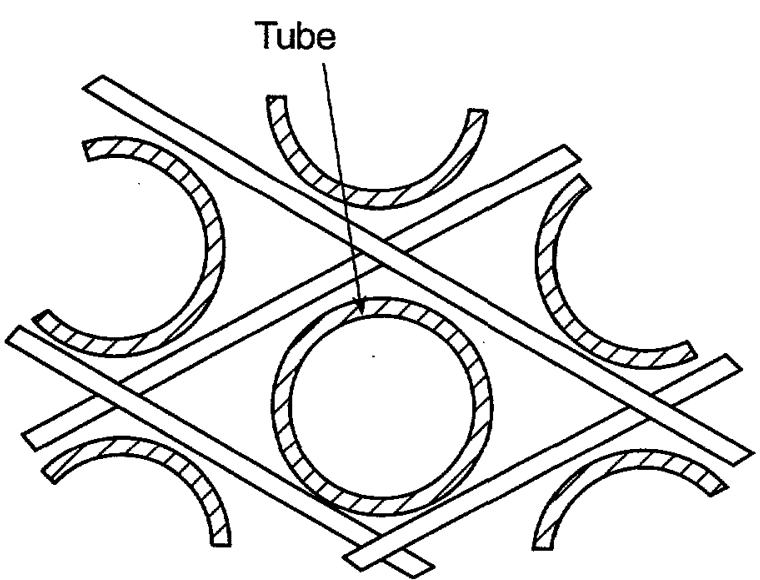

Eggcrate

Figure 6-3 Typical tube support configurations 
Table 6-1 Millstone 2 steam generator tube inspections (1987 to replacement)

\begin{tabular}{|c|c|}
\hline Outage Date/Designation & Comments \\
\hline January $1987(8 \mathrm{~A})$ & Outage as a result of a leaking circumferential crack near the top of tubesheet on the hot-leg side. \\
\hline January 1988 (EOC 8) & Hot-leg circumferential indications detected near the top of tubesheet. 1987 leaker was pulled. \\
\hline February 1989 (EOC 9) & $\begin{array}{l}\text { Circumferential indications were detected in both the hot and cold legs near the top of the } \\
\text { tubesheet. }\end{array}$ \\
\hline October $1989(10 \mathrm{~A})$ & $\begin{array}{l}\text { Scheduled midcycle inspection (in part, because of the large number of cracks detected in EOC 9). } \\
\text { Circumferential indications were detected in both the hot and cold legs near the top of the } \\
\text { tubesheet. }\end{array}$ \\
\hline May 1990 (10B) & $\begin{array}{l}\text { Increasing primary-to-secondary leakage led to tube inspection outage. Leakage attributed to } \\
\text { leaking plugs and sleeves. Circumferential indications were detected in both the hot and cold legs } \\
\text { near the top of the tubesheet. }\end{array}$ \\
\hline September 1990 (EOC 10) & $\begin{array}{l}\text { Circumferential indications were detected in both the hot and cold legs near the top of the } \\
\text { tubesheet. }\end{array}$ \\
\hline April 1991 (11A) & $\begin{array}{l}\text { Increasing primary-to-secondary leakage led to tube inspection outage. Leakage attributed to a } \\
\text { circumferential crack in chord region (near eggerate support } 8 \text { and just below the } 90 \text {-degree bend). }\end{array}$ \\
\hline May 1991 (11B) & $\begin{array}{l}\text { Increasing primary-to-secondary leakage led to tube inspection outage. Leakage attributed to a } \\
\text { circumferential crack in chord region (at the } 90 \text {-degree hot-leg bend above the ninth eggcrate } \\
\text { support). Circumferential indications were also detected in both the hot and cold legs near the top } \\
\text { of the tubesheet. }\end{array}$ \\
\hline January 1992 & $\begin{array}{l}\text { Increasing primary-to-secondary leakage led to tube inspection outage. Leakage attributed to a } \\
\text { circumferential crack near the top of the tubesheet and a circumferential crack near the } 90 \text {-degree } \\
\text { hot-leg bend. }\end{array}$ \\
\hline
\end{tabular}


Table 6-2 Inspections at the expansion transition region in CE plants (Part 1)

\begin{tabular}{|c|c|c|c|}
\hline Plant & $\begin{array}{l}\text { Expansion Transition } \\
\text { Past Inspection }\end{array}$ & $\begin{array}{l}\text { Expansion Transition Future } \\
\text { Inspection }\end{array}$ & Notes \\
\hline Arkansas Nuclear One - 2 & $\begin{array}{l}100 \% \text { RPC in Ho sludge } \\
\text { pile; } 20 \% \text { RPC in CL } \\
\text { sludge pile in } 2 \mathrm{R} 10\end{array}$ & $\begin{array}{l}100 \% \text { in HL with Appendix H circ. } \\
\text { cracking technique. }\end{array}$ & $\begin{array}{l}\text { Performing mid-cycle outages. Sludge pile } \\
\text { constitutes } \sim 65 \% \text { of tubes. References } 44 \text { and } \\
46 .\end{array}$ \\
\hline Calvert Cliffs 1 & $\begin{array}{l}100 \% \mathrm{RPC} \text { in } \mathrm{HL} ; \\
\text { Sample distorted bobbin in } \\
\mathrm{CL}\end{array}$ & $100 \% \mathrm{PP}$ in $\mathrm{HL}$. & $\begin{array}{l}\text { Only } 3 \text { circumferential indications detected. } \\
\text { References } 58 \text { and } 60 \text {. }\end{array}$ \\
\hline Calvert Cliffs 2 & $\begin{array}{l}100 \% \mathrm{PP} \text { in } \mathrm{HL} ; \text { Sample } \\
\text { distorted bobbin in CL }\end{array}$ & $100 \% \mathrm{PP}$ in $\mathrm{HL}$. & $\begin{array}{l}\text { Assessment of PP and RPC indicate relatively the } \\
\text { same detection threshold for conditions at the } \\
\text { plant. } 115 \text { circumferential indications. } \\
\text { References } 58 \text { and } 60 \text {. }\end{array}$ \\
\hline Fort Calhoun & $40 \% \mathrm{RPC}$ in $\mathrm{HL}$ & $\begin{array}{l}100 \% \text { in HL with Appendix H circ. } \\
\text { cracking technique. Will expand to CL } \\
\text { based on EPRI criteria. }\end{array}$ & $\begin{array}{l}\text { Orifice plate prevents RPC insertion in HL for R1 } \\
\text { through R18. Orifice plate installed to eliminate } \\
\text { potential for phosphate corrosion due to steam } \\
\text { blanketing in the U-bend area. Orifice plate } \\
\text { affects } 22 \% \text { of tubes. Will remove orifice plate } \\
\text { in } 1996 \text { for inspections and install a new plate } \\
\text { after inspections are complete. References } 56 \\
\text { and } 79 \text {. }\end{array}$ \\
\hline Maine Yankee & $\begin{array}{l}\text { Sleeving HL; } 100 \% \text { RPC } \\
\text { in CL with some PP and } \\
\text { high frequency RPC in CL }\end{array}$ & $\begin{array}{l}20 \% \mathrm{CS} \text { or } \mathrm{PP} \text { in } \mathrm{CL} \text {. If detect, } 100 \% \\
\text { in CL. }\end{array}$ & $\begin{array}{l}\text { Penetrant testing on several tubes. Sleeving } \\
\text { entire HL. References } 59 \text { and } 80 \text {. }\end{array}$ \\
\hline Palisades & $\begin{array}{l}200 \text { tubes } w / 2 \text {-coil } R P C \text { in } \\
\text { HL }\end{array}$ & $\begin{array}{l}20 \% \text { RPC in HL ( } 320 \text { PP exams from } \\
20 \% \text { sample). If detect, } 100 \% \text { in HL. } \\
\text { If widespread cracking, } 20 \% \text { RPC in } \\
\text { CL. }\end{array}$ & References 68 and 81. \\
\hline Palo Verde 1 & $\begin{array}{l}100 \% \mathrm{PP} \text { in } \mathrm{HL} ; 20 \% \mathrm{PP} \\
\text { in } \mathrm{CL}\end{array}$ & $100 \%$ PP in $\mathrm{HL}$. & References 36 and 82 . \\
\hline Palo Verde 2 & $\begin{array}{l}100 \% \mathrm{PP} \text { in } \mathrm{HL} \text { and } \mathrm{CL} \text { in } \\
\mathrm{SG} 21 ; 37 \% \mathrm{PP} \text { in } \mathrm{HL} \text { in } \\
\mathrm{SG} 22 ; 100 \% \mathrm{PP} \text { in } \mathrm{CL} \\
\text { in } \mathrm{SG} 22\end{array}$ & $\begin{array}{l}100 \% \text { PP in HL. } 500 \text { PP exams in CL. } \\
\text { If detect in CL, } 100 \% \text { PP in CL. If } \\
\text { detect more than } 50 \text { indications in } \mathrm{HL} \text {, } \\
20 \% \mathrm{PP} \text { in CL. }\end{array}$ & References 36 and 82 . \\
\hline Palo Verde 3 & $\begin{array}{l}100 \% \text { RPC in sludge pile } \\
\text { (i.e., 3\% in SG } 31 \text { and } \\
6 \% \text { in SG 32) }\end{array}$ & $100 \% \mathrm{PP}$ in $\mathrm{HL} .10 \% \mathrm{PP}$ in CL. & References 36 and 82 . \\
\hline San Onofre 2 & $100 \% \mathrm{RPC}$ in $\mathrm{HL}$ & $100 \% \mathrm{PP}$ in $\mathrm{HL}$. & $\begin{array}{l}75 \% \text { of cracks are ID initiated based on phase } \\
\text { angle analysis. } 12 \text { circ. cracks identified in } 1993 \\
\text { and } 27 \text { in } 1995 \text {. References } 65 \text { and } 83 \text {. }\end{array}$ \\
\hline San Onofre 3 & $100 \% \mathrm{RPC}$ in $\mathrm{HL}$ & $100 \% \mathrm{PP}$ in $\mathrm{HL}$. & References 65 and 83 . \\
\hline
\end{tabular}


Table 6-2 Inspections at the expansion transition region in CE plants (Part 2)

\begin{tabular}{|l|l|l|l|}
\hline \multicolumn{1}{|c|}{ Plant } & $\begin{array}{c}\text { Expansion Transition } \\
\text { Past Inspection }\end{array}$ & $\begin{array}{c}\text { Expansion Transition Future } \\
\text { Inspection }\end{array}$ & Notes \\
\hline St. Lucie 1 & $\begin{array}{l}100 \% \text { RPC in HL; 3\% } \\
\text { RPC in CL }\end{array}$ & $100 \%$ RPC in HL. 3\% RPC in CL. & References 67 and 84. \\
\hline St. Lucie 2 & $\begin{array}{l}100 \% \text { RPC in HL; 3\% } \\
\text { RPC in CL }\end{array}$ & $\begin{array}{l}100 \% \text { RPC in HL. 3\% RPC in CL. } \\
\text { [Performed 20\% in CL sludge pile } \\
\text { region with no indications detected.] }\end{array}$ & References 67 and 84. \\
\hline Waterford 3 & $\begin{array}{l}\text { 65\% RPC in HL including } \\
100 \% \text { of sludge pile }\end{array}$ & $\begin{array}{l}\text { 20\% in HL plus 500 additional tubes } \\
\text { with Appendix H circ. cracking } \\
\text { technique focused in sludge pile area. } \\
\text { If detect, 100\% of both SGs. }\end{array}$ & References 85 and 86. \\
\hline
\end{tabular}


Table 6-3 Inspections at dented locations in CE plants (Part 1)

\begin{tabular}{|c|c|c|c|}
\hline Plant & $\begin{array}{c}\text { Dented TSP Past } \\
\text { Inspection }\end{array}$ & Dented TSP Future Inspection & Notes \\
\hline Arkansas Nuclear One - 2 & $\begin{array}{l}\text { 20\% RPC of } 10 \text { th TSP } \\
\text { dents }\end{array}$ & None. Will reassess every outage. & $\begin{array}{l}\text { Denting observed in partial drilled TSPs. } \\
\text { Locations with greater than } 0.001 \text {-inch radial } \\
\text { deformation were recorded as dents. Calibration: } \\
0.001 \text {-inch radial dent corresponds to } 1 \mathrm{~V} \text { on } 400 \\
\text { kHz absolute. References } 44 \text { and } 46 \text {. }\end{array}$ \\
\hline Calvert Cliffs 1 & $\begin{array}{l}\text { RPC sampling of largest } \\
\text { solid TSP dents }\end{array}$ & $\begin{array}{l}20 \% \text { PP of dents }>5 \mathrm{~V} \text {. If detect, } \\
\text { expand based on EPRI guidelines. }\end{array}$ & $\begin{array}{l}\text { Calibration: } 4-20 \% \text { holes set to } 4 \mathrm{~V} \text { on all } \\
\text { differential channels. References } 58 \text { and } 60 \text {. }\end{array}$ \\
\hline Calvert Cliffs 2 & $\begin{array}{l}20 \text { PP exams of largest } \\
\text { solid TSP dents }\end{array}$ & $\begin{array}{l}20 \% \text { PP of dents > 5V. If detect, } \\
\text { expand based on EPRI guidelines. }\end{array}$ & $\begin{array}{l}\text { Calibration: } 4-20 \% \text { holes set to } 4 \mathrm{~V} \text { on all } \\
\text { differential channels. References } 58 \text { and } 60 .\end{array}$ \\
\hline Fort Calhoun & 44 RPC exams & $\begin{array}{l}20 \% \text { of dents }>5 \mathrm{~V} \text { at } \mathrm{H} 1 \text { with } \\
\text { Appendix } \mathrm{H} \text { circ. cracking technique. } \\
20 \% \text { of dents at } \mathrm{H} 1<5 \mathrm{~V} \text {. If detect, } \\
100 \% \text { at } \mathrm{H} 1,20 \% \text { at } \mathrm{H} 2 \text { and so on until } \\
\text { none detected. } 20 \% \text { sample of } \mathrm{HL} \\
\text { dents equal to or exceeding } 0.010 \text {-inch } \\
\text { deformation will be inspected with } \\
\text { probe qualified for circ. crack } \\
\text { detection. }\end{array}$ & $\begin{array}{l}\text { Calibration: } 0.001 \text {-inch radial dent corresponds } \\
\text { to } 1 \mathrm{~V} \text { on } 400 \mathrm{kHz} \text { absolute. References } 56 \text { and } \\
79 .\end{array}$ \\
\hline Maine Yankee & 25 RPC exams & $\begin{array}{l}20 \% \text { of dents }>5 \mathrm{~V} \text { at drilled tube } \\
\text { supports. If detect, } 100 \% \text { of dents }> \\
5 \mathrm{~V} \text { and } 20 \% \text { of dents between } 1 \mathrm{~V} \text { and } \\
5 \mathrm{~V} \text {. If detect in } \mathrm{I} \text { to } 5 \mathrm{~V} \text { range, } 100 \% \\
\text { of dents between } 1 \mathrm{~V} \text { and } 5 \mathrm{~V} \text { and } 20 \% \\
\text { of nondented intersections. If detect in } \\
\text { nondented intersections, } 100 \% \text { of all } \\
\text { intersections and expand to cold leg } \\
\text { drilled supports. }\end{array}$ & $\begin{array}{l}\text { Calibration: } 0.010 \text { radial dent corresponds to } \\
10 \mathrm{~V} \text { on } 400 \mathrm{kHz} \text { absolute. Reported dents at } 1 \mathrm{~V} \text {. } \\
\text { References } 59 \text { and } 80 \text {. }\end{array}$ \\
\hline Palisades & $\mathrm{N} / \mathrm{A}$ & N/A & $\begin{array}{l}\text { No denting observed. Confirmed by visual } \\
\text { examination in upper tube bundle region in } 1 \text { SG. } \\
\text { Not susceptible (stainless steel supports and rigid } \\
\text { secondary water chemistry). References } 68 \text { and } \\
81 \text {. }\end{array}$ \\
\hline Palo Verde 1 & N/A & N/A & $\begin{array}{l}\text { No corrosion denting. Calibration: } 50 \% \\
\text { AVB/BW wear set to } 5 \text { volts (Vmax) on the } \\
500 / 100 \text { absolute mix. New dents or changes in } \\
\text { dent signals ( }>=20 \text { volts) require an RPC exam. } \\
\text { Extensive inspections at vertical straps and upper } \\
\text { two tube supports. References } 36 \text { and } 82 \text {. }\end{array}$ \\
\hline Palo Verde 2 & N/A & N/A & $\begin{array}{l}\text { No corrosion denting. Calibration: } 50 \% \\
\text { AVB/BW wear set to } 5 \text { volts (Vmax) on the } \\
500 / 100 \text { absolute mix. New dents or changes in } \\
\text { dent signals ( }>=20 \text { volts) require an RPC exam. } \\
\text { Extensive inspections at vertical straps and upper } \\
\text { two tube supports. References } 36 \text { and } 82 \text {. }\end{array}$ \\
\hline Palo Verde 3 & N/A & N/A & $\begin{array}{l}\text { No corrosion denting. Calibration: } 50 \% \\
\text { AVB/BW wear set to } 5 \text { volts (Vmax) on the } \\
500 / 100 \text { absolute mix. New dents or changes in } \\
\text { dent signals ( }>=20 \text { volts) require an RPC exam. } \\
\text { Extensive inspections at vertical straps and upper } \\
\text { two tube supports. References } 36 \text { and } 82 \text {. }\end{array}$ \\
\hline San Onofre 2 & N/A & N/A & $\begin{array}{l}\text { No denting at support locations. Denting at TTS } \\
\text { adjacent to tie rods. References } 65 \text { and } 83 \text {. }\end{array}$ \\
\hline San Onofre 3 & N/A & N/A & $\begin{array}{l}\text { No denting at support locations. Denting at TTS } \\
\text { adjacent to tie rods. References } 65 \text { and } 83 \text {. }\end{array}$ \\
\hline
\end{tabular}


Table 6-3 Inspections at dented locations in CE plants (Part 2)

\begin{tabular}{|l|l|l|l|}
\hline \multicolumn{1}{|c|}{ Plant } & \multicolumn{1}{|c|}{$\begin{array}{c}\text { Dented TSP Past } \\
\text { Inspection }\end{array}$} & Dented TSP Future Inspection & \multicolumn{1}{|c|}{ Notes } \\
\hline St. Lucie 1 & RPC sampling & $20 \%$ of HL dents in at least 1 SG. & $\begin{array}{l}\text { Calibration: 4-20\% ASME holes set to 5V on } \\
400 / 100 \mathrm{kHz} \text { mix. Larger dents given priority in } \\
\text { sampling scheme. References 67 and 84. }\end{array}$ \\
\hline St. Lucie 2 & RPC sampling & $\begin{array}{l}\text { 20\% of HL dents in at least 1 SG. } \\
\text { [nspected HL and CL dents with RPC } \\
\text { with no indications detected.] }\end{array}$ & $\begin{array}{l}\text { Calibration: 4-20\% ASME holes set to 5V on } \\
\text { 400/100 kHz mix. Larger dents given priority in } \\
\text { sampling scheme. References } 67 \text { and 84. }\end{array}$ \\
\hline Waterford 3 & $\begin{array}{l}\text { RPC inspect any location } \\
\text { with a bobbin signal } \\
\text { greater than 10 volts and } \\
\text { significant growth }\end{array}$ & $\begin{array}{l}\text { RPC inspect any location with a bobbin } \\
\text { signal greater than 10 volts and } \\
\text { significant growth (historic practice). }\end{array}$ & $\begin{array}{l}\text { Very little denting. Tubes adjacent to stay rods at } \\
\text { top of tubesheet and eggcrate supports are } \\
\text { considered most susceptible to denting. } \\
\text { References 85 and 86. }\end{array}$ \\
\hline
\end{tabular}


Table 6-4 Inspections in the U-bend region of small-radii tubes in CE plants (Part 1)

\begin{tabular}{|c|c|c|c|}
\hline Plant & U-bend Past Inspection & U-bend Future Inspection & Notes \\
\hline Arkansas Nuclear One - 2 & None & $\begin{array}{l}20 \% \text { PP in R1. If detect, } 100 \% \text { PP in } \\
\mathrm{R} 1 \text {. If detect in expansion, expand into } \\
\mathrm{R} 2 \text {. }\end{array}$ & References 44 and 46 \\
\hline Calvert Cliffs 1 & None & $\begin{array}{l}20 \% \text { PP in R1 and R2. If detect, } \\
\text { expand based on EPRI guidelines. }\end{array}$ & References 58 and 60. \\
\hline Calvert Cliffs 2 & None & $\begin{array}{l}20 \% \text { PP in R1 and R2. If derect, } \\
\text { expand based on EPRI guidelines. }\end{array}$ & References 58 and 60. \\
\hline Fort Calhoun & None & $\begin{array}{l}20 \% \text { in R1 through R4 with Appendix } \\
\mathrm{H} \text { circ. cracking technique. }\end{array}$ & References 56 and 79. \\
\hline Maine Yankee & $\begin{array}{l}100 \% \mathrm{RPC} \text { in R1 through } \\
\mathrm{R} 12\end{array}$ & $100 \%$ RPC in R1 through R12 & References 59 and 80. \\
\hline Palisades & None & None. & References 68 and 81. \\
\hline Palo Verde 1 & $100 \% \mathrm{RPC}$ in $\mathrm{R} 1$ and $\mathrm{R} 2$ & None. & $\begin{array}{l}\text { First } 18 \text { rows are U-bend tubes. Remaining rows } \\
\text { have double } 90 \text {-degree bend tubes. Small radius } \\
\text { U-bends not susceptible to circ. cracking based } \\
\text { on previous examination results. References } 36 \\
\text { and } 82 \text {. }\end{array}$ \\
\hline Palo Verde 2 & $100 \% \mathrm{RPC}$ in $\mathrm{R} 1$ and $\mathrm{R} 2$ & $100 \% \mathrm{RPC}$ in $\mathrm{R} 1$ and $\mathrm{R} 2$. & $\begin{array}{l}\text { First } 18 \text { rows are U-bend tubes. Remaining rows } \\
\text { have double } 90 \text {-degree bend tubes. Small radius } \\
\text { U-bends not susceptible to circ. cracking based } \\
\text { on previous examination results. References } 36 \\
\text { and } 82 \text {. }\end{array}$ \\
\hline Palo Verde 3 & $100 \% \overline{R P C}$ in R1 and R2 & None. & $\begin{array}{l}\text { First } 18 \text { rows are U-bend tubes. Remaining rows } \\
\text { have double } 90 \text {-degree bend tubes. Small radius } \\
\text { U-bends not susceptible to circ. cracking based } \\
\text { on previous examination results. References } 36 \\
\text { and } 82 \text {. }\end{array}$ \\
\hline San Onofre 2 & None & None. & References 65 and 83 . \\
\hline San Onofre 3 & None & None. & References 65 and 83 . \\
\hline
\end{tabular}


Table 6-4 Inspections in the U-bend region of small-radii tubes in CE plants (Part 2)

\begin{tabular}{|l|l|l|l|}
\hline \multicolumn{1}{|c|}{ Plant } & U-bend Past Inspection & \multicolumn{1}{|c|}{ U-bend Future Inspection } & \multicolumn{1}{|c|}{ Notes } \\
\hline St. Lucie 1 & None & None. & References 67 and 84. \\
\hline St. Lucie 2 & None & None. & References 67 and 84. \\
\hline Waterford 3 & $\begin{array}{l}\text { 300 tubes in upper bundle } \\
\text { region susceptible to steam } \\
\text { drying }\end{array}$ & None. & $\begin{array}{l}\text { Steam blanket region not present in SGs. } \\
\text { References 85 and 86. }\end{array}$ \\
\hline
\end{tabular}


Table 6-5 Inspections at sleeve joints in CE plants (Part 1)

\begin{tabular}{|c|c|c|c|}
\hline Plant & Sleeve Past Inspection & Sleeve Future Inspection & Notes \\
\hline Arkansas Nuclear One - 2 & None (crosswound) & $\begin{array}{l}20 \% \text { with Appendix H circ. crack } \\
\text { qualified technique. If detect, } 100 \% \text {. }\end{array}$ & $\begin{array}{l}442 \text { B\&W kinetically sleeved tubes presently in } \\
\text { service. All sleeves installed in } 1992 \text { (2F92). } \\
\text { References } 44 \text { and } 46 .\end{array}$ \\
\hline Calvert Cliffs 1 & $\mathbf{N} / \mathbf{A}$ & N/A & No sleeves installed. References 58 and 60. \\
\hline Calvert Cliffs 2 & $\mathbf{N} / \mathbf{A}$ & N/A & No sleeves installed. References 58 and 60 . \\
\hline Fort Calhoun & N/A & N/A & No sleeves installed. References 56 and 79. \\
\hline Maine Yankee & N/A & $\begin{array}{l}20 \% \text { C5 or PP. If detect and } \\
\text { associated with unique installation } \\
\text { condition, } 100 \% \text { of sleeves with this } \\
\text { condition. If detect and not associated } \\
\text { with unique installation condition, } \\
100 \% \text {. }\end{array}$ & $\begin{array}{l}\text { Installed Westinghouse laser-welded sleeves } \\
\text { during } 1995 \text { outage. References } 59 \text { and } 80 \text {. }\end{array}$ \\
\hline Palisades & N/A & N/A & No sleeves installed. References 68 and 81 . \\
\hline Palo Verde 1 & N/A & N/A & No sleeves installed. References 36 and 82 . \\
\hline Palo Verde 2 & N/A & N/A & No sleeves installed. References 36 and 82 . \\
\hline Palo Verde 3 & N/A & N/A & No sleeves installed. References 36 and 82 . \\
\hline San Onofre 2 & N/A & $\mathbf{N} / \mathbf{A}$ & No sleeves installed. References 65 and 83 . \\
\hline San Onofre 3 & N/A & N/A & No sleeves installed. References 65 and 83 . \\
\hline
\end{tabular}


Table 6-5 Inspections at sleeve joints in CE plants (Part 2)

\begin{tabular}{|c|c|c|c|}
\hline Plant & Sleeve Past Inspection & Sleeve Future Inspection & Notes \\
\hline St. Lucie 1 & N/A & N/A & No sleeves installed. References 67 and 84 . \\
\hline St. Lucie 2 & N/A & $\overline{\text { N/A }}$ & No sleeves installed. References 67 and 84 . \\
\hline Waterford 3 & $\bar{N} / \mathbf{A}$ & N/A & No sleeves installed. References 85 and 86 . \\
\hline
\end{tabular}




\section{WESTINGHOUSE STEAM GENERATORS}

\subsection{Design}

The steam generators in currently operating Westinghouse units have tubes that are made either from alloy 600 or alloy 690 . These steam generators are further distinguished in that the alloy 600 tubes were either heat treated with a mill-annealing process or a thermal treatment process, whereas all alloy 690 tubes received thermal treatment. For ease of reference, Appendix B contains several lists that provide information pertaining to the type of steam generators used at the various units. These lists include an alphabetical listing by plant name, an alphabetical listing by vendor, and an alphabetical listing by tube material and the method used to expand the tube into the tubesheet.

This section describes the features of steam generators in Westinghouse units with alloy 600 steam generator tubes in either the mill-annealed or thermally treated state. (Westinghouse plants with alloy 690 steam generator tubes are discussed in Section 8.) The first part of this section provides a generic description of the steam generator designs used in Westinghouse plants, followed by plant-specific design features that may affect a plant's susceptibility to circumferential cracking. Among the Westinghouse units with alloy 600 steam generator tubes, there are a variety of steam generators, each with slightly different operating experience. As a result, depending on the location of the circumferential cracking being discussed, the Westinghouse units are divided according to various design features, such as type of tube support plate material, heat treatment of the tube, and/or the method used to expand the tube into the tubesheet (e.g., hydraulic).

\subsubsection{Generic Features}

The Westinghouse steam generators are recirculating shell and U-tube heat exchangers with integral moisture separation equipment. A large cylindrical vessel encloses an inverted U-shaped tube bundle consisting of many thousands of individual tubes, each welded to a thick plate (called a tubesheet) with a hole for each tube end located near the bottom of the steam generator vessel. The reactor coolant enters the hemispherical bottom head through an inlet nozzle, flows through the U-tubes, and exits the lower plenum through an outlet nozzle. A divider plate in the lower plenum below the tubesheet separates the inlet and outlet primary coolant and directs the flow through the tubes. A cutaway view of a typical RSG is provided in Figure 7-1, and a conceptual illustration is provided in Figure 2-1.

As of June 1995, there were 51 operating Westinghouse units. Of these, 46 were operating with steam generators with alloy 600 steam generator tubes, while 5 (i.e., D.C. Cook 2, Indian Point 3, North Anna 1 and 2, and Summer) had alloy 690 tubes. Of the 46 units with alloy 600 tubes, 40 were operating with the original steam generators, while 6 had replaced their steam generators. As of June 1995, a total of 11 Westinghouse units had replacement steam generators ( 6 with alloy 600 tubes, 5 with alloy 690 tubes).

Between June 1995 and December 1996, three additional Westinghouse units (i.e., Ginna, Catawba 1 , and Point Beach 1) replaced their steam generators with steam generators with alloy 690 tubes. (Steam generators with alloy 690 tubes are discussed in Section 8.) In addition, the licensee for Salem commenced replacement of the Unit 1 steam generators in 1996 with steam generators with thermally treated alloy 600 tubes.

Each Westinghouse plant has two to four steam generators depending on the plant design. The number of tubes in a steam generator with alloy 600 tubes varies from approximately 3000 to 6000 , and these tubes are arranged in a rectangular pattern as shown in Figure 7-2.

A number of different Westinghouse steam generator designs exist in the United States. These designs include the model $27,44,51, \mathrm{D} 2, \mathrm{D} 3, \mathrm{D} 4, \mathrm{D} 5, \mathrm{E}$, and $\mathrm{F}$ steam generators. Some differences in these designs include the method and extent of tube expansion into the tubesheet, the type of heat treatment the tubes received, the type of tube support plate material (i.e., carbon steel or stainless steel), the design of the preheater (if any), and the tube diameter. In addition, differences exist among the steam generators of a given model. (For example, the expansion transition for model 51 steam 
generators can be one of several types.) Design differences that are pertinent to steam generator tube integrity (and particularly circumferential cracking) are discussed in the following paragraphs. In addition, Appendix B contains information related to the steam generator design at a given plant.

The tubes in the Westinghouse steam generators were expanded into the tubesheet by a variety of methods. These tubes are expanded in both the primary coolant inlet region (hot leg) and the outlet region (cold leg). As a result, the expansion transitions are frequently referred to as the hot-leg and cold-leg expansion transitions, as appropriate. Typically, only one method was used to expand the tubes into the tubesheet.

Early Westinghouse steam generators were partially mechanically rolled into the tubesheet (i.e., the tubes were only expanded a few inches into the tubesheet). Later Westinghouse steam generators contained tubes that were mechanically (i.e., roll) expanded for the entire length (i.e., thickness) of the tubesheet. As a result, the expansion transition, where the tube changes from being fully expanded against the tubesheet to its nominal size, was located at, or near, the top of the tubesheet. (Illustrations of partial- and full-depth expanded tubes are provided in Figure 6-2.)

In addition to mechanically expanding tubes into the tubesheet, tubes in some steam generators were explosively expanded into the tubesheet using the Westinghouse Explosive Tube Expansion (WEXTEX) process. The resultant expansion transition was located at, or near, the top of the tubesheet. Most later-model Westinghouse steam generators, and replacement steam generators, contain tubes that were hydraulically expanded the full depth of the tubesheet.

In summary, the types of expansion transitions in Westinghouse model steam generators include partial-depth roll expansions, full-depth roll expansions, WEXTEX expansions, and hydraulic expansions. The relative susceptibility of the expansion transition to cracking depends, in part, on the type of expansion transition.

In addition to the different tube expansion methods, the different steam generator models have tubes that received different heat treatments. The heat treatment that a steam generator tube receives is very important, since this treatment has an effect on the tubes susceptibility to corrosion. Most of the earlier model steam generators have tubes that were mill-annealed at a relatively low temperature (i.e., low temperature mill-annealed). The residual stresses and microstructure of the tube material are such that these tubes are relatively susceptible to primary- and secondary-side SCC (Ref. 24). Most of the later operating model steam generators (e.g., models D5, E, F, and replacement steam generators) contain tubes that were thermally treated. These thermally treated tubes generally have an improved microstructure as a result of the precipitation of chromium carbides at the grain boundaries. In the thermal treatment process, the chromium diffused from the grain interiors to the chromium-depleted regions near the grain boundaries, thereby preventing sensitization (Ref. 24).

The tubes in most Westinghouse steam generators with alloy 600 tubes are supported with plates at a number of fixed axial locations along the tube bundle, and have variously shaped bars and/or plates in the U-bend region of the tube bundle. Most of the earlier model steam generators (i.e., models 27,44 , $51, \mathrm{D} 2, \mathrm{D} 3$, and D4) have horizontally oriented tube supports that are drilled hole carbon steel plates. Later model steam generators (i.e., models D5, E, F, and non-alloy 690 replacements) typically have horizontally oriented tube support plates which are constructed of stainless steel. These plates are either of the drilled hole or the broached-quatrefoil design (refer to Figure 6-3).

The support structures in the U-bend portion of the tubes are typically referred to as AVBs and are diagonally oriented in the tube bundle. The AVBs in Westinghouse steam generators stiffen the tubes and/or prevent tube-to-tube contact (Ref. 24).

The construction material and design of the tube support structures play an integral role in determining the degradation mechanisms that may affect a tube. For example, carbon steel plates are more susceptible to corrosion than stainless steel plates in the steam generator operating environment. The corrosion of the plates can lead to tube denting and can limit the flow past the tube, resulting in the accumulation of corrosive impurities. 
Depending on the steam generator model, the secondary system water (i.e., feedwater) may pass through a separate preheater region in the steam generator. Feedwater for many of the earlier model steam generators (i.e., models 27,44 , and 51 ) does not pass through such a preheater. In these steam generators, the feedwater is generally fed through a feedwater nozzle, to a feedring, into the downcomer, where it mixes with recirculating water draining from the moisture separation equipment. Later-model steam generators typically have a separate economizer section (i.e., preheater) near the cold-leg outlet. The feedwater flows into the preheater through a nozzle located in the lower part of the vessel, and auxiliary feedwater is injected through a separate nozzle in the upper part of the vessel. Two different types of preheaters have been used in the Westinghouse steam generators. These include split-flow preheaters (models D2 and D3) and counterflow preheaters (models D4, D5, and E). In the model F steam generators, which represent some of the newer steam generators, preheaters were not included in the design. Figure 7-3 illustrates a typical Westinghouse steam generator with a preheater.

\subsubsection{Plant-Specific Features}

There are unique features that affect steam generator tube integrity in several of the Westinghouse RSGs. The following paragraphs describe some of the more pertinent features that may affect a tube's susceptibility to circumferential cracking or its inspectability.

To field test advanced steam generator tubing materials, a few plants installed implant sections (implant tubes) with sleeve-like inserts in selected tubes during initial steam generator fabrication. Diablo Canyon 1 is one of the few Westinghouse model 51 steam generator plants which installed these sleeve-like inserts. To install the implant tubes at Diablo Canyon 1, approximately $76 \mathrm{~cm}$ (30 inches) of tubing from the hot-leg side of 16 steam generator tubes was removed, and the $76 \mathrm{~cm}$ (30-inch) implant tubes were installed and joined to the respective parent tubes by a $2.5 \mathrm{~cm}$ (1-inch) sleeve-like insert, which was then welded. The licensee for Diablo Canyon 1 has not identified the inserts as being susceptible to circumferential cracking; however, the licensee did inspect the insert region of the implant tubes with a rotating pancake coil probe during the sixth refueling outage in 1994 . No indication of degradation was identified during these inspections (Ref. 87).

Tube wear has been observed in the outer tube rows near the secondary side inlet nozzle in the preheater region in several Westinghouse steam generators. This wear has been observed both in the split-flow preheaters (D2 and D3) and in the counterflow preheaters (D4, D5, and E). The degradation was determined to be caused by large flow velocities and turbulence, as well as insufficient tube restraint. The wear/fretting problem in the D2 and D3 steam generators was addressed by redistributing feedwater flow between the primary and auxiliary feedwater inlets to reduce the flow into the preheater through the primary inlet, and by incorporating a preheater manifold to reduce cross-flow vibration. For the counterflow preheaters, the problem was addressed by expanding the tubes within the tube baffle plates at certain preheater locations, in effect changing the tube's natural frequency. In addition, the feedwater flow was also split between primary and auxiliary inlets on the D4 and D5 steam generators (Ref. 24). The stresses associated with these transitions (i.e., the expanded tubes within the baffle plates of the preheater) may lead to corrosion cracking, although this is less likely than other transitions (such as the hot-leg expansion transition) because of the lower temperature in the preheater region (compared to the hot leg).

At Byron 1 and Braidwood 1, several tubes were expanded both above and below various tube support plate elevations. These expansions were performed to lock the tube support plates in place to permit the use of higher-voltage limits than those described in GL 95-05 (Ref. 1) for predominantly axially oriented ODSCC. The stresses associated with the transitions at the tube support plate elevations of these expanded tubes may lead to corrosion cracking, although this is less likely than other transitions because these tubes are at a lower temperature since they were removed from service by plugging.

\subsection{Locations Susceptible to Circumferential Cracking}

At the time of the original responses to GL 95-03, the Westinghouse Owners Group (WOG) identified three regions as having exhibited circumferential cracking. Specifically, these regions included the expansion transition area located within, or near, the 
tubesheet, the Row 1 and 2 U-bend area, and the dented tube support plate intersections. Circumferential indications had also been detected in sleeve joints.

\subsubsection{Expansion Transition and/or Top of Tubesheet Region}

Tubes in Westinghouse steam generators have been expanded into the tubesheet using a variety of methods (e.g., mechanically, explosively, and hydraulically) and the tubes were expanded either a partial distance into the tubesheet (typically 2.5 to 7.6 $\mathrm{cm}$ ( 1 to 3 inches)) or for the full length of the tubesheet (approximately $61 \mathrm{~cm}$ (24 inches)) as depicted in Figure 6-2. The older Westinghouse steam generators typically have tubes that were partially expanded into the tubesheet, whereas later-model Westinghouse steam generators all have tubes that were fully expanded throughout the length of the tubesheet. Partial-depth tube expansions were only used in steam generators that were mechanically expanded (i.e., rolled) into the tubesheet. These plants are commonly referred to as partial-depth hardroll plants. Mechanically rolling the tube the full length of the tubesheet was also used in several plants, which are commonly known as full-depth hardroll plants. Other Westinghouse steam generators have tubes that were either explosively or hydraulically expanded the full length of the tubesheet. The explosive tube expansion process is referred to as the WEXTEX process, and plants with WEXTEX expansion transitions are referred to as WEXTEX plants. Plants with steam generator tubes that have been hydraulically expanded the full length of the tubesheet are commonly referred to as hydraulically expanded plants. Most of the newer steam generators have tubes that have been hydraulically expanded into the tubesheet.

Since the circumferential cracking operating experience at the expansion transition varies with the type of transition, the operating experience for each type of transition is discussed separately in the following sections.

\subsubsection{Partial-Depth Hardroll Steam Generators}

Of the Westinghouse plants operating in June 1995, 10 plants had steam generators with expansion transitions located well within the tubesheet region (refer to Appendix B). The steam generator tubes for these plants were mechanically rolled for only a few inches into the tubesheet starting at the primary face of the tubesheet. As a result, a crevice exists between the tube and the tubesheet for the portion of the tube within the tubesheet that is not expanded. Since the tube was mechanically rolled into the tubesheet, the expansion transition is commonly referred to as a roll transition. Plants with steam generator tubes that are only roll expanded for a small distance within the tubesheet are referred to as partial-depth hardroll plants. All partial-depth hardroll plants have mill-annealed alloy 600 tubes, which are supported by carbon steel tube support plates along the straight span portion of the tubes.

The crevice region has been a site for corrosion that has led, in part, to extensive sleeving campaigns in the tubesheet region. In addition, degradation in the crevice and/or at the roll transition has led some plants to re-roll the tubes above the original rolled region to provide a new pressure boundary free of any detectable defects. By so doing, the licensees have been able to apply alternate repair criteria, such as the F-star criteria, in which tubes with degradation a certain specified distance below the top of the tubesheet or the bottom of the roll transition (whichever is lower), may remain in service regardless of the depth of degradation. Tubes accepted for continued service on the basis of the F-star criteria have structural and leakage integrity consistent with regulatory criteria. In summary, the expansion transition (or roll transition in this case) for steam generators with partial-depth expansions is typically located well below the top of tubesheet; however, the possibility exists that licensees with such steam generators may eventually re-roll the tube the entire length of the tubesheet.

The plants with partial-depth hardroll steam generators are among the oldest PWRs in this country. The steam generators for these plants are of various models, including model 27 steam generators (Haddam Neck), model 44 steam generators (Ginna, Indian Point 2, and Point Beach 2), and model 51 steam generators (D.C. Cook 1, Kewaunee, Prairie Island 1 and 2, and Zion 1 and 2). As of December 1996, Ginna had replaced its steam generators with a more advanced design, and Point Beach 2 was in the process of a similar replacement. The replacement steam generators at Ginna and Point Beach 2 have tubes that have been hydraulically expanded the full depth of the tubesheet. 
In general, plants with steam generators that have only been partially expanded into the tubesheet have exhibited very little circumferentially oriented degradation either at the expansion (i.e., roll) transition or at the top of the tubesheet. Some of the more pertinent experience is summarized in the following paragraphs. In general, most of these plants have exhibited axially oriented PWSCC at the roll transition, axially oriented ODSCC in the tubesheet crevice region, and/or intergranular attack in the tubesheet crevice region.

In 1992, the licensee for D.C. Cook 1 detected indications of a circumferential nature in several steam generator tubes using a rotating probe with a pancake coil (i.e., a rotating pancake coil probe) at the top of the tubesheet region. Four tubes were pulled to characterize the degradation being observed. The destructive examinations revealed that these indications were attributable to outside diameter initiated cellular corrosion. In cellular corrosion, axial cracking dominates the crack morphology; however, short circumferential crack components of lesser depth than the dominant axial cracking can cause linkage between the axial cracks. The degradation was attributed to localized denting of the tube (Ref. 88).

In 1995, circumferentially oriented indications in the partial-depth expansion transition region were reported at Indian Point 2. Although no tube samples were obtained to verify the degradation morphology, the indications are believed to be bands of closely spaced axial cracks, rather than distinct circumferential cracks (Ref. 88). Axial primary water stress corrosion cracks at the roll transition have been detected at Indian Point 2.

In 1991, indications of circumferential cracking were detected at the hot-leg roll transitions at Ginna. Subsequent inspections before steam generator replacement identified additional indications of circumferential cracking at the hot-leg roll transitions. Inspections of the cold-leg roll transitions were performed, and no circumferential indications were observed.

In general, partial-depth hardroll plants have exhibited very little circumferential cracking at the expansion transition. For partial-depth hardroll plants operating in June 1995, the eddy current indications at Ginna are perhaps the only circumferential cracks located at the expansion transition region. The indications at Indian Point 2 are believed to be closely spaced axial cracks, although no tube pulls have been performed to confirm this, and the indications at D.C. Cook 1 are attributable to cellular corrosion rather than distinct circumferential cracks.

\subsubsection{Full-Depth Hardroll Steam Generators}

Of the Westinghouse plants operating in June 1995, 11 plants had steam generator tubes that were mechanically expanded (i.e., rolled) for the entire length (i.e., thickness) of the tubesheet (refer to Appendix B). As a result, the crevice that existed between the tube and the tubesheet in partial-depth expanded tubes, no longer exists, and the expansion transition is located at or near the top of the tubesheet. As with the partial-depth hardroll plants, the expansion transition is commonly referred to as a roll transition, since the tube was mechanically rolled into the tubesheet. Plants with steam generator tubes that have been roll expanded for the entire thickness of the tubesheet are referred to as full-depth hardroll plants. All full-depth hardroll plants have mill-annealed alloy 600 tubes supported by carbon steel tube support plates along the straight span portion of the tubes. Full-depth hardroll plants have tubes with outside diameters of either $22.22 \mathrm{~mm}$ (7/8 inch) or $19.05 \mathrm{~mm}$ (3/4 inch).

The steam generators for full-depth hardroll plants are of various models. That is, there are model 51 and $51 \mathrm{M}$ steam generators (Farley 2 and Beaver Valley 2, respectively), model D2 steam generators (McGuire 1), model D3 steam generators (Catawba 1, McGuire 2, and Watts Bar 1), model D4 steam generators (Braidwood 1, Byron 1, Comanche Peak 1, and Shearon Harris 1), and model E steam generators (South Texas Project 1). As of December 1996, Catawba 1 had replaced its steam generators with a more advanced design that has full-depth hydraulically expanded tubes. Farley 2 and Beaver Valley 2 (model 51 and $51 \mathrm{M}$ steam generators) are the only two plants that use $22.22 \mathrm{~mm}$ (7/8-inch) outside diameter tubing with full-depth mechanical expansions.

In general, plants with steam generators that have been mechanically expanded the full length of the tubesheet have exhibited circumferentially oriented degradation primarily at the expansion (i.e., roll) transition. Some of the more pertinent experience is 
summarized below. In addition to circumferential cracking at the expansion transition, most of these plants have exhibited primarily axially oriented ODSCC at the tube support plate elevations.

Of the 11 operating plants with steam generators that have full-depth mechanical expansion transitions, 7 had exhibited circumferential cracking at the roll transition as of June 1995. These seven plants include Braidwood 1, Byron 1, Catawba 1, Farley 2, McGuire 1 and 2, and South Texas Project 1. The four units that did not exhibit circumferential indications include two units that just recently commenced commercial operation (Watts Bar 1 and Comanche Peak 1) and one unit that has $22.22 \mathrm{~mm}$ (7/8-inch) (outside diameter) tubing (Beaver Valley 2).

Peening of the expansion transitions was performed at all of the plants with steam generator tubes that were full-depth hardroll expanded into the tubesheet. Both rotopeening and shotpeening have been performed. In some instances, the peening was done before commercial operation while in other instances it was performed after commencing commercial operation. The shotpeening and rotopeening process impart a thin layer of compressive stress on the tube inside diameter which is intended to inhibit the initiation of PWSCC (Ref. 89). Nonetheless, circumferential cracks have been found in these plants, regardless of when the peening was performed. However, the predominant mode of circumferential cracking in units with full-depth expansion transitions has been initiated on the secondary side rather than the primary side, suggesting that the peening application may be successful at mitigating the initiation of PWSCC, particularly when applied before operation (Refs. 89 and 90). Peening may delay the onset of primary side cracking, although no formal assessment was performed as part of this review.

At Beaver Valley 2 and Farley 2 (which have $22.22 \mathrm{~mm}$ (7/8-inch) outside diameter tubes), a low rate of occurrence of circumferential cracking was observed through June 1995. As of June 1995, circumferential indications at the expansion transition had not been observed at Beaver Valley 2, and only one circumferential indication had been detected at Farley 2. As with the other full-depth hardroll plants, both of these units peened the hot-leg expansion transition region to mitigate the occurrence of both circumferential and axial cracking. Beaver Valley peened before commercial operation (Ref. 91).

Subsequent to June 1995, a number of circumferential indications were detected at both Beaver Valley 2 and Farley 2. The licensee for Beaver Valley 2 reported identifying 21 circumferential indications at the expansion transition during their fall 1996 outage (Ref. 92). At Farley 2, 192 circumferential indications were identified during their fall 1996 outage. Most of the circumferential indications at Farley 2 were attributed to ODSCC. The licensee for Farley 2 attributed the increase in the number of detected indications at the expansion transition, in part, to the first time use of the plus-point probe (Ref. 93).

Several tube specimens were removed from the steam generators at plants with full-depth hardroll expansion transitions to characterize circumferentially oriented tube degradation at the roll transition. These tube specimens include both $22.22 \mathrm{~mm}(7 / 8$-inch) and $19.05 \mathrm{~mm}$ (3/4-inch) outside diameter tubes. The results from several of these specimens are discussed below.

Several tube specimens were removed from Farley 2 (which has $22.22 \mathrm{~mm}$ (7/8-inch) outside diameter tubes) for destructive examination of indications at the tube support plate elevations; however, information regarding the integrity of the expansion transition region was obtained. For example, one tube pulled from Farley 2 in 1989 had some circumferentially oriented PWSCC at the roll transition, while the other tube had no detectable degradation at the roll transition. Additional tube pulls performed by the licensee for Farley 2 (for reasons not related to circumferential cracking at the expansion transition) did not reveal any significant roll transition degradation (Ref. 90). The licensee for Farley 2 also removed several tube specimens during their 1996 outage to characterize the cracking (axial and circumferential) occurring at the expansion transition (Ref. 93). The results from the destructive examination of these specimens were not available at the time this report was prepared.

The licensee for McGuire removed a tube from one of the McGuire 1 steam generators for destructive examination in January 1990. McGuire 1 has steam generators with $19.05 \mathrm{~mm}$ (3/4-inch) outside diameter tubes. The pulled tube was burst tested and exhibited 
a burst pressure of 648 bar ( 9400 pounds per square inch (psi)) and bent over before bursting. The crack initiated on the outside of the tube and was intergranular in nature. The crack was through-wall for 90 degrees and less than 40-percent through-wall ODSCC for the remaining part of the circumference (Refs. 52 and 90).

In 1991, a tube was pulled from Catawba 1 (19.05 mm (3/4-inch) outside diameter tubes) for a circumferential indication at the top of the tubesheet. This tube had a burst pressure of 634 bar (9200 psi). The corrosion for this tube initiated from the outside of the tube. The degradation was characterized as a 360-degree band of circumferential intergranular attack which was less than 15-percent through the tube wall (Ref. 52).

Tubes that were pulled from the hot leg of the steam generators at South Texas Project $1(19.05 \mathrm{~mm}$ (3/4-inch) outside diameter tubes) to characterize the nature of circumferential indications at the expansion transition indicate that the morphology of the cracking is ODSCC. The locations of the tubes with eddy current indications indicate enhanced susceptibility in the central portion of the tube bundle on the hot leg. The licensee concluded that this enhanced susceptibility is most likely the result of thermal hydraulic conditions in this area, which affect the local hot-leg top-of-tubesheet environment (Ref. 94). Mapping the location of the detected circumferential indications reveal a preference for reported hardened sludge piles concentrated around the hot-leg T-slot (Ref. 90). The T-slot is an "untubed" region in the tube bundle, which is in the shape of a " $\mathrm{T}$ ". This region contains steam generator blowdown piping at the top of the tubesheet and was designed with the objective of enhancing sludge removal from the steam generator.

Approximately 12 tube sections were removed from the steam generators at Byron $1(19.05 \mathrm{~mm}$ (3/4-inch) outside diameter tubes) during the 1994-1996 time-frame to address circumferential cracking at the expansion (i.e., roll) transition. The destructive examination revealed that the morphology of the degradation was consistent with tubes pulled from other steam generators. The circumferential indications at Byron 1 were attributed primarily to outside diameter initiated stress corrosion cracks. The crack network consisted of multiple initiation sites for short, discrete, non-coplanar circumferential cracks. The corrosion was contained to at least a 7.6 $\mathrm{mm}(0.3$-inch) band at the roll transition, and there were ligament areas of non-corroded material between the stress corrosion cracks. Some of the cracks extended through the tube wall, and some of the outside diameter cracks had an axial orientation. Furthermore, there were some inside diameter initiated axial cracks (i.e., axially oriented primary water stress corrosion cracks). These inside diameter initiated cracks did not interact with the outside diameter initiated cracks. The licensee's conclusions from the destructive examination of the pulled tubes is that the eddy current indications are difficult to size (in terms of average and maximum depth and circumferential arc length) to quantitatively assess the structural and leakage integrity of the tubes; however, the tubes have high structural integrity for the same reason the indications are difficult to size (i.e., the presence of ligaments of non-corroded material) (Ref. 95).

Whereas most full-depth hardroll plants have observed circumferential indications at the expansion transition, the number of tubes with these indications varies from plant to plant. At Braidwood 1 and Byron 1 (which have $19.05 \mathrm{~mm}$ (3/4-inch) outside diameter tubes), a significant number of circumferential indications have been detected at the roll transition (approximately 6000 affected tubes at Byron 1 and approximately 1000 tubes at Braidwood 1). The licensees for the other full-depth hardroll plants have not observed the number of circumferential indications at the expansion transition that Braidwood and Byron 1 have.

As a result of the structural and leakage integrity of the steam generator tube bundle, two full-depth hardroll units have performed midcycle steam generator tube inspections. At Braidwood 1, a midcycle inspection commenced in October 1996 as a result of circumferential cracking at the roll transition. At Byron 1, a midcycle inspection was performed in November 1995 as a result of axially oriented ODSCC at the tube support plate elevations and, in part, because of circumferential cracking at the roll transition. These midcycle inspections were warranted on the basis of the structural and leakage significance of the degradation in the tube bundle (not simply on the number of indications detected). That is, from a safety standpoint, the significance of the indications detected (e.g., length and depth) is more important than the number of indications. At 
Braidwood and Byron 1 (as of December 1996), all of the circumferential indications detected were capable of withstanding the required pressure loadings (although the operating interval was limited).

In summary, plants with full-depth hardroll expansion transitions have exhibited circumferential cracking at the expansion (i.e., roll) transition as evidenced through tube inspections and the destructive examination of pulled tubes. The vast majority of the indications have been located at the hot-leg roll transition; however, circumferential indications at the cold-leg roll transition have been observed in at least one unit (i.e., Byron 1) (Ref. 96). As of December 1996, the extent of the cracking in terms of the number of tubes affected was more severe in plants with $19.05 \mathrm{~mm}$ (3/4-inch) outside diameter tubes than in plants with $22.22 \mathrm{~mm}(7 / 8$-inch) outside diameter tubes; however, all full-depth hardroll plants with alloy 600 mill-annealed tubes are susceptible to circumferential cracking regardless of tube size. The severity of the circumferential indications at several plants has resulted in the performance of midcycle steam generator tube inspections.

\subsubsection{WEXTEX Steam Generators}

Of the Westinghouse plants operating in June 1995, nine plants had steam generator tubes that were expanded the entire length (i.e., thickness) of the tubesheet using the Westinghouse Explosive Tube Expansion (i.e., WEXTEX) process (refer to Appendix B). The WEXTEX tube expansion process uses an explosive charge to produce tube-to-tubesheet contact throughout the tubesheet region. Compared to the mechanical rolling process, WEXTEX tube expansion generally produces lower residual stresses within the expanded-to-unexpanded tube transition region. The WEXTEX process has been implemented only in alloy 600 mill-annealed tubing (Ref. 90). As a result of the WEXTEX process, the expansion transition is located at or near the top of the tubesheet.

Plants with steam generator tubes that were explosively expanded into the tubesheet by the Westinghouse process are referred to as WEXTEX plants. All WEXTEX plants have mill-annealed alloy 600 tubes supported by carbon steel tube support plates along the straight span portion of the tubes. Furthermore, all plants with WEXTEX expansion transitions have tubes with outside diameters of
$22.22 \mathrm{~mm}$ (7/8-inch), with the exception of Comanche Peak 1 which has $19.05 \mathrm{~mm}$ (3/4-inch) outside diameter tubes. (Comanche Peak 1 only has a limited number of WEXTEX expansion transitions; the majority of the expansion transitions are full-depth hardroll expansion transitions.) At Comanche Peak 1 , to facilitate a stayrod modification, 3839 tubes were removed in the shop. When the tubes were replaced, the WEXTEX process was used.

With the exception of Comanche Peak 1, the steam generators for WEXTEX plants are all model 51 steam generators (Beaver Valley 1, Diablo Canyon 1 and 2, Farley 1, Salem 1 and 2, and Sequoyah 1 and 2). The steam generators at Comanche Peak 1 are model D4 steam generators. As of 1996, plans currently exist to replace the Salem 1 steam generators with the steam generators originally purchased for the cancelled Seabrook unit (Ref. 97).

In general, plants with steam generators that have WEXTEX transitions have exhibited circumferentially oriented degradation primarily at the expansion (i.e., roll) transition. Some of the more pertinent experience is summarized below. In addition to circumferential cracking at the expansion transition, most of these plants have exhibited primarily axially oriented ODSCC at the tube support plate elevations.

In the 1991-1992 time-frame, the WEXTEX owners issued guidance for a top-of-tubesheet (i.e., WEXTEX transition) inspection plan. This inspection plan divides the tubesheet into four distinct zones. Zone 4 represents the central region of the tubesheet and is coincident with the low cross-flow velocity region where most sludge accumulation occurs. Additionally, about 95 percent of all industry WEXTEX cracking has been identified in Zone 4. The WEXTEX inspection plan uses an initial sample size of 50 percent of the active Zone 4 tubes (700 tubes minimum, which is approximately 20 percent of the total number of steam generator tubes) utilizing the motorized rotating pancake coil probe for the detection of circumferential indications at the top of the tubesheet. All steam generators are inspected with this minimum sample size during each refueling outage. The WEXTEX transition region is defined as the area from the bottom of the WEXTEX transition to $12.7 \mathrm{~mm}$ ( 0.5 inch) above the bottom of the WEXTEX transition. (The bottom of the WEXTEX transition is the first point of contact between the tube 
and the tubesheet, when traversing the tube from the unexpanded portion to the expanded portion.) The inspection focuses on the region of the tube bundle with the largest potential for finding indications, and thus results in the highest likelihood for requiring an expansion of the sample size (Refs. 87 and 91).

The criteria for expanding the initial sample size for WEXTEX steam generator tubes are predicated on the number of indications found in the WEXTEX transition region and their circumferential extent. The expansion criteria require an additional 8-percent increase in the sample size in the affected steam generator for the first indication identified, and then a stepwise increase in the sample size of at least 10-percent in the affected steam generator for each subsequent circumferential indication found. Expansion of the sample to include 100 percent of the tubes in the affected steam generator would be performed if more than seven circumferential indications were found (as summed over all inspected tubes in the initial or expanded samples) or if any circumferential or axial indication exceeds the structural criteria (Ref. 87). Additional sample expansion criteria exist; however, the above criteria indicate the general program.

Of the nine operating plants with steam generator tubes that have WEXTEX transitions (including Comanche Peak 1 , which only has a limited number of WEXTEX transitions), seven had exhibited circumferential cracking at the expansion transition as of June 1995. These seven plants include Beaver Valley 1, Diablo Canyon 2, Farley 1, Salem 1 and 2, and Sequoyah 1 and 2. The two units that had not exhibited circumferential indications include Comanche Peak 1 (which is a relatively new plant that has only 3839 tubes with WEXTEX transitions) and Diablo Canyon 1. However, subsequent to June 1995, a circumferential indication was detected at the expansion transition in Diablo Canyon 1 (Ref. 98).

Peening of the expansion transitions was performed in at least seven of the nine plants with steam generator tubes that have WEXTEX transitions. Neither Beaver Valley 1 nor Farley 1 indicated that peening had been performed in the steam generators at their plants. The steam generator tubes at the other WEXTEX units were peened using the shotpeening process. In one instance (i.e., Comanche Peak 1), the peening was done before commercial operation, while in the other instances it was performed after commencing commercial operation. As discussed earlier, the peening process imparts a thin layer of compressive stress on the tube's inside diameter in order to inhibit the initiation of PWSCC (Ref. 89). Regardless of when, or if, the peening was performed, circumferential indications have been found at the expansion transition. Unlike the experience for full-depth hardroll plants, the circumferential cracking in units with WEXTEX transitions appears to predominantly initiate from the primary side rather than from the secondary side (i.e., the outside diameter). However, as mentioned earlier, the peening process may delay the onset of the cracking (although no formal assessment was performed as part of this review).

Several tube specimens were removed from the steam generators at WEXTEX plants to characterize circumferentially oriented tube degradation at the expansion transition. The results from several of these specimens are discussed below.

Circumferential cracking in WEXTEX transitions was first observed at North Anna 1 in 1987. Tube pull results from two tubes removed from North Anna 1 revealed circumferentially oriented PWSCC. Non-corroded ligaments were detected in the crack network of both tube pull specimens. The measured burst pressures for these tubes exceeded 620 bar ( 9000 psi), which is well above the structural criteria contained within Reference 33 (Ref. 90).

Other tubes removed from WEXTEX plants were removed primarily to characterize predominantly axially oriented ODSCC at the tube support plate elevations. Laboratory analysis of the expansion transition portion of these tubes revealed degradation in several instances (Refs. 90 and 91). In other instances, no circumferentially oriented degradation was observed at the expansion transition (Ref. 99).

\subsubsection{Hydraulic Steam Generators}

Of the Westinghouse plants operating in June 1995, 17 had steam generator tubes that were hydraulically expanded the entire length (i.e., thickness) of the tubesheet (refer to Appendix B). Compared to mechanical rolling or WEXTEX processes, the hydraulic tube expansion process generally reduces residual stresses within the expanded-to-unexpanded tube transition region (Ref. 100). As a result of the hydraulic process, the expansion transition is located 
at or near the top of the tubesheet. Plants with steam generator tubes that were hydraulically expanded into the tubesheet are referred to as hydraulic plants. All alloy 600 hydraulic plants have tubes supported by stainless steel tube support plates along the straight span portion of the tubes. The alloy 600 tubes for all but two of these plants were thermally treated rather than mill-annealed. The diameter of the steam generator tubes varies from plant to plant. In general, however, the diameters used include 19.05 mm (3/4-inch) (e.g., Comanche Peak 2), 22.22 mm (7/8-inch) (e.g., Point Beach 1, Surry 1 and 2), and $17.46 \mathrm{~mm}$ (11/16-inch) (e.g., Callaway, Millstone 3, Seabrook 1, Vogtle 1 and 2, and Wolf Creek 1).

The steam generators for hydraulic plants are of various models, including model 44F (Point Beach 1, Robinson 2, and Turkey Point 3 and 4), model 51F (Surry 1 and 2), model D5 (Braidwood 2, Byron 2, Catawba 2, and Comanche Peak 2), model E (South Texas Project 2), and model F (Callaway, Millstone 3, Seabrook 1, Vogtle 1 and 2, and Wolf Creek 1). The steam generators currently in use at Point Beach 1, Robinson 2, Surry 1 and 2, and Turkey Point 3 and 4 are replacement steam generators. Two of these plants (Callaway and South Texas Project 2) have mill-annealed tubes, while the others have thermally treated tubes. Callaway, which is one of the oldest plants with hydraulic expansion transitions, is unique in that the first 10 rows of the steam generators contain thermally treated tubes, while the remaining rows contain mill-annealed tubing. Both Callaway and South Texas Project 2 have shotpeened the hot-leg expansion transition region. South Texas Project 2 also shotpeened the cold-leg expansion transition region.

In general, plants with steam generators that have hydraulic transitions have not exhibited circumferentially oriented degradation at any location. The one exception is Callaway, which detected circumferential indications at the hydraulic expansion transitions in 1995 and in 1996 . The relatively good operating experience at these plants is a result of a combination of design and operational improvements. The following paragraphs summarize some of the more pertinent experience.

Of the 17 operating plants with steam generator tubes that have hydraulic expansion transitions, only Callaway had exhibited circumferential indications at the expansion transition as of June 1995. As noted above, Callaway is one of two plants with mill-annealed tubes with hydraulic expansion transitions; the other is South Texas Project 2. In April 1995, the licensee for the Callaway plant identified circumferential indications at the hot-leg expansion transition in 10 tubes. In addition, 15 tubes were identified with axial indications at the expansion transition, including 2 tubes with both axial and circumferential indications. This was the first outage during which any evidence of cracking was observed. This indicates that axial indications need not be observed before finding circumferential indications. (That is, other forms of degradation need not precede the detection of circumferential indications.) It is important to note that only the mill-annealed tubes at Callaway exhibited indications of cracking during the 1995 inspection (i.e., no cracking was observed in the thermally treated tubes during the 1995 inspection).

At the Callaway plant, additional indications of tube degradation at the hot-leg expansion transition were observed in 1996. During the 1996 inspection outage, both axial and circumferential indications were identified (along with volumetric indications). However, unlike the 1995 inspection, indications were found both in thermally treated and mill-annealed tubes. Although the licensee has not removed any tubes for destructive examination to characterize the nature of these indications, one can speculate that these indications at the expansion transition are possibly attributed to SCC.

In 1990, two tubes were pulled from the Surry 1 replacement steam generators to characterize circumferentially oriented degradation detected in the field at the expansion transition. These steam generators contain thermally treated alloy 600 tubes, which were hydraulically expanded the full depth of the tubesheet. For one of the pulled tubes, the licensee concluded that the poorly defined rotating pancake coil probe signal was similar to that of a ding or mechanical deformation. Upon destructive testing of this tube, no SCC was detected on either the inside or outside diameter. The source of the eddy current signal was therefore attributed to probe liftoff in the expansion transition and mechanical imperfections in the tube resulting from the tube installation process. For the other pulled tube, the maximum diameter occurred approximately $15 \mathrm{~mm}$ (0.6-inch) above the top of the tubesheet. A 70-degree mechanical groove was found on the 
outside diameter of the tube and the licensee attributed this groove to the interaction of the tube with the edge of the tubesheet during the expansion process (Refs. 101 and 102). Although the hydraulic expansion process was designed to locate the transition slightly below the top of the tubesheet, the licensee concluded that the tube was overexpanded above the top of the tubesheet. Several other units also have steam generator tubes that were overexpanded (i.e., expanded above the top of the tubesheet), including Turkey Point 3 and 4. One licensee indicated that the overexpansion of these tubes can produce residual stresses in the affected locations, which could make them more susceptible to cracking than areas that are not overexpanded (Ref. 103).

As previously noted, the relatively good operating experience for these plants can be attributed to several factors including the method used to expand the tubes and the heat treatment that the tubes received. A study performed by Westinghouse led the manufacturer to conclude that the residual stress levels present in hydraulically expanded tubes at the expansion transition are lower than in either mechanically or explosively expanded tubing (Ref. 90). Since crack growth rate and time to crack initiation depend, in part, on the stress level, lower stresses may result in lower crack growth rates and/or longer time before crack initiation. The thermal treatment process used for most of the steam generator tubes in the hydraulically expanded plants is intended to provide enhanced corrosion resistance over the mill annealing process used in the steam generators at other plants (Ref. 90). Operating experience indicates that thermally treated tubes are less susceptible to SCC than mill-annealed tubes since no significant amount of cracking has yet to be detected in thermally treated tubes.

\subsubsection{Small-Radius U-Bends}

Susceptibility to circumferential SCC (and SCC in general) depends, in part, on the stresses exerted on the tube at the location of interest, as well as the microstructure of the alloy. For the case of SCC in the U-bend, the stresses at this location can be attributed to several sources including operating temperature and pressure, tolerances on tube hole position at the top support plate, hot-to-cold-leg temperature variations, differential expansion of the tube and support plate, twist of the tube resulting from rolling of the tube into the tubesheet, tube ovality, and residual stresses resulting from the manufacturing process (Ref. 104). Tube ovality can result from the manufacturing process and from tube denting. Tube denting, if excessive, can lead to tube support plate deformation and eventually to closure of the support plate flow slots (i.e., a row of rectangular slots located in the tube support plate between the hot and cold-leg side of the steam generator). Closure of the upper support plate flow slots can induce bending of the tube and ovality at the apex of the inner row U-bends (Ref. 30).

In addition to the stresses on a tube, tube microstructure affects a tube's susceptibility to SCC. Tube microstructure can vary from tube-to-tube and includes properties such as grain size, carbide distribution, chemistry, and hardness. Since many of these factors (stresses and microstructure) are plantand/or tube-specific, it is difficult to predict the relative SCC susceptibility of any particular steam generator or any given tube in a steam generator.

The tubes of certain model Westinghouse steam generators with small-radius U-bends (i.e., the tubes in rows 1 and 2) have exhibited axial and circumferential cracking. The vast majority of the these small-radius U-bend cracks have occurred in tubes with mill-annealed alloy 600 tubes with at least one reported instance of possible U-bend cracking in alloy 600 thermally treated tubing (the reported cracking in the alloy 600 thermally treated tube was axial in orientation). These cracks generally initiate from the primary side of the tube and occur at or near the apex of the U-bend and at the tangent transition between the $U$-bend and the straight span of the tube (refer to Figure 7-4). One licensee characterized the root causes of U-bend PWSCC as being the result of (1) high residual stresses in a susceptible material, (2) excess ovality during the tube bending process (apex location), (3) irregular transitions formed during the tube bending process (i.e., a bulge at the tangent point), and (4) top tube support plate denting (Ref. 105).

Small-radius tube U-bend cracking has led some plants with mill-annealed alloy 600 tubes to preventively plug tubes in this region (primarily the row 1 tubes). Additionally, some plants have applied an in situ heat treatment to the U-bend region. The intent of this in situ U-bend heat treatment (UBHT) 
is to reduce the susceptibility of the tube to axial and circumferential SCC, by altering its grain structure and reducing the residual stresses introduced during the bending process (Ref. 30). This in situ UBHT was performed in some units before commercial operation while in other units it was performed after commencing commercial operation. In addition, some plants have removed the plugs from small-radius tubes that were preventively plugged, in situ heat treated the U-bend region of these tubes, and returned these tubes to service (Ref. 90).

As discussed above, indications in the U-bend region of tubes with small-bend radii have been observed in mill-annealed and thermally treated tubes. The following paragraphs contain a summary of some of the more pertinent operating experience related to cracking in the U-bend region of tubes with small-bend radii. The operating experience is organized based on the type of expansion transition at the plant (e.g., full-depth hardroll plants) since plants with similar expansion transitions tend to be of the same vintage. As a result, many of the factors that influence a tube's susceptibility to cracking are considered to be similar at these plants.

As discussed above, the factors that influence a tube's susceptibility to cracking include the tube material, the tube microstructure, and the stresses exerted on the tube. The tube material for all the plants discussed in this section is alloy 600 . The tube microstructure, which is partially determined by the heat treatment that the material receives, differs from plant-to-plant; however, the steam generators in this section can be distinguished based on whether the tubes received a thermal treatment or were mill-annealed. In general, most of the older plants (i.e., the partial-depth hardroll plants, full-depth hardroll plants, and WEXTEX plants) have tubes that were mill-annealed and the newer plants have tubes that were thermally treated. The stresses exerted on the tubes arise from many sources including the design, fabrication, and operation of the steam generator. In general, improvements in each of these areas were made as the steam generator design evolved (from mechanical and explosive expansion of the tubes into the tubesheet to hydraulic expansion of the tubes).

For plants with partial-depth expansion transitions, the number of small-radius tubes affected by circumferential cracking in the U-bend region is minimal. The tubes in row 1 have been preventively plugged at Haddam Neck (in two of the four steam generators), Indian Point 2, and Zion 1. For the remaining steam generators with partial-depth expansion transitions, with the exception of the steam generators at Zion 2, circumferential indications at this location have not been observed. At Zion 2, a circumferential crack at the tangent point in a row 1 tube, which exhibited primary-to-secondary leakage, was detected in 1989. The crack was located on the cold-leg side approximately $9.4 \mathrm{~cm}$ (3.7 inches) above the top of the seventh (uppermost) tube support plate. The portion of the straight leg of the tube that extends above the top tube support plate is $8.4 \mathrm{~cm}$ (3.3 inches); therefore, this crack was located approximately $1.0 \mathrm{~cm}$ (0.4 inches) above the tangent of the U-bend (generally on the intrados of the tube). The tube was not removed for destructive examination (Ref. 104). The tubes in row 1 at Zion 2 were preventively plugged during the fall 1996 outage after detecting 64 tubes with row 1 U-bend indications (Ref. 106).

As of June 1995, no plants with full-depth hardroll expansion transitions reported circumferential indications in the U-bend region of small-radius tubes (Ref. 90) even though these locations were monitored at many of these plants (refer to Table 7-7). All of these plants have performed in situ heat treatment in the U-bend region of the small-radius tubes to reduce the susceptibility of the tubes to this degradation mechanism. A few of these plants performed this heat treatment before commencing commercial operation, while most of the plants performed the UBHT after commencing commercial operation. The licensee for South Texas Project 1, a full-depth hardroll plant, does not believe their small-radius U-bend tubes are susceptible to circumferential cracking since the model E steam generators have larger bend radii than other Westinghouse steam generators and the tubes were in situ heat treated. Nonetheless, the licensee takes the precaution to monitor these locations to provide additional assurance of tube integrity. (South Texas Project 1 is the only full-depth hardroll plant with model $\mathrm{E}$ steam generators.) Subsequent to June 1995 , at least one plant with steam generators with full-depth hardroll expansion transitions (i.e., Byron 1) has exhibited circumferential indications in the U-bend region of tubes with small-bend radii (Ref. 105). 
For plants with WEXTEX transitions, all of which have model 51 steam generators (with the exception of Comanche Peak 1 which has model D4 steam generators), in situ UBHT was performed in row 1 and/or row 2 (refer to Table 7-11). Most of these plants performed this UBHT of the tubes after commencing plant operation. The exception, Comanche Peak 1, in situ heat treated the small-radius U-bend tubes before commencing commercial operation. In some instances (e.g., Farley 1 and Sequoyah 2), tubes in row 1 were preventively plugged and then subsequently recovered and placed back in service following the UBHT. In other instances (e.g., Salem 1 and 2), the row 1 tubes were preventively plugged and never returned to service. Several of these plants have exhibited circumferential cracking in the U-bend region. Such plants include Diablo Canyon 1, which performed UBHT in 1988 and subsequently detected four circumferential indications in 1992 (Ref. 107), Farley 1, and Sequoyah 1 and 2. For Farley 1, most, if not all, of the circumferential indications detected were present in the tubes when the tubes were recovered and heat treated rather than having been initiated after the UBHT. Circumferential indications have been detected in heat-treated and non-heat-treated U-bends in the small-radius tubes of WEXTEX plants. In addition to circumferential indications, axial indications have been detected in small-radius U-bend tubes (e.g., at Farley 1, axial indications were detected even after UBHT (Ref. 35)).

For plants with steam generator tubes with hydraulic expansion transitions, only Callaway and South Texas Project 2 do not have steam generators with all thermally treated tubes. Of these two plants, South Texas Project 2 is the only plant with steam generator tubes with hydraulic expansion transitions that does not have thermally treated tubes in the small-radius tubes. (Callaway has thermally treated tubes in the first 10 rows of the tube bundle.) At South Texas Project 2, however, the bend radii for the low row tubes are greater than other Westinghouse steam generators with mill-annealed tubes, and these tubes were in situ heat treated. These features (i.e., larger bend radii and UBHT) are intended to reduce the susceptibility of the $U$-bend region of the small-radius tubes to cracking.
The remaining plants with hydraulic expansion transitions have thermally treated tubes. As previously noted for the expansion transition region, the steam generator operating experience with thermally treated tubes has thus far been much better than that for steam generators with mill-annealed tubes. As of June 1995, no indication of cracking had been found in the U-bend region of any of the small-radius tubes (i.e., rows 1 and 2) in these steam generators. This relatively good operating experience has been attributed, in part, to the thermal treatment which is intended to improve the resistance to cracking compared to mill-annealed tubes (Refs. 90 and 108). Other features to which this relatively good operating experience have been attributed include features similar to those at South Texas Project 2 (i.e., larger bend radii, stress-relieved U-bends). These features are present in some of the plants with thermally treated tubes and hydraulic expansion transitions.

For plants with model $F$ steam generators (all of which have thermally treated tubes), the design is intended to reduce the potential for tube cracking in the U-bend location. Actions taken in model F steam generators specifically to reduce the potential for crack initiation include using thermally treated alloy 600 tubes, as well as relieving stress in the U-bend region of several rows (e.g., rows 1 through 10) of tubes (Refs. 108 and 109). Starting with the model F steam generators, a set of U-bend manufacturing geometric controls were implemented. These controls included requirements on tube ovality, U-bend-to-leg flatness, and leg spacing. These improved manufacturing requirements are intended to ensure U-bend consistency, which in turn translates to consistent stresses. In summary, the geometric controls help to eliminate localized stress discontinuities (Ref. 100).

One licensee has indicated that the residual stresses in the tube-to-tubesheet hydraulic expansion transition region have been estimated to be as high as 2758 bar $(40,000 \mathrm{psi})$. The lack of degradation in this region (i.e., the expansion transition) suggests that other areas of the tube, operating at lower residual stresses and lower temperatures (such as the U-bend region of small-radius tubes), would be even less likely to exhibit degradation (Ref. 100).

Although the operating experience with small-radius (i.e., row 1 and 2) tubes in thermally treated alloy 
600 tubes has been relatively good to date, several indications have been detected in these tubes. At Callaway, one undefined indication was identified in a row 2 tube. This indication was not identified with the bobbin coil and was located just above the seventh cold-leg support plate. The licensee concluded that this indication was an anomaly since no degradation mechanism had been identified in this region. In addition, a senior eddy current analyst (i.e., a level III analyst) judged this indication to be a distorted signal caused by its location in the U-bend transition (this tube was not removed for destructive examination) (Ref. 110). Recently (i.e., after June 1995), the licensee for Braidwood 2, which has steam generators with alloy 600 thermally treated tubes, reported an axial indication in the U-bend region of one small-radius (i.e., Row 1) tube. The licensee concluded that the most likely cause for this indication is PWSCC (this tube was not removed for destructive examination) (Ref. 105). This licensee also reported that at least one other plant with alloy 600 thermally treated tubes and stress relieved U-bends has experienced axially oriented indications in row 1 and 2 (Ref. 105).

In summary, axial and circumferential cracking of the U-bend region of small-radius tubes has occurred in plants that have in situ stress relieved, as well as plants that have not in situ stress relieved the U-bend region of these tubes. The majority of the small-radius $U$-bend indications have been in plants with alloy 600 mill-annealed tubes; however, indications have also been detected in alloy 600 thermally treated tubes. The indications reported to-date in alloy 600 thermally treated tubes were axial in nature rather than circumferential. The root cause of the indications being detected in the thermally treated tubes has not been confirmed through the destructive examination of pulled tubes.

\subsubsection{Dented Locations}

Denting is the plastic deformation (constriction or mechanical deformation) of the steam generator tubes, and it has resulted from both corrosion and mechanical processes. Mechanically and corrosion induced dents have been observed at a number of locations in steam generators.

Mechanically-induced dents generally occur throughout the steam generator tube bundle and are frequently located in the tube free span (i.e., the region of the tube between tube support structures). These dents can be introduced during the manufacture and maintenance of the steam generators. In addition, mechanically induced dents on the steam generator tubes can arise from loose parts introduced during maintenance activities. All steam generators are susceptible to this type of denting, and many plants, if not all, have observed mechanically induced dents.

Corrosion induced dents typically occur at locations where the tube is in close proximity to a tube support structure fabricated from carbon steel and at the top of the tubesheet where sludge tends to accumulate near and around the tube. Corrosion-induced denting at tube support structures (e.g., carbon steel tube support plates) is typically the result of corrosion of the support structure. In the case of the carbon steel tube support plates, corrosion results in the buildup of corrosion products (typically magnetite) in the crevice between the tube and the tube support plate. Since the corrosion products (e.g., magnetite) typically occupy a larger volume than the base material (i.e., carbon steel), the buildup of magnetite (i.e., iron oxide) leads directly to the mechanical deformation of tubes where they meet the tube support plate; when it is extensive, denting can lead to the deformation and cracking of the tube support plates themselves. Corrosion induced dents have primarily been observed at the intersection of the tube and carbon steel tube supports.

The denting process is a concern because it can produce high levels of stress on both the tube and the support structure. In addition, it is of concern because reliably analyzing and interpreting the inspection data obtained with a bobbin coil from a dented tube is more difficult than for a non-dented tube. To reliably inspect dented locations for indications of degradation, many licensees currently (i.e., 1995) use rotating probes with pancake or plus-point coils as discussed below.

The stresses imparted on the tube as a result of the denting process can lead to axially and/or circumferentially oriented SCC. Furthermore, the stresses imparted on the tube support structure as a result of the denting process can result in cracking of this structure. Although both of these conditions have been observed (as discussed below), it is important to note that a tubes susceptibility to 
cracking at a dent depends on many factors including the magnitude of the dent (i.e., the level of stress), the temperature at the dented location, the microstructure of the material, and the operating environment.

Corrosion-induced denting was first identified and became prevalent in the early to mid 1970s. In the mid to late $1970 \mathrm{~s}$, excessive denting of tubes at the tube support structures was reported, resulting in (1) primary-to-secondary leaks (as a result of SCC which initiated primarily from the inside (primary side) surface of the dented tube), (2) cracking of the tube support structures (specifically horizontally oriented tube support plates), and (3) inability to pass standard-size inspection probes through the tubes. In some instances, steam generators were replaced as a result of extensive denting. As discussed above, operating plants with carbon steel tube support structures are susceptible to corrosion-induced tube denting.

Corrosion-induced denting of the steam generator tubes can be controlled in operating steam generators through proper water chemistry controls and a secondary system design that minimizes the likelihood of introducing impurities that contribute to denting. The corrosion-induced denting currently being observed in the field is relatively minor compared to the denting observed in the 1970s. (That is, the extent of tube deformation is minor, and standard-size probes can typically be passed through the tubes.) Improvements in water chemistry, which have limited the impact of denting, include more restrictive limits on impurity levels. Improved secondary system design measures include replacing copper-bearing components, replacing condenser tubes to reduce the potential for leakage, and (in the newer steam generators) using tube support structures of different designs (e.g., broached hole, lattice grids) and constructed from stainless steel, a more corrosion-resistant material.

In summary, both mechanically and corrosion induced dents can lead to increased levels of stress on the tubes. As a result, degradation, particularly SCC, can occur at either mechanically or corrosion induced dents. Most of the denting-related degradation, however, has primarily occurred at corrosion induced dents rather than at mechanically induced dents. Most of the newer steam generators (e.g., replacement steam generators and steam generators with tubes that were hydraulically expanded into the tubesheet) were designed and operated to reduce the likelihood of corrosion-induced denting.

Denting has led to SCC of the tubes in Westinghouse steam generators. In the 1970 s, the denting and SCC were so severe at some plants that the steam generators were replaced (as discussed above). Currently, however, the dents being observed in steam generators are less severe than those previously observed (i.e., in the pre-replacement steam generators) as a result of steam generator design and operational improvements. This is evidenced by the relatively limited number of tubes that are found in which the standard size eddy current inspection probes can not pass through the tubes. Even though the denting is minor, axially and circumferentially oriented SCC continues to occur. The axially oriented SCC generally initiates from either the inside or outside diameter of the tube and the circumferentially oriented SCC generally initiates from the outside diameter of the tube, although, in a few instances, circumferentially oriented SCC has been reported to initiate from the inside diameter of the tube.

Since the majority of the circumferential indications being detected at dents in Westinghouse steam generators occur at corrosion induced dents at tube support plate intersections, the following paragraphs, which summarize the operating experience at dented locations, emphasize degradation observed at these locations. Circumferential indications that propagate as a result of fatigue and are attributable to denting are discussed in Section 7.2.3.1. Circumferential indications that develop as a result of non-fatigue related mechanisms (e.g., SCC) are discussed in Section 7.2.3.2. The non-fatigue related circumferential indications occur primarily at corrosion induced dents. Corrosion-induced denting primarily occurs at carbon steel tube support structures rather than stainless steel tube support structures since stainless steel is more corrosion resistant in the steam generator operating environment. As a result, Section 7.2.3.2 is organized based on the type of expansion transition since most of the earlier model Westinghouse steam generators (i.e., in steam generators with partial-depth hardroll, full-depth hardroll, or WEXTEX expansion transitions) have carbon steel tube support plates and most of the later model 
Westinghouse steam generators (e.g., steam generators with hydraulically expanded tubes) have stainless steel tube support plates. The Westinghouse replacement steam generators, the model $F$, and some model $D$ and $E$ steam generators are fabricated with stainless steel tube supports.

\subsubsection{Fatigue Cracks at North Anna 1 and Indian Point 3}

Only a limited number of fatigue cracks that are attributable, in part, to the denting phenomena have been observed in Westinghouse steam generators. The limited number of fatigue cracks is attributable, in part, to the corrective actions taken by the licensee as a result of these events. The following paragraphs summarize the two circumstances in which fatigue cracks associated with the denting phenomena were observed.

In 1988, the NRC staff published Bulletin 88-02, "Rapidly Propagating Cracks in Steam Generator Tubes" (Ref. 23), which addressed the 1987 North Anna 1 tube rupture resulting from high cycle fatigue. In 1987, the steam generators at North Anna were Westinghouse model 51 steam generators with WEXTEX tube expansions, carbon steel tube support plates, and alloy 600 tubes that had been mill annealed. The 1987 rupture location was at the top support plate on the cold-leg side of the tube in row 9 column 51, a relatively small-radius tube. Bulletin 88-02 cited three conditions that could lead to a rapidly propagating fatigue failure similar to the occurrence at North Anna. These three conditions were (1) denting at the upper support plate, (2) fluid-elastic stability ratio approaching that for the tube that ruptured at North Anna, and (3) absence of effective AVB support. The WOG indicated that locally elevated steam velocities could be observed because of nonuniform AVB insertion depths (Ref. 90). The bulletin was issued to holders of operating licenses or construction permits for Westinghouse-designed nuclear power reactors with steam generators having carbon steel support plates.

As a result of Bulletin 88-02, all domestic Westinghouse steam generators with carbon steel tube support plates were analyzed using a methodology approved by the NRC to identify the potential to experience high cycle fatigue at the uppermost tube support plate. The WOG indicated that, in cases where the analysis indicated that fatigue usage could exceed 1.0 , the potentially affected tube was either plugged and stabilized or plugged using a leak-limiting sentinel plug (Ref. 90). Steam generators with stainless steel support plates and broached (quatrefoil and trefoil) tube holes were not expected to experience this phenomenon (Ref. 90). Nonetheless, some Westinghouse plants with steam generator tube support plates constructed from stainless steel (e.g., Catawba 2) have been analyzed for high cycle fatigue by evaluating the position of the AVBs (Ref. 52).

In addition to the North Anna 1 fatigue crack, a fatigue crack was also observed at Indian Point 3 in 1988. As discussed below, this crack occurred under slightly different circumstances. In October 1988, a primary-to-secondary leak occurred at the Indian Point 3, as detailed in NRC Information Notice 88-99, "Detection and Monitoring of Sudden and/or Rapidly Increasing Primary-to-Secondary Leakage" (Ref. 19). The steam generators at Indian Point 3 at the time of this leak were Westinghouse Model 44 steam generators. These steam generators had alloy 600 mill-annealed tubes, which were partially rolled on each end at the bottom of a $56 \mathrm{~cm}$ (22-inch) thick tubesheet. The tubes passed through drilled-hole tube support plates that were $19.05 \mathrm{~mm}(0.75$ inch) thick and constructed of carbon steel.

After replacing the model 44 steam generators at Indian Point 3 in a subsequent outage, the leaking tube, which had been plugged, was removed for destructive examination. The leak was attributed to a circumferential crack $1.52 \mathrm{~mm}$ (0.06 inches) above the top edge of the sixth tube support plate, the uppermost plate, on the hot-leg side of the tube in Row 45 Column 50. This tube is a peripheral (large-radius U-bend) steam generator tube with U-bend region supports at four locations (two hot-leg and two cold-leg locations) by AVBs. The crack extended 250 degrees around the circumference and was through-wall over its entire length. It was a single crack with no branching or major secondary cracks, with the exception of two short parallel secondary cracks. Profilometry of the tube indicated that the tube was dented at the six th hot-leg support plate from 0.267 to $0.381 \mathrm{~mm}(0.0105$ to 0.015 inches) radially. Field eddy current data indicated that this tube was also dented at its other support plate locations in both the hot and cold legs. The destructive examination indicated that the circumferential crack had only transgranular, fatigue 
type features (other than minor, typically $0.051 \mathrm{~mm}$ (0.002 inches) deep, intergranular corrosion that sporadically occurred at the outside diameter edge). The licensee concluded that the crack initiated on the outside diameter surface at a location where the maximum outside diameter stresses from tube displacement perpendicular to the U-bend plane are believed to occur (Ref. 111).

The fatigue failure of the tube in row 45 column 59 at Indian Point 3 indicates that large-radius steam generator tubes in Westinghouse steam generators may be susceptible to fatigue failure at the uppermost tube support plate, even though they are supported by AVBs. The failure at North Anna 1 involved a relatively small-radius tube (i.e., row 9 ), which did not have any AVB support. Both tubes (i.e., the tubes at North Anna 1 and Indian Point 3) were dented at the uppermost tube support plate near the location of the circumferential crack. Denting, per Bulletin 88-02, was considered to include evidence of upper tube support plate corrosion and the presence of magnetite in the tube-to-tube support plate crevices, regardless of whether there was detectable distortion (i.e., mechanical deformation) of the tubes.

\subsubsection{Non-Fatigue Cracks}

As of December 1996, circumferential indications had been reported at dented locations at a number of Westinghouse plants. Most of the reported circumferentially oriented indications occurred either at dents at the top of the tubesheet for partial-depth hardroll plants as discussed in Section 6.2.1.1 or at dents at the tube support plate elevations; however, at least one circumferentially oriented indication has occurred at a free-span dent (i.e., a dent not in the sludge pile or at a tube support structure). In addition, both inside and outside diameter initiated circumferential indications have been observed at dented tube support plate elevations. The inside diameter initiated circumferential indications were recently observed (i.e., 1996). The following paragraphs summarize recent operating experience with respect to circumferential indications at dented locations.

Circumferential cracks were detected and reported at dented tube support plate locations in the field at North Anna 1 in 1991 and then at North Anna 2 in 1992. These circumferential indications were the first reported in recent times for tubes with minor denting. At the time of the original GL 95-03 responses (i.e., June 1995), this cracking phenomenon had not been observed at other Westinghouse units; however, as discussed below, circumferential cracks at dented tube support plate elevations have been observed at other plants since June 1995. The circumferential indications detected at North Anna 1 and 2 were in the pre-replacement steam generators. The North Anna 1 and 2 pre-replacement steam generators were Westinghouse model 51 steam generators which had alloy 600 mill-annealed tubes, carbon steel drilled tube support plates, and WEXTEX transitions (Ref. 90).

Several tubes were pulled from the North Anna 1 steam generators to characterize the degradation at the tube support plates from 1985 until the steam generators were replaced in 1993. In 1985, two dented tubes were pulled to examine distorted eddy current indications at the edges of the tube support plates. The tube pulls revealed axially oriented PWSCC extending outside the confines of the tube support plate on both tubes. One tube showed two axially oriented primary water stress corrosion cracks separated by about 180 degrees. These cracks were located at the minor diameter of the ovalized tube (i.e., the tube was dented). The primary water stress corrosion cracks observed on both tubes showed multiple microcracks comprising the macrocracks. ODSCC within the tube support plate crevices was also found during the tube examinations. No circumferential indications were reported for either of these tubes. The maximum amount of deformation ranged from 4-percent ovality to 7-percent ovality depending upon the technique used to measure the deformation (Ref. 112).

In 1987, two additional tube specimens were removed from North Anna 1 for destructive examination of circumferential indications in the WEXTEX transition. For one of these specimens, the licensee obtained the portion of the tube located at a tube support plate elevation. The crevice region of this tube support plate intersection specimen had a 0.025 to $0.051 \mathrm{~mm}$ (0.001- to 0.002 -inch) radial dent. An outside diameter initiated, circumferentially oriented crack network was found just below the tube support plate top edge, which consisted primarily of circumferentially oriented microcracks. The microcracks formed a 90-degree long macrocrack. The morphology of these outside diameter initiated cracks was IGSCC with some intergranular attack. 
Axially oriented PWSCC was also found on this specimen extending from the top edge of the tube support plate to the mid-support plate region. Near the mid-support plate region, the cracking was axially oriented; near the support plate top edge, the cracking was tilted $\mathbf{4 5}$ degrees to the major tube axis (Ref. 112).

In 1991, a portion of the tube in row 11 , column 14, in steam generator B of North Anna 1 was pulled to assess circumferential indications found with $8 \times 1$ and rotating pancake coil probe inspections at the first tube support plate elevation. Circumferential cracks (predominantly ODSCC with some intergranular attack components) were found at locations corresponding to the top and bottom edges of the tube support plate. At the top edge, a 360-degree crack was present; however, the cracking was most significant (i.e., greater than 40-percent through the tube wall) for two areas of 124 degrees and 113 degrees with smaller crack depths between the two deeper circumferential cracks. At the bottom edge, circumferential cracks of 135 degrees and 112 degrees were found with no significant crack depth (i.e., less than 40-percent through the tube wall) between these cracks. The cracks were centered near the apex of the ovalized dented tube $(0.711 \mathrm{~mm}$ (0.028-inch) ovality). The field eddy current data evaluation for the crack at the bottom edge of the tube support plate did not result in the identification of an approximately 112-degree portion of the indication, which had a maximum depth of 61 percent and an average depth of 51 percent through the tube wall. The circumferentially oriented ODSCC on this tube was very similar to the cracking found in the tube pulled in 1987. In summary, the 1991 destructive examination indicated that the eddy current indication was attributable to circumferentially oriented ODSCC consisting of macrocracks formed by lineup of individual microcracks followed by corrosion of the separating ligaments (Ref. 112).

1991 was the first time circumferential indications were reported in the field at dented tube support plate elevations at North Anna 1. Earlier inspections with the $8 \times 1$ probes had discovered degradation at dented tube support plate elevations, but these were thought to be volumetric in character. Approximately 110 circumferential indications at dented tube support plate elevations were found during the 1991 inspection. All of these were detected by the 8x1 probe and confirmed with a rotating pancake coil probe. In addition, 5 tubes were found to have both circumferential and axial indications outside the same edge of the tube support plate. On the basis of previous tube pull results and the eddy current data, the licensee concluded that these indications were azimuthally separated by approximately 90 degrees. These indications were found at highly ovalized, dented locations. The licensee for North Anna 1 postulated that the circumferentially oriented ODSCC indications are located at the major diameter of the ovalized tubes and the PWSCC axial cracks at the minor diameter (Ref. 112).

In addition to identifying tube support plate elevations with both axial and circumferential indications during the 1991 inspection, the licensee for North Anna 1 also identified tube support plate elevations with multiple circumferential indications. Multiple circumferential indications are indications composed of typically two circumferential cracks at nearly the same elevation on the tube but circumferentially separated by a ligament of tube material that is not cracked.

As a result of the 1991 refueling outage inspection results, the NRC stipulated that the licensee for North Anna 1 must either implement a midcycle inspection of the steam generator tubes or provide the additional information necessary to justify a full cycle of operation. The licensee provided information intended to justify a full cycle of operation and the staff requested additional information from the licensee. As a result of the staff's and licensee's evaluation of tube integrity at North Anna 1, the licensee shut down North Anna 1 in late December 1991 for a midcycle steam generator tube inspection. The shutdown was a result of a review of the 1991 refueling outage eddy current data, which identified additional potential defects. The eddy current data re-review was requested in early December 1991 by the NRC. This request was a result of the licensee's identification of additional circumferential cracks (during the destructive examination of a tube) that were not identified in the field by the eddy current data analysts. The tube had been pulled during the 1991 refueling outage. Since some of these potential indications identified during the data re-review could exceed the tube repair criteria in the technical specifications, the licensee declared the steam generators inoperable after detailed discussions with the NRC (Ref. 113). 
During the January/February 1992 midcycle steam generator tube inspection outage, the licensee's inspection included a 100-percent rotating pancake coil examination at the hot-leg WEXTEX transitions and 100-percent rotating pancake coil examination at the tube support plate elevations. A similar examination at the WEXTEX transitions was performed during the 1991 refueling outage (i.e., 100-percent rotating pancake coil examination). The 100-percent rotating pancake coil examination of the tube support plate elevations was a result of a comparison test of the $8 \times 1$ arrayed pancake probe and the rotating pancake coil probe for indications at the tube support plates. This test showed that it was necessary to make conservative and possibly false $8 \times 1$ calls to achieve more than 90-percent detection of the signals identified by rotating pancake coil inspection. This was attributed to the inability to discriminate effectively between liftoff signals at the dented tube support plate intersections and crack indications at the tube support plate edges. This was the first time a 100-percent rotating pancake coil test of the tube support plate elevations was performed at North Anna 1. The 1991 refueling outage inspection primarily consisted of $8 \times 1$ probe examinations followed by further characterization with the rotating pancake coil probe. Some random rotating pancake coil exams were performed during the 1991 refueling outage inspection (Ref. 114).

The steam generators at North Anna 1 were replaced in the subsequent outage, which took place in early 1993. Similar circumferential indications at dented tube support plate elevations were detected at North Anna 2. The North Anna 2 steam generators were replaced in 1995.

The operating experience of the pre-replacement steam generators at North Anna 1 and 2 indicate that circumferential cracks can occur at dented tube support locations; however, circumferential indications can also occur at dents not associated with a tube support structure. At McGuire 1, a circumferential indication was detected near a dent in the U-bend region of the tube located in row 41 column 43 in steam generator $B$ in the August/September 1993 time-frame. This tube was identified during an outage which commenced as a result of a primary-to-secondary leak. Although the majority of the leakage was coming from another tube, observable leakage was detected from this tube. The source of the leak for this tube was determined to be a circumferential crack approximately $22.1 \mathrm{~cm}$ (8.7 inches) above the uppermost tube support plate on the cold-leg side of the steam generator near, or slightly above, the U-bend tangent. The indication was associated with a dent (Ref. 115). Although other circumferential indications have been detected in the U-bend region of steam generator tubes as discussed in Section 7.2.2, the indication detected at McGuire 1 is different than those discussed in Section 7.2.2 since it was not in a tube with a small bend radii.

As a result of industry experience regarding axially and circumferentially oriented tube degradation at dented locations, many plants have implemented a sample plan for inspecting such locations. This plan generally includes inspecting dents using techniques capable of reliably detecting axially and circumferentially oriented tube degradation when the bobbin coil voltage associated with the dented location exceeds a specified voltage. The bobbin coil probe can identify dented regions; however, it cannot reliably detect all forms of degradation that may potentially occur at dented regions. In many instances, this inspection plan includes a 100-percent examination of all dents with bobbin voltages of 5 volts or greater. Since the bobbin coil voltage corresponding to a dent depends, in part, on the calibration procedure of the bobbin coil, it is important to know the calibration procedure to ensure that the sample plan and results from one plant can be compared to another plant. The bobbin voltage associated with a dented region also depends, in part, on the magnitude and geometry of the dented region of the tube. The resultant bobbin voltage, therefore, may or may not be representative of the local stresses in the tube at the dented location. As a result, the susceptibility of a given dented location to cracking can not be determined based solely on the bobbin voltage; however, it can be used as a guide for performing examinations. Since the voltage threshold for inspecting dents is to some extent arbitrarily determined, a comprehensive sample plan for dents should include sample expansion criteria both for dented locations above the voltage threshold (when a 100-percent examination is not performed) and for dented locations below the voltage threshold.

Many plants implement the calibration procedure and inspection strategy specified in GL 95-05 (Ref. 1) for examining dented locations (specifically dented tube support plate elevations). For plants with many 
thousand dented locations, a 100 -percent sample of dents greater than 5 volts may not need be performed in order to determine whether degradation associated with dents is occurring. In these instances, even though a smaller initial sample in terms of the percentage of dented locations examined is performed, the large number of locations to be inspected can be sufficient to detect the onset of axially and circumferentially oriented degradation at dented locations. In addition, expansion of the sample to include dented locations above and below 5 volts provides added assurance that tubes containing axially or circumferentially oriented tube degradation at dented locations are identified (Ref. 116).

As of June 1995, plants with steam generators currently in service that have partial-depth expansion transitions (as opposed to plants that had replaced similarly designed steam generators) had not reported any circumferential indications at dented locations other than at dents near the top of the tubesheet. These indications were attributed to cellular corrosion as evidenced by tube pull data from D.C. Cook 1 as discussed in Section 6.2.1.1. Many of these plants have monitored these dented locations; these plants include two with severe denting by today's standards (i.e., some dents do not permit the passage of the nominal sized eddy current inspection probes for the tube size). Similar to the partial-depth expanded plants, the plants currently operating with full-depth or WEXTEX expansion transitions had not reported any occurrences of circumferential cracking at dents at tube support plate locations as of June 1995 although most plants with dents had monitored these locations.

Although no circumferential cracking at dented tube support plate locations had been identified as of June 1995 at plants currently operating with steam generator tubes with partial-depth hardroll, full-depth hardroll, and WEXTEX transitions, these plants are susceptible to circumferential cracking at dented locations regardless of the location of the dent (i.e., free-span dent, dent in sludge pile, dent at tube support structure). In general, operating experience has shown that dented locations are susceptible to circumferentially oriented tube degradation. For example, the circumferentially oriented tube degradation found at D.C. Cook 1 (which was discussed in Section 6.2.1.1), the circumferentially oriented tube degradation observed at dented tube support plate locations in the pre-replacement North
Anna 1 and 2 steam generators, and the circumferentially oriented tube degradation observed in the dented U-bend region at McGuire 1.

Since June 1995, axial and circumferential indications at dented tube support plate elevations were observed at a few other plants including Diablo Canyon 1 and Sequoyah 1 which are both WEXTEX plants. The results from the Diablo Canyon 1 steam generator tube inspection in the fall of 1995 revealed approximately 77 axially oriented primary water stress corrosion cracks at dented tube support plate elevations. Of these axial indications, 61 were located in dents less than 5 volts using the calibration procedure specified in GL 95-05 (Ref. 1). In addition, 17 of these axial indications were not identified with the bobbin coil. Three circumferentially oriented primary water stress corrosion cracks were identified at dented tube support plate elevations during this outage.

As a result of these findings, the licensee for Diablo Canyon 1 removed portions of four tubes for destructive examination. Three of the four tubes contained axial indications, and one of the pulled tubes had a circumferential indication. The circumferential indication that was removed for destructive examination was at a tube support plate elevation that had a 28 volt dent. The destructive examination revealed two circumferential bands of inside diameter initiated degradation; one band contained a single macrocrack, while the second band was a narrow band of microcracks (Ref. 98).

At Sequoyah 1, in the fall of 1995 , axially and circumferentially oriented tube degradation was observed at dented tube support plate elevations. In addition, portions of three tubes were removed for destructive examination. These included four tube support plate intersections from two of the three pulled tubes with eddy current indications attributed to axially oriented ODSCC and circumferential cracking. The dented tube support plate intersection with a circumferential indication was determined through destructive examination to be attributable to circumferentially oriented ODSCC (Ref. 117).

In summary, alloy 600 mill-annealed tubes have been shown through operating experience to be susceptible to circumferentially oriented tube degradation at dented locations. The circumferential degradation can occur at dents at various tube support structures 
(e.g., tube support plates), in the sludge pile region near the top of the tubesheet, and in the tube free span. Furthermore, the cracking may be inside or outside diameter initiated although to date the majority of the circumferential indications have been outside diameter initiated.

Several Westinghouse plants have steam generator tube support plates that are constructed from stainless steel. All plants with steam generator tubes that have hydraulic expansion transitions have stainless steel tube support plates. These support plates have either drilled holes (e.g., South Texas Project 2) or quatrefoil broached holes (e.g., model D5 and F steam generators). In addition, most of these plants have thermally treated alloy 600 tubes (Callaway and South Texas Project 2 are the exceptions). Corrosion-induced denting is not as likely at these plants (i.e., stainless steel tube support plate plants) as it is for plants with carbon steel tube support plates, since the stainless steel tube supports are not expected to corrode and form nonprotective magnetite as does carbon steel. Furthermore, for plants with steam generator tube support plates that have quatrefoil hole designs, the area of tube to tube support contact is reduced (compared to drilled holes), thereby allowing greater flow past the tube at the support gap and minimizing the buildup of corrosive deposits (Refs. 108 and 109). If denting were to occur in these plants (i.e., plants with steam generator tubes that were hydraulically expanded into the tubesheet and have stainless steel tube supports), the thermally treated tubes used in the vast majority of these plants are generally considered to be less susceptible to tube cracking than mill-annealed tubes. (Mill-annealed tubing is only used at Callaway and South Texas Project 2.)

Even though several design features exist to limit the potential for denting in the hydraulic plants, dents still occur in these steam generators. This denting can produce residual stresses in the affected locations which could make them more susceptible to cracking than non-dented areas (Ref. 103). The dents in these steam generators are generally attributable to steam generator manufacture, maintenance, or the presence of loose parts in the steam generator. These areas are sometimes referred to as either dents, dings, or expansion anomalies (Ref. 109). For the purposes of this report, these terms are considered synonymous.

\subsubsection{Sleeve Joints}

As discussed in Appendix A, various types of sleeve designs exist and some have exhibited circumferentially oriented degradation. In Westinghouse steam generators with partial-depth hardroll expansion transitions, several sleeve designs are used including the B\&W brazed, B\&W kinetic, Westinghouse hybrid expansion joint (HEJ), and CE TIG-welded sleeves. The B\&W brazed sleeves and the B\&W kinetic sleeves were only used in the pre-replacement Ginna steam generators. Consequently, of the currently operating Westinghouse plants with partial-depth expansion transitions, the only sleeve designs being used as of December 1996 are the Westinghouse HEJ sleeves and the CE TIG-welded sleeves.

In Westinghouse steam generators with full-depth hardroll expansion transitions, only Farley $2 \mathrm{had}$ sleeves installed and inservice as of June 1995. The sleeves in service at Farley 2 are Westinghouse laser-welded sleeves. Sleeves had been in service at other full-depth hardroll units (e.g., Catawba 1, McGuire 1 and 2) but were removed from service by plugging the tube in subsequent outages as discussed in Appendix A (Refs. 118 and 119). The preventively plugged sleeves at these other units were B\&W kinetically welded sleeves. Subsequent to June 1995, additional full-depth hardroll units had installed sleeves. These units include Braidwood and Byron 1. The sleeves installed at Byron 1 were Westinghouse laser-welded sleeves and CE TIG-welded sleeves while the sleeves being installed at Braidwood 1 in the fall of 1996 were Westinghouse laser-welded sleeves.

In Westinghouse steam generators with WEXTEX transitions, only Farley 1 had sleeves installed as of June 1995. The sleeves in service at Farley 1 are Westinghouse laser-welded sleeves. Subsequent to June 1995, additional units may have installed sleeves.

No sleeves have been installed in the Westinghouse steam generators with hydraulic expansion transitions as of June 1995. Subsequent to June 1995, Callaway installed Westinghouse laser-welded sleeves in some of the steam generator tubes. The Callaway steam generators have some thermally treated tubes and some mill-annealed tubes. 


\subsubsection{Preheater Expansion Transitions}

As discussed in Section 7.1.2, Westinghouse model D4, D5, and E steam generators have tubes that were expanded into the tube support plates in the preheater region as a result of concerns about tube wear. The steam generators that have expanded tubes in the preheater region include steam generators with either alloy 600 mill-annealed or alloy 600 thermally treated tubes. Furthermore, the expansion transitions at these plants are a result of either a full-depth hardrolling or hydraulic expansion process. (Note that Comanche Peak 1 has some WEXTEX expansion transitions.)

The preheater is on the cold-leg side of the steam generator. As such, the susceptibility to cracking would be expected to be lower as a result of the lower operating temperature, all other parameters (e.g., stresses) being equal. One licensee indicated that corrosion tests of hydraulic tubesheet expansions in highly caustic environments have shown that corrosion has been arrested at a temperature of 292 degrees Celsius (557 degrees Fahrenheit), while increasing corrosion rates were found at temperatures of 302 to 313 degrees Celsius (575 to 595 degrees Fahrenheit). That licensee also indicated that their preheater expansions are hydraulic expansions and are located in areas with a primary side temperature of approximately 288 degrees Celsius (550 degrees Fahrenheit), which is below the temperature at which corrosion was arrested in the corrosion tests (Ref. 120). Consequently, the susceptibility of these locations to cracking, including circumferential cracking, is expected to be low as a result of the lower temperature. In addition, since the susceptibility to circumferential cracking is a function of temperature as well as stress and operating time, the susceptibility to circumferential cracking of hydraulic expansions would be expected to be lower since the stresses induced as a result of the hydraulic expansion process are significantly lower than the stresses associated with a hardroll process.

Although the susceptibility to circumferential cracking at the preheater expansions is considered low (for the reasons discussed above), licensees inspect this region to ensure that comprehensive examinations are being performed. Byron 1 and Braidwood 1 both have model D4 steam generators with mill-annealed alloy 600 tubes. These steam generators have approximately 132 cold-leg preheater tubes in each steam generator that were hydraulically expanded at two baffle plates to mitigate flow induced vibration. The licensee for these plants has indicated that 20-percent of the expanded preheater tubes in one steam generator will be inspected with a rotating pancake coil during the next outage (i.e., the next outage per GL 95-03) (Ref. 120). Similarly, the licensee for Shearon Harris 1 indicated that it would inspect 20-percent of the expanded preheater tubes (at both expansion zones) in one steam generator. During this inspection of the mill-annealed alloy 600 preheater tubes at Shearon Harris 1, no circumferential cracks were detected (Ref. 121).

Byron and Braidwood 2 have model D5 steam generators that contain approximately 132 cold-leg preheater tubes per steam generator that were hydraulically expanded at two baffle plates to mitigate flow induced vibration. The tubes in the steam generators at these plants are thermally treated. The licensee for these plants has indicated that 20-percent of the preheater tube expansions in one steam generator will be inspected with a technique qualified to Appendix $\mathrm{H}$ of the Electric Power Research Institute report NP-6201, "PWR Steam Generator Examination Guidelines" (Ref. 122). If circumferential indications are detected during this 20-percent sample, the licensee indicated that 100-percent of preheater tube expansions will be inspected in all four steam generators. The licensee indicated that it considers the potential for circumferential cracking at this location to be low for the reasons cited above (i.e., relatively low temperature at this location, lower stresses associated with hydraulic expansion) and the use of thermally treated tubes rather than mill-annealed tubes (Ref. 120).

Catawba 2 has model D5 steam generators with 141 tubes expanded at two locations into the tube support plate to prevent vibration in the preheater section of each steam generator. The licensee indicated that other locations are more susceptible to cracking than the expanded preheater locations as a result of temperature and residual stress considerations. As a result, since no cracking had been observed at any other location in the Unit 2 steam generators, this area was not believed to be susceptible to cracking (Ref. 123).

Comanche Peak 1 and 2 have model D4 and D5 steam generators, respectively. In the preheater 
region of these steam generators, several tubes have been expanded at the " $B$ " and "D" baffle plates to reduce the potential for vibration induced wear. The licensee indicated that the expanded tubes in the preheater region may be susceptible to circumferential cracking. As a result; the licensee inspected 20-percent of the expanded intersections at the "B" and " $D$ " baffle plates in Unit 1 with a rotating pancake coil technique. For Unit 2 , the licensee plans to inspect a sample of the expanded intersections at the " $B$ " and " $D$ " baffle plates during their December 1996 outage (Ref. 124).

Preheater expansions have been performed at South Texas Projects 1 and 2 in nominally 160 tubes per steam generator to reduce the potential for vibration induce wear. The licensee for South Texas Projects 1 and 2 concluded that the original qualification program for the expansion process indicated that no definitive increase in outside or inside diameter stresses result from the maximum expected field expansions. The licensee for South Texas Projects 1 and 2 has examined process records from the field implementation of the process at South Texas Projects 1 and 2 and noted no examples of tubes that were overexpanded. Also, the licensee indicated that other operating Model E steam generators, which have operated several more cycles than South Texas Projects 1 and 2, have been examined at these expansions with no circumferential cracking being noted during the inspections. As a result, the licensee for South Texas Projects 1 and 2 considers the tube areas expanded in the preheater not to be susceptible to circumferential cracking. Nonetheless, the licensee has monitored a small sample of these preheater expansions for cracking of all types with a rotating pancake coil to provide additional assurance of tube integrity (Ref. 125).

\subsubsection{Summary}

Sections 7.2.6.1, 7.2.6.2, 7.2.6.3, and 7.2.6.4, contain a brief summary of the circumferential cracking operating experience of partial-depth hardroll, full-depth hardroll, WEXTEX, and hydraulic plants, respectively.

\subsubsection{Partial-Depth Hardroll Steam Generators}

Plants with steam generators that have tubes which are only partially expanded within the tubesheet region have had a low incidence of circumferential cracking at the expansion transition even though they are some of the oldest steam generators in the country and have mill-annealed alloy 600 tubes. Circumferential indications at the expansion transition have been detected at only two of these plants (i.e., Ginna and Indian Point 2), and the indications at one of these plants (Indian Point 2) are believed to be from closely spaced axial cracks rather than from circumferential cracks.

Circumferential indications have also been detected at other locations in partial-depth hardroll plants. Circumferential indications have been observed in the U-bend region of small-radius tubes, at dented locations at the top of the tubesheet, and in sleeve joints. The circumferential indications observed at the top of the tubesheet have been attributed to cellular corrosion rather than distinct circumferential cracks. The indications detected in the sleeve joints (in Westinghouse HEJ sleeves and CE TIG-welded sleeves (fabrication related)) are discussed in Appendix A. Although no circumferential indications have been found at dented tube support plate regions in currently operating partial-depth hardroll plants, this area is considered susceptible to such degradation since it has been observed in similarly designed steam generators (i.e., steam generators with mill-annealed tubes and carbon steel tube support plates).

\subsubsection{Full-Depth Hardroll Steam Generators}

In general, plants with steam generators that have tubes which are roll expanded the full length of the tubesheet have exhibited circumferential cracking. All of the tubes in these steam generators are mill-annealed alloy 600 . The circumferential cracking is predominantly associated with the expansion transition. In some instances the number of circumferential indications detected at the expansion transition has been extensive (e.g., thousands of indications). A limited number of circumferential indications have been detected in the $U$-bend region of small-radius tubes in these steam generators and at dented locations. The sleeves currently in service at these units are welded sleeves, and no service-induced circumferential cracking has been detected in these sleeves. Several of these units have preheaters which have expanded tubes. These locations have not exhibited any circumferential cracking. 


\subsubsection{WEXTEX Steam Generators}

In general, plants with steam generators that have tubes which have been expanded the full length of the tubesheet with the WEXTEX process have exhibited circumferential cracking. All of these plants have mill-annealed tubes. The circumferential cracking has occurred at the expansion transition, in the U-bends of small-radius tubes, and at dented locations. The sleeves currently in service at these units are welded sleeves, and no service-induced circumferential cracking has been detected in these sleeves.

\subsubsection{Hydraulic Steam Generators}

Plants with steam generators that have tubes which have been expanded the full length of the tubesheet with a hydraulic process can be broken into two categories: mill-annealed and thermally treated. Only two hydraulic plants have mill-annealed tubes in the steam generators (i.e., Callaway and South Texas Project 2). Circumferential indications have been observed at the expansion transition in the mill-annealed tubes at Callaway although tube pulls have not been performed to confirm the nature of these indications. No other circumferential indications have been detected at any other location in hydraulic plants with mill-annealed steam generator tubes.

For the hydraulic plants with thermally treated tubes, circumferential indications have been detected at the expansion transition at Callaway. (Callaway has thermally treated tubes in rows 1 through 10.) No other circumferential indications attributed to service-induced degradation have been observed at any other location in these steam generator tubes. No tubes have been removed for destructive examination from the Callaway steam generators to characterize the nature of the indications at the expansion transition in the thermally treated tubes. In addition to the circumferential indications detected at the expansion transition in the thermally treated tubes, it is important to note that axial indications have been observed in thermally treated tubes in the U-bend region of small-radius tubes and at the expansion transition.

The relatively good operating experience for the hydraulic plants (including those with mill-annealed tubes) can be attributed to improvements in design and operation with respect to the other plants which tend to be older. Like the full-depth hardroll plants, several of the hydraulic plants have preheaters which have expanded tubes. These locations have not exhibited any circumferential cracking.

\subsection{Justification for Continued Operation}

The majority of circumferential indications in the Westinghouse units with alloy 600 steam generator tubes occur at the expansion transition. The severity of these indications has led to midcycle inspections at a few plants (e.g., Braidwood 1). A limited number and typically less severe circumferential indications have been detected at dented locations, in the U-bend region of small-radius tubes, and in sleeve joints.

The staff evaluated each of the GL 95-03 responses submitted by Westinghouse plant owners with alloy 600 steam generator tubes to confirm that the plants could safely operate until the next scheduled steam generator tube inspection outage. The staff concluded that all of these units could operate until their next scheduled steam generator tube inspection. The staff based this conclusion on the following factors:

(1) scope and results of the prior inspection including the experience at other similarly designed units - In steam generators that do not exhibit signals that interfere with eddy current inspections (e.g., copper, denting), inspections may have been more effective in identifying tube degradation.

(2) preventive measures taken (e.g., peening of the expansion transition, U-bend heat treatment, etc.) - These measures are expected to reduce the rate of cracking from PWSCC (Ref. 94).

(3) removal of tubes for destructive examination Data from steam generator tubes removed for destructive examination provide useful information concerning the causal effects and morphology of the degradation. In many instances, tube pull data provide information that tubes with circumferential indications are able to withstand the pressure loadings specified in Reference 33. Because of the inability to reliably size and characterize the degradation, tube pulls are sometimes necessary to confirm tube integrity and degradation morphology. 
(4) in situ pressure test data indicating that the circumferential indications are capable of withstanding the pressure loadings specified in Reference 33 - When all circumferential indications are removed from service before an operating interval (i.e., the time between tube inspections) and the most severe indications identified at the end of this operating interval have adequate integrity based on in situ testing, it would be reasonable to conclude that the steam generator could be safely operated for a similar operating interval.

(5) operating conditions at the plant (e.g., hot-leg operating temperature, water chemistry practices) - Stringent water chemistry control in accordance with industry standards designed to prevent uncontrolled tube degradation (i.e., mitigate the initiation and propagation of $\mathrm{SCC}$ ) and transport of impurities into the steam generator provides confidence that tube integrity will be maintained consistent with previous observations. Sludge lancing and chemical cleaning to reduce sludge accumulation provides confidence that impurities that may affect the rate of crack initiation and growth are controlled. In addition, sludge lancing and chemical cleaning can be effective at removing corrosion products at the top of the tubesheet and at controlling the build up of conductive deposits which might interfere with the eddy current data analysis (Ref. 52).

Since SCC is a thermally activated process, reducing the hot-leg operating temperature takes advantage of the temperature dependence of SCC growth and initiation rates (i.e., the growth and initiation would be slower, with all other parameters being equal).

(6) operating time until the next steam generator tube inspections were to be conducted

(7) requirement to monitor primary-to-secondary leakage and to shut down the plant when leak rate limits are exceeded - Leakage monitoring is a defense-in-depth operating practice that can provide operators with a timely indication of a steam generator tube leak or tube rupture. Nitrogen 16 monitors can permit faster identification and isolation of a steam generator that has a tube that has degraded to the point of leakage. Improved integrated leak rate monitoring programs provide added confidence that tube integrity will be maintained. These programs feature administrative limits on primary-to-secondary leakage. They also use equipment and procedural upgrades to enable plant operators to detect and respond to changes in steam generator primary-to-secondary leakage, and to shut down the unit before a significant leak or steam generator tube rupture if tube degradation should exceed expected values.

(8) use of procedures (including emergency operating procedures) to diagnose and address steam generator tube leaks and ruptures Procedures, equipment, and training programs that are in place to identify and mitigate the consequences of failed tubes provide confidence that, in the event of a loss of tube integrity, the plant can be safely operated. These programs include simulator training on steam generator tube leaks and ruptures for control room operators.

(9) design enhancements present in the steam generators which are intended to reduce the susceptibility to cracking - These enhancements include using thermally treated tubes rather than mill-annealed tubes, using stainless steel tube support plates rather than carbon steel tube support plates, using larger bend radii in the small-radius tubes, using hydraulic expansion techniques rather than others, and using tube support plates with broached quatrefoil holes rather than drilled holes.

(10) the location of the expansion transition - If severe circumferentially oriented degradation were postulated to occur in the expansion transition region of a partial-depth expanded tube, the consequences would be different from a plant where the expansion transition is near the top of the tubesheet. In steam generators with partial-depth expansion transitions, the postulated circumferential crack would be well below the top of the tubesheet. The presence of the tubesheet essentially precludes the possibility of tube burst. In addition, if severe 
degradation were to occur, the tube would not be able to move significantly either in the axial or radial direction thereby restricting the flow of primary coolant when compared to a tube with similar degradation at the top of the tubesheet. This is a result of the proximity of the tube outside diameter and tubesheet hole inside diameter. In addition, sludge accumulation in the tube-to-tubesheet crevice, if present, could also act to restrict any potential leakage.

The tubesheet also provides lateral support which restrains bending of the tube during pressurization.

(11) the risk and potential consequences of a range of steam generator tube rupture events as discussed in Reference 27 - In Reference 27, the staff estimated the risk contribution due to the potential for single and multiple steam generator tube ruptures. In addition, this study examined the expected consequences of steam generator tube rupture scenarios, including beyond design basis situations, such as the potential for release due to containment bypass via failed tubes concurrent with a breach of secondary system integrity.

\subsection{Tube Inspections}

GL 95-03 requested, in part, a safety assessment justifying continued operation on the basis of past inspection results and a summary of inspection plans for the next scheduled steam generator tube inspection outage as they pertain to the detection of circumferential cracking. The inspection plans were to consist of both an initial scope and sample expansion criteria. For the Westinghouse units with alloy 600 steam generator tubes, the staff summarized some of the information provided by the licensees with respect to the previous and next inspection for each of the areas identified as being potentially susceptible to circumferential cracking. The designation of "previous" refers to inspections performed before issuing or responding to GL 95-03. The designation of "next" (and/or "future") refers to an inspection performed after issuing or responding to GL 95-03. The phrase, "if detect ${ }^{n}$, is used to describe the inspection expansion criteria when a circumferential indication is detected. In many instances, the next (and/or future) inspections have already been completed as a result of the time taken to prepare this document for publishing.

The inspection summary tables are divided into four plant groupings on the basis of the type of method used to expand the tube into the tubesheet. These four groupings are partial-depth hardroll plants, full-depth hardroll plants, WEXTEX plants, and hydraulic plants. For each of these groupings of plants, tables are provided for each location which has exhibited circumferential cracking (i.e., expansion transition and top of tubesheet region (partial-depth hardroll plants), U-bend region of small-radius tubes, dented locations, and sleeve joints). It should be noted that grouping of plants by other parameters may provide a better comparison of operating experience and inspection scope (e.g., for dented locations, it may be better to divide the plants into two groupings such as mill-annealed and thermally treated and/or mill-annealed with carbon steel tube support structures, mill-annealed with stainless steel support structures, and thermally treated with stainless steel support structures). The staff elected to group the plants by expansion transition type since plants with similar expansion transitions typically are of the same vintage. Appendix B can be used to determine other pertinent facts regarding the steam generator tubes at these plants.

Tables 7-1 through 7-5 summarize the scope of the past and future inspections at the expansion transition, at the top of the tubesheet, in the U-bend of small-radius tubes, dented locations, and sleeve joints, respectively, for partial-depth hardroll plants. Tables 7-6 through 7-9 provide the scope of the past and future inspections at the expansion transition, in the U-bend of small-radius tubes, dented locations, and sleeve joints, respectively, for full-depth hardroll plants, Tables 7-10 through 7-13 provide this information for WEXTEX plants, and Tables 7-14 through 7-17 provide this information for hydraulic plants. Tube inspections performed using a technique not capable of reliably detecting circumferentially oriented degradation were recorded as "None" in Tables 7-1 through 7-17. In instances where the results of the tube inspections were readily available, the results were included in the tables, as appropriate. Acronyms and abbreviations used in the tables are explained in Appendix C. 
As can be seen from evaluating the data in Tables 7-1 through 7-17, there are plant-specific differences in the inspection plans (e.g., probe type, scope of examination). These differences in the inspection plans were considered along with other plant-specific circumstances (e.g., preventive measures taken) in evaluating the acceptability of a licensee's response as discussed in Section 7.3. For example, even though a licensee may have implemented a smaller initial inspection scope than another licensee, this may have been considered acceptable if the cumulative operating time for the plant was less than that of the other plant (all other parameters being equal).

The staff has reviewed the submissions provided by the licensees that have Westinghouse steam generators with alloy 600 tubes and has concluded that they contain the information requested in GL 95-03. General conclusions regarding the responses are discussed in Section 9. 


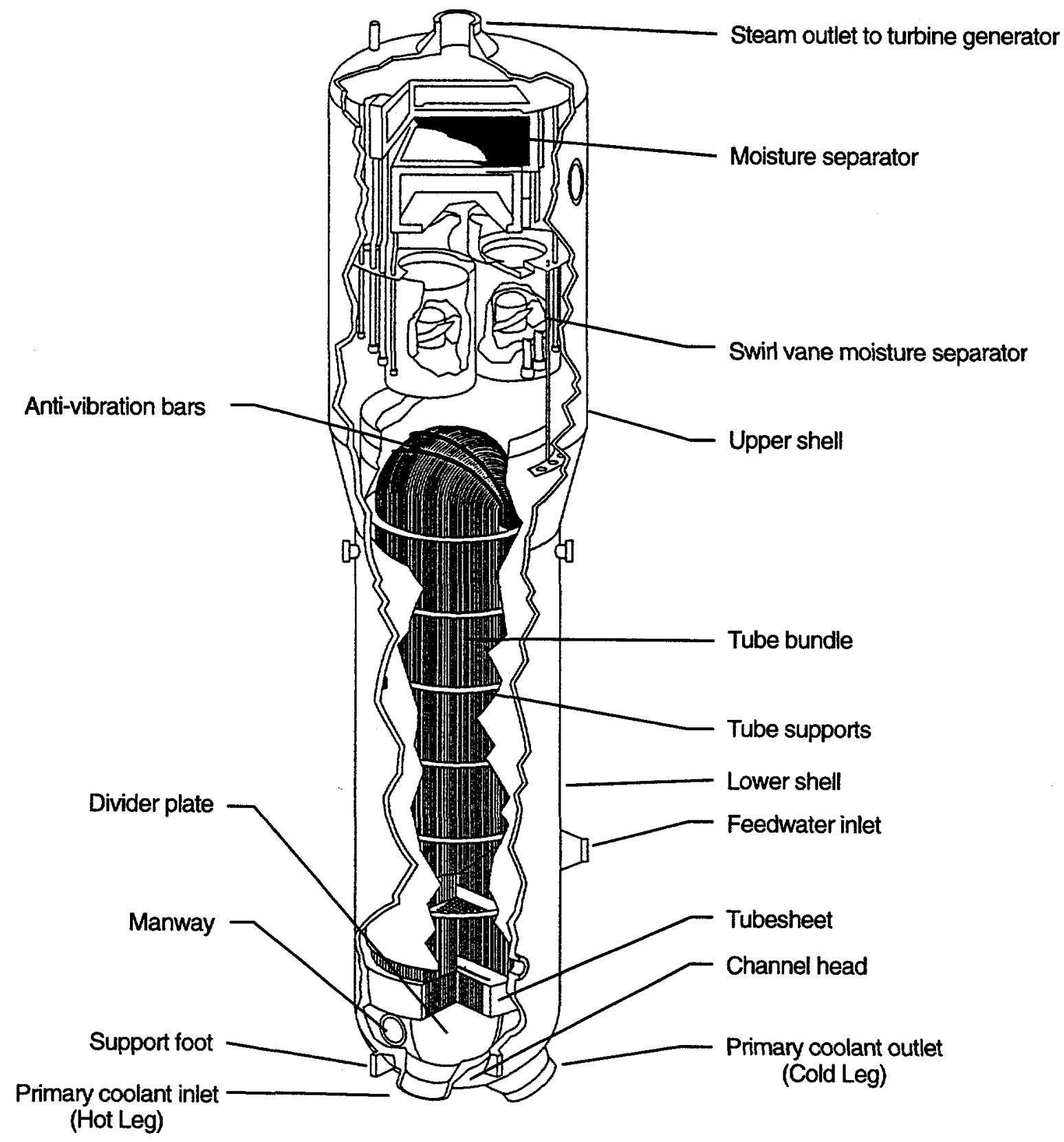

Figure 7-1 Cutaway view of a typical RSG 

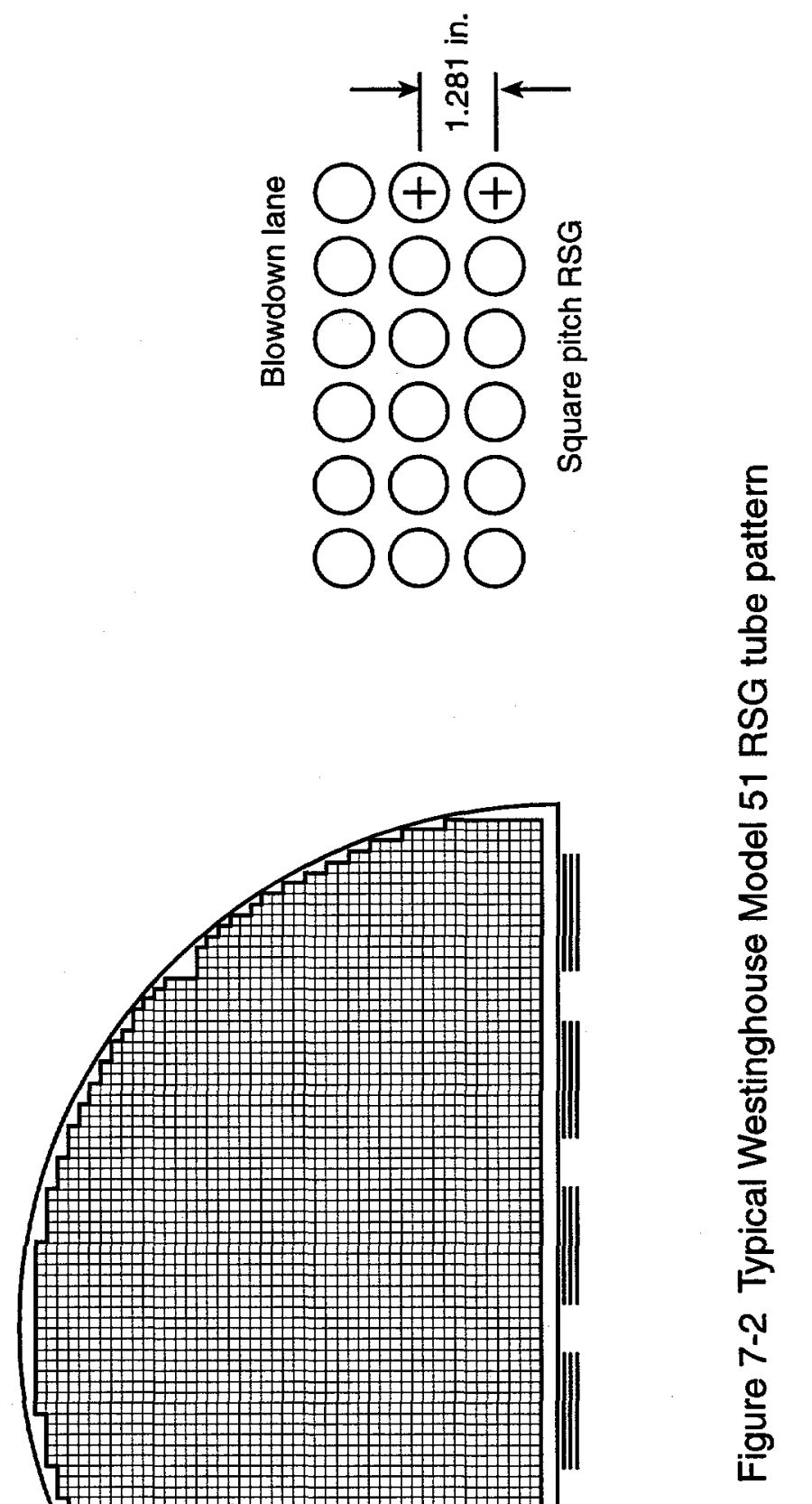


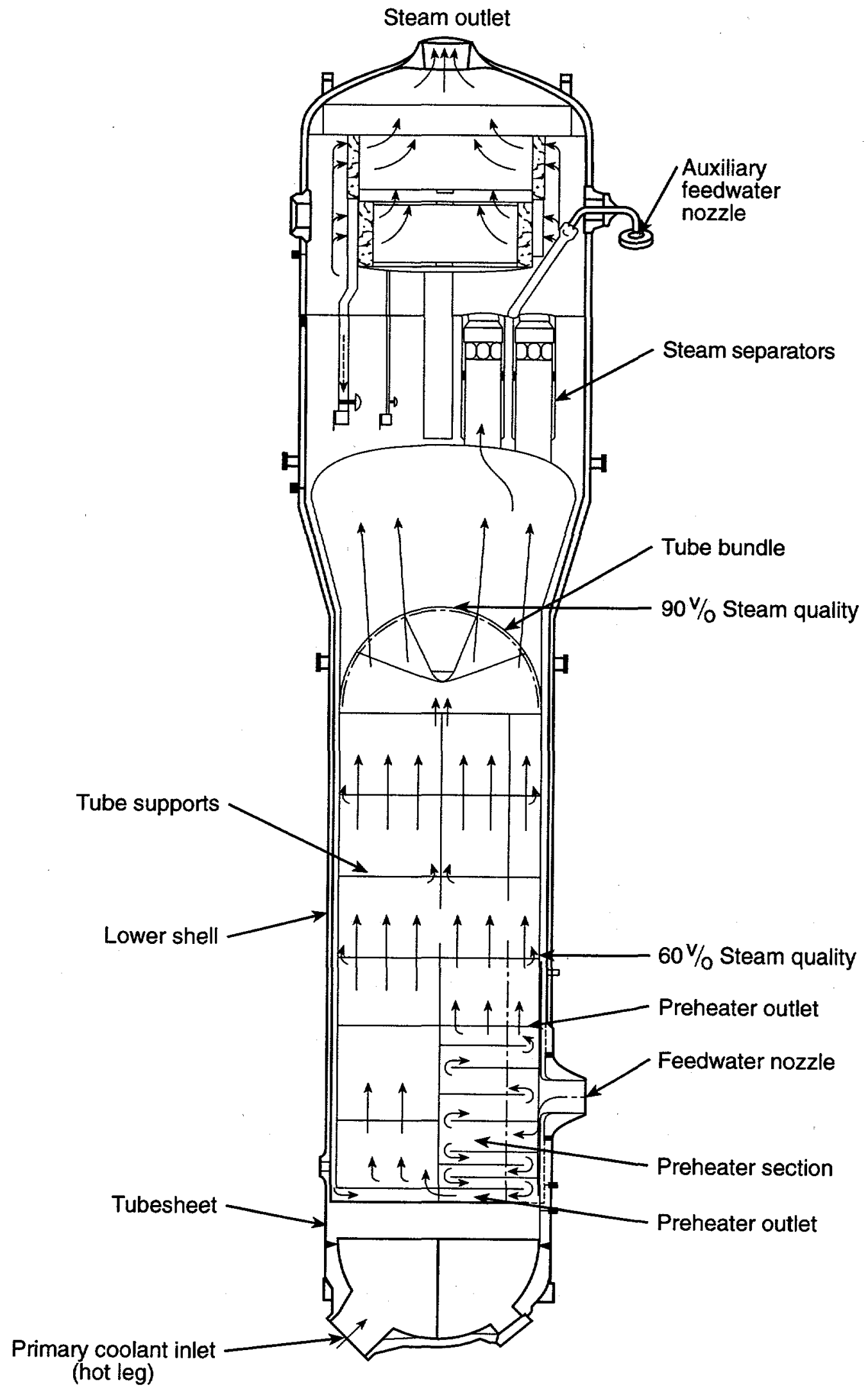

Figure 7-3 Typical Westinghouse steam generator with a preheater (Model D-2) 


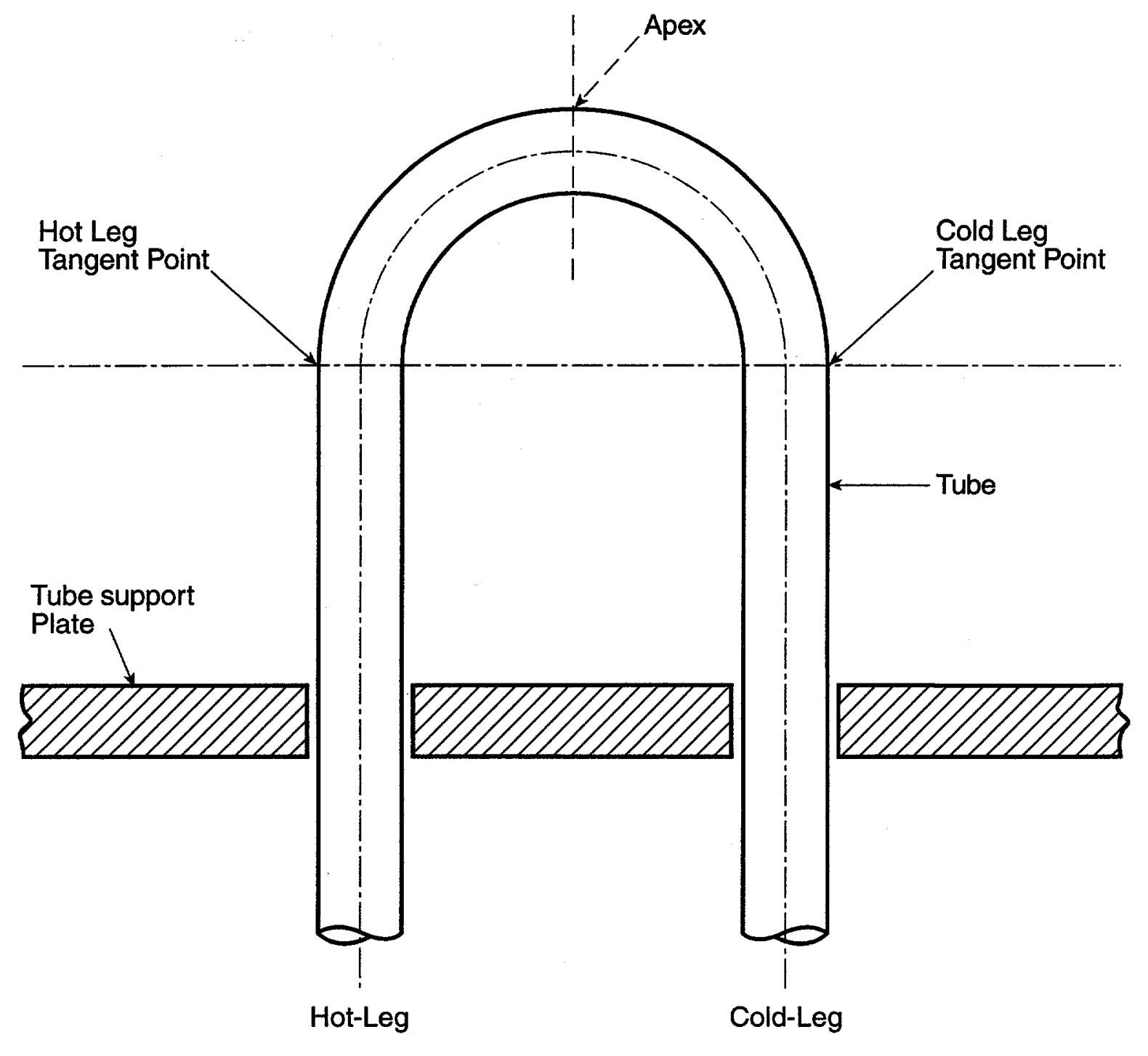

Figure 7-4 U-bend portion of a small-radius tube 
Table 7-1 Inspections at the expansion transition region in Westinghouse partial-depth hardroll plants

\begin{tabular}{|c|c|c|c|}
\hline Plant & $\begin{array}{l}\text { Expansion Transition } \\
\text { Past Inspection }\end{array}$ & $\begin{array}{l}\text { Expansion Transition Future } \\
\text { Inspection }\end{array}$ & Notes \\
\hline D.C. Cook 1 & $\begin{array}{l}39 \text { RPC exams to apply } \\
\text { F* criteria }^{*}\end{array}$ & $100 \%$ C5. & $\begin{array}{l}\text { Rerolled tubes in 1994. References 88, 126, and } \\
127 \text {. }\end{array}$ \\
\hline Ginna & $\begin{array}{l}100 \% \text { RPC of unsleeved } \\
\text { tubes }\end{array}$ & None (SG replacement). & $\begin{array}{l}\text { Sleeves installed within tubesheet region. } \\
\text { References } 128,129 \text {, and } 130 \text {. }\end{array}$ \\
\hline Haddam Neck & $\begin{array}{l}754 \mathrm{~F}^{*} \text { probe exams and } \\
254 \text { Combo probe exams }\end{array}$ & $\begin{array}{l}100 \% \text { combo probe in HIL. } 20 \% \\
\text { combo probe in CL. If detect in CL, } \\
\text { inspect an additional } 20 \% \text { in that } S G \text {. } \\
\text { If detect in CL expansion, expand to } \\
100 \% \text { in affected SG. }\end{array}$ & $\begin{array}{l}\text { The } F^{*} \text { probe contains } 2 \text { bobbin coils separated } \\
\text { by a fixed distance which accounts for field } \\
\text { spread and is used to determine if } 1^{*} \text { of sound roll } \\
\text { is present. The combo probe contains a bobbin, } \\
\text { pancake, and PP coil and performs the same } \\
\text { function as the F* probe and is used to } \\
\text { characterize the indication (e.g., cracklike). } \\
\text { References } 109,131 \text {, and } 132 \text {. }\end{array}$ \\
\hline Indian Point 2 & $100 \% \mathrm{C5}$ & $\begin{array}{l}100 \% \text { C5 in HL and } 20 \% \text { C5 in CL. If } \\
\text { detect, } 100 \% \text { in CL. }\end{array}$ & $\begin{array}{l}114 \text { logged circumferential indications ( } 66 \mathrm{SCls} \text {, } \\
48 \mathrm{MCIs} \text { ). These indications are believed to be } \\
\text { closely spaced axial cracks. Rerolled tubes to } \\
\text { apply } \mathrm{F}^{*} \text { criteria. References } 133 \text { and } 134 \text {. }\end{array}$ \\
\hline Kewaunee & $\begin{array}{l}100 \% \text { RPC of unsleeved } \\
\text { HL tubes }\end{array}$ & $100 \%$ RPC of unsleeved HL. & $\begin{array}{l}\text { Inspect from tube end to } 3 \text { inches above TTS. } \\
\text { References } 135 \text { and } 136 .\end{array}$ \\
\hline Point Beach 2 & None & None. & $\begin{array}{l}\text { Historically performed RPC inspection of } \\
\text { distorted bobbin indications. For next inspection, } \\
\text { will use PP to inspect distorted bobbin } \\
\text { indications. References } 137 \text { and } 138 \text {. }\end{array}$ \\
\hline Prairie Island 1 & $100 \% \mathrm{RPC}$ in $\mathrm{HL}$ & $100 \%$ PP or equivalent in HL. & $\begin{array}{l}\text { Did not shotpeen or rotopeen since unit was } \\
\text { already in service. References } 139 \text { and } 140 .\end{array}$ \\
\hline Prairie Island 2 & $100 \% \mathrm{PP}$ in $\mathrm{HL}$ & $100 \% \mathrm{PP}$ or equivalent in $\mathrm{HL}$. & $\begin{array}{l}\text { Did not shotpeen or rotopeen since unit was } \\
\text { already in service. References } 139 \text { and } 140 \text {. }\end{array}$ \\
\hline Zion 1 & 300 to 700 RPC exams & $\begin{array}{l}20 \% \text { in } \mathrm{HL} \text { with Appendix } \mathrm{H} \text { circ. } \\
\text { cracking technique. If detect, } 100 \% \text {. } \\
\text { If widespread cracking, sample } \mathrm{CL} \text {. }\end{array}$ & $\begin{array}{l}\text { Next inspections primarily with RPC unless } \\
\text { dented. References } 141,142 \text {, and } 143 \text {. }\end{array}$ \\
\hline Zion 2 & 300 to $700 \mathrm{RPC}$ exams & $\begin{array}{l}20 \% \text { in } \mathrm{HL} \text { with Appendix } \mathrm{H} \text { circ. } \\
\text { cracking technique. If detect, } 100 \% \text {. } \\
\text { If widespread cracking, sample } \mathrm{CL} \text {. }\end{array}$ & $\begin{array}{l}\text { Next inspections primarily with RPC unless } \\
\text { dented. References } 141,142 \text {, and } 143 \text {. }\end{array}$ \\
\hline
\end{tabular}


Table 7-2 Inspections at top-of-tubesheet dented locations in Westinghouse partial-depth hardroll plants

\begin{tabular}{|c|c|c|c|}
\hline Plant & $\begin{array}{l}\text { Other Dented Locations } \\
\text { (e.g., TTS) Past } \\
\text { Inspection }\end{array}$ & $\begin{array}{c}\text { Other Dented Locations (e.g., TTS) } \\
\text { Future Inspection }\end{array}$ & Notes \\
\hline D.C. Cook 1 & $100 \%$ RPC at TTS & $100 \% \mathrm{C} 5$ at TTS. & $\begin{array}{l}\text { OD cellular corrosion at TTS primarily associated } \\
\text { with dents. References } 88,126 \text {, and } 127 \text {. }\end{array}$ \\
\hline Ginna & $\begin{array}{l}\text { TTS inspections not } \\
\text { addressed }\end{array}$ & None (SG replacment). & References 128,129 , and 130 . \\
\hline Haddam Neck & $\begin{array}{l}81 \text { RPC exams focused in } \\
\text { the sludge pile region }\end{array}$ & $\begin{array}{l}20 \text { HL exams with Appendix H circ. } \\
\text { cracking technique plus all distorted } \\
\text { bobbin indications and all flaws } \\
\text { exceeding the repair limit. If detect, } \\
\text { expand to } 100 \% \text { of affected ("critical") } \\
\text { area in that } S G \text { and } 20 \% \text { in other SGs. }\end{array}$ & $\begin{array}{l}\text { Dents at the TTS are smaller than at the tube } \\
\text { support plates. Expect cracking at tube support } \\
\text { plates (large dents), roll transition, and in small } \\
\text { radius U-bend tubes before cracking at TTS } \\
\text { (temperature and stresses taken into } \\
\text { consideration). References } 109,131 \text {, and } 132 \text {. }\end{array}$ \\
\hline Indian Point 2 & $100 \%$ C5 through 1st TSP & $\begin{array}{l}100 \% \text { HL and } 20 \% \text { CL C5. If detect, } \\
100 \% \text { in CL. }\end{array}$ & References 133 and 134. \\
\hline Kewaunee & $\begin{array}{l}100 \% \text { RPC of unsleeved } \\
\text { HL at TTS }\end{array}$ & $100 \%$ RPC of unsleeved HL at TTS. & $\begin{array}{l}\text { Inspect from tube end to } 3 \text { inches above the TTS. } \\
\text { References } 135 \text { and } 136 \text {. }\end{array}$ \\
\hline Point Beach 2 & None & None. & $\begin{array}{l}\text { Historically performed RPC inspection of } \\
\text { distorted bobbin indications. For next inspection, } \\
\text { will use PP to inspect distorted bobbin } \\
\text { indications. References } 137 \text { and } 138 \text {. }\end{array}$ \\
\hline Prairie Island 1 & $100 \%$ RPC in HL at TTS & $100 \%$ PP or equivalent in HL at TTS. & $\begin{array}{l}\text { Performed as a result of D.C. Cook findings. } \\
\text { References } 139 \text { and } 140 .\end{array}$ \\
\hline Prairie Island 2 & $100 \% \mathrm{PP}$ in $\mathrm{HL}$ at TTS & $100 \%$ PP or equivalent in $\mathrm{HL}$ at TTS. & $\begin{array}{l}\text { Performed as a result of D.C. Cook findings. } \\
\text { References } 139 \text { and } 140 .\end{array}$ \\
\hline Zion 1 & N/A & N/A & $\begin{array}{l}\text { No denting at TTS. If denting develops, will } \\
\text { evaluate need for inspecting for circumferential } \\
\text { indications. References 141, 142, and 143. }\end{array}$ \\
\hline Zion 2 & N/A & N/A & $\begin{array}{l}\text { No denting at TTS. If denting develops, will } \\
\text { evaluate need for inspecting for circumferential } \\
\text { indications. References } 141,142 \text {, and } 143 \text {. }\end{array}$ \\
\hline
\end{tabular}


Table 7-3 Inspections in the U-bend region of small-radii tubes in Westinghouse partial-depth hardroll plants

\begin{tabular}{|c|c|c|c|}
\hline Plant & U-bend Past Inspection & U-bend Future Inspection & Notes \\
\hline D.C. Cook 1 & None & $\begin{array}{l}20 \% \mathbf{R P C} \text { in R1 and R2 in } 1 \text { SG. If } \\
\text { detect, } 100 \% \text { RPC in all SGs. [No } \\
\text { degradation detected.] }\end{array}$ & References 88,126 , and 127 . \\
\hline Ginna & $100 \% \mathrm{RPC}$ in R1 and R2 & None (SG replacement). & References 128,129 , and 130. \\
\hline Haddam Neck & $\begin{array}{l}95 \% \text { RPC of inner row } \\
\text { U-bends (R2 in SGs } 1 \text { and } \\
2 ; R 1 \text { in SGs } 3 \text { and } 4)\end{array}$ & $\begin{array}{l}20 \% \text { of inner row U-bends (R2 in SGs } \\
1 \text { and } 2 ; R 1 \text { in SGs } 3 \text { and } 4 \text { ) with } \\
\text { Appendix } H \text { circ. cracking technique. } \\
\text { Expand to } 100 \% \text { and } 20 \% \text { of next row. }\end{array}$ & $\begin{array}{l}\text { R1 tubes in SGs } 1 \text { and } 2 \text { were preventively } \\
\text { plugged in } 1983 \text { due to flow slot hourglassing. } \\
\text { References } 109,131 \text {, and } 132 \text {. }\end{array}$ \\
\hline Indian Point 2 & None & $100 \%$ C5 or RPC. & $\begin{array}{l}\text { R1 plugged during construction. Performed RPC } \\
\text { exams of bobbin indications only. References } \\
133 \text { and } 134 \text {. }\end{array}$ \\
\hline Kewaunee & $\begin{array}{l}100 \% \mathrm{RPC} \text { in R1 and } \\
30 \% \mathrm{RPC} \text { in } \mathrm{R} 2\end{array}$ & $\begin{array}{l}100 \% \mathrm{RPC} \text { in } \mathrm{R} 1 \text { and } 30 \% \mathrm{RPC} \text { in } \mathrm{R} 2 \text {. } \\
\text { If detect in R2,100\% in R2. }\end{array}$ & References 135 and 136. \\
\hline Point Beach 2 & None & None. & $\begin{array}{l}\text { Historically performed RPC inspection of } \\
\text { distorted bobbin indications. For next inspection, } \\
\text { will use PP to inspect distorted bobbin } \\
\text { indications. References } 137 \text { and } 138 \text {. }\end{array}$ \\
\hline Prairie Island 1 & $100 \% \mathrm{RPC}$ in R1 and R2 & $\begin{array}{l}100 \% \text { PP in R1 and R2. [No } \\
\text { indications detected.] }\end{array}$ & References 139 and 140. \\
\hline Prairie Island 2 & $\begin{array}{l}100 \% \mathrm{RPC} \text { or } \mathrm{PP} \text { in } \mathrm{R} 1 \\
\text { and } \mathrm{R} 2\end{array}$ & $100 \%$ rotating coil in $\mathrm{R} 1$ and $\mathrm{R} 2$. & References 139 and 140. \\
\hline Zion 1 & $\begin{array}{l}25 \text { segmented pancake coil } \\
\text { exams per SG }\end{array}$ & $\begin{array}{l}100 \% \text { in } \mathrm{R} 2 \text { with Appendix } \mathrm{H} \text { circ. } \\
\text { cracking technique. }\end{array}$ & $\begin{array}{l}\text { Preventively plugged R1 in RFO } 6 \text { (1982). Next } \\
\text { inspections primarily with RPC. References } 141 \text {, } \\
142 \text {, and } 143 \text {. }\end{array}$ \\
\hline Zion 2 & $\begin{array}{l}100 \% \text { segmented pancake } \\
\text { coil exams in } R 1 \text { and } 25 \\
\text { exams in } R 2 \text { per SG }\end{array}$ & $\begin{array}{l}100 \% \text { in } \mathrm{R} 1 \text { and } \mathrm{R} 2 \text { with Appendix } \mathrm{H} \\
\text { circ. cracking technique. }\end{array}$ & $\begin{array}{l}\text { R1 U-bend leak in } 1989 \text {. Next inspections } \\
\text { primarily with RPC. References } 141,142 \text {, and } \\
143 \text {. }\end{array}$ \\
\hline
\end{tabular}


Table 7-4 Inspections at dented locations in Westinghouse partial-depth hardroll plants

\begin{tabular}{|c|c|c|c|}
\hline Plant & $\begin{array}{l}\text { Dented TSP Past } \\
\text { Inspection }\end{array}$ & Dented TSP Future Inspection & Notes \\
\hline D.C. Cook 1 & $100 \% \mathrm{RPC}$ of dents $>5 \mathrm{~V}$ & GL 95-05 criteria. & $\begin{array}{l}\text { GL 95-05 calibration. References } 88,126 \text {, and } \\
127 .\end{array}$ \\
\hline Ginna & RPC sampling & None (SG replacement). & References 128,129 , and 130 . \\
\hline Haddam Neck & $\begin{array}{l}200 \text { gimbaled PP exams of } \\
\text { largest dents }\end{array}$ & $\begin{array}{l}200 \text { tubes with Appendix H circ. } \\
\text { cracking technique. Expand until } \\
\text { smallest dent size where cracking } \\
\text { would occur is determined. }\end{array}$ & $\begin{array}{l}\text { Used gimbaled PP. If find cracking at dents, will } \\
\text { perform evaluation relating dent size with tube } \\
\text { cracking. Expansion primarily based on } \\
\text { inspection results. Dent size determined by size } \\
\text { of bobbin probe that can successfully pass } \\
\text { through the location and by bobbin coil voltage. } \\
\text { Calibration: } 20 \text { volts for each } 0.001 \text {-inch of } \\
\text { denting for a } 0.012 \text {-inch radial dent at } 600 \mathrm{kHz} \text {. } \\
\text { References } 109,131 \text {, and } 132 \text {. }\end{array}$ \\
\hline Indian Point 2 & $\begin{array}{l}100 \% \text { C5 in SGs } 1 / 2,1 \text { st } \\
\text { TSP dents in SGs } 3 / 4\end{array}$ & $\begin{array}{l}100 \% \mathrm{HL} \text { and } 20 \% \mathrm{CL} \mathrm{C5} \text {. If detect, } \\
100 \% \text { in CL. }\end{array}$ & $\begin{array}{l}\text { Examined dents with restrictions that prevented } \\
\text { "adequate" examination with a } 0.680 \text { or } 0.700 \\
\text { probe. References } 133 \text { and } 134 .\end{array}$ \\
\hline Kewaunee & $100 \% \mathrm{RPC}$ of dents $>5 \mathrm{~V}$ & GL $95-05$ criteria. & GL $95-05$ calibration. References 135 and 136 . \\
\hline Point Beach 2 & None & None. & $\begin{array}{l}\text { Historically performed RPC inspection of } \\
\text { distorted bobbin indications. For next inspection, } \\
\text { will use PP to inspect distorted bobbin } \\
\text { indications. References } 137 \text { and } 138 \text {. }\end{array}$ \\
\hline Prairie Island 1 & Not addressed & $\begin{array}{l}100 \% \text { PP of dents }>5 \mathrm{~V} \text {. [No } \\
\text { indications detected.] }\end{array}$ & GL 95-05 calibration. References 139 and 140. \\
\hline Prairie Island 2 & Not addressed & $100 \%$ PP of dents $>5 \mathrm{~V}$ & GL 95-05 calibration. References 139 and 140. \\
\hline Zion 1 & None & $\begin{array}{l}20 \% \text { RPC of dents }>5 \mathrm{~V} \text { concentrating } \\
\text { at lowest TSP. If detect, } 100 \% \text { of all } \\
\text { HL TSPs with dents }>5 \mathrm{~V} \text {. }\end{array}$ & $\begin{array}{l}10 \text { dents }>5 \mathrm{~V} \text {. Calibration: } 0.001 \text {-inch dent is } \\
\text { set to } 1 \mathrm{~V} \text { on the } 400 \mathrm{kHz} \text { absolute channel. } \\
\text { References } 141,142 \text {, and } 143 \text {. }\end{array}$ \\
\hline Zion 2 & None & $\begin{array}{l}20 \% \text { RPC of dents }>5 \mathrm{~V} \text { concentrating } \\
\text { at lowest TSP. If detect, } 100 \% \text { of all } \\
\text { HL TSPs with dents }>5 \mathrm{~V} \text {. }\end{array}$ & $\begin{array}{l}1 \text { dent }>5 V \text {. Calibration: } 0.001 \text {-inch dent is set } \\
\text { to } 1 \mathrm{~V} \text { on the } 400 \mathrm{kHz} \text { absolute channel. } \\
\text { References } 141,142 \text {, and } 143 \text {. }\end{array}$ \\
\hline
\end{tabular}


Table 7-5 Inspections at sleeve joints in Westinghouse partial-depth hardroll plants

\begin{tabular}{|c|c|c|c|}
\hline Plant & Sleeve Past Inspection & Sleeve Future Inspection & Notes \\
\hline D.C. Cook 1 & None (crosswound) & $100 \%$ C5. [No degradation detected.] & $\begin{array}{l}1840 \text { Westinghouse HEJ sleeves installed in } 1992 \text {. } \\
\text { References } 88,126 \text {, and } 127 \text {. }\end{array}$ \\
\hline Ginna & $20 \%$ sampling & None (SG replacement). & $\begin{array}{l}\text { Probe type used dependent on type of sleeve } \\
\text { inspected (e.g., PP used for CE TIG welded } \\
\text { sleeves). Sleeve types used: B\&W brazed, } \\
\text { B\&W explosive, B\&W kinetic, CE TIG welded. } \\
\text { References 128, 129, and 130. }\end{array}$ \\
\hline Haddam Neck & N/A & N/A & $\begin{array}{l}\text { No sleeves installed. References } 109,131 \text {, and } \\
132 \text {. }\end{array}$ \\
\hline Indian Point 2 & N/A & $\mathbf{N} / \mathbf{A}$ & No sleeves installed. References 133 and 134. \\
\hline Kewaunee & $\begin{array}{l}\text { 100\% PP of upper joint of } \\
\text { HEJ sleeves; } 100 \% \text { PP of } \\
\text { the upper weld of CE } \\
\text { sleeves }\end{array}$ & $100 \%$ PP of upper joint of HEJ sleeves. & $\begin{array}{l}\text { Westinghouse HEJ sleeves installed in 1988, } \\
1989, \text { and } 1991 \text {. CE welded sleeves installed in } \\
1992 \text {. Majority of indications at top of lower } \\
\text { hardroll transition of HEJ sleeves. References } \\
135 \text { and } 136 .\end{array}$ \\
\hline Point Beach 2 & $100 \% \mathrm{C} 5$ & $\begin{array}{l}\text { 20\% PP or C5. Expansion based on } \\
\text { TS. }\end{array}$ & $\begin{array}{l}\text { HEJ cracking. } 222 \text { indications in } 3001 \text { sleeved } \\
\text { ubes. Nearly all indications at HEJ hardroll } \\
\text { lower transition. A few indications at the upper } \\
\text { and lower hydraulic transitions. References } 137 \\
\text { and } 138 \text {. }\end{array}$ \\
\hline Prairie Island 1 & 319 sleeves with I-coil & $\begin{array}{l}100 \% \text { PP. [No service induced } \\
\text { cracking.] }\end{array}$ & $\begin{array}{l}680 \text { CE TIG welded sleeves were installed as of } \\
1996 \text { (all in SG 12). Non-service induced } \\
\text { circumferential indications detected were } \\
\text { attributed to weld oxide inclusions and lack of } \\
\text { fusion caused by inadequate cleaning of the } \\
\text { parent tube prior to welding. References } 139 \text { and } \\
140 \text {. }\end{array}$ \\
\hline Prairie Island 2 & N/A & $\mathrm{N} / \mathrm{A}$ & No sleeves installed. References 139 and 140. \\
\hline Zion 1 & None (crosswound) & $100 \% \mathrm{PP}$ & $\begin{array}{l}47 \mathrm{HEJ} \text { and } 759 \text { CE TIG welded sleeves installed. } \\
\text { References } 141,142 \text {, and } 143 \text {. }\end{array}$ \\
\hline Zion 2 & $100 \% \mathrm{PP}$ & $100 \% \mathrm{PP}$. & $\begin{array}{l}414 \text { CE TIG welded sleeves installed. References } \\
141,142 \text {, and } 143 \text {. }\end{array}$ \\
\hline
\end{tabular}


Table 7-6 Inspections at the expansion transition region in Westinghouse full-depth hardroll plants

\begin{tabular}{|c|c|c|c|}
\hline Plant & $\begin{array}{l}\text { Expansion Transition } \\
\text { Past Inspection }\end{array}$ & $\begin{array}{l}\text { Expansion Transition Future } \\
\text { Inspection }\end{array}$ & Notes \\
\hline Beaver Valley 2 & $20 \% \mathrm{RPC}$ & $20 \%$ RPC. If detect, $100 \%$ RPC. & $\begin{array}{l}\text { Shotpeened prior to commercial service in } 1987 . \\
\text { References } 91 \text { and } 144 .\end{array}$ \\
\hline Braidwood 1 & $100 \% \mathrm{RPC}$ in $\mathrm{HL}$ & $\begin{array}{l}100 \% \text { in HL with Appendix } \mathrm{H} \text { circ. } \\
\text { cracking technique. If widespread } \\
\text { cracking, sample CL. }\end{array}$ & $\begin{array}{l}\text { Shotpeened HL and CL prior to operation. Next } \\
\text { inspections primarily with RPC unless dented. } \\
\text { References } 120,141 \text {, and } 143 \text {. }\end{array}$ \\
\hline Byron 1 & $100 \% \mathrm{RPC}$ in $\mathrm{KL}$ & $\begin{array}{l}100 \% \text { in HL with Appendix } \mathrm{H} \text { circ. } \\
\text { cracking technique. If widespread } \\
\text { cracking, sample CL. }\end{array}$ & $\begin{array}{l}\text { Shotpeened HL in RFO } 1 \text { and CL in RFO } 3 . \\
\text { Next inspections primarily with RPC unless } \\
\text { dented. References } 120,141 \text {, and } 143 \text {. }\end{array}$ \\
\hline Catawba 1 & $100 \% \mathrm{RPC}$ in $\mathrm{HL}$ & None (SG replacement). & $\begin{array}{l}\text { Shot peened HL in } 1987 \text { and CL in } 1991 . \mathrm{CL} \\
\text { inspected in 1992. References } 50,52 \text {, and } 123 \text {. }\end{array}$ \\
\hline Comanche Peak 1 & $\begin{array}{l}27 \% \text { RPC in } 2 \text { of } 4 \text { SGs } \\
\text { including } 100 \% \text { of the } \\
\text { WEXTEX tubes in these } 2 \\
\text { SGs }\end{array}$ & $\begin{array}{l}20 \% \text { in HL with Appendix H circ. } \\
\text { cracking technique. If detect, } 100 \% \text {. }\end{array}$ & $\begin{array}{l}89.5 \% \text { of tubes are hardroll expanded (14473 } \\
\text { tubes). The remainder (3839) have WEXTEX } \\
\text { expansions. Shotpeened transitions prior to } \\
\text { operation. Anomalous readings during } 1995 \\
\text { inspection. References } 89,124 \text {, and } 145 \text {. }\end{array}$ \\
\hline Farley 2 & $100 \% \mathrm{RPC}$ in $\mathrm{HL}$ & $\begin{array}{l}100 \% \mathrm{RPC} \text { in } \mathrm{HL} .20 \% \mathrm{RPC} \text { in CL. } \\
\text { Expansion based on inspection results. }\end{array}$ & $\begin{array}{l}\text { Shoppeened HL in } 1987 \text {. Only } 1 \text { circumferential } \\
\text { indication detected to-date. References } 35 \text { and } \\
146 .\end{array}$ \\
\hline McGuire 1 & $100 \%$ RPC in $\mathrm{HL}$ & $100 \%$ RPC in HL. $20 \%$ RPC in CL. & $\begin{array}{l}\text { Shotpeened HL in } 1986 \text { and CL in } 1990.100 \% \\
\text { RPC in CL in } 1991 \text {. References 50, 52, and } 147 .\end{array}$ \\
\hline McGuire 2 & $100 \% \mathrm{RPC}$ in $\mathrm{HL}$ & $100 \%$ RPC in HL. $20 \%$ RPC in CL. & $\begin{array}{l}\text { Shotpeened HL in } 1987 \text { and CL in } 1989.100 \% \\
\text { RPC in CL in } 1992 . \text { References } 50,52 \text {, and } 147 .\end{array}$ \\
\hline Shearon Harris 1 & $\begin{array}{l}-400 \mathrm{RPC} \text { exams in HL } \\
\text { in } 2 \text { of the } 3 \mathrm{SGs}\end{array}$ & $\begin{array}{l}20 \% \text { RPC in HL. If detect, } 100 \% \\
\text { RPC. [Actually performed } 100 \% \text { in } \\
\text { HL. Detected } 3 \text { circ. indications.] }\end{array}$ & $\begin{array}{l}\text { Rotopeened HL prior to service. Shotpeened CL } \\
\text { in RFO 3. References } 121 \text { and } 148 \text {. }\end{array}$ \\
\hline South Texas Project 1 & $100 \%$ RPC in HL & $\begin{array}{l}100 \% \mathrm{RPC} \text { in HL. If detect sufficient } \\
\text { amount of cracking, } 20 \% \mathrm{RPC} \text { in CL. }\end{array}$ & $\begin{array}{l}\text { Rotopeened HL and CL prior to commercial } \\
\text { service. Have identified some rolling anomalies - } \\
\text { these tubes are monitored more frequently. Circ. } \\
\text { indications located near terminal ends of the } \\
\text { blowdown pipe. References } 94,125 \text {, and } 149 \text {. }\end{array}$ \\
\hline Watts Bar 1 & N/A & $\begin{array}{l}20 \% \text { RPC, or equivalent, in HL. If } \\
\text { detect, } 100 \% \text { in affected SG. If } \\
\text { widespread cracking, } 20 \% \text { RPC in CL } \\
\text { in all SGs. }\end{array}$ & $\begin{array}{l}\text { Rotopeened HL and shotpeened CL prior to } \\
\text { commercial service. Expect plant to commence } \\
\text { commercial operation in late } 1995 \text {. Reference } \\
150 .\end{array}$ \\
\hline
\end{tabular}


Table 7-7 Inspections in the U-bend region of small-radii tubes in Westinghouse full-depth hardroll plants

\begin{tabular}{|c|c|c|c|}
\hline Plant & U-bend Past Inspection & U-bend Future Inspection & Notes \\
\hline Beaver Valley 2 & $100 \% \mathrm{RPC}$ in $\mathrm{R} 1$ and $\mathrm{R} 2$ & $100 \% \mathrm{RPC}$ in R1 and R2. & $\begin{array}{l}\text { UBHT in R1 and R2 prior to commercial } \\
\text { operation in 1987. References } 91 \text { and } 144 .\end{array}$ \\
\hline Braidwood 1 & None & $\begin{array}{l}20 \% \text { in } R 1 \text { and } R 2 \text { with Appendix } H \\
\text { circ. cracking technique. If detect, } \\
100 \% \text { in } R 1 \text { and } R 2 \text {. }\end{array}$ & $\begin{array}{l}\text { UBHT in R1 and R2 in RFO 1. } 100 \% \text { RPC in } \\
\text { R1 in RFO 2. Next inspection primarily with } \\
\text { RPC. References } 120,141 \text {, and } 143 \text {. }\end{array}$ \\
\hline Byron 1 & None & $\begin{array}{l}20 \% \text { in } \mathrm{R} 1 \text { and } \mathrm{R} 2 \text { with Appendix } \mathrm{H} \\
\text { circ. cracking technique. If detect, } \\
100 \% \text { in } \mathrm{R} 1 \text { and } \mathrm{R} 2 \text {. }\end{array}$ & $\begin{array}{l}\text { UBHT in R1 and R2 in RFO 2. Next inspection } \\
\text { primarily with RPC. References } 120,141 \text {, and } \\
\text { 143. }\end{array}$ \\
\hline Catawba 1 & $\begin{array}{l}100 \% \text { RPC in R1, R2, and } \\
\text { R3. } 20 \% \text { RPC in R4 }\end{array}$ & None (SG replacement). & $\begin{array}{l}\text { UBHT in R1 and R2 in 12/88. References 50, } \\
52 \text {, and } 123 \text {. }\end{array}$ \\
\hline Comanche Peak 1 & None & $\begin{array}{l}20 \% \text { in } R 1 \text { and } R 2 \text { with Appendix } H \\
\text { technique. If detect, } 100 \% \text { in } R 1 \text { and } \\
\mathbf{R} 2 \text {. }\end{array}$ & $\begin{array}{l}\text { UBHT in R1 and R2 prior to operation. } \\
\text { References } 89,124 \text {, and } 145 \text {. }\end{array}$ \\
\hline Farley 2 & $\begin{array}{l}100 \% \text { RPC in R1 and R2 } \\
\text { in one SG }\end{array}$ & $\begin{array}{l}100 \% R P C \text { in } R 1 \text { and } R 2 \text { in } 1 \text { SG. If } \\
\text { detect, } 100 \% \text { in } R 1 \text { and } R 2 \text { in all SGs. }\end{array}$ & $\begin{array}{l}\text { Preventively plugged low row U-bends in 1980s. } \\
\text { Recovered R1 in } 1990 \text { ( } 2 \text { R7). UBHT in } 1990 . \\
\text { No circ. cracking since UBHT. References } 35 \\
\text { and } 146 .\end{array}$ \\
\hline McGuire 1 & $\begin{array}{l}100 \% \mathrm{RPC} \text { in R1, R2 and } \\
\mathrm{R3} .20 \% \mathrm{RPC} \text { in R4 }\end{array}$ & $\begin{array}{l}100 \% \text { RPC in R1, R2, and R3; } 20 \% \\
\text { RPC in R4. }\end{array}$ & UBHT in 10/88. References 50,52, and 147 . \\
\hline McGuire 2 & $\begin{array}{l}100 \% \mathrm{RPC} \text { in R1, R2 and } \\
\mathrm{R} 3.20 \% \mathrm{RPC} \text { in R4 }\end{array}$ & $\begin{array}{l}100 \% \text { RPC in R1, R2, and R3; } 20 \% \\
\text { RPC in R4. }\end{array}$ & UBHT in 6/88. References 50, 52, and 147. \\
\hline Shearon Harris 1 & None & $\begin{array}{l}20 \% \mathrm{RPC} \text { in R1 and R2. If detect, } \\
100 \% \mathrm{RPC} \text { in R1 and R2. [No circ. } \\
\text { cracking detected.] }\end{array}$ & $\begin{array}{l}\text { UBHT in R1 and R2 prior to service. References } \\
121 \text { and } 148 \text {. }\end{array}$ \\
\hline South Texas Project 1 & Some RPC sampling & None. & $\begin{array}{l}\text { Larger bend radii than other Westinghouse SGs. } \\
\text { UBHT in R1 and R2. Not susceptible to circ. } \\
\text { cracking in this region. Monitoring of this region } \\
\text { done for conservatism. References } 94,125 \text {, and } \\
149 .\end{array}$ \\
\hline Watts Bar 1 & N/A & $\begin{array}{l}20 \% \text { RPC, or equivalent, in R1 and } \\
\text { R2. If detect, } 100 \% \text { in R1 and R2 in } \\
\text { affected SG. }\end{array}$ & $\begin{array}{l}\text { UBHT in R1 and R2 in } 1986 \text { (prior to commercial } \\
\text { service). Expect plant to commence commercial } \\
\text { operation in late 1995. Reference } 150 \text {. }\end{array}$ \\
\hline
\end{tabular}


Table 7-8 Inspections at dented locations in Westinghouse full-depth hardroll plants

\begin{tabular}{|c|c|c|c|}
\hline Plant & $\begin{array}{l}\text { Dented TSP Past } \\
\text { Inspection }\end{array}$ & Dented TSP Future Inspection & Notes \\
\hline Beaver Valley 2 & $7 \%$ RPC of dents $>5 \mathrm{~V}$ & $\begin{array}{l}100 \% \text { RPC of dents }>5 \mathrm{~V} \text {. Expand } \\
\text { based on dependence of indications on } \\
\text { voltage. }\end{array}$ & $\begin{array}{l}\text { Denting not prevalent. Most dents/dings present } \\
\text { since preservice. Dents at uppermost hot and } \\
\text { cold leg TSP inspected for Bulletin 88-02 } \\
\text { phenomena. Considered a dent if voltage exceods } \\
5 \mathrm{~V} \text {. Calibration: } 4-20 \% \text { holes set to } 4 \mathrm{~V} \\
\text { peak-to-peak on all channels. References } 91 \text { and } \\
144 \text {. }\end{array}$ \\
\hline Braidwood 1 & $100 \%$ RPC of dents $>5 \mathrm{~V}$ & GL 95-05 criteria. & $\begin{array}{l}\text { GL } 95-05 \text { calibration. Next inspection will } \\
\text { primarily be with RPC. References } 120,141 \text {, } \\
\text { and } 143 \text {. }\end{array}$ \\
\hline Byron 1 & $100 \% \mathrm{RPC}$ of dents $>5 \mathrm{~V}$ & GL 95-05 criteria. & $\begin{array}{l}\text { GL 95-05 calibration. Next inspection will } \\
\text { primarily be with RPC. References } 120,141 \text {, } \\
\text { and } 143 \text {. }\end{array}$ \\
\hline Catawba 1 & $100 \% \mathrm{RPC}$ of dents $>4 \mathrm{~V}$ & None (SG replacement), & $\begin{array}{l}\text { GL 95-05 calibration. References 50, 52, and } \\
123 \text {. }\end{array}$ \\
\hline Comanche Peak 1 & None & $\begin{array}{l}100 \% \text { of dents }>5 \mathrm{~V} \text { at lowest HL TSP } \\
\text { with Appendix } \mathrm{H} \text { technique. If detect, } \\
100 \% \text { of dents }>5 \mathrm{~V} \text { in all SGs. }\end{array}$ & $\begin{array}{l}\text { Calibration: } 4-20 \% \text { holes set to } 2.75 \mathrm{~V} \text { on } \\
\text { 550/130 mix. References } 89,124 \text {, and } 145 \text {. }\end{array}$ \\
\hline Farley 2 & $100 \% \mathrm{RPC}$ of dents $>5 \mathrm{~V}$ & GL 95-05 criteria. & GL 95-05 calibration. References 35 and 146. \\
\hline McGuire 1 & $100 \%$ RPC of dents $>4 \mathrm{~V}$ & $100 \%$ RPC of dents $>4 \mathrm{~V}$ & $\begin{array}{l}\text { GL 95-05 calibration. For freespan dents, the } \\
\text { dent voltage is measured using the } 400 \mathrm{kHz} \\
\text { differential channel. References } 50,52 \text {, and } 147 \text {. }\end{array}$ \\
\hline McGuire 2 & $100 \%$ RPC of dents $>4 \mathrm{~V}$ & $100 \%$ RPC of dents $>4 \mathrm{~V}$ & $\begin{array}{l}\text { GL 95-05 calibration. For freespan dents, the } \\
\text { dent voltage is measured using the } 400 \mathrm{kHz} \\
\text { differential channel. References } 50,52 \text {, and } 147 \text {. }\end{array}$ \\
\hline Shearon Harris 1 & None & $\begin{array}{l}20 \% \text { of dents }>5 \mathrm{~V} \text { with Appendix } \mathrm{H} \\
\text { circ. cracking technique. If detect, } \\
100 \% \text { of } \mathrm{HL} \text { dents in affected SG and } \\
20 \% \text { of CL dents in affected SG. [No } \\
\text { circ. cracks detected.] }\end{array}$ & $\begin{array}{l}\text { Calibration: } 20 \% \text { holes set to } 4 \mathrm{~V} \text { on } 550 \mathrm{kHz} \\
\text { differential channel. Record dents at } 5 \mathrm{~V} \text {. } \\
\text { References } 121 \text { and } 148 \text {. }\end{array}$ \\
\hline South Texas Project 1 & None & $\begin{array}{l}\text { RPC exam of the one dent that may be } \\
\text { service related. }\end{array}$ & $\begin{array}{l}\text { Less than } 50 \text { dents. Most dents are traceable } \\
\text { back to manufacturing artifacts with the exception } \\
\text { of one possible service induced dent. Record } \\
\text { dents at } 3 \mathrm{~V} \text {. GL } 95-05 \text { calibration. References } \\
94,125 \text {, and } 149 \text {. }\end{array}$ \\
\hline Watts Bar 1 & N/A & $\begin{array}{l}20 \% \text { RPC, or equivalent, of dents }> \\
5 \mathrm{~V} \text { at TSPs } 1 \text { and } 2 \text {. If detect, } 100 \% .\end{array}$ & $\begin{array}{l}\text { A few fabrication related dents were observed } \\
\text { during the preservice inspection. Expect plant to } \\
\text { commence commercial operation in late } 1995 \text {. } \\
\text { Reference } 150 \text {. }\end{array}$ \\
\hline
\end{tabular}


Table 7-9 Inspections at sleeve joints in Westinghouse full-depth hardroll plants

\begin{tabular}{|c|c|c|c|}
\hline Plant & Sleeve Past Inspection & Sleeve Future Inspection & Notes \\
\hline Beaver Valley 2 & N/A & N/A & No sleeves installed. References 91 and 144. \\
\hline Braidwood 1 & N/A & If installed, Appendix $\mathrm{H}$ technique. & $\begin{array}{l}\text { No sleeves installed. Next inspections, if any, } \\
\text { will primarily be with PP or Cecco. References } \\
120,141 \text {, and } 143 \text {. }\end{array}$ \\
\hline Byron 1 & N/A & If installed, Appendix $\mathrm{H}$ technique. & $\begin{array}{l}\text { No sleeves installed. Next inspections, if any, } \\
\text { will primarily be with PP or Cecco. References } \\
120,141 \text {, and } 143 \text {. }\end{array}$ \\
\hline Catawba 1 & N/A & $\mathbf{N} / \mathbf{A}$ & $\begin{array}{l}\text { No sleeves in service. Plugged all previously } \\
\text { sleeved tubes. References } 50,52 \text {, and } 123 \text {. }\end{array}$ \\
\hline Comanche Peak 1 & N/A & N/A & $\begin{array}{l}\text { No sleeves installed. References } 89,124 \text {, and } \\
145 \text {. }\end{array}$ \\
\hline Farley 2 & $100 \%$ C5 in $1 \mathrm{SG}$ & $100 \%$ C5. & $\begin{array}{l}\text { Only laser welded sleeves installed. First } \\
\text { installation in } 1992 \text {. All sleeves have been heat } \\
\text { treated. References } 35 \text { and } 146 .\end{array}$ \\
\hline McGuire 1 & N/A & N/A & $\begin{array}{l}\text { No sleeves in service. Plugged ail previously } \\
\text { sleeved tubes. References 50, 52, and } 147 \text {. }\end{array}$ \\
\hline McGuire 2 & N/A & N/A & $\begin{array}{l}\text { No sleeves in service. Plugged all previously } \\
\text { sleeved tubes. References 50, 52, and } 147 \text {. }\end{array}$ \\
\hline Shearon Harris 1 & N/A & N/A & No sleeves installed. References 121 and 148 . \\
\hline South Texas Project 1 & N/A & N/A & $\begin{array}{l}\text { No sleeves installed. References } 94,125 \text {, and } \\
149 .\end{array}$ \\
\hline Watts Bar 1 & N/A & N/A & No sleeves installed. Reference 150 . \\
\hline
\end{tabular}


Table 7-10 Inspections at the expansion transition region in Westinghouse WEXTEX plants

\begin{tabular}{|c|c|c|c|}
\hline Plant & $\begin{array}{l}\text { Expansion Transition } \\
\text { Past Inspection }\end{array}$ & $\begin{array}{l}\text { Expansion Transition Future } \\
\text { Inspection }\end{array}$ & Notes \\
\hline Beaver Valley 1 & $100 \% \mathrm{RPC}$ & $\begin{array}{l}100 \% \text { with Appendix H circ. cracking } \\
\text { technique. }\end{array}$ & $\begin{array}{l}\text { Only } 1 \text { circumferential indication detected. } \\
\text { References } 91 \text { and } 144 \text {. }\end{array}$ \\
\hline Comanche Peak 1 & $\begin{array}{l}27 \% \text { RPC in } 2 \text { of } 4 \text { SGs } \\
\text { including } 100 \% \text { of the } \\
\text { WEXTEX tubes in these } 2 \\
\text { SGs }\end{array}$ & $\begin{array}{l}20 \% \text { in } \mathrm{HL} \text { with Appendix } \mathrm{H} \text { circ. } \\
\text { cracking technique. If detect, } 100 \% \text {. }\end{array}$ & $\begin{array}{l}89.5 \% \text { of tubes are hardroll expanded (14473 } \\
\text { tubes). The remainder ( } 3839 \text { ) have WEXTEX } \\
\text { expansions. Shotpeened transitions prior to } \\
\text { operation. Anomalous readings during } 1995 \\
\text { inspection. References } 89 \text { and } 145 \text {. }\end{array}$ \\
\hline Diablo Canyon 1 & $\begin{array}{l}22 \% \text { RPC in HL in SGs } \\
11,12 \text {, and } 14 ; 23 \% \mathrm{RPC} \\
\text { in } \mathrm{HL} \text { in SG } 13\end{array}$ & $\begin{array}{l}\text { 50\% PP in zone 4. Sample outside } \\
\text { zone 4. If detect, expand per WOG } \\
\text { WEXTEX guidelines. }\end{array}$ & $\begin{array}{l}\text { Shotpeened HL in 1R5 (1992). References 87, } \\
107 \text {, and } 151 \text {. }\end{array}$ \\
\hline Diablo Canyon 2 & $\begin{array}{l}28 \% \text { RPC in HL in SG } \\
21 ; 22 \% \text { RPC in HL in } \\
\text { SGs } 22 \text { and } 23 ; 46 \% \text { RPC } \\
\text { in HL in SG } 24\end{array}$ & $\begin{array}{l}\text { 50\% PP in zone } 4 \text {. Sample outside } \\
\text { zone 4. If detect, expand per WOG } \\
\text { WEXTEX guidelines. }\end{array}$ & $\begin{array}{l}\text { Shotpeened HL in 2R5 (1993). } 1 \text { circumferential } \\
\text { indication detected in } 1993 \text { and } 1 \text { circumferential } \\
\text { indication detected in } 1994 . \text { References } 87,107 \text {, } \\
\text { and } 151 .\end{array}$ \\
\hline Farley 1 & $100 \% \mathrm{RPC}$ in $\mathrm{HL}$ & $\begin{array}{l}100 \% \mathrm{RPC} \text { in HL. } 20 \% \mathrm{RPC} \text { in CL. } \\
\text { If detect, expand per WOG WEXTEX } \\
\text { guidelines. }\end{array}$ & References 35 and 146. \\
\hline Salem 1 & $\begin{array}{l}39 \% \text { RPC in } \mathrm{HL} \text { in SG } \\
11 ; 21 \% \text { RPC in } \mathrm{HL} \text { in } \\
\text { SGs } 12 \text { and } 14 ; 100 \% \\
\text { RPC in } \mathrm{HL} \text { in SG } 13\end{array}$ & $\begin{array}{l}100 \% \text { C5 or PP in HL zone } 4.200 \\
\text { tube sample with C5 or PP in HL zones } \\
1,2 \text {, and } 3 \text {. If detect, expand per } \\
\text { WOG WEXTEX guidelines. [Actually } \\
\text { inspected } 100 \% .]\end{array}$ & $\begin{array}{l}\text { Shotpeened HL in 1993. } 4 \text { circumferential } \\
\text { indications detected. Previous exams } \\
\text { concentrated in zone } 4 \text {. References } 152 \text { and } 153 \text {. }\end{array}$ \\
\hline Salem 2 & $\begin{array}{l}100 \% \text { RPC in HL in SG } \\
21 ; 21 \% \text { RPC in HL zone } \\
4 \text { in SGs } 22 \text { and } 23 ; 27 \% \\
\text { RPC in HL zone } 4 \text { in SG } \\
24\end{array}$ & $\begin{array}{l}100 \% \text { C5 or PP in HL zone } 4.200 \\
\text { tube sample with C5 or PP in HL zones } \\
1,2 \text {, and } 3 \text {. If detect, expand per } \\
\text { WOG WEXTEX guidelines. }\end{array}$ & $\begin{array}{l}\text { Shotpeened HL in 1994. } 1 \text { circumferential } \\
\text { indication detected. Previous exams concentrated } \\
\text { in zone 4. References } 152 \text { and } 153 \text {. }\end{array}$ \\
\hline Sequoyah 1 & $\begin{array}{l}50 \% \text { RPC in SGs } 1 \text { and } 2 ; \\
61 \% \text { RPC in SG 3;100\% } \\
\text { RPC in SG } 4\end{array}$ & $\begin{array}{l}100 \% \text { RPC, or equivalent, in zone } 4 \\
\text { If detect, expand per WOG WEXTEX } \\
\text { guidelines. }\end{array}$ & $\begin{array}{l}\text { Shopeened in Cycle } 5 \text { RFO (10/91). References } \\
99 \text { and } 154 \text {. }\end{array}$ \\
\hline Sequoyah 2 & $\begin{array}{l}45 \% \text { RPC in SGs } 1 \text { and } 4 \\
100 \% \text { RPC in SG } 2 ; 63 \% \\
\text { RPC in SG } 3\end{array}$ & $\begin{array}{l}100 \% \text { RPC, or equivalent, in zone } 4 . \\
\text { If detect, expand per WOG WEXTEX } \\
\text { guidelines. }\end{array}$ & $\begin{array}{l}\text { Shotpeened in Cycle } 5 \text { RFO (1992). References } \\
99 \text { and } 154 .\end{array}$ \\
\hline
\end{tabular}


Table 7-11 Inspections in the U-bend region of small-radii tubes in Westinghouse WEXTEX plants

\begin{tabular}{|c|c|c|c|}
\hline Plant & U-bend Past Inspection & U-bend Future Inspection & Notes \\
\hline Beaver Valley 1 & $100 \% \mathrm{RPC}$ in R1 and R2 & $\begin{array}{l}100 \% \text { in } R 1 \text { and } R 2 \text { with Appendix } H \\
\text { circ. cracking technique. }\end{array}$ & $\begin{array}{l}\text { UBHT in } R 1 \text { and } R 2 \text { in } 1995 \text {. References } 91 \text { and } \\
144 .\end{array}$ \\
\hline Comanche Peak 1 & None & $\begin{array}{l}20 \% \text { in } \mathrm{R} 1 \text { and } \mathrm{R} 2 \text { with Appendix } \mathrm{H} \\
\text { technique. If detect, } 100 \% \text { in } \mathrm{R} 1 \text { and } \\
\mathrm{R} 2 \text {. }\end{array}$ & $\begin{array}{l}\text { UBHT in R1 and R2 prior to operation. } \\
\text { References } 89 \text { and } 145 .\end{array}$ \\
\hline Diablo Canyon 1 & $100 \% \mathrm{RPC}$ in $\mathrm{R} 1$ and $\mathrm{R} 2$ & $100 \% \mathrm{RPC}$ in $\mathrm{R} 1$ and $\mathrm{R} 2$ & $\begin{array}{l}\text { UBHT in R1 and R2 in 1R2 (1988). } 4 \\
\text { circumferential indications detected in R1 in } \\
\text { 1992. References } 87,107 \text {, and } 151 \text {. }\end{array}$ \\
\hline Diablo Canyon 2 & $100 \% \mathrm{RPC}$ in $\mathrm{R} 1$ and $\mathrm{R} 2$ & $100 \% \mathrm{RPC}$ in $\mathrm{R} 1$ and $\mathrm{R} 2$. & $\begin{array}{l}\text { UBHT in R1 and R2 in 2R1 (1986). References } \\
87,107 \text {, and } 151 \text {. }\end{array}$ \\
\hline Farley 1 & $100 \% \mathrm{RPC}$ in $\mathrm{R} 1$ and $\mathrm{R} 2$ & $100 \% \mathrm{RPC}$ in $\mathrm{R} 1$ and $\mathrm{R} 2$. & $\begin{array}{l}\text { Preventively plugged low Row U-bends in 1980s. } \\
\text { Recovered R1 in } 1991 \text { (1R10). UBHT in R1 and } \\
\text { R2 in } 1991.3 / 91 \text { indications were present prior } \\
\text { to UBHT (i.e., recovered tubes). No } \\
\text { circumferential indications detected since UBHT. } \\
\text { References } 35 \text { and } 146 .\end{array}$ \\
\hline Salem 1 & Not addressed & $\begin{array}{l}20 \% \mathrm{RPC} \text { in } \mathrm{R} 2 \text {. If detect, } 100 \% \text { in } \\
\mathrm{R} 2 \text {. }\end{array}$ & $\begin{array}{l}\text { Preventively plugged R1 U-bends in } 1989 . \\
\text { UBHT in R2 in } 1991 \text {. References } 152 \text { and } 153 .\end{array}$ \\
\hline Salem 2 & Not addressed & $\begin{array}{l}20 \% \text { RPC in R2. If detect, } 100 \% \text { in } \\
\mathrm{R} 2 \text {. }\end{array}$ & $\begin{array}{l}\text { Preventively plugged R1 U-bends in } 1988 . \\
\text { UBHT in R2 in 1990. References } 152 \text { and } 153 .\end{array}$ \\
\hline Sequoyah 1 & $\begin{array}{l}100 \% \mathrm{RPC} \text { in R1. RPC } \\
\text { sampling in R2 }\end{array}$ & $\begin{array}{l}20 \% \mathrm{RPC} \text { in } \mathrm{R} 1 \text { and } \mathrm{R} 2 \text {. If detect, } \\
100 \% \mathrm{RPC} \text { in R1 and } \mathrm{R} 2 \text {. }\end{array}$ & $\begin{array}{l}\text { UBHT in R1 and R2 during cycle } 3 \text { RFO (1987). } \\
\text { References } 99 \text { and } 154 \text {. }\end{array}$ \\
\hline Sequoyah 2 & $100 \% \mathrm{RPC}$ in $\mathrm{R} 1$ and $\mathrm{R} 2$ & $\begin{array}{l}20 \% \mathrm{RPC} \text { in R1 and R2. If detect, } \\
100 \% \mathrm{RPC} \text { in } \mathrm{R} 1 \text { and } \mathrm{R} 2 \text {. }\end{array}$ & $\begin{array}{l}\text { Preventively plugged R1 in 4/88. Deplugged R1 } \\
\text { in Cycle } 6 \text { RFO (1994). UBHT in R1 and R2 in } \\
\text { Cycle } 6 \text { RFO (1994). References } 99 \text { and } 154 \text {. }\end{array}$ \\
\hline
\end{tabular}


Table 7-12 Inspections at dented locations in Westinghouse WEXTEX plants

\begin{tabular}{|c|c|c|c|}
\hline Plant & $\begin{array}{l}\text { Dented TSP Past } \\
\text { Inspection }\end{array}$ & Dented TSP Future Inspection & Notes \\
\hline Beaver Valley 1 & $100 \%$ RPC of dents $>5 \mathrm{~V}$ & GL $95-05$ criteria. & $\begin{array}{l}\text { Denting not prevalent. GI 95-05 calibration. } \\
\text { References } 91 \text { and } 144 \text {. }\end{array}$ \\
\hline Comanche Peak 1 & None & $\begin{array}{l}100 \% \text { of dents }>5 V \text { at lowest HL TSP } \\
\text { with Appendix } \mathrm{H} \text { technique. If detect, } \\
100 \% \text { of dents }>5 \mathrm{~V} \text { in all SGs. }\end{array}$ & $\begin{array}{l}\text { Calibration: } 4-20 \% \text { holes set to } 2.75 \mathrm{~V} \text { on } \\
550 / 130 \text { mix. References } 89 \text { and } 145 \text {. }\end{array}$ \\
\hline Diablo Canyon 1 & $\begin{array}{l}10 \% \text { to } 26 \% \text { RPC of dents } \\
>5 V\end{array}$ & $\begin{array}{l}20 \% \text { PP of HL dents }>5 \mathrm{~V} \text {. If detect, } \\
100 \% \text { PP of dents }>5 \mathrm{~V} \text { at affected } \\
\text { TSP elevation and the lower TSP } \\
\text { elevations and } 20 \% \text { PP of dents }>5 \mathrm{~V} \\
\text { at the next higher TSP elevation. }\end{array}$ & $\begin{array}{l}\text { GL 95-05 calibration. Exams will be focused at } \\
\text { dents at the lower hot leg TSP elevations. Will } \\
\text { perform } 100 \% \text { PP of dents }>5 \mathrm{~V} \text { at } 1 \mathrm{H}, 2 \mathrm{H} \text {, and } \\
3 \mathrm{H} \text {. If more exams are needed to obtain a } 20 \% \\
\text { sample, additional exams above } 3 \mathrm{H} \text { will be } \\
\text { performed. References } 87,107 \text {, and } 151 \text {. }\end{array}$ \\
\hline Diablo Canyon 2 & $100 \% \mathrm{RPC}$ of dents $>5 \mathrm{~V}$ & $\begin{array}{l}20 \% \text { PP of HL dents }>5 \mathrm{~V} \text {. If detect, } \\
100 \% \text { PP of dents }>5 \mathrm{~V} \text { at affected } \\
\text { TSP elevation and the lower TSP } \\
\text { elevations and } 20 \% \mathrm{PP} \text { of dents }>5 \mathrm{~V} \\
\text { at the next higher TSP elevation. }\end{array}$ & $\begin{array}{l}\text { GL } 95-05 \text { calibration. Exams will be focused at } \\
\text { dents at the lower hot leg TSP elevations. } \\
\text { References } 87,107 \text {, and } 151 \text {. }\end{array}$ \\
\hline Farley 1 & $100 \%$ RPC of dents $>5 \mathrm{~V}$ & GL $95-05$ criteria. & GL $95-05$ calibration. References 35 and 146. \\
\hline Salem 1 & $\begin{array}{l}580 \mathrm{RPC} \text { exams of dents } \\
>5 \mathrm{~V}\end{array}$ & $\begin{array}{l}100 \% \text { C5 or PP of dents }>5 \mathrm{~V} \text { at TSPs } \\
1,2 \text {, and } 3.20 \% \text { C5 or PP of dents }> \\
5 \mathrm{~V} \text { at TSP } 4 . \text { If detect, } 100 \% \mathrm{CS} \text { or } \\
\text { PP of dents }>5 \mathrm{~V} \text { at affected TSP } \\
\text { elevation and } 20 \% \mathrm{C5} \text { or PP of dents } \\
>5 \mathrm{~V} \text { at next higher TSP elevation. }\end{array}$ & $\begin{array}{l}\text { No circumferential indications detected; however, } \\
5 \text { axial indications detected. Calibration: } 20 \% \\
\text { ASME defect set to } 4 \mathrm{~V} \text { on } 400 \mathrm{kHz} \text { differential } \\
\text { channel and saved to all channels. Record dents } \\
\text { at } 5 \mathrm{~V} \text { from } 400 / 100 \mathrm{kHz} \text { differential mix. } \\
\text { References } 152 \text { and } 153 \text {. }\end{array}$ \\
\hline Salem 2 & $\begin{array}{l}641 \text { RPC exams of dents } \\
>5 \mathrm{~V}\end{array}$ & $\begin{array}{l}20 \% \text { C5 or PP of dents }>5 \mathrm{~V} \text { at TSP } \\
1 \text {. If detect, } 100 \% \text { C5 or PP of dents } \\
>5 \mathrm{~V} \text { at affected TSP elevation and } \\
20 \% \text { C5 or PP of dents }>5 \mathrm{~V} \text { at next } \\
\text { higher TSP elevation. }\end{array}$ & $\begin{array}{l}\text { No circumferential indications detected. } \\
\text { Calibration: } 20 \% \text { ASME defect set to } 4 \mathrm{~V} \text { on } 400 \\
\mathrm{kHz} \text { differential channel and saved to all } \\
\text { channels. Record dents at } 5 \mathrm{~V} \text { from } 400 / 100 \mathrm{kHz} \\
\text { differential mix. References } 152 \text { and } 153 \text {. }\end{array}$ \\
\hline Sequoyah 1 & $\begin{array}{l}100 \% \text { RPC of dents }>5 \mathrm{~V} \\
\text { through HL TSP } 5\end{array}$ & $\begin{array}{l}100 \% \text { RPC, or equivalent, of dents > } \\
5 \mathrm{~V} \text { at HL TSPs } 1 \text { and } 2 \text { in SGs } 3 \text { and 4; } \\
20 \% \text { RPC, or equivalent, of dents > } \\
5 \mathrm{~V} \text { at HL TSP } 3 \text { in SGs } 3 \text { and } 4 ; 100 \% \\
\text { RPC, or equivalent, of HL dents }>5 \mathrm{~V} \\
\text { in SGs } 1 \text { and } 2 \text {. If detect, expand } \\
\text { based on results. }\end{array}$ & $\begin{array}{l}\text { SGs } 3 \text { and } 4 \text { have a large number of dents }>5 \mathrm{~V} \text {. } \\
\text { GL } 95-05 \text { calibration. Expansion criteria } \\
\text { specified in technical specification amendment } \\
\text { related to voltage-based tube repair criteria } \\
\text { (10-11-95). References } 99 \text { and } 154 \text {. }\end{array}$ \\
\hline Sequoyah 2 & $\begin{array}{l}100 \% \text { RPC of dents }>5 V \\
\text { through HL TSP } 3\end{array}$ & $\begin{array}{l}100 \% \text { RPC, or equivalent, of dents }> \\
5 \mathrm{~V} \text { at HL TSPs } 1 \text { and } 2 ; 20 \% \text { of dents } \\
>\text { SV at HL TSP 3. If detect, } 100 \% \\
\text { RPC, or equivalent, of dents }>5 \mathrm{~V} \text { at } \\
\text { affected HL TSP elevation and } 20 \% \text { of } \\
\text { dents }>5 \mathrm{~V} \text { at next higher HL TSP } \\
\text { elevation. }\end{array}$ & $\begin{array}{l}\text { Small number of dents >5V. GL } 95-05 \\
\text { calibration. References } 99 \text { and } 154 \text {. }\end{array}$ \\
\hline
\end{tabular}


Table 7-13 Inspections at sleeve joints in Westinghouse WEXTEX plants

\begin{tabular}{|c|c|c|c|}
\hline Plant & Sleeve Past Inspection & Sleeve Future Inspection & Notes \\
\hline Beaver Valley 1 & N/A & N/A & No sleeves installed. References 91 and 144. \\
\hline Comanche Peak 1 & N/A & N/A & No sleeves installed. References 89 and 145 . \\
\hline Diablo Canyon 1 & $\mathbf{N} / \mathbf{A}$ & N/A & $\begin{array}{l}\text { No sleeves installed. Sleeve like inserts installed } \\
\text { in } 16 \text { tubes. Inserts periodically tested with RPC } \\
\text { probe. References } 87,107 \text {, and } 151 \text {. }\end{array}$ \\
\hline Diablo Canyon 2 & $\mathrm{~N} / \mathrm{A}$ & $\mathbf{N} / \mathbf{A}$ & $\begin{array}{l}\text { No sleeves installed. References } 87,107 \text {, and } \\
151 \text {. }\end{array}$ \\
\hline Farley 1 & None (crosswound) & $100 \% \mathrm{C5}$ & $\begin{array}{l}\text { Only laser welded sleeves installed. 1st } \\
\text { installation in } 1992 \text {. All free span joints have } \\
\text { received a post weld stress relief. References } 35 \\
\text { and } 146 .\end{array}$ \\
\hline Salem 1 & N/A & N/A & No sleeves installed. References 152 and 153 . \\
\hline Salem 2 & N/A & $\mathrm{N} / \mathrm{A}$ & No sleeves installed. References 152 and 153 . \\
\hline Sequoyah 1 & N/A & N/A & No sleeves installed. References 99 and 154. \\
\hline Sequoyah 2 & N/A & N/A & No sleeves installed. References 99 and 154 . \\
\hline
\end{tabular}


Table 7-14 Inspections at the expansion transition region in Westinghouse hydraulic plants (Part 1)

\begin{tabular}{|c|c|c|c|}
\hline Plant & $\begin{array}{l}\text { Expansion Transition } \\
\text { Past Inspection }\end{array}$ & $\begin{array}{l}\text { Expansion Transition Future } \\
\text { Inspection }\end{array}$ & Notes \\
\hline Braidwood 2 & $\begin{array}{l}10 \% \text { RPC in HL in } 2 \text { of } 4 \\
\text { SGs }\end{array}$ & $\begin{array}{l}20 \% \text { in HL with Appendix H circ. } \\
\text { cracking technique in each SG } \\
\text { inspected. If detect, } 100 \% \text { in } \mathrm{HL} \text { in all } \\
\text { SGs. If widespread cracking, sample } \\
\text { CL. }\end{array}$ & $\begin{array}{l}\text { Next inspections primarily with RPC unless } \\
\text { dented. References } 120,141 \text {, and } 143 \text {. }\end{array}$ \\
\hline Byron 2 & $\begin{array}{l}20 \% \mathrm{RPC} \text { in } \mathrm{HL} \text { in } 1 \text { of } 4 \\
\text { SGs }\end{array}$ & $\begin{array}{l}20 \% \text { in HL with Appendix H circ. } \\
\text { cracking technique in each SG } \\
\text { inspected. If detect, } 100 \% \text { in } \mathrm{HL} \text { in all } \\
\text { SGs. If widespread cracking, sample } \\
\text { CL. }\end{array}$ & $\begin{array}{l}\text { Next inspections primarily with RPC unless } \\
\text { dented. References } 120,141 \text {, and } 143 \text {. }\end{array}$ \\
\hline Callaway & $\begin{array}{l}100 \% \text { RPC in HL MA } \\
\text { ubes; } 8.3 \% \text { RPC in HL } \\
\text { TT tubes }\end{array}$ & $\begin{array}{l}100 \% \text { in HL with Appendix } \mathbf{H} \\
\text { technique. }\end{array}$ & $\begin{array}{l}\text { Shotpeened HL in } 1992 \text {. TT tubes in rows } 1 \\
\text { through } 10 \text { (1214 tubes per steam generator). } \\
\text { Remaining tubes are MA. Previous exams } \\
\text { concentrated in sludge zone. References } 110 \text { and } \\
155 \text {. }\end{array}$ \\
\hline Catawba 2 & $100 \% \mathrm{RPC}$ in $\mathrm{HL}$ & $\begin{array}{l}>50 \% \text { RPC in HL. If detect, } 100 \% \\
\text { RPC. }\end{array}$ & References 50, 52, and 123. \\
\hline Commanche Peak 2 & $\begin{array}{l}359 \text { RPC exams in HL in } \\
3 \text { of } 4 \text { SGs }\end{array}$ & $\begin{array}{l}40 \% \text { with Appendix H circ. cracking } \\
\text { technique in each SG inspected. If } \\
\text { detect, } 100 \% \text { in all SGs. }\end{array}$ & References 89 and 145 . \\
\hline Millstone 3 & $\begin{array}{l}500 \text { C5 exams in } 2 \text { of } 4 \\
\text { SGs }\end{array}$ & $\begin{array}{l}500 \text { tubes with Appendix H circ. } \\
\text { cracking technique in } 2 \text { of } 4 \text { SGs. If } \\
\text { detect, } 100 \% \text { in affected SG in critical } \\
\text { area and } 20 \% \text { outside critical area plus } \\
20 \% \text { in critical area in all other SGs. }\end{array}$ & $\begin{array}{l}\text { Will concentrate inspections in sludge pile. } \\
\text { References } 109,131 \text {, and } 132 \text {. }\end{array}$ \\
\hline Point Beach 1 & None & None. & References 137 and 138. \\
\hline Robinson 2 & None & $40 \%$ rotating probe in 1 SG. & References 156,157, and 158 \\
\hline Seabrook 1 & None & $\begin{array}{l}500 \text { tubes with Appendix } \mathrm{H} \text { circ. } \\
\text { cracking technique in } 2 \text { of } 4 \text { SGs. If } \\
\text { detect, } 100 \% \text { in sludge pile and } 20 \% \\
\text { outside sludge pile in all } 4 \text { SGs. }\end{array}$ & $\begin{array}{l}\text { Will concentrate inspections in sludge pile. If } \\
\text { find circs. outside sludge pile, } 100 \% \text { of tubes in } \\
\text { all } 4 \text { SGs will be inspected. References } 89 \text { and } \\
132 \text {. }\end{array}$ \\
\hline South Texas Project 2 & $21 \% \mathrm{RPC}$ in $\mathrm{HL}$ & $\begin{array}{l}100 \% \text { RPC in HL. If detect sufficient } \\
\text { amount of cracking, } 20 \% \mathrm{RPC} \text { in CL. }\end{array}$ & $\begin{array}{l}\text { Shotpeened HL and CL in 1st and 2nd RFO. } \\
\text { References 94, 125, and } 149 .\end{array}$ \\
\hline Surry 1 & $3 \%$ RPC in 1 of 3 SGs & $\begin{array}{l}\text { 3\% of all tubes in } 1 \mathrm{SG} \text { with Appendix } \\
\mathrm{H} \text { technique. If detect, } 6 \% \text { of all tubes } \\
\text { in affected SG. Further sample } \\
\text { expansions based on results. }\end{array}$ & $\begin{array}{l}\text { Some tubes overexpanded above the TTS. } 100 \% \\
\text { RPC exam in } 1990 \text {. Inspections focused in } \\
\text { sludge pile area. References } 100 \text { and } 101 .\end{array}$ \\
\hline Surry 2 & $3 \%$ RPC in 1 of 3 SGs & $\begin{array}{l}3 \% \text { of all tubes in } 1 \text { SG with Appendix } \\
H \text { technique. If detect, } 6 \% \text { of all tubes } \\
\text { in affected SG. Further sample } \\
\text { expansions based on results. }\end{array}$ & $\begin{array}{l}\text { Some tubes overexpanded above the TTS. } \\
\text { Inspections focused in sludge pile area. } \\
\text { References } 100 \text { and } 101 .\end{array}$ \\
\hline
\end{tabular}


Table 7-14 Inspections at the expansion transition region in Westinghouse hydraulic plants (Part 2)

\begin{tabular}{|c|c|c|c|}
\hline Plant & $\begin{array}{l}\text { Expansion Transition } \\
\text { Past Inspection }\end{array}$ & $\begin{array}{l}\text { Expansion Transition Future } \\
\text { Inspection }\end{array}$ & Notes \\
\hline Turkey Point 3 & $\begin{array}{l}100 \% \text { RPC of } \\
\text { overexpanded tubes in } 2 \\
\text { of } 3 \text { SGs }\end{array}$ & $\begin{array}{l}20 \% \text { RPC in HL overexpanded tubes in } \\
1 \text { or more SGs. If detect, } 100 \% \text { RPC } \\
\text { in HL overexpanded tubes in affected } \\
\text { SG, sample in CL, 20\% RPC in HL } \\
\text { expanded tubes in at least one other } \\
\text { SG, and sample of non-overexpanded } \\
\text { tubes. }\end{array}$ & $\begin{array}{l}\text { Several tubes expanded above the tubesheet. } \\
\text { Larger expansions receive priority in determining } \\
\text { which tubes to examine. References } 103,159 \text {, } \\
160,161 \text {, and } 162 \text {. }\end{array}$ \\
\hline Turkey Point 4 & $\begin{array}{l}12 \% \text { RPC of } \\
\text { overexpanded tubes in } 1 \\
\text { of } 3 \text { SGs }\end{array}$ & $\begin{array}{l}20 \% \text { RPC in HL overexpanded tubes in } \\
1 \text { or more SGs. If detect, } 100 \% \text { RPC } \\
\text { in HL overexpanded tubes in affected } \\
\text { SG, sample in CL, } 20 \% \text { RPC in HL } \\
\text { expanded tubes in at least one other } \\
\text { SG, and sample of non-overexpanded } \\
\text { tubes. }\end{array}$ & $\begin{array}{l}\text { Several tubes expanded above the tubesheet. } \\
\text { Larger expansions receive priority in determining } \\
\text { which tubes to examine. Overexpanded tubes in } \\
\text { other SGs were sampled in previous inspections. } \\
\text { References } 103,159,160,161 \text {, and } 162 \text {. }\end{array}$ \\
\hline Vogtle 1 & None & $\begin{array}{l}20 \% \text { RPC in HL in } 2 \text { of } 4 \text { SGs with } \\
\text { Appendix H circ. cracking technique. } \\
\text { If detect outside sludge pile, } 100 \% \text { in } \\
\text { affected SG. If detect inside sludge } \\
\text { pile, inspect sludge pile in other } 2 \text { SGs } \\
\text { and inspect } 3 \text { columns and rows of } \\
\text { tubes outside defined sludge pile in that } \\
\text { SG. Continue until bounded. }\end{array}$ & $\begin{array}{l}20 \% \text { sample includes } 420 \text { tubes ( } 7.5 \% \text { ) in sludge } \\
\text { pile. Sludge pile surrounded by rows } 1 \text { and } 20 \text {, } \\
\text { columns } 50 \text { and } 70 \text {. References } 102 \text { and } 163 \text {. }\end{array}$ \\
\hline Vogtle 2 & None & $\begin{array}{l}\text { Same as for Vogtle Unit I except that } \\
\text { EPRI sample size guidelines may be } \\
\text { used. Expansion criteria is the same as } \\
\text { for Unit } 1 .\end{array}$ & See Vogtle Unit 1. References 102 and 163. \\
\hline Wolf Creek 1 & $\begin{array}{l}11 \% \mathrm{RPC} \text { in } \mathrm{HL} \text { in } 1 \text { of } 4 \\
\text { SGs }\end{array}$ & $\begin{array}{l}10 \% \text { in HI in } 2 \text { of } 4 \text { SGs with } \\
\text { Appendix } H \text { technique. If detect, } \\
100 \% \text { in all } 4 \text { SGs. }\end{array}$ & $\begin{array}{l}\text { Focus exams in sludge pile. References } 164 \text { and } \\
165 .\end{array}$ \\
\hline
\end{tabular}


Table 7-15 Inspections in the U-bend region of small-radii tubes in Westinghouse Hydraulic plants (Part 1)

\begin{tabular}{|c|c|c|c|}
\hline Plant & U-bend Past Inspection & U-bend Future Inspection & Notes \\
\hline Braidwood 2 & None & $\begin{array}{l}20 \% \text { in R1 and R2 with Appendix H } \\
\text { circ. cracking technique in each SG } \\
\text { inspected. If detect, } 100 \% \text { in all SGs. }\end{array}$ & $\begin{array}{l}\text { Rows } 1 \text { through } 7 \text { received an additional heat } \\
\text { treatment after bending. Next inspection } \\
\text { primarily with RPC. References } 120,141 \text {, and } \\
143 \text {. }\end{array}$ \\
\hline Byron 2 & None & $\begin{array}{l}20 \% \text { in R1 and } \mathrm{R} 2 \text { with Appendix H } \\
\text { circ. cracking technique in each SG } \\
\text { inspected. If detect, } 100 \% \text { in all SGs. }\end{array}$ & $\begin{array}{l}\text { Rows } 1 \text { through } 7 \text { received an additional heat } \\
\text { treatment after bending. Next inspection } \\
\text { primarily with RPC. References } 120,141 \text {, and } \\
143 \text {. }\end{array}$ \\
\hline Callaway & None & $\begin{array}{l}100 \% \text { in R1 with Appendix H } \\
\text { technique in SG C. }\end{array}$ & $\begin{array}{l}\text { Tubes in rows } 1 \text { through } 10 \text { were thermally } \\
\text { treated after bending. Found } 1 \text { undefined } \\
\text { indication in a } R 2 \text { ube in } 1992 \text { which was } \\
\text { considered by the licensee to be an anomaly. } \\
\text { References } 110 \text { and } 155 \text {. }\end{array}$ \\
\hline Catawba 2 & Not Addressed & $\begin{array}{l}20 \% \mathrm{RPC} \text { in } \mathrm{R} 1 \text { and } \mathrm{R} 2 \text {. If detect, } \\
100 \% \mathrm{RPC} \text { in } \mathrm{R} 1 \text { and } \mathrm{R} 2 \text {. }\end{array}$ & References 50,52 , and 123. \\
\hline Commanche Peak 2 & None & $\begin{array}{l}40 \% \text { in } \mathrm{R} 1 \text { and } \mathrm{R} 2 \text { with Appendix } \mathrm{H} \\
\text { technique in each SG selected. If } \\
\text { detect, } 100 \% \text { in all SGs. }\end{array}$ & $\begin{array}{l}\text { Rows } 1 \text { through } 9 \text { were heat treated prior to SG } \\
\text { assembly. References } 89 \text { and } 145 \text {. }\end{array}$ \\
\hline Millstone 3 & None & $\begin{array}{l}20 \% \text { in R1 with Appendix } H \text { circ. } \\
\text { cracking technique in } 2 \text { of } 4 \text { SGs. If } \\
\text { detect, } 100 \% \text { in } R 1 \text { and } R 2 \text { in all SGs. }\end{array}$ & $\begin{array}{l}\text { Rows } 1 \text { through } 10 \text { were stress relieved. } \\
\text { References } 109,131 \text {, and } 132 \text {. }\end{array}$ \\
\hline \begin{tabular}{|l|} 
Point Beach 1 \\
\end{tabular} & None & None. & References 137 and 138 . \\
\hline Robinson 2 & None & $\begin{array}{l}20 \% \text { rotating probe in } \mathrm{R} 1 \text { and } \mathrm{R} 2 \text { in } 1 \\
\text { SG. }\end{array}$ & References 156,157 , and 158 . \\
\hline Seabrook 1 & None & $\begin{array}{l}20 \% \text { in } R 1 \text { with Appendix } H \text { circ. } \\
\text { cracking technique in } 2 \text { of } 4 \text { SGs. If } \\
\text { detect, } 100 \% \text { in } R 1 \text { and } R 2 \text { in all SGs. }\end{array}$ & $\begin{array}{l}\text { Rows } 1 \text { through } 10 \text { were stress relieved. } \\
\text { References } 89 \text { and } 132 \text {. }\end{array}$ \\
\hline South Texas Project 2 & Some RPC sampling & Some RPC sampling. & $\begin{array}{l}\text { Larger bend radii than other Westinghouse SGs. } \\
\text { UBHT in R1 and R2. Not susceptible to circ. } \\
\text { cracking in this region. Monitoring of this region } \\
\text { done for conservatism. References } 94,125 \text {, and } \\
149 .\end{array}$ \\
\hline Surry 1 & None & None. & $\begin{array}{l}\text { Rows } 1 \text { through } 8 \text { were stress relieved after } \\
\text { bending. References } 100 \text { and } 101 \text {. }\end{array}$ \\
\hline Surry 2 & None & None. & $\begin{array}{l}\text { Rows } 1 \text { through } 8 \text { were stress relieved after } \\
\text { bending. References } 100 \text { and } 101 \text {. }\end{array}$ \\
\hline
\end{tabular}


Table 7-15 Inspections in the U-bend region of small-radii tubes in Westinghouse Hydraulic plants (Part 2)

\begin{tabular}{|c|c|c|c|}
\hline Plant & U-bend Past Inspection & U-bend Future Inspection & Notes \\
\hline Turkey Point 3 & None & None. & References $103,159,160,161$, and 162 . \\
\hline Turkey Point 4 & None & None. & References $103,159,160,161$, and 162 . \\
\hline Vogtle 1 & None & None. & $\begin{array}{l}\text { Thermally treated tubes. References } 102 \text { and } \\
163 \text {. }\end{array}$ \\
\hline Vogtle 2 & None & None. & $\begin{array}{l}\text { Thermally treated tubes. References } 102 \text { and } \\
163 \text {. }\end{array}$ \\
\hline Wolf Creek 1 & None & $\begin{array}{l}20 \% \text { in } \mathrm{R1} \text { with Appendix } \mathrm{H} \text { technique } \\
\text { in } 2 \text { of } 4 \text { SGs. If detect, } 100 \% \text { of R1 } \\
\text { and } \mathrm{R} 2 \text { in these } 2 \text { SGs. If detect in } \\
\text { expansion, expand to higher rows in } \\
\text { original } 2 \text { SGs and inspect in R1 and } \\
\mathrm{R} 2 \text { in other } 2 \text { SGs. Continue until } \\
\text { bounded. }\end{array}$ & $\begin{array}{l}\text { R1 U-bend radius slightly larger than older model } \\
\text { Westinghouse SGs. References } 164 \text { and } 165 \text {. }\end{array}$ \\
\hline
\end{tabular}


Table 7-16 Inspections at dented locations in Westinghouse Hydraulic plants (Part 1)

\begin{tabular}{|c|c|c|c|}
\hline Plant & $\begin{array}{l}\text { Dented TSP Past } \\
\text { Inspection }\end{array}$ & Dented TSP Future Inspection & Notes \\
\hline Braidwood 2 & None & $\begin{array}{l}20 \% \text { of dents }>5 \mathrm{~V} \text { at HL TSPs with } \\
\text { Appendix } \mathrm{H} \text { circ. cracking technique in } \\
\text { each SG inspected. If detect, } 100 \% \text { of } \\
\text { dents }>5 \mathrm{~V} \text { at } \mathrm{HL} \text { and } C L \text { TSPs in all } \\
\text { SGs. }\end{array}$ & $\begin{array}{l}\text { GL } 95-05 \text { calibration. References } 120,141 \text {, and } \\
\text { 143. }\end{array}$ \\
\hline Byron 2 & None & $\begin{array}{l}20 \% \text { of dents }>5 \mathrm{~V} \text { at HL TSPs with } \\
\text { Appendix } \mathrm{H} \text { circ. cracking technique in } \\
\text { each SG inspected. If detect, } 100 \% \text { of } \\
\text { dents }>5 \mathrm{~V} \text { at HL and CL TSPs in all } \\
\text { SGs. }\end{array}$ & $\begin{array}{l}\text { GL } 95-05 \text { calibration. References } 120,141 \text {, and } \\
\text { 143. }\end{array}$ \\
\hline Callaway & None & None. & $\begin{array}{l}\text { No service induced denting. References } 110 \text { and } \\
\text { 155. }\end{array}$ \\
\hline Catawba 2 & N/A & N/A & No denting. References 50,52 , and 123 . \\
\hline Commanche Peak 2 & None & $\begin{array}{l}100 \% \text { of dents }>5 V \text { at lowest HL TSP } \\
\text { with Appendix } \mathrm{H} \text { technique. If detect, } \\
100 \% \text { of dents }>5 \mathrm{~V} \text { in all SGs. }\end{array}$ & $\begin{array}{l}\text { Calibration: } 4-20 \% \text { holes set to } 2.75 \mathrm{~V} \text { on } \\
550 / 130 \text { mix. References } 89 \text { and } 145 \text {. }\end{array}$ \\
\hline Milistone 3 & $\begin{array}{l}100 \text { exams with Appendix } \\
\mathrm{H} \text { technique during } \\
\text { previous } 2 \text { outages }\end{array}$ & None. & $\begin{array}{l}\text { Calibration: } 4-20 \% \text { holes set to } 4 \mathrm{~V} \text { on } 630 / 150 \\
\text { kHz differential mix. Dents (TSPs, sludge pile) } \\
\text { reported from } 630 / 150 \mathrm{kHz} \text { mix if voltage }>5 \mathrm{~V} \text {. } \\
\text { Dings (freespan) reported from } 630 \mathrm{kHz} \\
\text { differential channel with no voltage threshold. } \\
\text { No corrosion induced denting has been observed. } \\
\text { References } 109,131 \text {, and } 132 \text {. }\end{array}$ \\
\hline Point Beach 1 & None & None. & References 137 and 138. \\
\hline Robinson 2 & None & $\begin{array}{l}100 \% \text { rotating probe of } \mathrm{HL} \text { dents }> \\
2 \mathrm{~V} \text {. 100\% rotating probe of dents }> \\
2 \mathrm{~V} \text { at a HL structure or }>10 \mathrm{~V} \text { in } \\
\text { freespan in I SG. }\end{array}$ & $\begin{array}{l}\text { Calibration: } 4-20 \% \text { holes set to } 5 \mathrm{~V} \text { on } 400 \mathrm{kHz} \\
\text { channel and saved to other channels. Not } \\
\text { experiencing an active denting mechanism. Dents } \\
\text { in freespan (not at a structure or at TTS) recorded } \\
\text { at } 10 \mathrm{~V} \text { from } 400 \mathrm{kHz} \text { channel. Dents at } \\
\text { structures recorded at } 2 \mathrm{~V} \text { from } 400 / 100 \mathrm{kHz} \text { mix } \\
\text { channel. References } 156,157 \text {, and } 158 \text {. }\end{array}$ \\
\hline Seabrook 1 & $\begin{array}{l}12 \text { rotating probe exams } \\
\text { during previous } 2 \text { outages }\end{array}$ & None. & $\begin{array}{l}\text { Calibration: 4-20\% holes set to } 4 \mathrm{~V} \text { on } 630 \mathrm{kHz} \\
\text { differential channel. Record dents at } 5 \mathrm{~V} \text { from } \\
630 / 150 \mathrm{kHz} \text { differential mix. Dents in freespan } \\
\text { are called dings. Dings are recorded from } 630 \\
\mathrm{kHz} \text { with no voltage threshold. References } 89 \\
\text { and } 132 \text {. }\end{array}$ \\
\hline South Texas Project 2 & None & None. & $\begin{array}{l}\text { Less than } 50 \text { dents. Most dents are traceable } \\
\text { back to manufacturing artifacts. Stainless steel } \\
\text { TSPs make unit resistant to denting and, } \\
\text { therefore, not susceptible to circ. cracking in the } \\
\text { TSP area. References } 94,125 \text {, and } 149 \text {. }\end{array}$ \\
\hline Surry 1 & None & None. & $\begin{array}{l}\text { Denting not expected due to stainless steel TSPs. } \\
\text { References } 100 \text { and } 101 .\end{array}$ \\
\hline Surry 2 & None & None. & $\begin{array}{l}\text { Denting not expected due to stainless steel TSPs. } \\
\text { References } 100 \text { and } 101 .\end{array}$ \\
\hline
\end{tabular}


Table 7-16 Inspections at dented locations in Westinghouse Hydraulic plants (Part 2)

\begin{tabular}{|c|c|c|c|}
\hline Plant & $\begin{array}{l}\text { Dented TSP Past } \\
\text { Inspection }\end{array}$ & Dented TSP Future Inspection & Notes \\
\hline Turkey Point 3 & $2 \%$ RPC in 1 of 3 SGs & $\begin{array}{l}20 \% \text { RPC of HL dents in } 1 \text { or more } \\
\text { SGs. If detect, } 100 \% \text { RPC of HL dents } \\
\text { in affected SG, sample in CL, } 20 \% \\
\text { RPC of HL dents in at least one other } \\
\text { SG, and sample of non-dented tubes. }\end{array}$ & $\begin{array}{l}\text { Calibration: } 4-20 \% \text { holes set to } 5 \mathrm{~V} \text { on } 400 / 100 \\
\mathrm{kHz} \text { mix. Denting is from manufacturing } \\
\text { process. Criteria for calling a dent not specified. } \\
\text { Larger dents receive priority in determining } \\
\text { which dents to examine. References } 103,159 \text {, } \\
160,161 \text {, and } 162 \text {. }\end{array}$ \\
\hline Turkey Point 4 & $54 \% \mathrm{RPC}$ in 1 of $3 \mathrm{SGs}$ & $\begin{array}{l}20 \% \text { RPC of HL dents in } 1 \text { or more } \\
\text { SGs. If detect, } 100 \% \text { RPC of HL dents } \\
\text { in affected SG, sample in CL, } 20 \% \\
\text { RPC of HL dents in at least one other } \\
\text { SG, and sample of non-dented tubes. }\end{array}$ & $\begin{array}{l}\text { Calibration: } 4-20 \% \text { holes set to } 5 \mathrm{~V} \text { on } 400 / 100 \\
\mathrm{kHz} \text { mix. Denting is from manufacturing } \\
\text { process. Criteria for calling a dent not specified. } \\
\text { Larger dents receive priority in determining } \\
\text { which dents to examine. References } 103,159, \\
160,161 \text {, and } 162 \text {. }\end{array}$ \\
\hline Vogtle 1 & N/A & N/A & No denting. References 102 and 163 . \\
\hline Vogtle 2 & N/A & N/A & No denting. References 102 and 163 . \\
\hline Wolf Creek 1 & N/A & N/A & No denting. References 164 and 165 . \\
\hline
\end{tabular}


Table 7-17 Inspections at sleeve joints in Westinghouse hydraulic plants (Part 1)

\begin{tabular}{|c|c|c|c|}
\hline Plant & Sleeve Past Inspection & Sleeve Future Inspection & Notes \\
\hline Braidwood 2 & N/A & N/A & $\begin{array}{l}\text { No sleeves installed. References } 120,141 \text {, and } \\
143 \text {. }\end{array}$ \\
\hline Byron 2 & N/A & N/A & $\begin{array}{l}\text { No sleeves installed. References } 120,141 \text {, and } \\
143 \text {. }\end{array}$ \\
\hline Callaway & N/A & N/A & No sleeves installed. References 110 and 155 . \\
\hline Catawba 2 & N/A & N/A & $\begin{array}{l}\text { No sleeves in service. References } 50,52 \text {, and } \\
123 \text {. }\end{array}$ \\
\hline Commanche Peak 2 & N/A & N/A & No sleeves installed. References 89 and 145 . \\
\hline Millstone 3 & N/A & N/A & $\begin{array}{l}\text { No sleeves installed. References } 109,131 \text {, and } \\
132 \text {. }\end{array}$ \\
\hline Point Beach 1 & N/A & N/A & No sleeves installed. References 137 and 138 . \\
\hline Robinson 2 & $\mathbf{N} / \mathbf{A}$ & N/A & $\begin{array}{l}\text { No sleeves installed. References } 156,157 \text {, and } \\
158 \text {. }\end{array}$ \\
\hline Seabrook 1 & N/A & N/A & No sleeves installed. References 89 and 132 . \\
\hline South Texas Project 2 & N/A & N/A & $\begin{array}{l}\text { No sleeves installed. References } 94,125 \text {, and } \\
149 .\end{array}$ \\
\hline Surry 1 & N/A & N/A & No sleeves installed. References 100 and 101. \\
\hline Surry 2 & N/A & N/A & No sleeves installed. References 100 and 101 . \\
\hline
\end{tabular}


Table 7-17 Inspections at sleeve joints in Westinghouse hydraulic plants (Part 2)

\begin{tabular}{|c|c|c|c|}
\hline Plant & Sleeve Past Inspection & Sleeve Future Inspection & Notes \\
\hline Turkey Point 3 & N/A & N/A & $\begin{array}{l}\text { No sleeves installed. References 103, 159, 160, } \\
161 \text {, and } 162 \text {. }\end{array}$ \\
\hline \begin{tabular}{|l|} 
Turkey Point 4 \\
\end{tabular} & $\mathbf{N} / \mathrm{A}$ & N/A & $\begin{array}{l}\text { No sleeves installed. References } 103,159,160 \text {, } \\
161 \text {, and } 162 \text {. }\end{array}$ \\
\hline Vogtle 1 & $\mathbf{N} / \mathbf{A}$ & N/A & No sleeves installed. References 102 and 163 . \\
\hline Vogtle 2 & $\mathbf{N} / \mathbf{A}$ & $\mathbf{N} / \mathbf{A}$ & No sleeves installed. References 102 and 163 \\
\hline Wolf Creek 1 & $\mathbf{N} / \mathbf{A}$ & $\mathrm{N} / \mathrm{A}$ & No sleeves installed. References 164 and 165 . \\
\hline
\end{tabular}




\section{STEAM GENERATORS WITH ALLOY 690 TUBES}

\subsection{Design and Locations Susceptible to Circumferential Cracking}

Because of steam generator tube degradation, a number of plants have replaced their original steam generators (refer to Appendix B). For the vast majority of these replacement steam generators, changes in the design and materials of construction were made to reduce the susceptibility of the steam generator tubes to degradation. As of June 1995, 13 plants had replaced their steam generators. Between June 1995 and December 1996, an additional 3 plants had replaced their steam generators. A fourth plant, Salem 1 , began replacing their steam generators in December 1996. The steam generators that have been replaced are presented in Table B-6.

Steam generators have been replaced at Westinghouse and CE units. No B\&W steam generators have been replaced to date. The tube material in use in the steam generators at the 16 units which have replaced their steam generators include mill-annealed alloy 600 tubes ( 1 plant), thermally treated alloy 600 tubes (6 plants), and thermally treated alloy 690 ( 9 plants). Steam generators currently (1990s) being put into service in the United States generally have alloy 690 thermally treated tubes. For the 6 units with steam generators with alloy 690 tubes at the time GL 95-03 was issued, one unit (Indian Point 3) installed Westinghouse model $44 \mathrm{~F}$ steam generators, three units (D.C. Cook 2, North Anna 1 and 2) installed Westinghouse model 54F steam generators, one unit (Millstone 2) installed steam generators manufactured by Babcock and Wilcox, Canada (BWC), and one unit (Summer) installed Westinghouse model Delta 75 steam generators.

The design of the replacement steam generators with alloy 690 tubes can vary from plant-to-plant. However, there are some similarities particularly with respect to susceptibility, or lack of susceptibility, to degradation. In general, the materials and design of these steam generators are intended to reduce the potential for tube degradation. Since circumferential cracking has occurred in alloy 600 mill-annealed tubes at the expansion transition, in the U-bend region of small-radius tubes (i.e., rows 1 and 2), at dented locations, and in sleeve joints, design and operational features of the steam generators which limit the susceptibility of the alloy 690 tubes to degradation at these locations are described below.

The alloy 690 material used in these replacement steam generators is intended to be less susceptible to degradation than alloy 600 material. In addition, the thermal treatment of the alloy 690 tubes is intended to further reduce the potential for tube cracking compared to mill-annealed tubes. To date, thermally treated alloy 690 tubes in operating steam generators have not experienced cracking although the operating experience has been limited (Ref. 109). In summary, thermally treated alloy 690 is intended to provide a substantial increase in the resistance to corrosion compared to mill-annealed tubing and compared to alloy 600 thermally treated tubing (Ref. 100).

The susceptibility of the expansion transition region to cracking is expected to be lower in steam generators with alloy 690 tubes. This is a result of the hydraulic process used in these steam generators to expand the tubes within the tubesheet. This hydraulic process is expected to result in residual stresses at the expansion transition which are lower than for tubes expanded within the tubesheet with other techniques (e.g., hardrolling, explosive) (Ref. 100). The licensee for D.C. Cook 2 concluded that the inherent corrosion resistance of the steam generator tubes (i.e., alloy 690 thermally treated tubes) coupled with the low design stress levels in the full-depth hydraulically expanded tube-to-tubesheet joint effectively preclude concerns about circumferential cracking in the tubesheet region (Ref. 88).

The design of the tube support structures in the replacement steam generators with alloy 690 tubes is intended to limit the potential for tube denting since degradation has been associated with dented locations. Specifically, the replacement steam generators in use at the plants with alloy 690 tubes have tube supports made from stainless steel rather than from carbon steel. As discussed in Section 7.2.3, carbon steel tube supports can lead to corrosion-induced tube denting. The stainless steel tube supports are not expected to corrode and form nonprotective magnetite as does carbon steel (Ref. 109). Furthermore, the design of the tube supports has been modified to reduce the area of tube to 
support contact which permits greater secondary water flow past the tube-to-tube support gap. This greater secondary water flow can limit the buildup of corrosive deposits which may lead to tube degradation. The design of these tube supports varies from plant-to-plant. The designs include a lattice grid system at Millstone 2 (Ref. 109) and quatrefoil broached holes at D.C. Cook 2 (Ref. 88) and North Anna 1 and 2 (Ref. 100) and trefoil holes at Summer (Ref. 166).

No appreciable corrosion-induced denting has been observed at any of the units with alloy 690 steam generator tubes. However minor geometry variations (i.e., dents) have been observed at a few plants. These variations were introduced before the steam generators were put into operation. Geometry variations placed in the tubes during the steam generator manufacturing process could result in areas of higher stress which could potentially increase the susceptibility of the tube to degradation (Ref. 109). At North Anna 1, some dents have been noticed in the steam generator tubes in the tube free span (Ref. 100).

The design of the replacement steam generators with alloy 690 tubes is also intended to reduce the likelihood of cracking in the U-bend region of small-radius tubes (i.e., rows 1 and 2 ). The measures taken at a specific plant to reduce the likelihood of U-bend cracking vary. For example, at Millstone 2, the inner row U-bends were designed such that the tubes in rows 1 through 4 have essentially the same bend radius. The licensee for this plant expects the stresses in these tubes to be substantially lower than those present in the inner row tubes of other steam generator designs (Ref. 132). At D.C. Cook 2 the potential for U-bend cracking was addressed in the design of the steam generators by increasing the minimum bend radius and heat treating the U-bends after bending (Ref. 88). At North Anna 1 and 2, the tubes in rows 1 through 8 received a supplemental thermal treatment (stress relieving) after bending (Ref. 109). This thermal treatment is intended to reduce the residual stresses in the U-bend region. In addition, as discussed in Section 7.2.2, a set of U-bend manufacturing geometric controls were implemented to reduce the likelihood of cracking in the U-bend region for the North Anna 1 and 2 steam generators.

\subsection{Justification for Continued Operation}

The staff evaluated the GL 95-03 responses submitted by plant owners with alloy 690 steam generator tubes to confirm that the plants could safely operate until the next scheduled steam generator tube inspection outage. The staff concluded that all of these units could operate until their next scheduled steam generator tube inspection. The staff based this conclusion on the following factors:

(1) the scope and results of the prior inspection including the experience at other similarly designed units

(2) the alloy 690 thermally treated tube material, which has shown excellent resistance to primary side cracking on the basis of laboratory testing

(3) the design enhancements cited in Section 8.1

(4) the short amount of time that these steam generators have been in service

\subsection{Tube Inspections}

GL 95-03 requested, in part, a safety assessment justifying continued operation on the basis of past inspection results and a summary of inspection plans for the next scheduled steam generator tube inspection outage as they pertain to the detection of circumferential cracking. The inspection plans were to consist of both an initial scope and sample expansion criteria. For the units with alloy 690 steam generator tubes, the staff summarized some of the information provided by the licensees with respect to the previous and next inspection for each of the areas historically identified in alloy 600 mill-annealed tubes as being susceptible to circumferential cracking. The designation of "previous" refers to inspections performed before issuing or responding to GL 95-03. The designation of "next" (and/or "future") refers to an inspection performed after issuing or responding to GL 95-03. The phrase, "if detect", is used to describe the inspection expansion criteria when a circumferential indication is detected. In many instances, the next (and/or future) inspections have already been completed as a result of the time taken to prepare this document for publishing. 
Tables 8-1 through 8-3 provide the scope of the past and future inspections at the expansion transition, in the U-bend of small-radius tubes, and dented locations, respectively for plants with alloy 690 steam generator tubes. No sleeves have been installed in any of these units. Tube inspections performed using a technique not capable of reliably detecting circumferentially oriented degradation were recorded as "None" in Tables 8-1 through 8-3. The past inspection scope and future inspection plans provided by the licensees were considered in evaluating the acceptability of a licensee's response. Acronyms and abbreviations used in the tables are explained in Appendix C.

The staff has reviewed the submissions provided by the licensees with alloy 690 steam generator tubes and has concluded that they contain the information requested in GL 95-03. General conclusions regarding the responses are discussed in Section 9. 
Table 8-1 Inspections at the expansion transition region in plants with alloy 690 steam generator tubes

\begin{tabular}{|c|c|c|c|}
\hline Plant & $\begin{array}{l}\text { Expansion Transition } \\
\text { Past Inspection }\end{array}$ & $\begin{array}{l}\text { Expansion Transition Future } \\
\text { Inspection }\end{array}$ & Notes \\
\hline D.C. Cook 2 & None & $\begin{array}{l}20 \% \mathrm{C5} \text { in HL in } 1 \mathrm{SG} \text {. If detect, } \\
100 \% \mathrm{C5} \text { in affected SG and } 20 \% \text { in } \\
\text { remaining SGs. If detect in expanded } \\
20 \% \text { sample, } 100 \% \text { in all SGs. }\end{array}$ & References 88,126 , and 127 . \\
\hline Indian Point 3 & None & $\begin{array}{l}\text { Initial scope and expansion criteria per } \\
\text { Technical Specifications with an } \\
\text { Appendix H circ. cracking technique. }\end{array}$ & References 167 and 168 . \\
\hline Millstone 2 & None & None & $\begin{array}{l}0.007 \text { inch diametric expansion. References } 109 \text {, } \\
131 \text {, and } 132 \text {. }\end{array}$ \\
\hline North Anna 1 & None & $\begin{array}{l}3 \% \text { of all tubes in } 1 \text { of } 3 \text { SGs with } \\
\text { Appendix } \mathrm{H} \text { circ. cracking technique. } \\
\text { If detect, } 6 \% \text { of all tubes in affected } \\
\text { SG. Further expansions based on } \\
\text { results. }\end{array}$ & References 100 and 101. \\
\hline North Anna 2 & None & $\begin{array}{l}3 \% \text { of all tubes in } 1 \text { of } 3 \text { SGs with } \\
\text { Appendix } \mathrm{H} \text { circ. cracking technique. } \\
\text { If detect, } 6 \% \text { of all tubes in affected } \\
\text { SG. Further expansions based on } \\
\text { results. }\end{array}$ & $\begin{array}{l}\text { Past inspection was the preservice inspection. } \\
\text { References } 100 \text { and } 101 \text {. }\end{array}$ \\
\hline Summer & $100 \% \mathrm{RPC}$ in $\mathrm{HL}$ and $\mathrm{CL}$ & 100 RPC exams. & $\begin{array}{l}\text { Past inspection was the preservice inspection. } \\
\text { References } 166,169 \text {, and } 170 \text {. }\end{array}$ \\
\hline
\end{tabular}


Table 8-2 Inspections in the U-bend region of small-radii tubes in plants with alloy 690 steam generator tubes

\begin{tabular}{|c|c|c|c|}
\hline Plant & U-bend Past Inspection & U-bend Future Inspection & Notes \\
\hline D.C. Cook 2 & None & None & $\begin{array}{l}\text { Increased R1 radius and heat treated low row } \\
\text { U-bends after bending. References } 88,126 \text {, and } \\
127 \text {. }\end{array}$ \\
\hline Indian Point 3 & None & $\begin{array}{l}\text { Initial scope and expansion criteria per } \\
\text { Technical Specifications with an } \\
\text { Appendix H circ. cracking technique. }\end{array}$ & References 167 and 168 . \\
\hline Millstone 2 & None & None & $\begin{array}{l}\text { Tubes in R1 through R4 have a radius of } 3.9 \\
\text { inches which should reduce susceptibility to } \\
\text { cracking. References } 109,131 \text {, and } 132 \text {. }\end{array}$ \\
\hline North Anna 1 & None & None & $\begin{array}{l}\text { Rows } 1 \text { through } 8 \text { were stress relieved after } \\
\text { bending. References } 100 \text { and } 101 \text {. }\end{array}$ \\
\hline North Anna 2 & None & None & $\begin{array}{l}\text { Rows } 1 \text { through } 8 \text { were stress relieved after } \\
\text { bending. References } 100 \text { and } 101 \text {. }\end{array}$ \\
\hline Summer & None & 100 RPC exams. & $\begin{array}{l}\text { Past inspection was the preservice inspection. } \\
\text { Small radii U-bend tubes were stress relieved } \\
\text { during manufacture. References } 166,169 \text {, and } \\
170 .\end{array}$ \\
\hline
\end{tabular}


Table 8-3 Inspections at dented locations in plants with alloy 690 steam generator tubes

\begin{tabular}{|c|c|c|c|}
\hline Plant & $\begin{array}{l}\text { Dented TSP Past } \\
\text { Inspection }\end{array}$ & Dented TSP Future Inspection & Notes \\
\hline D.C. Cook 2 & None & None & References 88,126 , and 127 . \\
\hline Indian Point 3 & None & $\begin{array}{l}\text { Initial scope and expansion criteria per } \\
\text { Technical Specifications with an } \\
\text { Appendix H circ. cracking technique. }\end{array}$ & $\begin{array}{l}\text { No voltage threshold will be used to determine } \\
\text { dents of concern for sample size considerations. } \\
\text { References } 167 \text { and } 168 \text {. }\end{array}$ \\
\hline Millstone 2 & None & None & $\begin{array}{l}\text { Calibration: } 4-100 \% \text { holes set to } 6 \mathrm{~V} \text { on } 550 \mathrm{kHz} \\
\text { differential. Dents (TSPs, sludge pile) reported } \\
\text { from 550/130 mix if voltage }>5 \mathrm{~V} \text {. Dents in } \\
\text { freespan are called dings. No corrosion induced } \\
\text { denting has been observed. References } 109, \\
131 \text {, and } 132 \text {. }\end{array}$ \\
\hline North Anna 1 & None & None & References 100 and 101. \\
\hline North Anna 2 & None & None & References 100 and 101. \\
\hline Summer & N/A & N/A & $\begin{array}{l}\text { No denting; however, } 100 \text { RPC exams will be } \\
\text { performed at TSP intersections. References } 166 \text {, } \\
169 \text {, and } 170 \text {. }\end{array}$ \\
\hline
\end{tabular}




\section{CONCLUSIONS}

Mill-annealed alloy 600 steam generator tubes are susceptible to circumferential cracking. For B\&W plants (all of which have alloy 600 mill-annealed tubes), circumferential indications have been observed in the tubesheet area (associated with intergranular attack), in the lane/wedge region, and at dented locations. Although service-induced circumferential indications have not been observed at the expansion transition in B\&W plants, the expansion transition is considered to be potentially susceptible to this form of degradation since axially oriented $\mathrm{SCC}$ has been observed at this location. For CE plants with alloy 600 mill-annealed tubes, circumferential indications have been detected on both the hot- and cold-leg sides of the steam generator at the expansion transition, at dented locations, and at non-dented drilled hole tube support plate locations (primarily in the chord region). In addition, circumferential indications were observed in the pre-replacement Millstone 2 and Palisades steam generators at various locations in the upper portion of the tube bundle on both the hot- and cold-leg sides of the steam generator. Denting and tube bowing are believed to have contributed to these indications. The circumferential cracking operating experience for Westinghouse plants with alloy 600 mill-annealed tubes is summarized in Section 7.2.6. The results from the $B \& W, C E$, and Westinghouse plants indicate that alloy 600 mill-annealed tubes are potentially susceptible to circumferential cracking at a variety of locations on both the hot- and cold-leg sides of the steam generator.

The operating experience for steam generators with thermally treated tubes has been relatively good when compared to steam generators with mill-annealed tubes. However, the length of service for some of the steam generators with thermally treated tubes is limited when compared to the steam generators with alloy 600 mill-annealed tubes. No circumferential indications have been observed in thermally treated alloy 690 tubes, although a few circumferential indications have recently been identified in the alloy 600 thermally treated tubes at Callaway. These indications were located at the expansion transition. No tube pulls were performed to confirm the nature of these indications. In addition to these circumferential indications, axial indications have been observed in the U-bend region and at the expansion transition region of a limited number of thermally treated alloy 600 tubes. The nature of these axial indications is uncertain since these tubes were not removed for destructive examination. These results, however, indicate that thermally treated alloy 600 tubes are potentially susceptible to cracking.

In addition to the locations mentioned above, circumferential indications associated with sleeve joints have occurred in a number of sleeve designs. Service-induced circumferential indications have been observed in the joints of B\&W kinetically welded sleeves and Westinghouse HEJ sleeves. Non-service induced circumferential indications have been detected in CE TIG-welded sleeve joints. In addition, circumferential indications have been observed in B\&W mechanical sleeve joints although no tube pulls have been performed to confirm the nature of these indications.

On the basis of the staff's review of the GL 95-03 responses and from discussions with various PWR licensees during public meetings, inspections, and telephone conversations in which steam generator inspection scope and results were discussed, the NRC identified potential weaknesses in a few steam generator tube integrity programs. The staff considered these weaknesses along with other factors (e.g., other elements of a licensee's tube integrity program, pertinent operating experience, etc.) in determining the acceptability of a licensee's response to GL 95-03. Although weaknesses were identified in several licensee's responses to GL 95-03, the staff believes these weaknesses have been and will continue to be addressed in the short-term through ongoing regulatory oversight performed in headquarters and in the regions. In the long-term, revisions of the regulatory framework, which are currently being developed, will provide more direct oversight of licensee programs to ensure that steam generator tube integrity is maintained. 


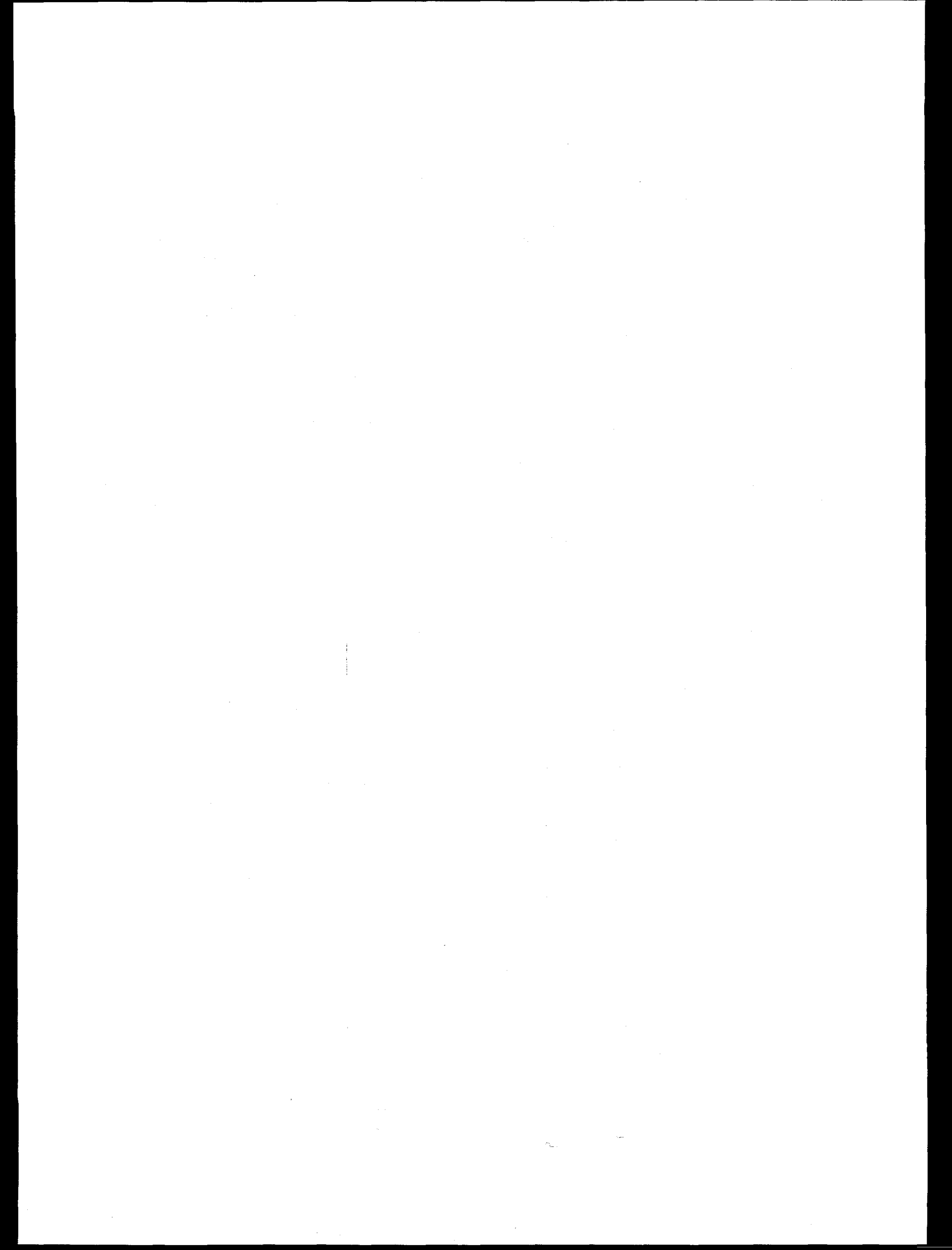




\section{APPENDIX A: STEAM GENERATOR TUBE SLEEVES}

The installation of steam generator tube plugs removes the heat transfer surface of the plugged tube from service and leads to a reduction in the primary coolant flow available for core cooling. To prolong the life of severely degraded steam generator tubes, some utilities, with prior NRC approval, have repaired defective tubes by sleeving since steam generator tube sleeves do not greatly affect the heat transfer capability of the tube being sleeved and after sleeving, the repaired tube may remain in service. A large number of sleeves can be installed without significantly affecting primary flow rate.

The tube sleeving procedure involves inserting a tube of smaller diameter and length (a sleeve) inside the tube to be repaired. The sleeve is positioned to span the degraded portion of the original tube (i.e., the parent tube) and the ends of the sleeve are secured to the parent tube forming a new pressure boundary and structural element between the attachment points. As a result, there are at least two joints in a sleeve: one at the top of the sleeve and the other at the bottom of the sleeve. Sleeves vary in length and are typically attached to the parent tube by a mechanical seal (e.g., hydraulic expansion, roll expansion, and/or explosive expansion) or weld (Ref. 171). After installation of the sleeve, stress relief of the joints can be performed to relieve residual stresses. In general, most sleeves installed recently have been stress relieved. A variety of sleeve designs exist, and the names for the various types of sleeves typically reflect the method by which one or more of the sleeve ends is secured to the parent tube.

Sleeving repairs to restore primary coolant boundary integrity have been performed at several plants. These repairs are typically performed on the straight portion of tubing degraded by such mechanisms as wastage, intergranular attack, and SCC. Severely dented locations have generally not been sleeved. Tubesheet, expansion transition zone, and tube support plate sleeve designs exist. Currently, most sleeves are hydraulically expanded into the tube and then welded (laser or TIG-welded) to ensure structural and leakage integrity. Sleeves made from alloys 600 and 690 have been used throughout the industry. Currently, the material of choice for sleeves is alloy 690 .
For the steam generators in service as of December 1996, the majority of the inservice sleeves (i.e., non-plugged sleeves) are one of five major designs: Westinghouse hybrid expansion joint (HEJ) sleeves, B\&W kinetically welded sleeves, B\&W mechanical sleeves, CE TIG-welded sleeves, and Westinghouse laser-welded sleeves. With respect to circumferential cracking, one major difference between the sleeves (besides the material of the sleeve) is the method of attaching the sleeve to the parent tube. Each of the sleeves in use are described below along with relevant operating experience.

The Westinghouse HEJ sleeves have upper joints that were formed by first hydraulically expanding a portion of the sleeve into the parent tube and then by mechanically roll expanding the central portion of this hydraulically expanded region. This joint is typically referred to as a HEJ and is depicted in Figure A-1. The intent of the initial hydraulic expansion is to lessen the residual stress levels in the joint area (Ref. 90). Although the lower joint of an HEJ sleeve consists of a hydraulic expansion and hardroll as well, it is not referred to as an HEJ joint. An illustration of the entire Westinghouse HEJ sleeve is depicted in Figure A-2. Westinghouse HEJ sleeves are currently (1995) in service at Kewaunee, Point Beach 1, D.C. Cook 1, and Ginna. The Point Beach 1 and Ginna steam generators were replaced in 1996 (Ref. 171).

Circumferential crack-like indications in the parent tube associated with the upper joint of Westinghouse HEJ sleeves were first identified at Kewaunee in 1994. Additional indications were detected in a subsequent inspection outage (i.e., 1995). The majority of the indications detected were in the lower hardroll transition of the upper joint (i.e., the HEJ) (refer to Figure A-1). As a result of these indications, the licensee for Kewaunee removed 3 sleeved tubes for destructive examination. As a result of the destructive examination, the licensee for Kewaunee concluded that the eddy current indications were attributable to circumferentially oriented, inner diameter initiated, intergranular stress corrosion cracks on the parent tube. The crack network was segmented and the crack initiation sites were scattered in elevation (i.e., non-coplanar). No indication of 
corrosion or cracking were detected on the sleeves (Ref. 172).

The B\&W kinetically welded sleeve design generally consists of at least one kinetic expansion joint and may have a mechanical joint depending on the installation location. In general, tube support plate sleeves (Figure A-3) have two kinetic expansion joints whereas tubesheet sleeves (Figure A-4) can either have one kinetic expansion joint and one mechanical joint or two kinetic expansion joints. The free span joints of both the tubesheet and tube support plate sleeves are performed by a kinetic welding process. In this process, the sleeve is expanded into the parent tube by detonating a kinetic weld device. The kinetically expanded region is narrow (axially) and it results in the outer sleeve wall being fused to the inner tube wall. These kinetically expanded free span joints are stress relieved to improve corrosion characteristics (i.e., reduce residual stresses to make material less susceptible to corrosion). The lower joint (i.e., tubesheet joint), if not kinetically expanded, can be formed by mechanically rolling the sleeve into the tube (Refs. 173 and 174). B\&W kinetically welded sleeves are currently (1995) in service at ANO-2. These sleeves had been used in several other plants; however, in these instances, the sleeves were either removed from service by plugging (e.g., Catawba 1 and McGuire 1 and 2), the steam generators were replaced (e.g., Summer), and/or the plant was shut down permanently (e.g., Trojan).

Degradation of B\&W kinetically expanded joints has been observed at a few plants. As a result of a tube leak that resulted in a plant shutdown, multiple indications in the parent tube material in the area of the lower sleeve-to-tube kinetic weld were observed in a B\&W kinetically welded tube support plate sleeve at Trojan in November 1992. The indications spanned a region estimated to exceed 180 degrees of the tube circumference. The cause of the leak was determined to be the failure to properly stress relieve the tube after the sleeve was kinetically welded (Ref. 175). Circumferential indications were detected in B\&W kinetically welded sleeves in 1993 at McGuire 1 as a result of a tube leak (Ref. 176). A tube pull from the McGuire 1 confirmed a circumferential crack in the parent tube approximately $2.5 \mathrm{~mm}(0.1 \mathrm{inch})$ above the apex of the upper weld that joined the tube and sleeve. The circumferential crack was through-wall for 270 degrees around the tube and 50-percent through the wall for the remaining 90 degrees. The crack had initiated from the inside of the parent tube and was characteristic of PWSCC (Refs. 11 and 174). These tubes had been stress relieved; however, the stress relief temperature did not assure a long service-life for this tube. Additional circumferential indications were detected at McGuire 1 in January 1994, as a result of a tube leak event. This tube leak event, and uncertainty in the root cause of the sleeve failures, led the licensee to preventively plug the remaining sleeved tubes in this unit (Ref. 118). Indications have recently been detected in the ANO-2 sleeves. The nature of these indications was described as non-quantifiable parent tube indications (Ref. 62).

The B\&W mechanical sleeve design has only been used in B\&W OTSGs and has three mechanical joints as depicted in Figure A-5. The sleeve joints are made by roller expanding the ends of the sleeve into the tube. The upper joint is typically located in the UTS region. The other two joints are located in the tube free span region and are in close proximity to each other and to the lower end of the sleeve. All B\&W OTSGs have B\&W mechanical sleeves installed (Refs. 43 and 177). These sleeves are typically located in the lane/wedge region of the steam generator, which is discussed in Section 5.2.1.

Circumferential indications have recently been detected in the joints of B\&W mechanical sleeves at ANO-1 although no tube pulls have been performed to identify the nature of the degradation. The licensee believes the majority of the indications detected are associated with the parent tube rather than the sleeve itself. The degradation has been observed at both the upper joint (within the tubesheet) and the lower joints (in the tube free span) (Ref. 42).

There are 3 basic types of CE TIG-welded sleeves that may be installed in various combinations within a steam generator tube. Each of the sleeve types includes a chamfer at both ends to prevent hang-up of equipment used to install or inspect the sleeve or tube. The three types of sleeve are the expansion transition zone (or roll transition zone) sleeve, the tubesheet sleeve, and the tube support plate sleeve.

The CE TIG-welded expansion transition zone sleeve spans the expansion transition zone at the top of the tubesheet to a maximum height of $10 \mathrm{~cm}$ ( 4 inches) above the first support. This sleeve configuration is 
depicted in Figure A-6. This sleeve is welded near the top end of the sleeve, which is above the secondary face of the tubesheet, and rolled near the bottom end of the sleeve, which is near the neutral axis of the tubesheet. Before the welding and rolling; the sleeve is hydraulically expanded into the sleeve to hold the sleeve in place. The sleeve has a band of nickel at one end to improve sealing of the sleeve when the lower end is hardrolled, and it has a band of chromium oxide, which has a rough surface, to provide a strong mechanical joint.

The CE TIG-welded tubesheet sleeve, illustrated in Figure A-7, spans the tubesheet and a portion of the tube to a maximum height of approximately $23 \mathrm{~cm}(9$ inches) above the tubesheet. The sleeve is welded near each end. Before welding the upper end of the sleeve, the upper end of the sleeve is hydraulically expanded into the tube. The lower end of the sleeve is tapered so as to limit the insertion of the sleeve to the proper elevation during installation, to temporarily hold the sleeve in place, and to provide a tight contact with the tube for welding. The lower end of the sleeve is positioned flush with the bottom of the steam generator tube.

As its name implies, the CE TIG-welded tube support plate sleeve, illustrated in Figure A-8, spans a tube support plate. The upper and lower ends of the sleeve are hydraulically expanded into the tube to hold the sleeve in place for welding and to provide the sleeve to tube fit-up necessary for welding. This sleeve is welded near each end (Ref. 178).

CE TIG-welded sleeves are currently (1996) in service at a number of plants including Prairie Island 1, Zion 2, ANO-2, Kewaunee, and Byron 1. As a result of identifying circumferential and volumetric indications in the sleeve joints, the licensee for Prairie Island 1 removed several sleeve specimens from their steam generators for destructive examination in early 1996 . From the metallurgical examinations, the licensee concluded that the eddy current indications were a result of the radial component of either or both of two weld conditions termed incomplete fusion and sleeve outside diameter (OD) suckback. Incomplete fusion manifests itself in two forms: (1) the formation of refractory oxides in the weld nugget creating laminar, non-linear, inclusions emanating from the intersection of the sleeve and tube faying surfaces; and (2) a lack of fusion flaw where the indigenous oxide layer on the tube surface prevents wetting of the joint faying surfaces during welding and blocks coalescence. Sleeve OD suckback is a term given to a rounded cavity formed on the edge of the weld. The rounded nature of this type of discontinuity indicates that it is due to the evolution of a gas within the joint.

The licensee attributed both the incomplete fusion and OD suckback to an anomaly associated with the sleeve installation process. The licensee attributed both forms of incomplete fusion to insufficient removal of the tube surface oxide from the inside diameter of the parent tube before sleeve installation (i.e., improper cleaning of the tube before sleeve installation). The sleeve $O D$ suckback occurred predominately on the upper (non-pressure boundary portion of the weld, and when it did occur below the weld it was localized and limited to less than 15-percent through the sleeve wall. The licensee indicated that the source of the gas forming the OD suckback regions could be a result of contamination of the tube surface or from moisture behind the sleeve. No service-induced propagation, including environmental degradation, of any type was observed during the destructive examinations. Most all inclusion termination points, many of which were rounded pores, were oxide filled. In addition, the licensees comparison of previous outage eddy current volumetric and circumferential signals exhibited no or very minor change (Ref. 179). In summary, the licensee concluded that the eddy current indications observed in these sleeves were fabrication related rather than service-induced. The NRC staff agreed that the indications in the CE sleeves appeared to be installation induced rather than service-induced (Ref. 180). Similar eddy current indications to those observed at Prairie Island 1 have been observed at other plants that have installed CE sleeves.

Post weld heat treatment can be performed on these sleeves to reduce the residual stresses present in the sleeve/tube joint without significantly affecting the microstructure of the materials. Reducing residual stresses is desirable since $\mathrm{SCC}$ is dependent to a large extent on these stresses; therefore, a reduction in the residual stress level in the sleeve welds will enhance the corrosion resistance of the joints.

Like the CE TIG-welded sleeve, there are several basic types of Westinghouse laser-welded sleeves that may be installed in various combinations within a steam generator tube. The types of Westinghouse 
laser-welded sleeves include the full length tubesheet sleeve (FLTS), the elevated tubesheet sleeve (ETS), and the tube support sleeve (TSS).

The FLTS, illustrated in Figure A-9, extends from the tubesheet primary face to above the tubesheet secondary face. The lower joint of this sleeve is formed at the bottom of the tubesheet and this joint is made by first hydraulically expanding the sleeve into the parent tube and then rolling a section of the sleeve within the hydraulically expanded region into the parent tube. The upper joint of the sleeve is made by first hydraulically expanding a portion of the sleeve into the tube to achieve the proper fit-up geometry for welding and then by performing an autogenous weld between the sleeve and tube using the laser welding process. This joint is located above the tubesheet and occurs in the tube free span. For the lower joint, a seal weld can be added, as an option.

The ETS, illustrated in Figure A-10, extends over approximately one-third of the tube length within the tubesheet and is joined to the tube approximately 36 $\mathrm{cm}$ (14 inches) above the tubesheet bottom (i.e., lower joint) and above the tubesheet secondary face (i.e., upper joint). This type of sleeve allows greater radial coverage of the bundle (i.e., closer to the bundle periphery) than the FLTS since it is smaller and is less likely to interfere with the primary channel head during installation. The upper and lower joints of the ETS are identical to the joints in the FLTS (i.e., the upper joint is hydraulically expanded and then welded; the lower joint is hydraulically expanded then rolled and can be laser-welded as an option). The ETS is similar to the FLTS in that it is designed to address degradation at or near the top of the tubesheet; however, they are dissimilar in that the ETS is not designed to address degradation in the remainder of the tube within the tubesheet.

The tube support plate sleeve, illustrated in Figure A-11, can be used to span degradation at the tube supports (i.e., flow distribution baffle plates, drilled plates, and eggcrates) or in the tube free span. Each end of the sleeve has a hydraulic expansion region within which the weld is placed.

Post weld heat treatment can be performed for each of the three Westinghouse laser-welded sleeves discussed above. Post weld heat treatment was developed to reduce the residual stresses present in the sleeve/tube joint without significantly affecting the microstructure of the material. Reducing residual stresses is desirable since SCC is dependent to a large extent on residual stresses; therefore, a reduction in the residual stress level in the laser sleeve welds will enhance the corrosion resistance of the welded joints (Ref. 181).

Westinghouse laser-welded sleeves have been used at a number of plants including Farley 1 and 2, Maine Yankee, and Byron 1. The sleeves at Farley 1 and 2 have been in service the longest, they were installed in 1992 (Ref. 90). To date, the operating experience with Westinghouse laser-welded sleeves has been good (although limited) with no reports of degradation to the staff's knowledge.

Other sleeve designs have been used throughout the industry; however, the extent to which they are currently being used is minimal. For example, in the pre-replacement Ginna steam generators, B\&W brazed sleeves and B\&W explosive sleeves were used (Ref. 128). In addition, at Oconee 1, there are a few (approximately 4) sleeves which have been hydraulically expanded into the tube (Ref. 38).

In addition to these other sleeve types, other forms of sleeve degradation have occurred; however, the number of reported occurrences has been minimal. For example, bulging of the sleeve has been observed in at least one plant (e.g., Farley 2) (Ref. 146).

In summary, most types of sleeves currently in service have exhibited either fabrication induced or service-induced degradation. This degradation is normally associated with the parent tube and is located at the point of attachment of the sleeve to the tube (i.e., the sleeve joint). Due, in part, to the relatively good operating experience to date, most sleeves currently (1996) being installed are welded (laser- or TIG-welded) to the parent tube. After the welding, the resultant joint is frequently heat treated to reduce the residual stresses in the joint. Currently, the material of choice for sleeves is alloy 690 . 


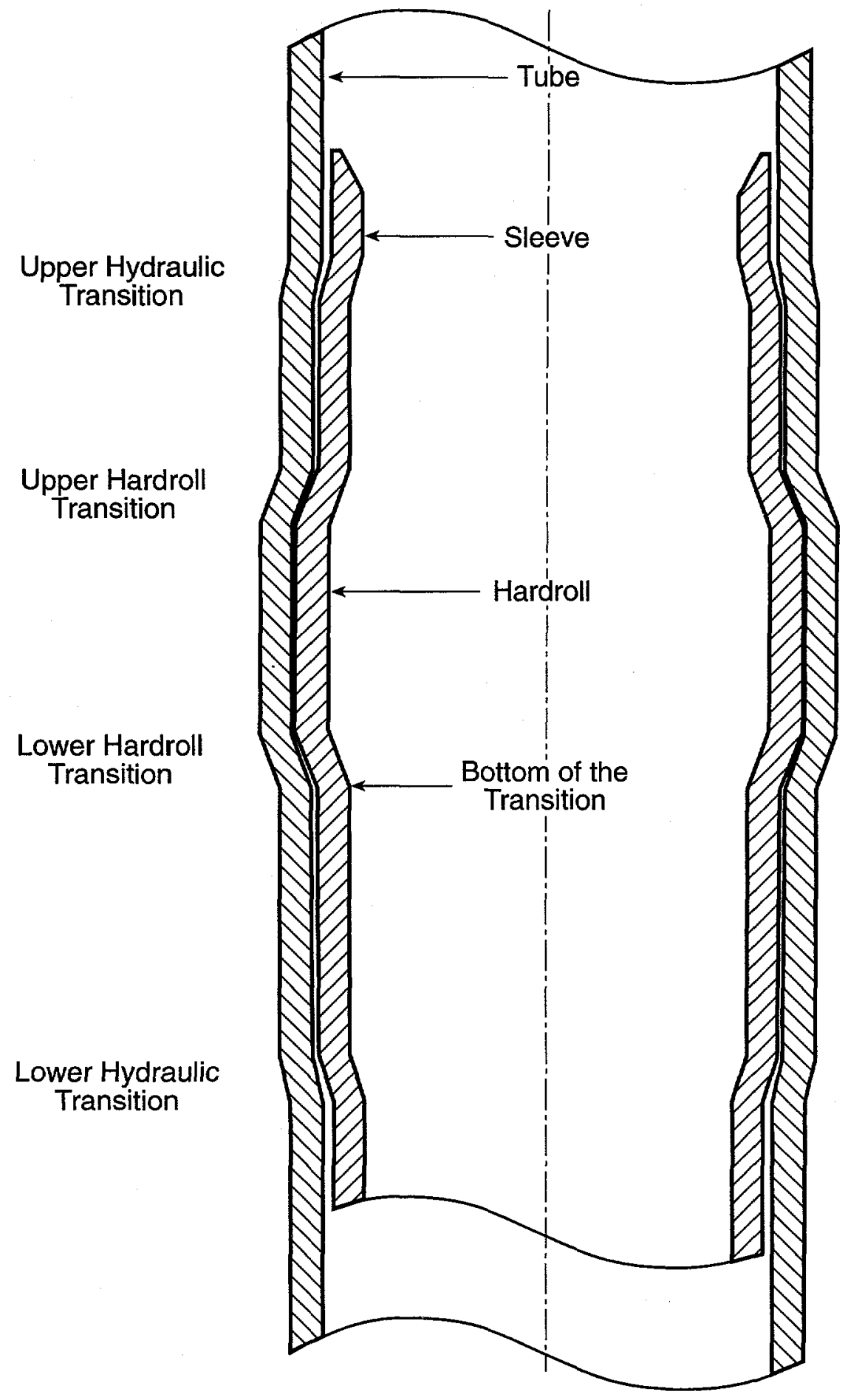

Figure A-1 Westinghouse hybrid expansion joint configuration 


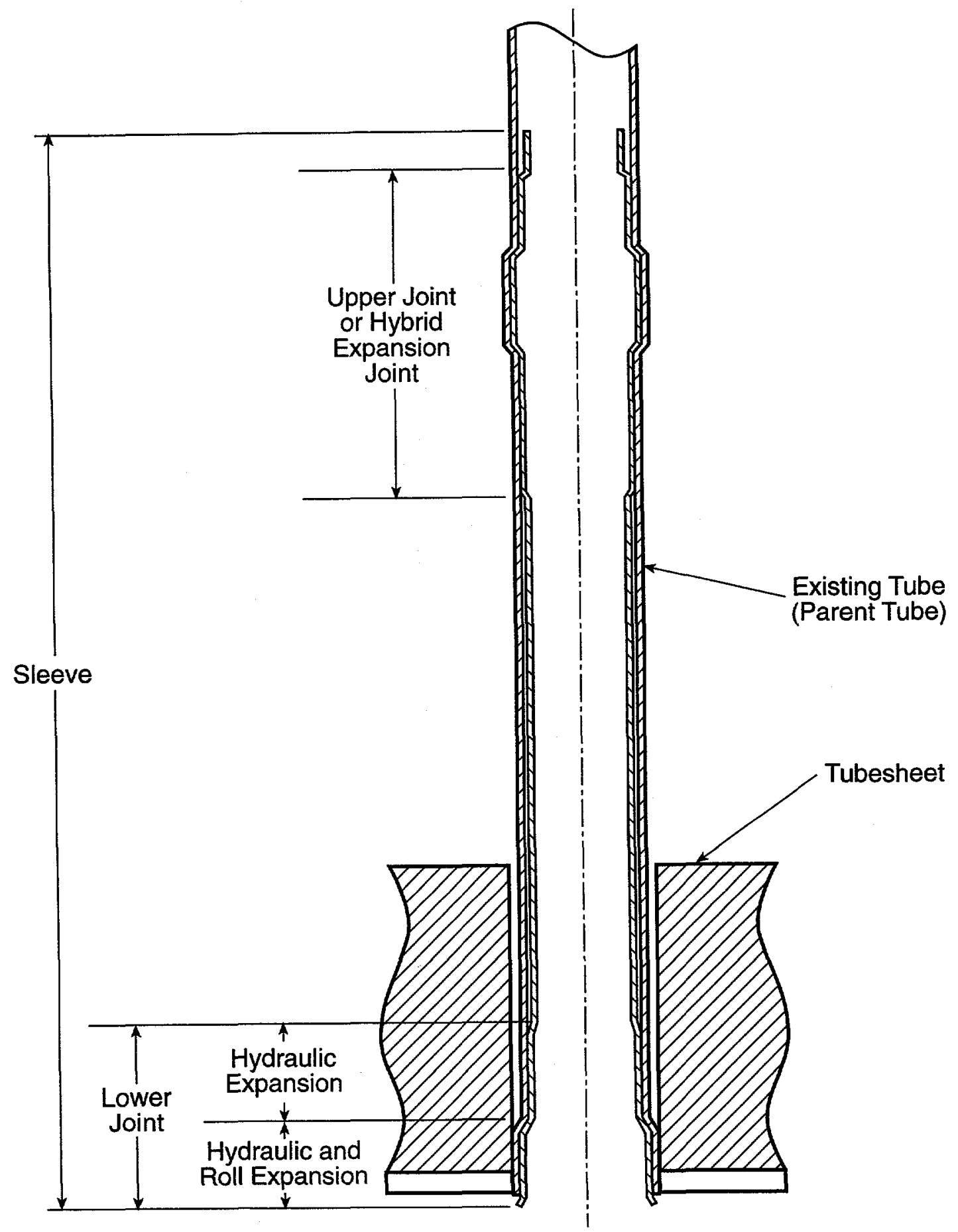

Figure A-2 Westinghouse hybrid expansion joint sleeve 


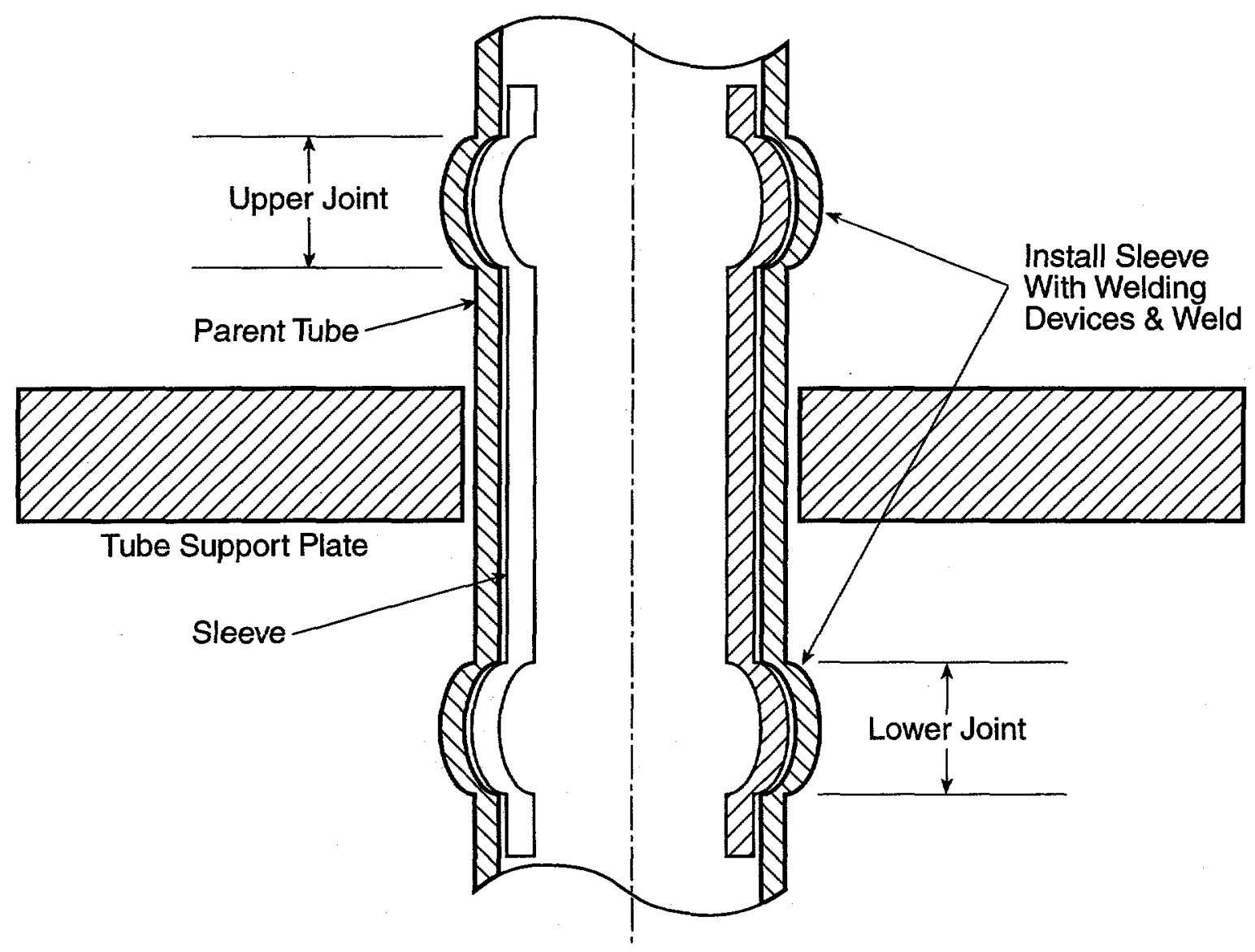

Figure A-3 B\&W Kinetically welded tube support plate sleeve 


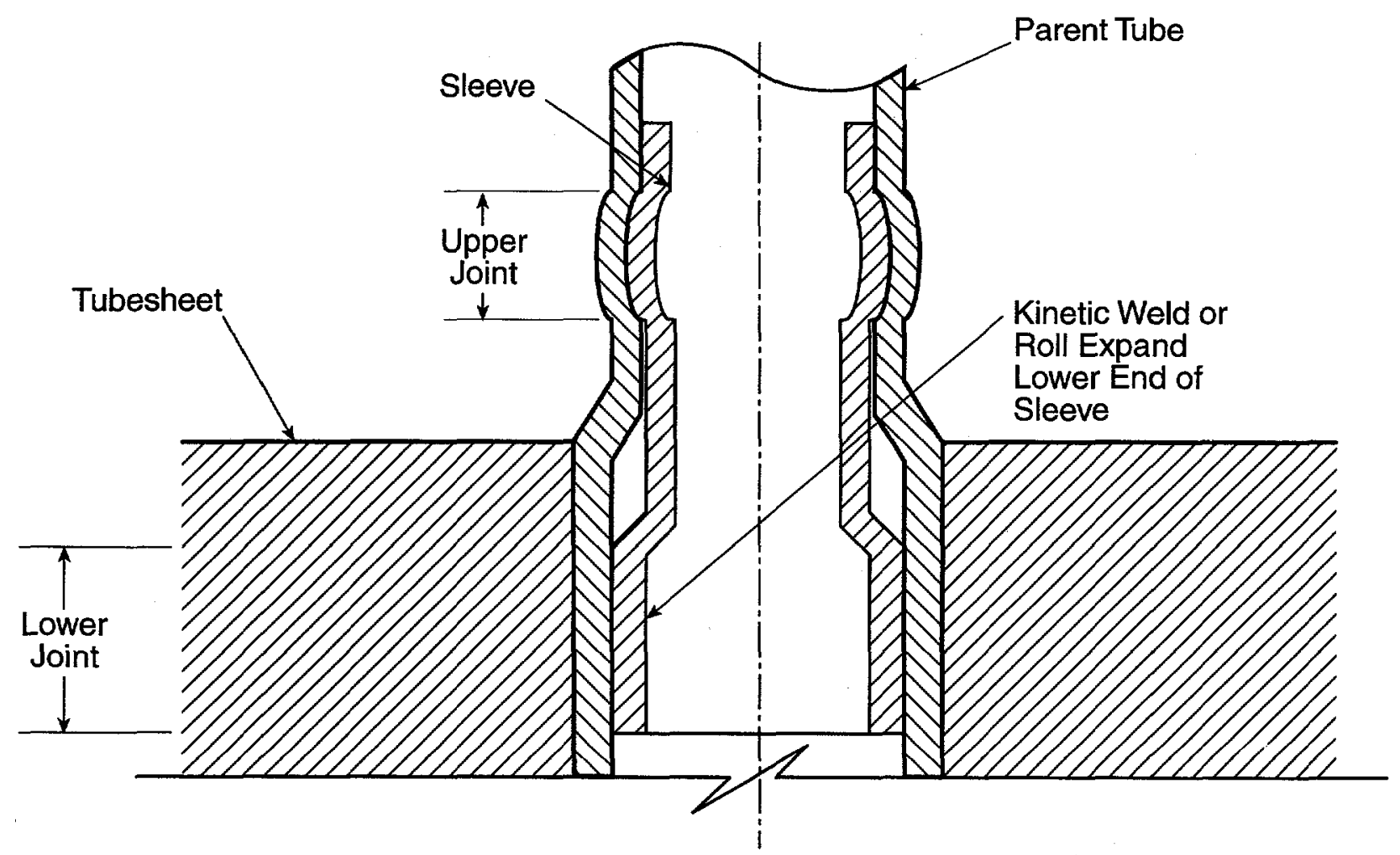

Figure A-4 B \& W kinetically welded tubesheet sleeve 


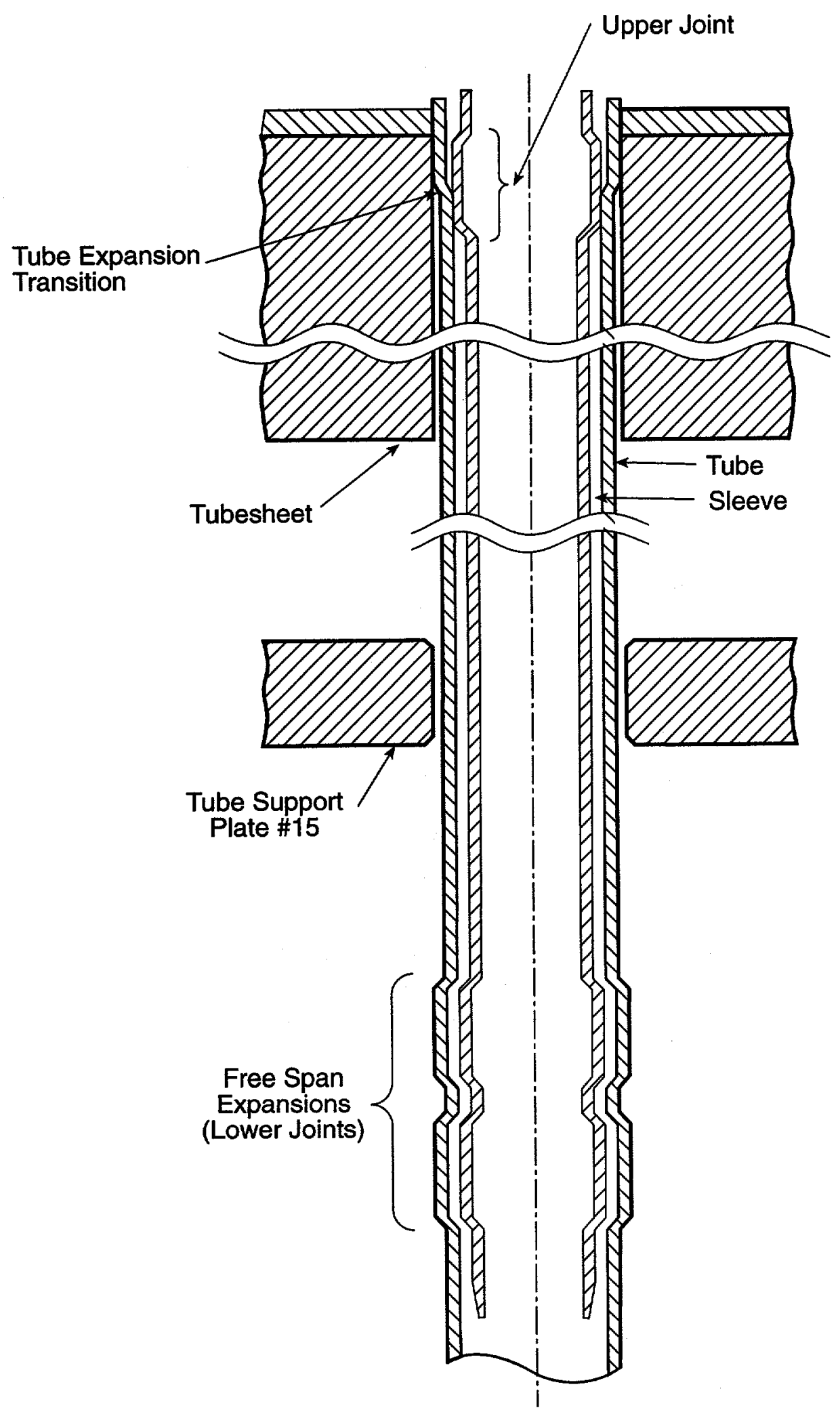

Figure A-5 B\&W mechanical sleeve 


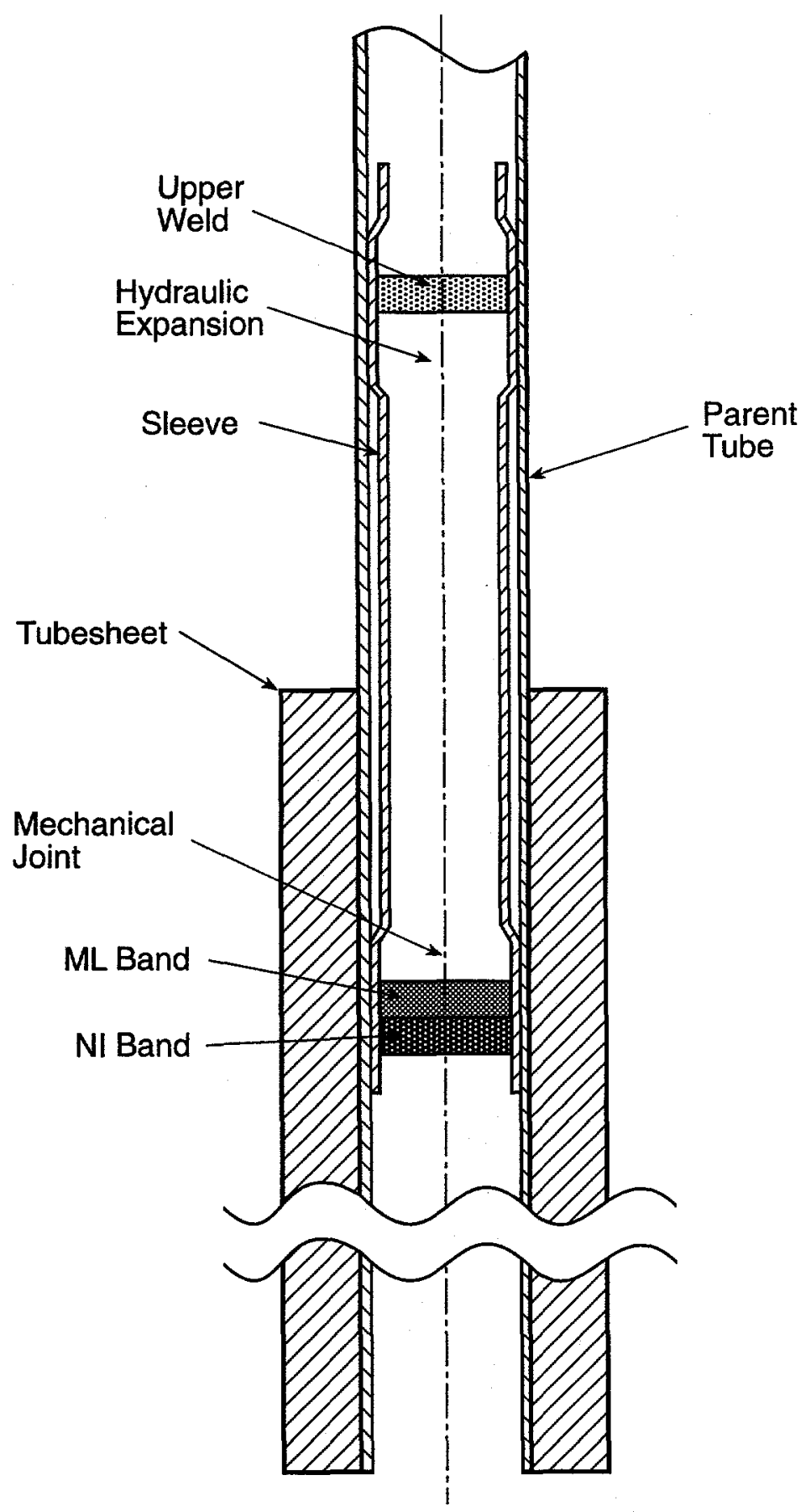

Figure A-6 CE TIG-welded expansion transition zone sleeve 


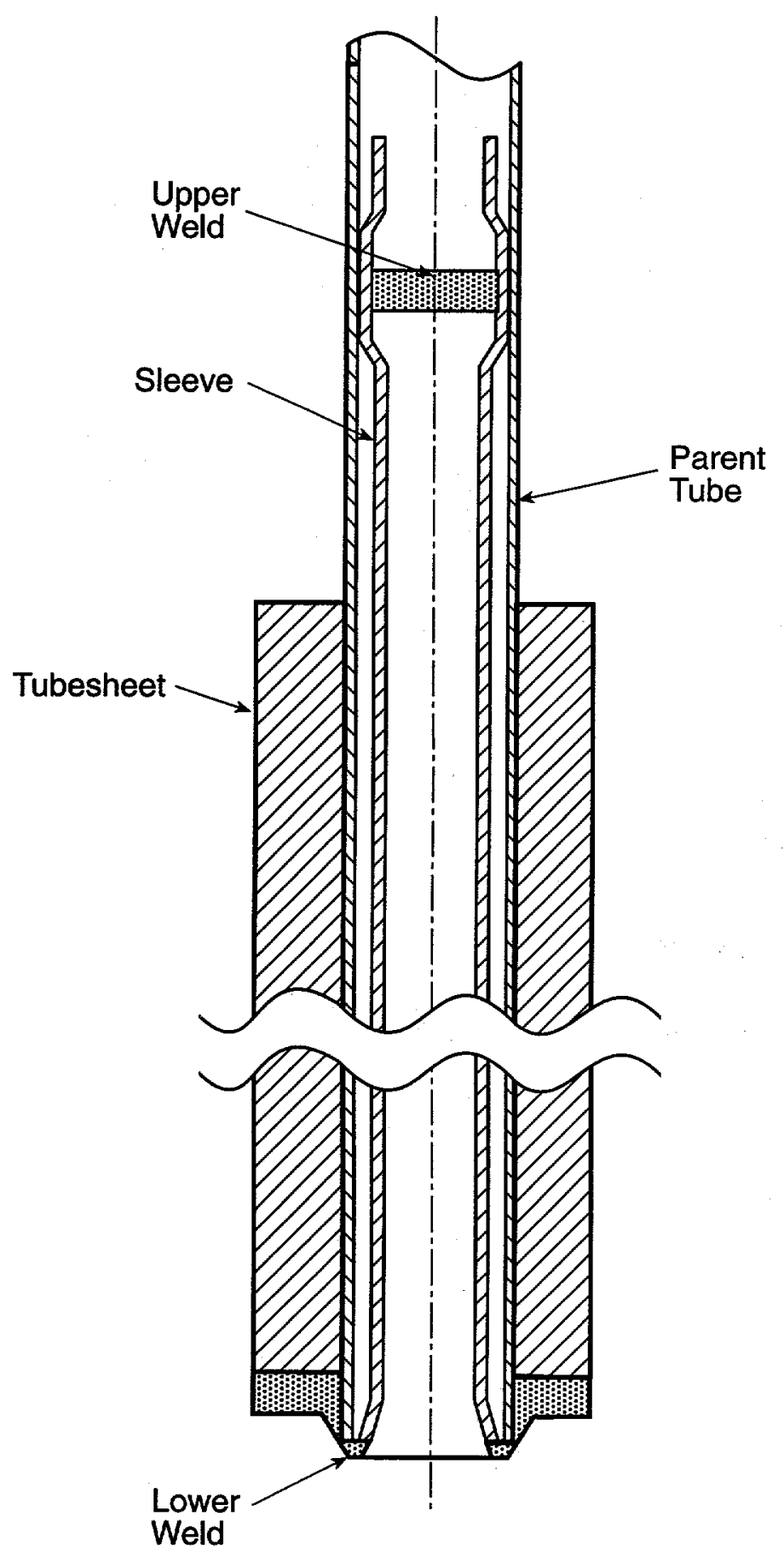

Figure A-7 CE TIG-welded tubesheet sleeve 


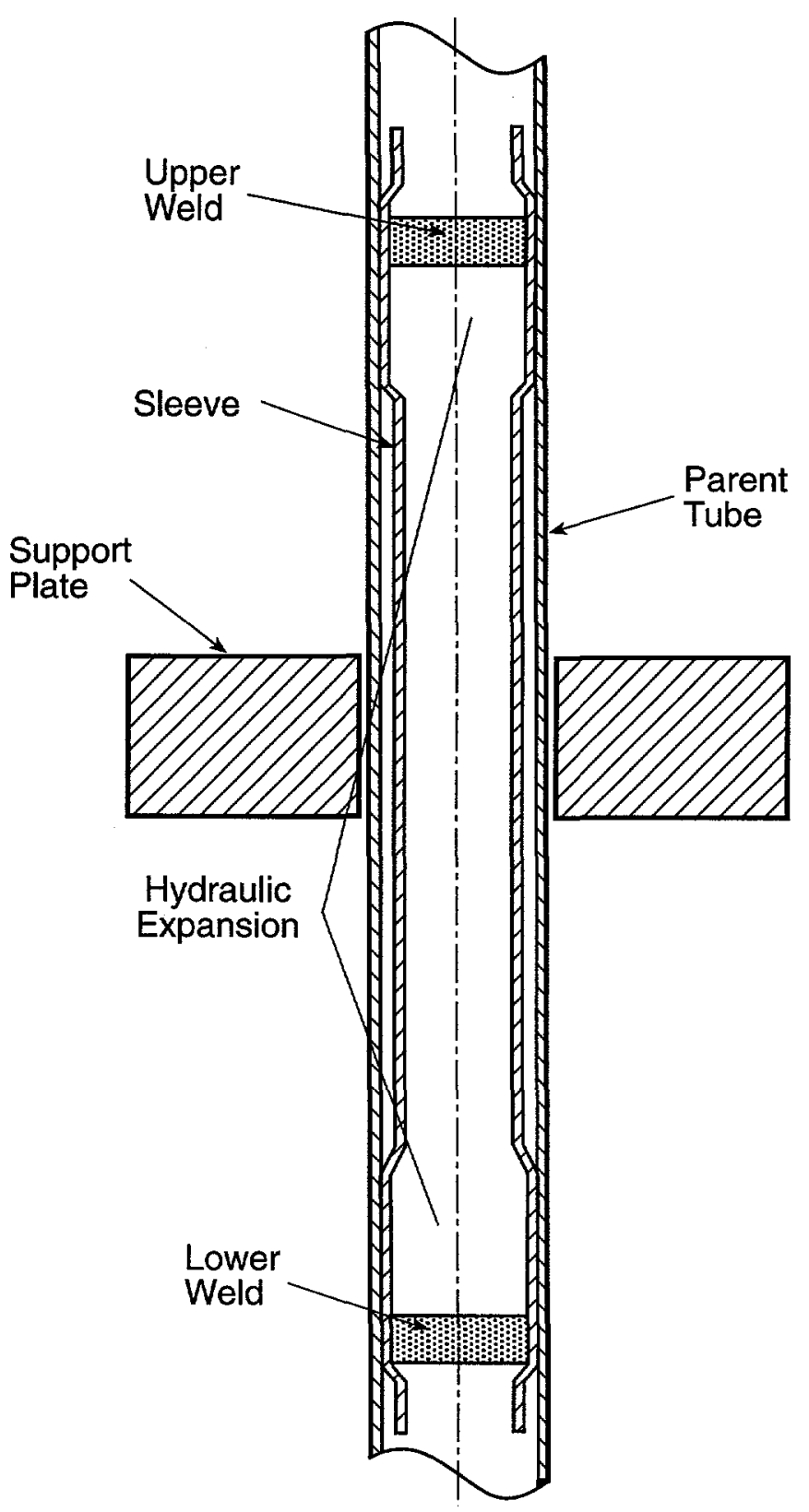

Figure A-8 CE TIG-welded tube support plate sleeve 


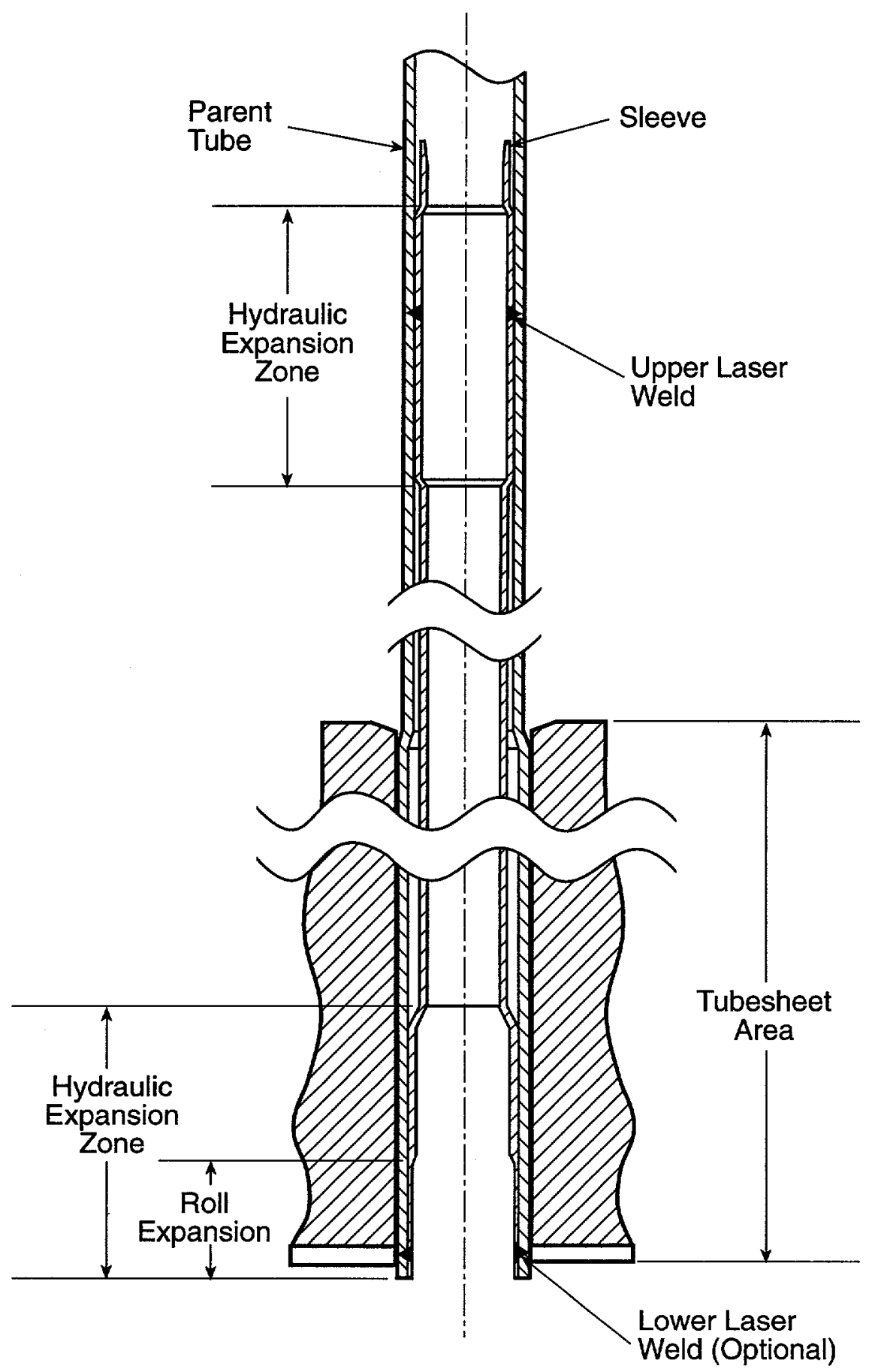

Figure A-9 Westinghouse laser-welded full-length tubesheet sleeve 


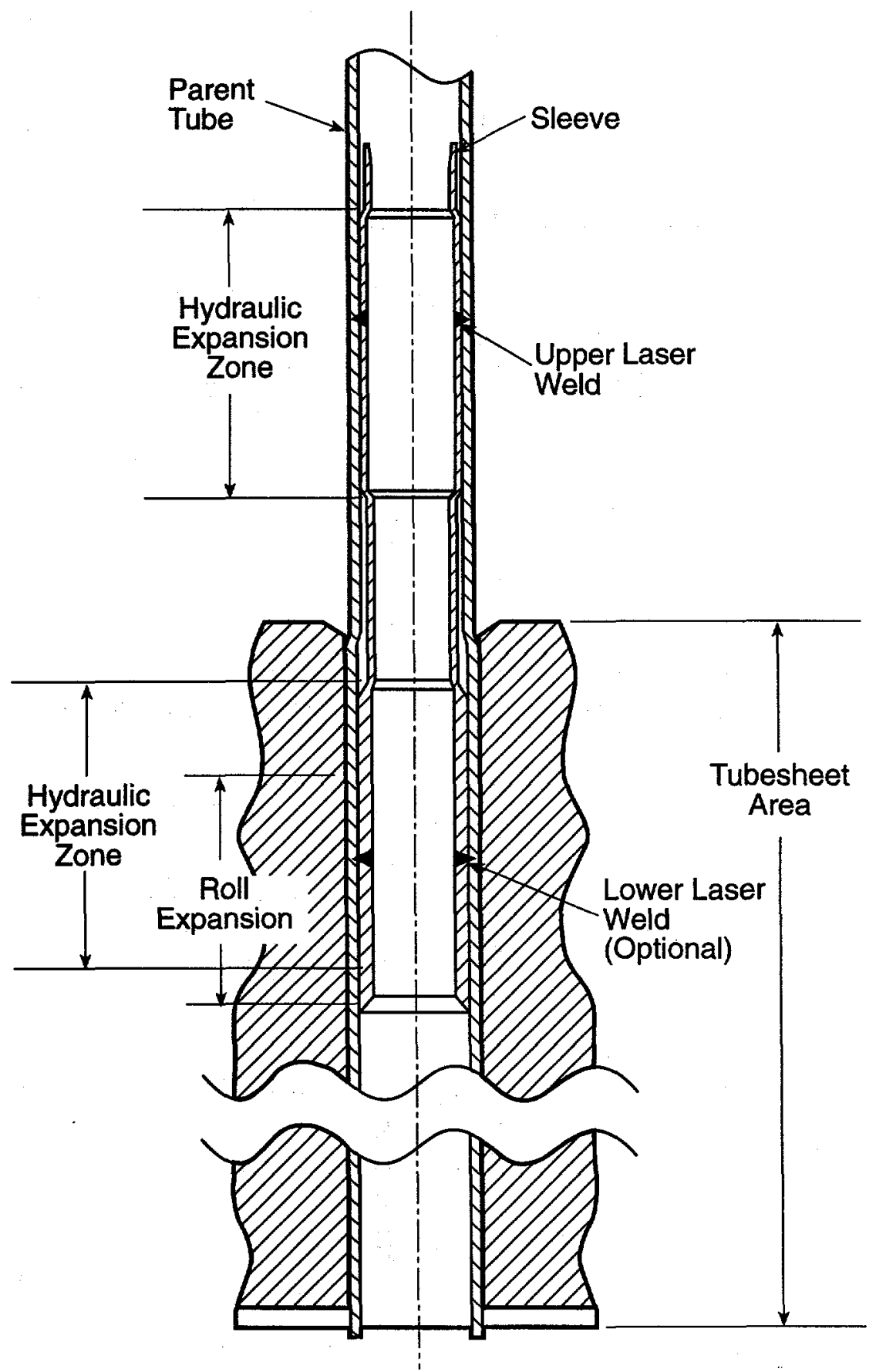

Figure A-10 Westinghouse laser-welded elevated tubesheet sleeve 


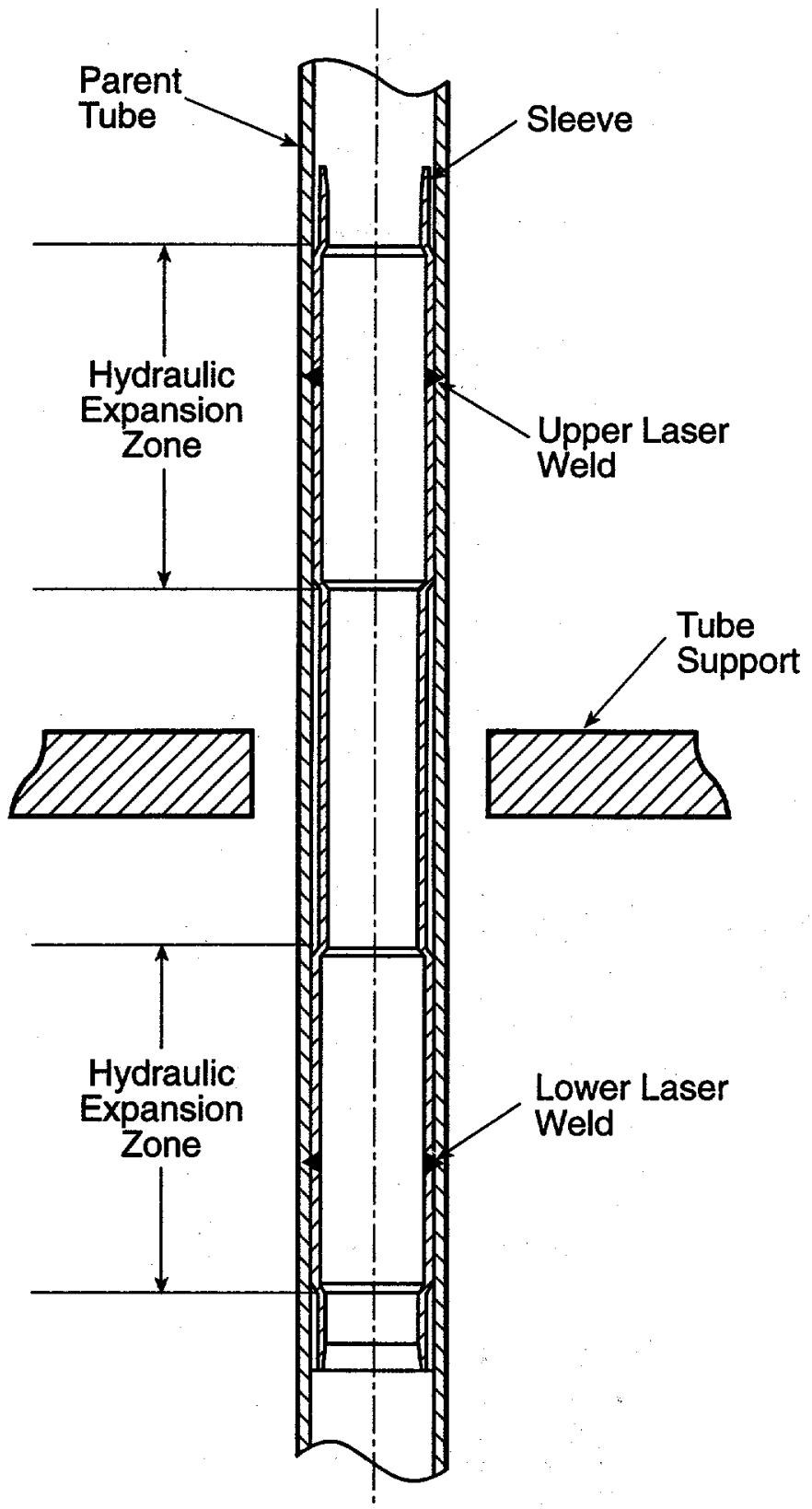

Figure A-11 Westinghouse laser-welded tube support plate sleeve 


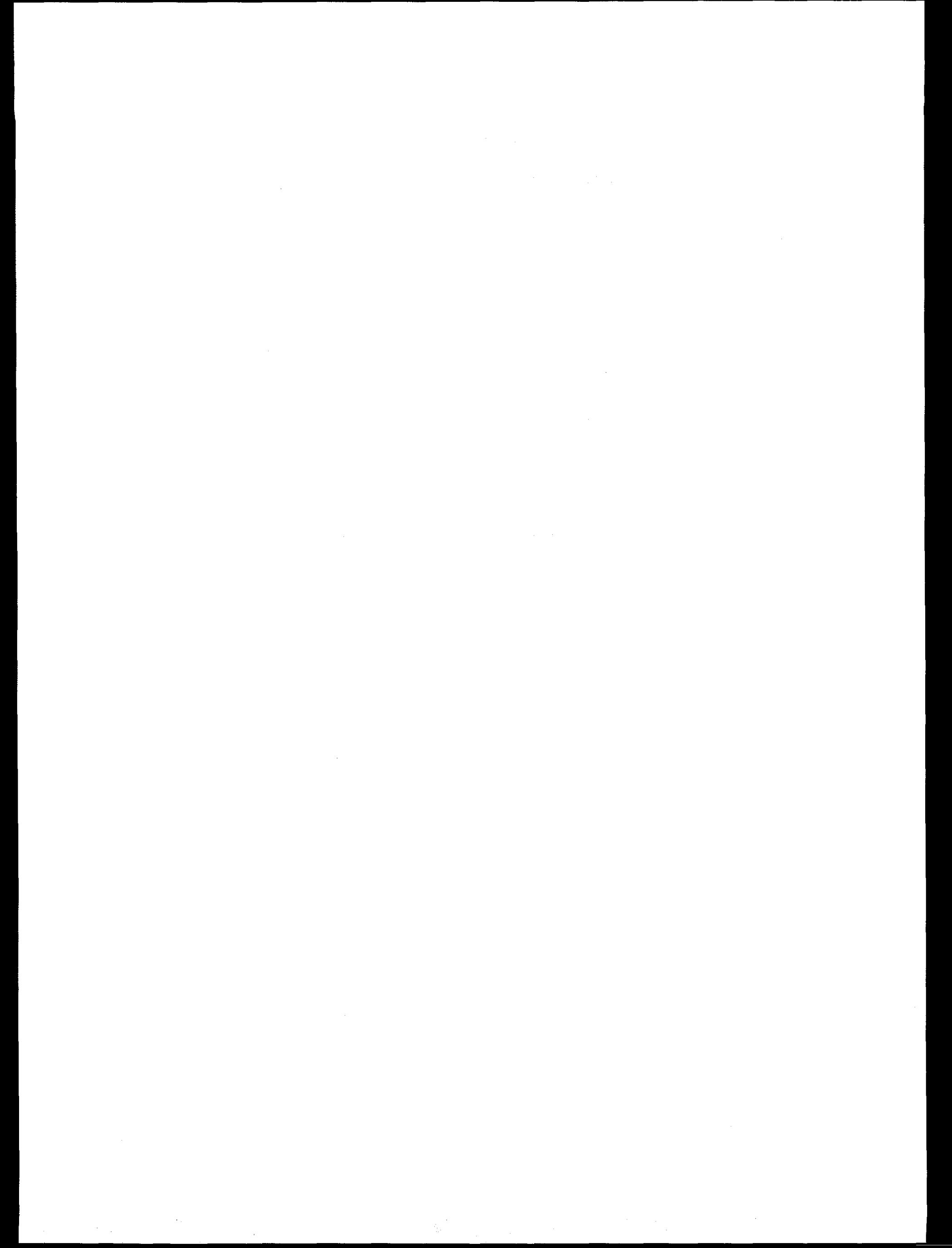




\section{APPENDIX B: PLANT LISTINGS}

Information related to the steam generators at plants in operation in June 1995 is provided in Tables B-1 through B-6. The following information is included in these tables.

(1) Table B-1: Alphabetical listing of plants indicating the steam generator vendor and model number as well as the steam generator tube material, heat treatment, and outside diameter.

(2) Table B-2: Alphabetical listing of the plants on the basis of tube material and heat treatment (e.g., plants with alloy 600 mill-annealed tubes).

(3) Table B-3: Alphabetical listing of the plants based on nuclear steam supply system vendor (e.g., B\&W plants).

(4) Table B-4: Alphabetical listing of Westinghouse plants on the basis of tube material and expansion method (e.g., partial-depth hardroll plants with alloy 600 tubes).

(5) Table B-5: Alphabetical listing of Westinghouse plants on the basis of steam generator model.

(6) Table B-6: Listing of plants that have replaced their steam generators indicating the number of steam generators and the pre- and post-replacement steam generator manufacturer and model number. The table is ordered based on the approximate completion date for the steam generator replacement project. 
Table B-1 Plant Listing by Name

\begin{tabular}{|c|c|c|c|c|}
\hline Plant Name & Vendor'/Model \# & Tube Material & Heat Treatment ${ }^{2}$ & $\begin{array}{l}\text { Outside Diameter } \\
\text { (inch) }\end{array}$ \\
\hline Arkansas Nuclear One - 1 & B\&W & 600 & MA - sensitized & 0.625 \\
\hline Arkansas Nuclear One - 2 & CE & 600 & MA & 0.750 \\
\hline Beaver Valley 1 & Westinghouse/51 & 600 & MA & 0.875 \\
\hline Beaver Valley 2 & Westinghouse/51M & 600 & MA & 0.875 \\
\hline Braidwood 1 & Westinghouse/D4 & 600 & MA & 0.750 \\
\hline Braidwood 2 & Westinghouse/DS & 600 & TT & 0.750 \\
\hline Byron 1 & Westinghouse/D4 & 600 & $\mathbf{M A}$ & 0.750 \\
\hline Byron 2 & Westinghouse/D5 & 600 & TT & 0.750 \\
\hline Callaway & Westinghouse/F & 600 & MA TT $^{3}$ & 0.6875 \\
\hline Calvert Cliffs 1 & $\mathrm{CE}$ & 600 & MA & 0.750 \\
\hline Calvert Cliffs 2 & $\mathrm{CE}$ & 600 & MA & 0.750 \\
\hline Catawba $1^{s}$ & Westinghouse/D3 & 600 & MA & 0.750 \\
\hline Catawba 2 & Westinghouse/D5 & 600 & TT & 0.750 \\
\hline Comanche Peak 1 & Westinghouse/D4 & 600 & MA & 0.750 \\
\hline Comanche Peak 2 & Westinghouse/D5 & 600 & TT & 0.750 \\
\hline Crystal River 3 & B\&W & 600 & MA - sensitized & 0.625 \\
\hline Davis-Besse & B\&W & 600 & MA - sensitized & 0.625 \\
\hline D.C. Cook 1 & Westinghouse/51 & 600 & MA & 0.875 \\
\hline D.C. Cook $2^{4}$ & Westinghouse/54F & 690 & TT & 0.875 \\
\hline Diablo Canyon 1 & Westinghouse/51 & 600 & MA & 0.875 \\
\hline Diablo Canyon 2 & Westinghouse/51 & 600 & MA & 0.875 \\
\hline Farley 1 & Westinghouse/51 & 600 & MA & 0.875 \\
\hline Farley 2 & Westinghouse/51 & 600 & MA & 0.875 \\
\hline Fort Calhoun & $\mathrm{CE}$ & 600 & MA & 0.750 \\
\hline Ginnas & Westinghouse/44 & 600 & MA & 0.875 \\
\hline Haddam Neck & Westinghouse/27 & 600 & MA & 0.750 \\
\hline Indian Point 2 & Westinghouse/44 & 600 & MA & 0.875 \\
\hline Indian Point $3^{4}$ & Westinghouse/44F & 690 & TT & 0.875 \\
\hline Kewaunee & Westinghouse/51 & 600 & MA & 0.875 \\
\hline Maine Yankee & $\mathrm{CE}$ & 600 & MA & 0.750 \\
\hline McGuire 1 & Westinghouse/D2 & 600 & MA & 0.750 \\
\hline McGuire 2 & Westinghouse/D3 & 600 & MA & 0.750 \\
\hline Millstone $2^{4}$ & BWC & 690 & TT & 0.750 \\
\hline Millstone 3 & Westinghouse/F & 600 & TT & 0.6875 \\
\hline North Anna $1^{4}$ & Westinghouse/54F & 690 & TT & 0.875 \\
\hline North Anna $2^{4}$ & Westinghouse/54F & 690 & TT & 0.875 \\
\hline Oconee 1 & B\&W & 600 & MA - sensitized & 0.625 \\
\hline Oconee 2 & B\&W & 600 & MA - sensitized & 0.625 \\
\hline Oconee 3 & B\&W & 600 & MA - sensitized & 0.625 \\
\hline Palisades ${ }^{4}$ & $\mathrm{CE}$ & 600 & MA & 0.750 \\
\hline
\end{tabular}


Table B-1 Plant Listing by Name (continued)

\begin{tabular}{|c|c|c|c|c|}
\hline Plant Name & Vendor 1 Model \# & Tube Material & Heat Treatment ${ }^{2}$ & $\begin{array}{l}\text { Outside Diameter } \\
\text { (inch) }\end{array}$ \\
\hline Palo Verde 1 & $\mathrm{CE}$ & 600 & MA & 0.750 \\
\hline Palo Verde 2 & $\mathrm{CE}$ & 600 & MA & 0.750 \\
\hline Palo Verde 3 & CE & 600 & MA & 0.750 \\
\hline Point Beach $1^{4}$ & Westinghouse/44F & 600 & TT & 0.875 \\
\hline Point Beach $2^{5}$ & Westinghouse/44 & 600 & MA & 0.875 \\
\hline Prairie Island 1 & Westinghouse/51 & 600 & $\mathbf{M A}$ & 0.875 \\
\hline Prairie Island 2 & Westinghouse/51 & 600 & MA & 0.875 \\
\hline Robinson $2^{4}$ & Westinghouse/44F & 600 & TT & 0.875 \\
\hline Salem 1 & Westinghouse/51 & 600 & MA & 0.875 \\
\hline Salem 2 & Westinghouse/51 & 600 & MA & 0.875 \\
\hline San Onofre 2 & $\mathrm{CE}$ & 600 & MA & 0.750 \\
\hline San Onofre 3 & $\mathrm{CE}$ & 600 & MA & 0.750 \\
\hline Seabrook 1 & Westinghouse/F & 600 & $\mathbf{T T}$ & 0.6875 \\
\hline Sequoyah 1 & Westinghouse/51 & 600 & MA & 0.875 \\
\hline Sequoyah 2 & Westinghouse/51 & 600 & MA & 0.875 \\
\hline Shearon Harris 1 & Westinghouse/D4 & 600 & MA & 0.750 \\
\hline South Texas Project 1 & Westinghouse/E & 600 & MA & 0.750 \\
\hline South Texas Project 2 & Westinghouse/E & 600 & MA & 0.750 \\
\hline St. Lucie 1 & $\mathrm{CE}$ & 600 & MA & 0.750 \\
\hline St. Lucie 2 & $\mathrm{CE}$ & 600 & MA & 0.750 \\
\hline Summer" & Westinghouse/delta 75 & 690 & TT & 0.6875 \\
\hline Surry $1^{4}$ & Westinghouse/51F & 600 & $\mathbf{T T}$ & 0.875 \\
\hline Surry $2^{4}$ & Westinghouse/51F & 600 & TT & 0.875 \\
\hline Three Mile Island 1 & B\&W & 600 & MA - sensitized & 0.625 \\
\hline Turkey Point $3^{4}$ & Westinghouse/44F & 600 & TT & 0.875 \\
\hline Turkey Point $4^{4}$ & Westinghouse/44F & 600 & TT & 0.875 \\
\hline Vogtle 1 & Westinghouse/F & 600 & $\mathrm{TT}$ & 0.6875 \\
\hline Vogtle 2 & Westinghouse/F & 600 & TT & 0.6875 \\
\hline Waterford 3 & $\mathrm{CE}$ & 600 & MA & 0.750 \\
\hline Watts Bar 1 & Westinghouse/D3 & 600 & MA & 0.750 \\
\hline Wolf Creek 1 & Westinghouse/F & 600 & TT & 0.6875 \\
\hline Zion 1 & Westinghouse/51 & 600 & MA & 0.875 \\
\hline Zion 2 & Westinghouse/51 & 600 & MA & 0.875 \\
\hline
\end{tabular}

$1 \quad$ B\&W $=$ Babcock and Wilcox; $C E=$ Combustion Engineering

2 MA = mill-annealed; $\mathbf{T T}=$ thermally treated

3 The tubes in rows 1 through 10 in each steam generator are thermally treated. The remainder are mill-annealed.

4 Replacement steam generators

3 Steam generators were replaced during 1996. 
Table B-2 Plant Listing by Tube Material

\begin{tabular}{|c|c|}
\hline \multicolumn{2}{|c|}{ Alloy 600 Mill-annealed } \\
\hline 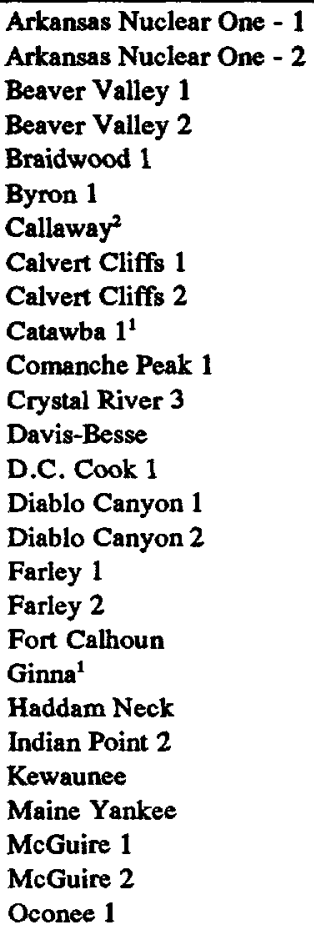 & 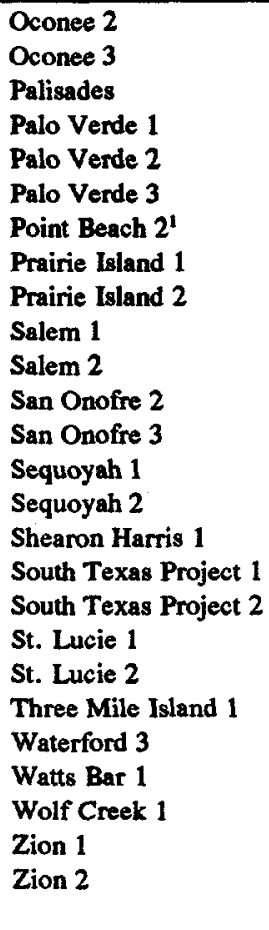 \\
\hline \multicolumn{2}{|c|}{ Alloy 600 Thermally Treated } \\
\hline $\begin{array}{l}\text { Braidwood } 2 \\
\text { Byron } 2 \\
\text { Callaway } \\
\text { Catawba } 2 \\
\text { Comanche Peak } 2 \\
\text { Millstone } 3 \\
\text { Point Beach } 1 \\
\text { Robinson } 2\end{array}$ & $\begin{array}{l}\text { Seabrook } 1 \\
\text { Surry } 1 \\
\text { Surry } 2 \\
\text { Turkey Point } 3 \\
\text { Turkey Point } 4 \\
\text { Vogtle } 1 \\
\text { Vogtle } 2 \\
\text { Wolf Creek } 1\end{array}$ \\
\hline \multicolumn{2}{|c|}{ Alloy 690 Thermally Treated ${ }^{3}$} \\
\hline $\begin{array}{l}\text { D.C. Cook 2 } \\
\text { Indian Point } 3 \\
\text { Millstone } 2\end{array}$ & $\begin{array}{l}\text { North Anna } 1 \\
\text { North Anna } 2 \\
\text { Summer }\end{array}$ \\
\hline
\end{tabular}

${ }^{1}$ Steam generators were replaced during 1996. Replacement steam generators have alloy 690 thermally treated tubes.

${ }^{2}$ Rows 11 and higher are mill-annealed. Rows 1 through 10 are thermally treated.

${ }^{3}$ Catawba 1, Ginna, and Point Beach 2 replaced their original steam generators in 1996 with steam generators that have alloy 690 thermally treated tubes. 
Table B-3 Plant Listing by Vendor

\begin{tabular}{|c|c|}
\hline \multicolumn{2}{|c|}{ Babcock and Wilcox Plants } \\
\hline $\begin{array}{l}\text { Arkansas Nuclear One - } 1 \\
\text { Crystal River } 3 \\
\text { Davis-Besse } \\
\text { Oconee } 1 \\
\end{array}$ & $\begin{array}{l}\text { Oconee } 2 \\
\text { Oconee } 3 \\
\text { Three Mile Island } 1\end{array}$ \\
\hline \multicolumn{2}{|c|}{ Combustion Engineering Plants } \\
\hline $\begin{array}{l}\text { Arkansas Nuclear One - } 2 \\
\text { Calvert Cliffs } 1 \\
\text { Calvert Cliffs } 2 \\
\text { Fort Calhoun } \\
\text { Maine Yankee } \\
\text { Millstone } 2^{1} \\
\text { Palisades } \\
\text { Palo Verde } 1 \\
\end{array}$ & $\begin{array}{l}\text { Palo Verde } 2 \\
\text { Palo Vende } 3 \\
\text { San Onofre } 2 \\
\text { San Onofre } 3 \\
\text { St. Lucie } 1 \\
\text { St. Lucie } 2 \\
\text { Waterfond } 3\end{array}$ \\
\hline \multicolumn{2}{|c|}{ Westinghouse Plants } \\
\hline $\begin{array}{l}\text { Beaver Valley } 1 \\
\text { Beaver Valley } 2 \\
\text { Braidwood } 1 \\
\text { Braidwood } 2 \\
\text { Byron 1 } \\
\text { Byron 2 } \\
\text { Callaway } \\
\text { Catawba } 1^{2} \\
\text { Catawba } 2 \\
\text { Comanche Peak } 1 \\
\text { Comanche Peak } 2 \\
\text { D.C. Cook 1 } \\
\text { D.C. Cook } 2 \\
\text { Diablo Canyon } 1 \\
\text { Diablo Canyon } 2 \\
\text { Farley 1 } \\
\text { Farley } 2 \\
\text { Ginna } \\
\text { Haddam Neck } \\
\text { Indian Point } 2 \\
\text { Indian Point } 3 \\
\text { Kewaunee } \\
\text { McGuire } 1 \\
\text { McGuire 2 } \\
\text { Millstone } 3 \\
\text { North Anna } 1\end{array}$ & $\begin{array}{l}\text { North Anna } 2 \\
\text { Point Beach } 1 \\
\text { Point Beach } 2 \\
\text { Prairie Island 1 } \\
\text { Prairie Island } 2 \\
\text { Robinson } 2 \\
\text { Salem } 1 \\
\text { Salem } 2 \\
\text { Seabrook 1 } \\
\text { Sequoyah 1 } \\
\text { Sequoyah } 2 \\
\text { Shearon Harris 1 } \\
\text { South Texas Project } 1 \\
\text { South Texas Project } 2 \\
\text { Summer } \\
\text { Surry } 1 \\
\text { Surry } 2 \\
\text { Turkey Point } 3 \\
\text { Turkey Point } 4 \\
\text { Vogtle 1 } \\
\text { Vogtle } 2 \\
\text { Watts Bar } 1 \\
\text { Wolf Creek } 1 \\
\text { Zion } 1 \\
\text { Zion } 2\end{array}$ \\
\hline
\end{tabular}

'Millstone 2 is a CE plant with replacement steam generators fabricated by B\&W Canada.

${ }^{2}$ Catawba 1 and Ginna are Westinghouse plants which replaced their original steam generators in 1996 with steam generators fabricated by B\&W Canada. 
Table B-4 Westinghouse Plant Listing by Tube Expansion Type and Material

\begin{tabular}{|c|c|c|}
\hline $\begin{array}{l}\text { EXPANSION TYPEJTUBE } \\
\text { MATERIAL }\end{array}$ & PLANT NAME & \\
\hline $\begin{array}{l}\text { Partial-Depth Hardroll - } \\
\text { Alloy } 600\end{array}$ & $\begin{array}{l}\text { D.C. Cook } 1 \\
\text { Ginna } \\
\text { Haddam Neck } \\
\text { Indian Point } 2 \\
\text { Kewaunee }\end{array}$ & $\begin{array}{l}\text { Point Beach } 2^{1} \\
\text { Prairie Island } 1 \\
\text { Prairie Island } 2 \\
\text { Zion } 1 \\
\text { Zion } 2\end{array}$ \\
\hline $\begin{array}{l}\text { Full-Depth Fardroll - } \\
\text { Alloy } 600\end{array}$ & $\begin{array}{l}\text { Beaver Valley } 2 \\
\text { Braidwood } 1 \\
\text { Byron } 1 \\
\text { Catawba } 1^{1} \\
\text { Comanche Peak } 1^{2} \\
\text { Farley } 2 \\
\end{array}$ & $\begin{array}{l}\text { McGuire } 1 \\
\text { McGuire } 2 \\
\text { Shearon Harris } 1 \\
\text { South Texas Project } 1 \\
\text { Watts Bar } 1\end{array}$ \\
\hline WEXTEX - Alloy 600 & $\begin{array}{l}\text { Beaver Valley } 1 \\
\text { Comanche Peak } 1^{2} \\
\text { Diablo Canyon } 1 \\
\text { Diablo Canyon } 2 \\
\text { Farley } 1\end{array}$ & $\begin{array}{l}\text { Salem } 1 \\
\text { Salem } 2 \\
\text { Sequoyah } 1 \\
\text { Sequoyah } 2\end{array}$ \\
\hline $\begin{array}{l}\text { Full-Depth Hydraulic - } \\
\text { Alloy } 600\end{array}$ & $\begin{array}{l}\text { Braidwood } 2 \\
\text { Byron } 2 \\
\text { Callaway } \\
\text { Catawba } 2 \\
\text { Comanche Peak } 2 \\
\text { Millstone } 3 \\
\text { Point Beach } 1 \\
\text { Robinson } 2 \\
\text { Seabrook } 1\end{array}$ & $\begin{array}{l}\text { South Texas Project } 2 \\
\text { Surry } 1 \\
\text { Surry } 2 \\
\text { Turkey Point } 3 \\
\text { Turkey Point } 4 \\
\text { Vogtle } 1 \\
\text { Vogtle } 2 \\
\text { Wolf Creek } 1\end{array}$ \\
\hline $\begin{array}{l}\text { Full-Depth Hydraulic - } \\
\text { Alloy } 690^{1}\end{array}$ & $\begin{array}{l}\text { D.C. Cook } 2 \\
\text { Indian Point } 3 \\
\text { North Anna } 1\end{array}$ & $\begin{array}{l}\text { North Anna } 2 \\
\text { Summer }\end{array}$ \\
\hline
\end{tabular}

- Catawba 1, Ginna, and Point Beach 2 replaced their original steam generators in 1996 with steam generators that have alloy 690 thermally treated tubes that have been hydraulically expanded the full length of the tubesheet.

2 89.5-percent of the tubes have full depth hardroll expansion transitions $(14,473$ tubes). The remaining tubes have WEXTEX transitions (3839 tubes). 
Table B-5 Westinghouse Plant Listing by Steam Generator Model

\begin{tabular}{|c|c|c|}
\hline $\begin{array}{l}\text { STEAM GENERATOR } \\
\text { MODEL }\end{array}$ & PLANT NAME & \\
\hline Westinghouse model 27 & Haddam Neck & \\
\hline Westinghouse model 44 & $\begin{array}{l}\text { Ginna }{ }^{1} \\
\text { Indian Point } 2\end{array}$ & Point Beach $2^{2}$ \\
\hline Westinghouse model 51 & $\begin{array}{l}\text { Beaver Valley } 1 \\
\text { D.C. Cook } 1 \\
\text { Diablo Canyon } 1 \\
\text { Diablo Canyon } 2 \\
\text { Farley } 1 \\
\text { Farley } 2 \\
\text { Kewaunee } \\
\text { Prairie Island 1 }\end{array}$ & $\begin{array}{l}\text { Prairie Island } 2 \\
\text { Salem 1 } \\
\text { Salem } 2 \\
\text { Sequoyah 1 } \\
\text { Sequoyah } 2 \\
\text { Zion } 1 \\
\text { Zion } 2\end{array}$ \\
\hline Westinghouse model 51M & Beaver Valley 2 & \\
\hline Westinghouse model D2 & McGuire 1 & \\
\hline Westinghouse model D3 & $\begin{array}{l}\text { Catawba } 1^{3} \\
\text { McGuire } 2\end{array}$ & Watts Bar 1 \\
\hline Westinghouse model D4 & $\begin{array}{l}\text { Braidwood 1 } \\
\text { Byron 1 }\end{array}$ & $\begin{array}{l}\text { Comanche Peak } 1 \\
\text { Shearon Harris } 1\end{array}$ \\
\hline Westinghouse model D5 & $\begin{array}{l}\text { Braidwood 2 } \\
\text { Byron 2 }\end{array}$ & $\begin{array}{l}\text { Catawba } 2 \\
\text { Comanche Peak } 2\end{array}$ \\
\hline Westinghouse model E & South Texas Project 1 & South Texas Project 2 \\
\hline Westinghouse model F & $\begin{array}{l}\text { Callaway } \\
\text { Millstone } 3 \\
\text { Seabrook } 1 \\
\end{array}$ & $\begin{array}{l}\text { Vogtle } 1 \\
\text { Vogtle } 2 \\
\text { Wolf Creek } 1\end{array}$ \\
\hline Westinghouse model 44F & $\begin{array}{l}\text { Indian Point } 3 \\
\text { Point Beach } 1 \\
\text { Robinson } 2\end{array}$ & $\begin{array}{l}\text { Turkey Point } 3 \\
\text { Turkey Point } 4\end{array}$ \\
\hline Westinghouse model 51F & Surry 1 & Surry 2 \\
\hline Westinghouse model 54F & $\begin{array}{l}\text { D.C. Cook } 2 \\
\text { North Anna } 1\end{array}$ & North Anna 2 \\
\hline Westinghouse delta 75 & Summer & \\
\hline Westinghouse delta 47 & Point Beach $2^{2}$ & \\
\hline B\&W Canada & Ginna $^{1}$ & Catawba $1^{3}$ \\
\hline
\end{tabular}

1 Ginna replaced their original Westinghouse model 44 steam generators in 1996 with steam generators fabricated by B\&W Canada.

2 Point Beach 2 replaced their original Westinghouse model 44 steam generators in 1996 with Westinghouse delta 47 steam generators.

3 Catawba 1 replaced their original Westinghouse model D3 steam generators in 1996 with steam generators fabricated by B\&W Canada 
Table B-6 Plants with Replacement Steam Generators (December 1996)

\begin{tabular}{||l|c|c|c|c||}
\hline \multirow{2}{*}{ Plant Name } & \multirow{2}{*}{$\begin{array}{c}\text { No. of Steam } \\
\text { Generators }\end{array}$} & \multicolumn{2}{|c|}{ SG Manufacturer/Model } & Approximate \\
\cline { 3 - 5 } & & Original & New & $\begin{array}{c}\text { Cotetion } \\
\text { Date }\end{array}$ \\
\hline \hline Surry 2 & 3 & W/51 & W/51F & $9 / 80$ \\
\hline Surry 1 & 3 & W/51 & W/51F & $7 / 81$ \\
\hline Turkey Point 3 & 3 & W/44 & W/44F & $4 / 82$ \\
\hline Turkey Point 4 & 3 & W/44 & W/44F & $5 / 83$ \\
\hline Point Beach 1 & 2 & W/44 & W/44F & $3 / 84$ \\
\hline Robinson 2 & 3 & W/44 & W/44F & $10 / 84$ \\
\hline D.C. Cook 2 & 4 & W/51 & W/54F & $3 / 89$ \\
\hline Indian Point 3 & 4 & W/44 & W/44F & $6 / 89$ \\
\hline Palisades & 2 & CE & CE & $3 / 91$ \\
\hline Millstone 2 & 2 & CE & BWC & $1 / 93$ \\
\hline North Anna 1 & 3 & W/51 & W/54F & $4 / 93$ \\
\hline Summer & 3 & W/D3 & W/D75 & $12 / 94$ \\
\hline North Anna 2 & 3 & W/51 & W/54F & $5 / 95$ \\
\hline Ginna & 2 & W/44 & BWC & $6 / 96$ \\
\hline Catawba 1 & 4 & W/D3 & BWC & $9 / 96$ \\
\hline Point Beach 2 & 2 & W/44 & W/D47 & On-going \\
\hline
\end{tabular}

$1 \mathrm{~W}=$ Westinghouse; $\mathrm{CE}=$ Combustion Engineering; $\mathrm{BWC}=$ Babcock and Wilcox, Canada; D75 = delta 75; D47 = delta 47 


\section{APPENDIX C: ACRONYMS}

ANO Arkansas Nuclear One

App. $\mathrm{H}$ Appendix $\mathrm{H}$ of Reference 122

AVB anti-vibration bar

B\&W Babcock and Wilcox

BWC Babcock and Wilcox, Canada

CL cold leg

cm centimeter

C5 Cecco 5

CE Combustion Engineering

CFR Code of Federal Regulations

circ circumferential

ECT eddy current testing

EOC end-of-cycle

EPRI Electric Power Research Institute

ETS elevated tubesheet sleeve

FLTS full-length tubesheet sleeve

GL generic letter

HEJ hybrid expansion joint

HL hot leg

ID inside diameter

IGA intergranular attack

IGSCC intergranular stress corrosion cracking

IN information notice

kHz kilohertz

LTS lower tubesheet

LTSF lower tubesheet secondary face

MA mill-annealed

MAI multiple axial indication

mm millimeter

NRC U.S. Nuclear Regulatory Commission

ODSCC outside diameter stress corrosion cracking

OTSG once-through steam generator 


\section{APPENDIX C: ACRONYMS (cont'd)}

PP plus-point

psi pounds per square inch

PVNGS Palo Verde Nuclear Generating Station

PWR pressurized-water reactor

PWSCC primary water stress corrosion cracking

RAI request for additional information

RPC rotating pancake coil

RSG recirculating steam generator

$\mathrm{Rx}$ row " $\mathrm{x}$ "

SAI single axial indication

SCC stress corrosion cracking

SG steam generator

SGMP Steam Generator Strategic Management Program

TIG tungsten inert gas

TMI Three Mile Island

TSP tube support plate

TSS tube support sleeve

TT thermally treated

TTS top of tubesheet

UBHT U-bend heat treatment

UTS upper tubesheet

UTSF upper tubesheet secondary face

V volt

WEXTEX Westinghouse Explosive Tube Expansion

WOG Westinghouse Owners Group 


\section{APPENDIX D: REFERENCES}

1. U.S. NRC Generic Letter 95-05, "Voltage-Based Repair Criteria for Westinghouse Steam Generator Tubes Affected by Outside Diameter Stress Corrosion Cracking," August 3, 1995.

2. U.S. NRC Generic Letter 95-03, "Circumferential Cracking of Steam Generator Tubes," April 28, 1995.

3. U.S. NRC Generic Letter 91-04, "Changes in Technical Specification Surveillance Intervals to Accommodate a 24-Month Fuel Cycle," April 2, 1991.

4. U.S. NRC Information Notice 96-38, "Results of Steam Generator Tube Examinations, " June 21, 1996.

5. U.S. NRC Information Notice 96-09, Supplement 1, "Damage in Foreign Steam Generator Internals," July 10, 1996.

6. U.S. NRC Information Notice 96-09, "Damage in Foreign Steam Generator Internals," February 12, 1996.

7. U.S. NRC Information Notice 95-40, "Supplemental Information to Generic Letter 95-03, 'Circumferential Cracking of Steam Generator Tubes'," September 20, 1995.

8. U.S. NRC Information Notice 94-88, "Inservice Inspection Deficiencies Result in Severely Degraded Steam Generator Tubes," December 23, 1994.

9. U.S. NRC Information Notice 94-62, "Operational Experience on Steam Generator Tube Leaks and Tube Ruptures," August 30, 1994.

10. U.S. NRC Information Notice 94-43, "Determination of Primary-to-Secondary Steam Generator Leak Rate, " June 10, 1994.

11. U.S. NRC Information Notice 94-05, "Potential Failure of Steam Generator Tubes Sleeved With Kinetically Welded Sleeves," January 19, 1994.

12. U.S. NRC Information Notice 93-56, "Weaknesses in Emergency Operating Procedures Found as a Result of Steam Generator Tube Rupture," July 22, 1993.

13. U.S. NRC Information Notice 93-52, "Draft NUREG-1477, 'Voltage-Based Interim Plugging Criteria for Steam Generator Tubes'," July 14, 1993.

14. U.S. NRC Information Notice 92-80, "Operation With Steam Generator Tubes Seriously Degraded," December 7, 1992.

15. U.S. NRC Information Notice 91-67, "Problems With the Reliable Detection of Intergranular Attack (IGA) of Steam Generator Tubing," October 21, 1991.

16. U.S. NRC Information Notice 91-43, "Recent Incidents Involving Rapid Increases in Primary-to-Secondary Leak Rate," July 5, 1991.

17. U.S. NRC Information Notice 90-49, "Stress Corrosion Cracking in PWR Steam Generator Tubes," August 6, 1990. 
18. U.S. NRC Information Notice 89-65, "Potential for Stress Corrosion Cracking in Steam Generator Tube Plugs Supplied by Babcock and Wilcox," September 8, 1989.

19. U.S. NRC Information Notice 88-99, "Detection and Monitoring of Sudden and/or Rapidly Increasing Primary-to-Secondary Leakage," December 20, 1988.

20. U.S. NRC Bulletin 89-01, Supplement 2, "Failure of Westinghouse Steam Generator Tube Mechanical Plugs," June 28, 1991.

21. U.S. NRC Bulletin 89-01, Supplement 1, "Failure of Westinghouse Steam Generator Tube Mechanical Plugs," November 14, 1990.

22. U.S. NRC Bulletin 89-01, "Failure of Westinghouse Steam Generator Tube Mechanical Plugs," May 15, 1989.

23. U.S. NRC Bulletin 88-02, "Rapidly Propagating Cracks in Steam Generator Tubes, " February 5, 1988.

24. U.S. NRC, "Steam Generator Tube Failures," NUREG/CR-6365 (INEL-95/0383), April 1996.

25. U.S. NRC, "Steam Generator Operating Experience, Update for 1989-1990," NUREG/CR-5796, December 1991.

26. U.S. NRC, "Steam Generator Operating Experience, Update for 1987-1988, " NUREG/CR-5349 (SAIC-89/1113), June 1989.

27. U.S. NRC, "NRC Integrated Program for the Resolution of Unresolved Safety Issues A-3, A-4, and A-5 Regarding Steam Generator Tube Integrity," NUREG-0844, September 1988.

28. U.S. NRC, "Steam Generator Operating Experience, Update for 1984-1986, " NUREG/CR-5150 (SAIC-87/3014), June 1988.

29. U.S. NRC, "Steam Generator Operating Experience Update for 1982-1983, " NUREG-1063, June 1984.

30. U.S. NRC, "Steam Generator Tube Experience," NUREG-0886, February 1982.

31. U.S. NRC, "Summary of Tube Integrity Operating Experience with Once-Through Steam Generators," NUREG-0571, March 1980.

32. U.S. NRC, "Summary of Operating Experience with Recirculating Steam Generators, " NUREG-0523, January 1979.

33. U.S. NRC, "Bases for Plugging Degraded PWR Steam Generator Tubes," Regulatory Guide 1.121.

34. Letter from C.S. Welty, Jr., Manager, Steam Generator Program, Electric Power Research Institute (EPRI), to the NRC, dated March 31, 1995, "Guidance on Circumferential Crack Detection and Length Sizing."

35. Letter from D. Morey, Vice President, Farley Project, Southern Nuclear Operating Company, to the NRC, dated June 26, 1995, "Joseph M. Farley Nuclear Plant; Response to Generic Letter 95-03." 
36. Letter from W.L. Stewart, Executive Vice President, Nuclear, Arizona Public Service, to the NRC, dated June 27, 1995, "Palo Verde Nuclear Generating Station (PVNGS) Units 1, 2, and 3; Docket Nos. STN 50-528/529/530; Response to Generic Letter 95-03, Circumferential Cracking of Steam Generator Tubes."

37. Letter from P.M. Beard, Jr., Senior Vice President Nuclear Plant Operations, Florida Power Corporation, to the NRC, dated July 25, 1996, "Generic Letter 95-03, Request for Additional Information."

38. Letter from J.A. Selva, B\&W Owners Group Steering Committee Chairman, The B\&W Owners Group, to the NRC, dated June 13, 1995, "B\&W Owners Group Generic Response to GL 95-03."

39. Letter from J. Knubel, Vice President and Director, TMI, General Public Utilities Nuclear Corporation, to the NRC, dated October 30, 1995, "Three Mile Island Nuclear Station, Unit 1 (TMI-1); Operating License No. DPR-50; Docket No. 50-289; Additional Information in Response to Generic Letter (GL) 95-03, "Circumferential Cracking of Steam Generator Tubes'."

40. Letter from J.R. Marshall, Manager, Licensing, Arkansas Power \& Light Company, to the NRC, dated September 15, 1983, "Arkansas Nuclear One - Unit 1; Docket No. 50-313; License No. DPR-51; ANO-1 OTSG Mid-Cycle Inspection \& Tube Pull Examination Results."

41. Letter from J.P. Stetz, Vice President - Nuclear, Davis-Besse, Centerior Energy, to the NRC, dated June 3, 1996, "Revision of Toledo Edison's Responses to Generic Letter 95-03, 'Circumferential Cracking of Steam Generator Tubes' (TAC No. M92238)."

42. Letter from D.C. Mims, Director, Nuclear Safety, Entergy Operations, Inc., to the NRC, dated February 5, 1997, "Arkansas Nuclear One - Unit 1; Docket No. 50-313; License No. DPR-51; Additional Information Related to Inservice Inspection of Once Through Steam Generator Tubes (TAC No. M97485)."

43. Letter from J.P. Stetz, Vice President - Nuclear, Davis-Besse, Centerior Energy, to the NRC, dated February 1, 1996, "Response to NRC Request for Additional Information Regarding the Toledo Edison Response to Generic Letter 95-03, 'Circumferential Cracking of Steam Generator Tubes' (TAC No. M92238)."

44. Letter from D.C. Mims, Director, Licensing, Entergy Operations, Inc., to the NRC, dated October 12, 1995, "Arkansas Nuclear One - Units 1 and 2; Docket Nos. 50-313 and 50-368; License Nos. DPR-51 and NPF-6; Additional Information in Response to Generic Letter 95-03 (TAC Nos. M92220 and M92221)."

45. Meeting summary from D. Scaletti, Senior Project Manager, NRC, dated April 16, 1996, "Summary of Meeting Held with the B\&W Owners Group Steam Generator Committee."

46. Letter from D.C. Mims, Director, Licensing, Entergy Operations, Inc.; to the NRC, dated June 27, 1995, "Arkansas Nuclear One - Units 1 and 2; Docket Nos. 50-313 and 50-368; License Nos. DPR-51 and NPF-6; Response to Generic Letter 95-03, "Circumferential Cracking of Steam Generator Tubes'."

47. Letter from N.C. Kazanas, General Manager, Tennessee Valley Authority, to the NRC, dated June 27, 1995, "Bellefonte Nuclear Plant (BLN) - Response to NRC Generic Letter 95-03 - 'Circumferential Cracking of Steam Generator Tubes'."

48. Letter from G.L. Boldt, Vice President Nuclear Production, Florida Power Corporation, to the NRC, dated June 22, 1995, "Response to Generic Letter 95-03, 'Circumferential Cracking of Steam Generator Tubes'." 
49. Letter from J.P. Stetz, Vice President - Nuclear, Davis-Besse, Centerior Energy, to the NRC, dated June 23, 1995, "Toledo Edison Response to Generic Letter 95-03, 'Circumferential Cracking of Steam Generator Tubes'."

50. Letter from M.S. Tuckman, Senior Vice President, Nuclear Generation, Duke Power Company, to the NRC, dated October 25, 1995, "McGuire Nuclear Station Docket Nos. 50-369, 370; Catawba Nuclear Station Docket Nos. 50-413, 414; Oconee Nuclear Station Docket Nos. 50-269, 270, 287; Response to Request for Additional Information Concerning Generic Letter 95-03."

51. Letter from M.S. Tuckman, Senior Vice President, Nuclear Generation, Duke Power Company, to the NRC, dated October 2, 1995, "Oconee Nuclear Station Units 1, 2, and 3; Docket Nos. 50-269, 270, 287; Response to Request for Additional Information Concerning Generic Letter 95-03."

52. Letter from M.S. Tuckman, Senior Vice President, Nuclear Generation, Duke Power Company, to the NRC, dated June 27, 1995, "McGuire Nuclear Station Docket Nos. 50-369, 370; Catawba Nuclear Station Docket Nos. 50-413, 414; Oconee Nuclear Station Docket Nos. 50-269, 270, 287; Response to Generic Letter 95-03: Circumferential Cracking of Steam Generator Tubes."

53. Letter from J. Knubel, Vice President and Director, TMI, General Public Utilities Nuclear Corporation, to the NRC, dated November 21, 1995, "Three Mile Island Nuclear Station, Unit 1 (TMI-1); Operating License No. DPR-50; Docket No. 50-289; Additional Information in Response to Generic Letter (GL) 95-03, 'Circumferential Cracking of Steam Generator Tubes'."

54. Letter from T.G. Broughton, Vice President and Director, TMI, General Public Utilities Nuclear Corporation, to the NRC, dated June 20, 1995, "Three Mile Island Nuclear Station, Unit 1 (TMI-1); Operating License No. DPR-50; Docket No. 50-289; GPU Nuclear Response Generic Letter (GL) 95-03 "Circumferential Cracking of Steam Generator Tubes'."

55. Letter from W.F. Conway, Executive Vice President, Nuclear, Arizona Public Service Company, to the NRC, dated July 18, 1993, "Palo Verde Nuclear Generating Station (PVNGS) Unit 2; Docket No. STN 50-529; Steam Generator Confirmatory Action Letter; File: 93-056-026."

56. Letter from T.L. Patterson, Division Manager, Nuclear Operations, Omaho Public Power District, to the NRC, dated July 31, 1996, "Response to Request for Additional Information (RAI) for Generic Letter (GL) 95-03, 'Circumferential Cracking of Steam Generator Tubes' (TAC No. M92243)."

57. Letter from P.W. Richardson, Assistant Project Manager, CE Owners Group Project Office, Combustion Engineering Owners Group, to Mr. C. Callaway, Nuclear Energy Institute, dated May 25, 1995, "CEOG Experience Summary Regarding Circumferential Cracking of Steam Generator Tubes." Included as an attachment to Reference 51.

58. Letter from R.E. Denton, Vice President, Nuclear Energy, Baltimore Gas and Electric Company, to the NRC, dated June 27, 1995, "Calvert Cliffs Nuclear Power Plant, Unit Nos. 1 \& 2; Docket Nos. 50-317 \& 50-318; Response to NRC Generic Letter 95-03: Circumferential Cracking of Steam Generator Tubes."

59. Letter from G.D. Whittier, Vice President, Licensing \& Eng. Support Dept., Maine Yankee Atomic Power Company, to the NRC, dated June 27, 1995, "NRC Generic Letter 95-03: Circumferential Cracking of Steam Generator Tubes." 
60. Letter from R.E. Denton, Vice President, Nuclear Energy, Baltimore Gas and Electric Company, to the NRC, dated October 5, 1995, "Calvert Cliffs Nuclear Power Plant, Unit Nos. 1 \& 2; Docket Nos. 50-317 \& 50-318; Response to NRC's Request for Additional Information Concerning Baltimore Gas and Electric Company's Response to NRC Generic Letter 95-03, 'Circumferential Cracking of Steam Generator Tubes,' - (Units 1 \& 2, TAC Nos. M92229 \& M92230)."

61. Meeting summary from P.F. McKee, Director, Project Directorate I-3, Division of Reactor Projects I/II, Office of Nuclear Reactor Regulation, NRC, dated June 1, 1995, "Summary of May 11, 1995, Meeting on Maine Yankee Steam Generator Inspections and Plans for Repair."

62. Letter from D.C. Mims, Director, Nuclear Safety, Entergy Operations, Inc., to the NRC, dated February 29, 1996, "Arkansas Nuclear One - Unit 2; Docket No. 50-268 [368]; License No. NPF-6; 1995 Annual Report of Steam Generator Tubing Inservice Inspections."

63. Letter from J.A. Stall, Vice President, St. Lucie Plant, Florida Power \& Light Company, to the NRC, dated October 24, 1996, "St. Lucie Unit 1; Docket No. 50-335, Steam Generator Run Time Analysis for Cycle 14."

64. Letter from J.J. Fisicaro, Director, Nuclear Safety, Entergy Operations, Inc., to the NRC, dated October 10, 1996, "Waterford 3 SES; Docket No. 50-382; License No. NPF-38; Reporting of Special Report."

65. Letter from W.C. Marsh, Manager of Nuclear Regulatory Affairs, Southern California Edison Company, to the NRC, dated November 29, 1995, "Docket Nos. 50-361 and 50-362; Additional Information Generic Letter 95-03, 'Circumferential Cracking of Steam Generator Tubes' (TAC Nos. M92271 and M92272); San Onofre Nuclear Generating Station Units 2 and 3."

66. Letter from J.A. Stall, Vice President, St. Lucie Plant, Florida Power \& Light Company, to the NRC, dated December 17, 1996, "St. Lucie Unit 1; Docket No. 50-335; Outage SL1-14 Steam Generator Tube Inspection; NRC Information Request Response."

67. Letter from D.A. Sagar, Vice President, St. Lucie Plant, Florida Power \& Light Company, to the NRC, dated December 11, 1995, "St. Lucie Units 1 and 2; Docket Nos. 50-335 and 50-389; Supplemental Information Generic Letter 95-03."

68. Letter from R.W. Smedley, Manager, Licensing, Consumers Power, to the NRC, dated October 25, 1995, "Docket 50-255 - License DPR-20 - Palisades Plant; Response to Request for Additional Information - Generic Letter 95-03 - Circumferential Cracking of Steam Generator Tubes."

69. Letter from B.D. Johnson, Senior Licensing Engineer, Consumers Power Company, to the NRC, dated July 9, 1982, "Docket 50-255 - License DPR-20 - Palisades Plant - Steam Generator Tube Inspection Report."

70. Letter from D.J. VandeWalle, Director, Nuclear Licensing, Consumers Power Company, to the NRC, dated April 19, 1984, "Docket 50-255 - License DPR-20 - Palisades Plant - 1983/1984 Steam Generator Evaluation and Repair Report."

71. Letter from D.M. Crutchfield, Chief, Operating Reactors Branch \#5, Division of Licensing, NRC, to D.J. VandeWalle, Consumers Power Company, dated June 11, 1984, "1983-84 Steam Generator Inspection."

72. Letter from J.L. Kuemin, Staff Licensing Engineer, Consumers Power, to the NRC, dated February 8, 1988, "Docket 50-255 - License DPR-20 - Palisades Plant - 1987 Steam Generator Inservice Inspection Report." 
73. Letter from K.W. Berry, Director, Nuclear Licensing, Consumers Power, to the NRC, dated November 3, 1989, "Docket 50-255 - License DPR-20 - Palisades Plant - 1989 Maintenance Outage Steam Generator Inspection Results (TAC NO 69344)."

74. Letter from E.J. Mroczka, Senior Vice President, Northeast Utilities, to the NRC, dated February 7, 1990, "Millstone Nuclear Power Station, Unit No. 2 Steam Generator Inspection."

75. Meeting summary from G.S. Vissing, Senior Project Manager, Project Directorate I-4, Division of Reactor Projects - I/II, Office of Nuclear Reactor Regulation, NRC, dated May 29, 1990, "Summary of Meeting with Representatives of Northeast Utilities Concerning the Steam Generator Tube Integrity of Millstone Unit 2 - May 11, 1990."

76. Letter from E. J. Mroczka, Senior Vice President, Northeast Utilities, to the NRC, dated July 3, 1990, "Millstone Nuclear Power Station, Unit No. 2 Steam Generator Inspection."

77. Letter from G.S. Vissing, Senior Project Manager, Project Directorate I-4, Division of Reactor Projects - I/II, NRC, dated September 23, 1991, "Summary of Meeting with Representatives of Northeast Utilities Concerning the Assessment of the Steam Generators at Millstone 2, August 28, 1991."

78. Letter from E.C. Wenzinger, Chief, Projects Branch No. 4, Division of Reactor Projects, NRC, to J.F. Opeka, Northeast Nuclear Energy Company, dated March 9, 1992, "Millstone Combined Inspection 92-04."

79. Letter from T.L. Patterson, Division Manager, Nuclear Operations, Omaho Public Power District, to the NRC, dated June 23, 1995, "Response to Generic Letter (GL) 95-03, Circumferential Cracking of Steam Generator Tubes."

80. Letter from J.R. Hebert, Manager, Licensing \& Engineering Support Department, Maine Yankee, to the NRC, dated December 3, 1996, "Response to Generic Letter 95-03 'Circumferential Cracking of Steam [Generator] Tubes' Request for Additional Information."

81. Letter from K.M. Haas, Plant Safety and Licensing Director, Consumers Power, to the NRC, dated June 27, 1995, "Docket 50-255 - License DPR-20 - Palisades Plant; Response to Generic Letter 95-03 Circumferential Cracking of Steam Generator Tubes."

82. Letter from W.L. Stewart, Executive Vice President, Nuclear, Arizona Public Service, to the NRC, dated February 8, 1996, "Palo Verde Nuclear Generating Station (PVNGS) Units 1, 2, and 3; Docket Nos. STN 50-528/529/530; Response to the Request for Additional Information Regarding Generic Letter 95-03."

83. Letter from W.C. Marsh, Manager of Nuclear Regulatory Affairs, Southern California Edison Company, to the NRC, dated June 27, 1995, "Docket Nos. 50-361 and 50-362; Response to NRC Generic Letter 95-03, 'Circumferential Cracking of Steam Generator Tubes'; San Onofre Nuclear Generating Station Units 2 and 3."

84. Letter from D.A. Sagar, Vice President, St. Lucie Plant, Florida Power \& Light Company, to the NRC, dated June 23, 1995, "St. Lucie Units 1 and 2; Docket Nos. 50-335 and 50-389; Generic Letter 95-03 Response."

85. Letter from R.F. Burski, Director, Nuclear Safety, Waterford 3, Entergy Operations, Inc., to the NRC, dated October 5, 1995, "Waterford 3 SES; Docket No. 50-382; License No. NPF-38; Request for Additional Information Regarding NRC Generic Letter 95-03." 
86. Letter from R.F. Burski, Director, Nuclear Safety, Waterford 3, Entergy Operations, Inc., to the NRC, dated June 27, 1995, "Waterford 3 SES; Docket No. 50-382; License No. NPF-38; NRC Generic Letter 95-03, 'Circumferential Cracking of Steam Generator Tubes'."

87. Letter from G.M. Rueger, Senior Vice President and General Manager, Nuclear Power Generation, Pacific Gas and Electric Company, to the NRC, dated October 2, 1995, "Docket No. 50-275, OL-DPR-80; Docket No. 50-323, OL-DPR-82; Diablo Canyon Units 1 and 2; Response to NRC Requests for Additional Information Related to Generic Letter 95-03, 'Circumferential Cracking of Steam Generator Tubes'."

88. Letter from E.E. Fitzpatrick, Vice President, Indiana Michigan Power Company, to the NRC, dated June 27, 1995, "Donald C. Cook Nuclear Plant Units 1 and 2; Generic Letter 95-03 Response Circumferential Cracking of Steam Generator Tubes."

89. Letter from C.L. Terry, Group Vice President, TU Electric, to the NRC, dated June 27, 1995, "Comanche Peak Steam Electric Station (CPSES); Docket Nos. 50-445 and 50-446 Units 1 and 2; Response to Generic Letter 95-03, 'Circumferential Cracking of Steam Generator Tubes'."

90. Letter from T.V. Greene, Vice Chairman, Westinghouse Owners Group, to the NRC, dated June 26, 1995, "Westinghouse Owners Group; Circumferential Cracking of Steam Generator Tubes GL-95-03 WOG Report; 'Operating Experience Data and Safety Assessment,' MUHP-4101."

91. Letter from T.P. Noonan, Division Vice President, Nuclear Operations, Duquesne Light Company, to the NRC, dated June 23, 1995, "Beaver Valley Power Station, Unit No. 1 and No. 2; BV-1 Docket No. 50-334, License No. DPR-66; BV-2 Docket No. 50-412, License No. NPF-73, Generic Letter 95-03 Response; Circumferential Cracking of Steam Generator Tubes."

92. Letter from S.C. Jain, Division Vice President, Nuclear Services, Nuclear Power Division, Duquesne Light Company, to the NRC, dated October 9, 1996, "Beaver Valley Power Station, Unit No. 2; Docket No. 50-412, License No. NPF-73, Special Report."

93. Letter from D. Morey, Vice President, Farley Project, Southern Nuclear Operating Company, to the NRC, dated December 6, 1996, "Joseph M. Farley Nuclear Plant - Unit 2; Licensee Event Report Number 96-003-00; Steam Generator Tube Degradation and Tube Status."

94. Letter from T.H. Cloninger, Vice President, Nuclear Engineering, Houston Lighting \& Power, to the NRC, dated June 27, 1995, "South Texas Project, Units 1 and 2; Docket Nos. STN 50-498; STN 50-499; Response to NRC Generic Letter 95-03: 'Circumferential Cracking of Steam Generator Tubes'."

95. Letter from K.L. Kaup, Site Vice President, Braidwood Generating Station, Commonwealth Edison Company, to the NRC, dated February 23, 1996, "Additional Information on the Braidwood Unit 1 Interim Inspection; Braidwood Nuclear Power Station Unit 1; NRC Docket Nos. 50-456."

96. Note from K.J. Karwoski, Materials Engineer, NRC, to E.J. Sullivan, NRC, dated December 3, 1996, "Steam Generator Tube Circumferential Indications at the Cold Leg Expansion Transition at Byron 1."

97. Meeting summary from L.N. Olshan, Senior Project Manager, Project Directorate I-2, Division of Reactor Projects - I/II, Office of Nuclear Reactor Regulation, NRC, dated June 19, 1996, "Summary of May 28, 1996, Meeting to Discuss Steam Generators (TAC Nos. M94797 and M94798)." 
98. Meeting summary from S.D. Bloom, Project Manager, Project Directorate IV-2, Division of Reactor Projects III/IV, Office of Nuclear Reactor Regulation, NRC, dated July 26, 1996, "Summary of Meeting Held on February 23, 1996, with Pacific Gas and Electric and Westinghouse to Discuss Diablo Canyon Unit 1 Steam Generator Tube Inspection Results and Tube Integrity Analyses."

99. Letter from R.H. Shell, Manager, SQN Site Licensing, Tennessee Valley Authority, to the NRC, dated June 27, 1995, "Sequoyah Nuclear Plant (SQN) - Response to NRC Generic Letter (GL) 95-03, "Circumferential Cracking of Steam Generator Tubes'."

100. Letter from J.P. O'Hanlon, Senior Vice President - Nuclear, Virginia Electric and Power Company, to the NRC, dated October 5, 1995, "Virginia Electric and Power Company; Surry Power Station Units 1 and 2; North Anna Power Station Units 1 and 2; Response to NRC Request for Additional Information Regarding Our Response to Generic Letter 95-03; Circumferential Cracking of Steam Generator Tubes."

101. Letter from J.P. O'Hanlon, Senior Vice President - Nuclear, Virginia Electric and Power Company, to the NRC, dated June 27, 1995, "Virginia Electric and Power Company; Surry Power Station Units 1 and 2; North Anna Power Station Units 1 and 2; Response to NRC Generic Letter 95-03; Circumferential Cracking of Steam Generator Tubes."

102. Letter from C.K. McCoy, Vice President, Nuclear, Vogtle Project, Georgia Power Company, to the NRC, dated June 27, 1995, "Vogtle Electric Generating Plant, Response to NRC Generic Letter 95-03."

103. Letter from T.F. Plunkett, Vice President, Turkey Point Plant, Florida Power and Light Company, to the NRC, dated October 11, 1995, "Turkey Point Units 3 and 4; Docket Nos. 50-250 and 50-251; Response to Request for Additional Information - Generic Letter 95-03, 'Circumferential Cracking of Steam Generator Tubes'."

104. Letter from G.E. Trzyna, Nuclear Licensing Administrator, Zion Station, Commonwealth Edison Company, to the NRC, dated March 2, 1989, "Zion Nuclear Power Station, Unit 2; License No. DPR-48; NRC Docket No. 50-304; Evaluation of Degraded Tube in 2A Steam Generator."

105. Meeting summary from G.F. Dick, Jr., Project Manager, Project Directorate III-2, Division of Reactor Projects - III/IV, Office of Nuclear Reactor Regulation, NRC, dated July 3, 1996, "Summary of Meeting Discussing Steam Generator Tube U-Bend Flaws and Length of Byron 1 Operating Cycle - June 20, 1996."

106. Letter from J.B. Hosmer, Engineering Vice President, Commonwealth Edison Company, to the NRC, dated January 30, 1997, "Additional Information Pertaining to Zion Unit 2 Steam Generator Inspection; Zion Nuclear Power Station Unit 2; NRC Docket Number: 50-304."

107. Letter from W.H. Fujimoto, Vice President--Diablo Canyon, Operations and Plant Manager, Pacific Gas and Electric Company, to the NRC, dated June 29, 1995, "Docket No. 50-275, OL-DPR-80; Docket No. 50-323, OL-DPR-82; Diablo Canyon Units 1 and 2; Response to NRC Generic Letter 95-03, 'Circumferential Cracking of Steam Generator Tubes'."

108. Letter from T.C. Feigenbaum, Senior Vice President \& Chief Nuclear Officer, North Atlantic Energy Service Corporation, to the NRC, dated October 23, 1995, "Response to Request for Additional Information Related to Generic Letter 95-03."

109. Letter from F.R. Dacimo, Vice President, Northeast Utilities System, to the NRC, dated February 16, 1996, "Haddam Neck Plant; Millstone Nuclear Power Station, Unit Nos. 2 and 3; Generic Letter 95-03, 'Circumferential Cracking of Steam Generator Tubes'; Response to Request for Additional Information." 
110. Letter from D.F. Schnell, Senior Vice President, Nuclear, Union Electric, to the NRC, dated January 12, 1996, "Callaway Plant; Docket Number 50-483; Circumferential Cracking of Steam Generator Tubes."

111. Letter from R.E. Beedle, Executive Vice President, Nuclear Generation, New York Power Authority, to the NRC, dated May 24, 1991, "Indian Point 3 Nuclear Power Plant; Docket No. 50-286; Analysis of Steam Generator Tube Crack."

112. Letter from W.L. Stewart, Senior Vice President - Nuclear, Virginia Electric and Power Company, to the NRC, dated August 30, 1991, "Virginia Electric and Power Company; North Anna Power Station Unit 1; Steam Generator Operating Cycle Evaluation; Transmittal of the Westinghouse WCAP Reports."

113. Letter from G.E. Kane, Station Manager, Virginia Electric and Power Company, to the NRC, dated January 21, 1992, "Licensee Event Report (LER): Unit Shutdown Due to Indeterminate Status of Steam Generators Following Eddy Current Data Re-Review."

114. Letter from W.L. Stewart, Senior Vice President - Nuclear, Virginia Electric and Power Company, to the NRC, dated May 1, 1992, "Virginia Electric and Power Company; North Anna Power Station Unit 1; Mid-Cycle Steam Generator Inspection Results and Steam Generator Operating cycle Evaluation."

115. Letter from C.A. Julian, Chief, Engineering Branch, Division of Reactor Safety, NRC, to T.C. McMeekin, Duke Power Company, dated September 29, 1993, "NRC Inspection Report Nos. 50-369/93-19 and 50-370/93-19."

116. Letter from D.E. LaBarge, Senior Project Manager, Project Directorate II-3, Division of Reactor Projects - I/I[I], Office of Nuclear Reactor Regulation, NRC, to O.D. Kingsley, Jr., Tennessee Valley Authority, dated October 11, 1995, "Issuance of Technical Specification Amendment for the Sequoyah Nuclear Plant Unit 1 (TAC No. M92961) (TS 95-15)."

117. Meeting summary from D.E. LaBarge, Senior Project Manager, Project Directorate II-3, Division of Reactor Projects - I/II, Office of Nuclear Reactor Regulation, NRC, dated January 16, 1996, "Summary of the December 11, 1995, Meeting on the Unit 1 Steam Generator Tube Inspection Results."

118. Letter from C.A. Julian, Chief, Engineering Branch, Division of Reactor Safety, NRC, to T.C. McMeekin, Duke Power Company, March 9, 1994, "NRC Inspection Report Nos. 50-369/94-05 and 50-370/94-05."

119. Letter from C.A. Julian, Chief, Engineering Branch, Division of Reactor Safety, NRC, to D.L. Rehn, Duke Power Company, dated December 30, 1993, "Notice of Violation (NRC Inspection Report No. 50-413/93-32 and 50-414/93-32)."

120. Letter from D.M. Saccomando, Senior Nuclear Licensing Administrator, Commonwealth Edison Company, to the NRC, dated October 13, 1995, "Response to Request for Additional Information Regarding GL 95-03, 'Circumferential Cracking of Steam Generator Tubes'; Byron Station Units 1 and 2; Braidwood Station Units 1 and 2; NRC Docket Numbers: 50-454, and 50-455; NRC Docket Numbers: 50-456 and 50-457."

121. Letter from W.R. Robinson, Vice President, Harris Nuclear Plant, Carolina Power \& Light Company, to the NRC, dated October 11, 1995, "Shearon Harris Nuclear Power Plant; Docket No. 50-400/License No. NPF-63; Generic Letter 95-03, Circumferential Cracking of Steam Generator Tubes, Request for Additional Information." 
122. Electric Power Research Institute report NP-6201, Revision 3, "PWR Steam Generator Examination Guidelines: Revision 3," November 1992.

123. Letter from M.S. Tuckman, Senior Vice President, Nuclear Generation, Duke Power Company, to the NRC, dated September 19, 1995, "Catawba Nuclear Station Units 1 \& 2; Docket Nos. 50-413, 414; Response to Request for Additional Information Concerning Generic Letter 95-03."

124. Letter from C.L. Terry, Group Vice President, TU Electric, to the NRC, dated December 13, 1996, "Comanche Peak Steam Electric Station (CPSES) - Units 1 and 2; Docket Nos. 50-445 and 50-446;

Response to Request for Additional Information on CPSES Response to Generic Letter 95-03, 'Circumferential Cracking of Steam Generator Tubes' (TAC Nos. M92233 and M92234)."

125. Letter from T.H. Cloninger, Vice President, Nuclear Engineering, Houston Lighting \& Power, to the NRC, dated October 2, 1995, "South Texas Project Electric Generating Station, Units 1 and 2; Docket Nos. STN 50-498, STN 50-499; Additional Information Regarding NRC Generic Letter 95-03: 'Circumferential Cracking of Steam Generator Tubes'."

126. Letter from E.E. Fitzpatrick, Vice President, Indiana Michigan Power Company, to the NRC, dated December 19, 1995, "Donald C. Cook Nuclear Plant Units 1 and 2; Generic Letter (GL) 95-03: Circumferential Cracking of Steam Generator Tubes; Request for Additional Information."

127. Letter from E.E. Fitzpatrick, Vice President, Indiana Michigan Power Company, to the NRC, dated October 13, 1995, "Donald C. Cook Nuclear Plant Units 1 and 2; Generic Letter 95-03 Response Circumferential Cracking of Steam Generator Tubes; Request for Additional Information (RAI)."

128. Letter from R.C. Mecredy, Vice President, Nuclear Operations, Rochester Gas and Electric Corporation, to the NRC, dated July 25, 1996, "Response to Request for Additional Information (RAI) Concerning Circumferential Cracking of Steam Generator Tubes (TAC No. M92244); R.E. Ginna Nuclear Power Plant; Docket No. 50-244."

129. Letter from R.C. Mecredy, Vice President, Nuclear Operations, Rochester Gas and Electric Corporation, to the NRC, dated March 22, 1996, "Generic Letter (GL) 95-03 dated April 28, 1995, 'Circumferential Cracking of Steam Generator Tubes'; Response to NRC Request for Additional Information (RAI); R.E. Ginna Nuclear Power Plant; Docket No. 50-244."

130. Letter from R.C. Mecredy, Vice President, Nuclear Operations, Rochester Gas and Electric Corporation, to the NRC, dated June 27, 1995, "Response to Generic Letter 95-03, 'Circumferential Cracking of Steam Generator Tubes,' dated April 28, 1995; R.E. Ginna Nuclear Power Plant; Docket No. 50-244."

131. Letter from E.A. DeBarba, Vice President, Northeast Utilities System, to the NRC, dated January 2, 1996, "Haddam Neck Plant; Millstone Nuclear Power Station, Unit Nos. 2 and 3; Generic Letter 95-03, 'Circumferential Cracking of Steam Generator Tubes' -- Request for Additional Information."

132. Letter from J.F. Opeka, Executive Vice President, Northeast Utilities System, to the NRC, dated June 27, 1995, "Haddam Neck Plant; Millstone Nuclear Power Station, Unit Nos. 2 and 3; Seabrook Station; Response to Generic Letter 95-03, 'Circumferential Cracking of Steam Generator Tubes'."

133. Letter from S.E. Quinn, Vice President, Consolidated Edison Company of New York, Inc., to the NRC, dated January 12, 1996, "Response to NRC's Request for Additional Information (RAI), Response to Generic Letter 95-03, Circumferential Cracking of Steam Generator Tubes, Indian Point Nuclear Generating Station Unit No. 2 (TAC No. M92247)." 
134. Letter from S.E. Quinn, Vice President, Consolidated Edison Company of New York, Inc., to the NRC, dated June 26, 1995, "Generic Letter 95-03."

135. Letter from C.R. Steinhardt, Senior Vice President - Nuclear Power, Wisconsin Public Service Corporation, to the NRC, dated January 12, 1996, "Docket 50-305; Operating License DPR-43; Kewaunee Nuclear Power Plant; Response to Request for Additional Information Regarding Generic Letter 95-03."

136. Letter from C.R. Steinhardt, Senior Vice President - Nuclear Power, Wisconsin Public Service Corporation, to the NRC, dated June 27, 1995, "Docket 50-305; Operating License DPR-43; Kewaunee Nuclear Power Plant; Response to NRC Generic Letter 95-03 'Circumferential Cracking of Steam Generator Tubes'."

137. Letter from B. Link, Vice President, Nuclear Power, Wisconsin Electric Power Company, to the NRC, dated October 6, 1995, "Dockets 50-266 and 50-301; Request for Additional Information Regarding Generic Letter 95-03, Circumferential Cracking of Steam Generator Tubes; Point Beach Nuclear Plant, Units 1 and 2."

138. Letter from B. Link, Vice President, Nuclear Power, Wisconsin Electric Power Company, to the NRC, dated June 26, 1995, "Dockets 50-266 and 50-301; Response to Generic Letter 95-03; Circumferential Cracking of Steam Generator Tubes; Point Beach Nuclear Plant, Units 1 and 2."

139. Letter from M.D. Wadley, Plant Manager, Prairie Island Nuclear Generating Plant, Northern States Power Company, to the NRC, dated April 8, 1996, "Prairie Island Nuclear Generating Plant; Docket Nos. 50-282 and 50-306; License Nos. DPR-42 and DPR-60; Response to Request for Additional Information, Prairie Island Nuclear Generating Plant, Units 1 and 2, Generic Letter 95-03, 'Circumferential Cracking of Steam Generator Tubes' (TAC Nos. M92266 and M92267)."

140. Letter from R.O. Anderson, Director, Licensing and Management Issues, Northern States Power Company, to the NRC, dated June 27, 1995, "Prairie Island Nuclear Generating Plant; Docket Nos. 50-282 and 50-306; License Nos. DPR-42 and DPR-60; Response to Generic Letter 95-03, 'Circumferential Cracking of Steam Generator Tubes'."

141. Letter from D.M. Saccomando, Senior Nuclear Licensing Administrator, Commonwealth Edison Company, to the NRC, dated November 10, 1995, "Response to Request for Additional Information Pertaining to GL 95-03 'Circumferential Crack[ing] of Steam Generator Tubes'."

142. Letter from G.K. Schwartz, Station Manager, Zion Station, Commonwealth Edison Company, to the NRC, dated September 28, 1995, "Zion Response to NRC Request for Additional Information for Generic Letter 95-03, 'Circumferential Cracking of Steam Generator Tubes'; Zion Nuclear Power Station Units 1 and 2; NRC Dockets 50-295 and 50-304."

143. Letter from M.J. Vonk, Generic Issues Administrator, Nuclear Regulatory Services, Commonwealth Edison Company, to the NRC, dated June 27, 1995, "Braidwood Station Units 1 and 2; Byron Station Units 1 and 2; Zion Station Units 1 and 2; ComEd Response to NRC Generic Letter 95-03: 'Circumferential Cracking of Steam Generator Tubes'; NRC Dockets 50-456 and 50-457; NRC Dockets 50-454 and 50-455; NRC Dockets 50-295 and 50-304."

144. Letter from G.S. Thomas, Division Vice President, Nuclear Services, Nuclear Power Division, Duquesne Light Company, to the NRC, dated January 10, 1996, "Beaver Valley Power Station, Unit No. 1 and No. 2; BV-1 Docket No. 50-334, License No. DPR-66; BV-2 Docket No. 50-412, License No. NPF-73, Response to Request for Additional Information Dated December 7, 1995." 
145. Letter from C.L. Terry, Group Vice President, TU Electric, to the NRC, dated January 18, 1996, "Comanche Peak Steam Electric Station (CPSES); Docket Nos. 50-445 and 50-446 Units 1 and 2; Response to Request for Additional Information on CPSES Response to Generic Letter 95-03, 'Circumferential Cracking of Steam Generator Tubes' (TAC Nos. M92233 and M92234)."

146. Letter from D. Morey, Vice President, Farley Project, Southern Nuclear Operating Company, to the NRC, dated September 26, 1995, "Joseph M. Farley Nuclear Plant; Request for Additional Information Concerning Generic Letter 95-03."

147. Letter from M. S. Tuckman, Senior Vice President - Nuclear Generation, Duke Power Company, to the NRC, dated October 9, 1995, "McGuire Nuclear Station Units 1 \& 2; Docket Nos. 50-369, 370; Response to Request for Additional Information Concerning Generic Letter 95-03."

148. Letter from W.R. Robinson, Vice President, Harris Nuclear Plant, Carolina Power \& Light Company, to the NRC, dated June 27, 1995, "Shearon Harris Nuclear Power Plant; Docket No. 50-400/License No. NPF-63; Generic Letter 95-03, Circumferential Cracking of Steam Generator Tubes."

149. Letter from S.E. Thomas, Manager, Design Engineering, Houston Lighting \& Power, to the NRC, dated October 23, 1995, "South Texas Project Electric Generating Station, Units 1 and 2; Docket Nos. STN 50-498, STN 50-499; Additional Information Regarding NRC Generic Letter 95-03: 'Circumferential Cracking of Steam Generator Tubes'."

150. Letter from R.R. Baron, Nuclear Assurance and Licensing Manager (Acting), Tennessee Valley Authority, to the NRC, dated June 27, 1995, "Watts Bar Nuclear Plant (WBN) - NRC Generic Letter (GL) 95-03 - Circumferential Cracking of Steam Generator Tubes."

151. Letter from W.H. Fujimoto, Vice President-Diablo Canyon, Operations and Plant Manager, Pacific Gas and Electric Company, to the NRC, dated November 28, 1995, "Docket No. 50-275, OL-DPR-80; Docket No. 50-323, OL-DPR-82; Diablo Canyon Units 1 and 2; Clarification of Eddy Current Probes Used for Steam Generator Inspections."

152. Letter from E.C. Simpson, Senior Vice President - Nuclear Engineering, Public Service Electric and Gas Company, to the NRC, dated October 17, 1995, "Response to NRC Request for Additional Information; Generic Letter 95-03 - Circumferential Cracking of Steam Generator Tubes; Salem Generating Station Units 1 and 2; Facility Operating License Nos. DPR-70 and DPR-75; Docket Nos. 50-272 and 50-311."

153. Letter from J.J. Hagan, Vice President - Nuclear Operations, Public Service Electric and Gas Company, to the NRC, dated July 17, 1995, "Response to Generic Letter 95-03; Circumferential Cracking of Steam Generator Tubes; Salem Generating Station Units 1 and 2; Facility Operating License Nos. DPR-70 and DPR-75; Docket Nos. 50-272 and 50-311."

154. Letter from R.H. Shell, Manager, SQN Site Licensing, Tennessee Valley Authority, to the NRC, dated December 6, 1995, "Sequoyah Nuclear Plant (SQN) - Units 1 and 2 - Response to NRC Request for Additional Information Regarding Generic Letter (GL) 95-03."

155. Letter from D.F. Schnell, Senior Vice President, Nuclear, Union Electric, to the NRC, dated June 27, 1995, "Callaway Plant; Docket Number 50-483; Circumferential Cracking of Steam Generator Tubes."

156. Letter from R.M. Krich, Manager - Regulatory Affairs, Carolina Power \& Light Company, to the NRC, dated July 31, 1996, "H.B. Robinson Steam Electric Plant, Unit No. 2; Docket No. 50-261/License No. DPR-23; Response to Request for Additional Information Regarding Response to Generic Letter 95-03, 'Circumferential Cracking of Steam Generator Tubes'." 
157. Letter from R.M. Krich, Manager - Regulatory Affairs, Carolina Power \& Light Company, to the NRC, dated July 22, 1996, "H.B. Robinson Steam Electric Plant, Unit No. 2; Docket No. 50-261/License No. DPR-23; Response to Request for Additional Information Regarding Response to Generic Letter 95-03, "Circumferential Cracking of Steam Generator Tubes'."

158. Letter from R.M. Krich, Manager - Regulatory Affairs, Carolina Power \& Light Company, dated June 27, 1995, "H.B. Robinson Steam Electric Plant, Unit No. 2; Docket No. 50-261/License No. DPR-23; Response to NRC Generic Letter 95-03, "Circumferential Cracking of Steam Generator Tubes'."

159. Letter from R.P. Croteau, Project Manager, Project Directorate II-1, Division of Reactor Projects - I/II, Office of Nuclear Reactor Regulation, NRC, to T.F. Plunkett, Florida Power and Light Company, dated March 18, 1996, "Turkey Point Units 3 and 4-Generic Letter 95-03 - Circumferential Cracking of Steam Generator Tubes (TAC Nos. M92284 and M92285)."

160. Letter from R.J. Hovey, Vice President, Turkey Point Plant, Florida Power and Light Company, to the NRC, dated February 27, 1996, "Turkey Point Unit 4; Docket No. 50-251; Generic Letter 95-03 'Circumferential Cracking of Steam Generator Tubes'."

161. Letter from R.J. Hovey, Vice President, Turkey Point Plant, Florida Power and Light Company, to the NRC, dated January 16, 1996, "Turkey Point Unit 4; Docket No. 50-251; Generic Letter 95-03 'Circumferential Cracking of Steam Generator Tubes'."

162. Letter from W.H. Bohlke, Vice President, Nuclear Engineering and Licensing, Florida Power and Light Company, to the NRC, dated June 22, 1995, "Turkey Point Units 3 and 4; Docket Nos. 50-250 and 50-251; Response to Generic Letter 95-03, Circumferential Cracking of Steam Generator Tubes."

163. Letter from C.K. McCoy, Vice President, Nuclear, Vogtle Project, Georgia Power Company, to the NRC, dated December 22, 1995, "Vogtle Electric Generating Plant, Response to Request for Additional Information; Generic Letter 95-03, 'Circumferential Cracking of Steam Generator Tubes'."

164. Letter from N.S. Carns, Chairman, President, and Chief Executive Officer, Wolf Creek Nuclear Operating Corporation, to the NRC, dated January 9, 1996, "Docket 50-482: Response to Request for Additional Information for Generic Letter 95-03."

165. Letter from R.C. Hagan, Vice President Engineering, Wolf Creek Nuclear Operating Corporation, to the NRC, dated June 23, 1995, "Docket 50-482: Response to Generic Letter 95-03."

166. Letter from G.J. Taylor, Vice President, Nuclear Operations, South Carolina Electric \& Gas Company, to the NRC, dated February 1, 1996, "Virgil C. Summer Nuclear Station; Docket No. 50/395; Operating License No. NPF-12; 'Request for Additional Information, Generic Letter 95-03, Circumferential Cracking of Steam Generator Tubes'."

167. Letter from W.J. Cahill, Jr., Chief Nuclear Officer, Nuclear Generation, New York Power Authority, to the NRC, dated January 17, 1996, "Indian Point 3 Nuclear Power Plant; Docket No. 50-286; Response to Request for Additional Information (RAI), Response to Generic Letter (GL) 95-03, Circumferential Cracking of Steam Generator Tubes."

168. Letter from W.J. Cahill, Jr., Chief Nuclear Officer, Nuclear Generation, New York Power Authority, to the NRC, dated June 27, 1995, "Indian Point 3 Nuclear Power Plant; Docket No. 50-286; License No. DPR-64; Response to NRC Generic Letter 95-03: 'Circumferential Cracking of Steam Generator Tubes'." 
169. Letter from G.J. Taylor, Vice President, Nuclear Operations, South Carolina Electric \& Gas Company, to the NRC, dated August 16, 1995, "Virgil C. Summer Nuclear Station (VCSNS); Docket No. 50/395; Operating License No. NPF-12; 'Circumferential Cracking of Steam Generator Tubes Generic Letter 95-03,' Supplement 1-Notarization."

170. Letter from G.J. Taylor, Vice President, Nuclear Operations, South Carolina Electric \& Gas Company, to the NRC, dated June 27, 1995, "Virgil C. Summer Nuclear Station; Docket No. 50/395; Operating License No. NPF-12; 'Circumferential Cracking of Steam Generator Tubes Generic Letter 95-03'."

171. Letter from B. Link, Vice President, Nuclear Power, Wisconsin Electric Power Company, to the NRC, dated August 26, 1994, "Dockets 50-266 and 50-301; Technical Specifications Change Request 175; Modifications to Section 15.4.2, 'In-Service Inspection of Safety Class Components'; Point Beach Nuclear Plant, Units 1 and 2."

172. Letter from C.R. Steinhardt, Senior Vice President - Nuclear Power, Wisconsin Public Service Corporation, to the NRC, dated May 1, 1996, "Docket 50-305; Operating License DPR-43; Kewaunee Nuclear Power Plant; Proposed Amendment 136a to the Kewaunee Nuclear Power Plant Technical Specifications; Pressure Boundary Redefinition for Westinghouse Hybrid Expansion Joint Sleeved Tubes. "

173. Letter from J.H. Taylor, Manager, Licensing Services, B\&W Nuclear Technologies, to the NRC, dated September 21, 1992, "Accepted Versions of Topical Report BAW-2045P, Rev. 1 and BAW-2045, Rev. 1, 'Recirculating Steam Generators Kinetic Sleeve Qualification for 3/4 Inch O.D. Tubes'."

174. Meeting summary from V. Nerses, Project Manager, Project Directorate II-3, Division of Reactor Projects - I/II, Office of Nuclear Reactor Regulation, NRC, dated October 29, 1993, "Summary of Meeting with Duke Power Company."

175. Letter from W.R. Robinson for J.E. Cross, Vice President and Chief Nuclear Officer, Portland General Electric Company, to the NRC, dated November 26, 1992, "License Change Application (LCA) 227 Deferral of Unscheduled Steam Generator Inservice Inspection."

176. Letter from J.H. Taylor, Manager, Licensing Services, B\&W Nuclear Technologies, to the NRC, dated September 29, 1993, "Information to Utilities Regarding McGuire Tube Leak."

177. Letter from J.T. Enos, Manager, Licensing, Arkansas Power \& Light Company, to the NRC, dated October 22, 1984, "Arkansas Nuclear One - Unit 1; Docket No. 50-313; License No. DPR-51; Steam Generator Surveillance Technical Specification Change Request."

178. Letter from M.D. Wadley, Plant Manager, Prairie Island Nuclear Generating Plant, Northern States Power Company, to the NRC, dated August 9, 1996, "Prairie Island Nuclear Generating Plant; Docket Nos. 50-282 and 50-306; License Nos. DPR-42 and DPR-60; Steam Generator Tube Sleeves Metallurgical Examination Results."

179. Letter from M.D. Wadley, Plant Manager, Prairie Island Nuclear Generating Plant, Northern States Power Company, to the NRC, dated June 27, 1996, "Prairie Island Nuclear Generating Plant; Docket Nos. 50-282 and 50-306; License Nos. DPR-42 and DPR-60; January 1996 Steam Generator Sleeving Issues Ninety Day Response Letter."

180. Meeting summary from B. Wetzel, Project Manager, Project Directorate III-1, Division of Reactor Projects - III/IV, Office of Nuclear Reactor Regulation, NRC, dated June 26, 1996, "Meeting with NSP to Discuss Issues Pertaining to the CE Steam Generator Sleeves Installed at Prairie Island Unit 1." 
181. Letter from G.M. Leitch, Vice President Operations, Maine Yankee Atomic Power Company, to the NRC, dated April 14, 1995, "Proposed Technical Specification Change No. 190: Maine Yankee Steam Generator Tube Sleeving." 


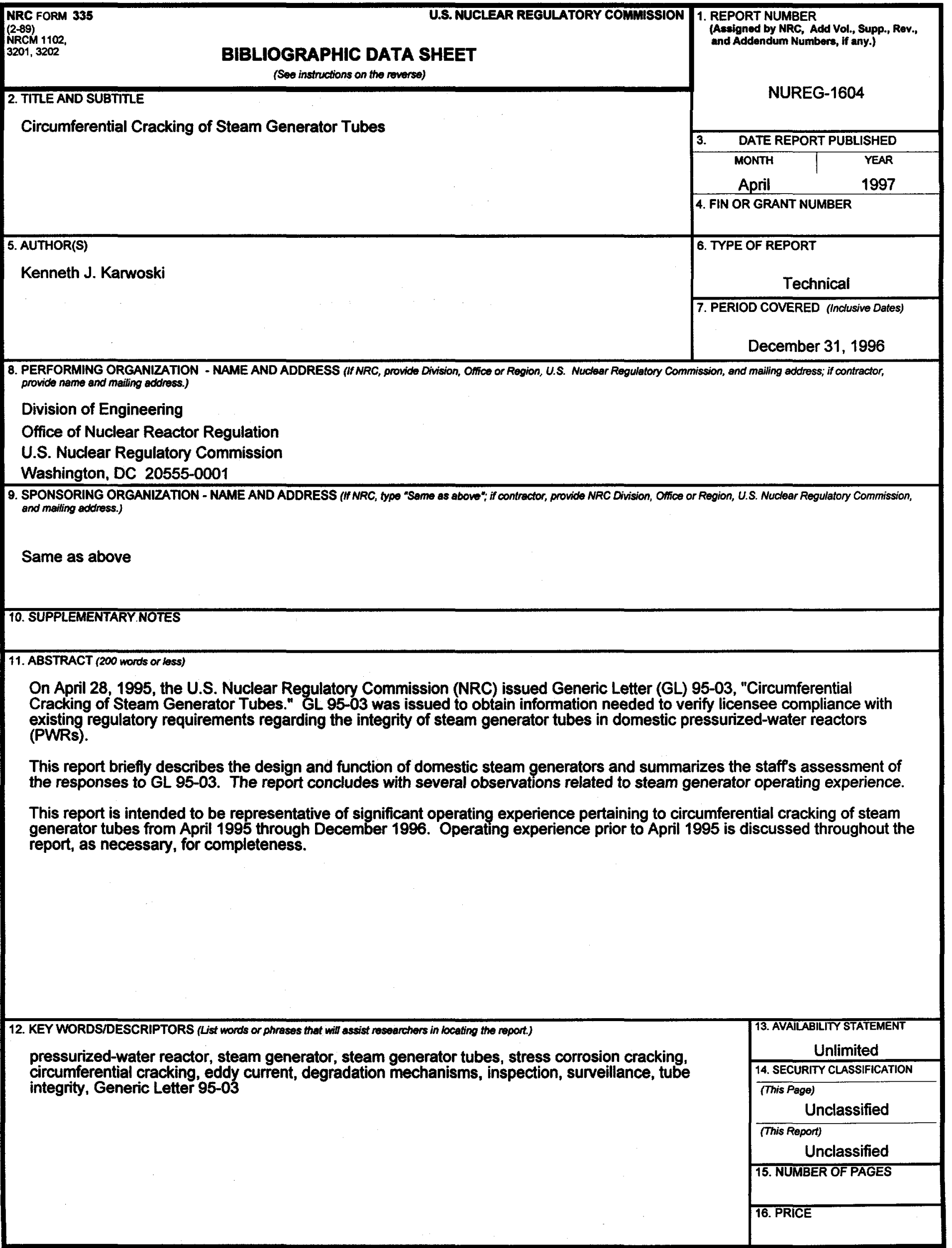

